\title{
ESSAYS ON THE EFFECT OF INFLATION VOLATILITY AND INSTITUTIONS ON GROWTH AND DEVELOPMENT
}

by

\section{NOHA EMARA}

\author{
A Dissertation submitted to the \\ Graduate School - New Brunswick \\ Rutgers, The State University of New Jersey \\ In partial fulfillment of the requirements \\ For the Degree of \\ Doctor of Philosophy \\ Graduate Program in Economics \\ Written under the direction of \\ Ira Gang \\ And approved by
}

New Brunswick, New Jersey

May, 2009 


\author{
ABSTRACT OF THE DISSERTATION \\ Essays on the Effect of Inflation Volatility and Institutions \\ On Growth and Development \\ by \\ NOHA EMARA \\ Dissertation Director: \\ Ira Gang
}

The purpose of this dissertation is to analyze empirically and theoretically the impact of the decrease in inflation volatility versus the impact of the improvement in institutions on growth and development. The first chapter of this dissertation estimates the effects of inflation and inflation volatility on economic growth in the presence of different degrees of legal and financial institutions. The main contribution of this chapter is to show that while the level of inflation does not have a significant effect on growth, which is in line with previous studies; inflation volatility does significantly impact growth even for countries with moderately high levels on inflation. In addition, improving either legal or financial institutions has a statistically significant positive impact on growth and helps to reduce the negative impact of inflation volatility on growth.

The second chapter analyzes the channel through which inflation volatility and financial institutions affect a country's ability to borrow on international capital markets; 
which affects their ability to invest and therefore grow. The findings of this chapter show that reducing inflation volatility or improving financial institutions will significantly improve a country's sovereign debt rating leading to a drop in its cost of borrowing, which is to be quantified. One important contribution of this chapter is to show that it is inflation volatility that is important in determining a country's sovereign debt rating rather than the level of inflation which has been argued in the literature.

The welfare implications of the decrease in inflation volatility versus the improvement in institutions are quantified in chapter three. This chapter analyzes a micro-foundation based small open economy model that is used to help fully understand the dynamics of a decrease in inflation volatility and an improvement in institutions for a developing economy. The study finds that the welfare effect of improving institutions and of reducing inflation volatility is large with the largest effect being caused by an improvement in financial institutions. One policy implication of these results is that developing economies can get larger welfare gains from improving their institutions than from reducing inflation volatility. 


\section{ACKNOWLEDGMENTS}

I gratefully acknowledge Professor John Landon-Lane, my main dissertation advisor, who encouraged me to launch this dissertation project, and guided me with patience all along. This dissertation would have been impossible without his ongoing support.

I owe many thanks to Ira Gang, Chairman of my dissertation, and to Michael Bordo and the outside member, Rob Vos, for their helpful comments as I developed the successive drafts of this dissertation.

I would also like to thank Dorothy Rinaldi for her help, kindness, and her advice. Since my first day in the graduate program at Rutgers, Dorothy has been always supportive and encouraging.

I would like also to thank all my friends for their help and support. Among many, I would like specifically to thank Haruhiko Shimizu who spent long hours with me to help me study and prepare for the qualifying and the field exams, Demet Tunali who shared with me all my moral and emotional highs and lows throughout the graduate school, Leah Traub for her valuable comments and advice at the various stages of developing this dissertation.

I will never find words of thanks and gratitude to my father who made all of my life accomplishments possible. To my mother for her continuous prayers and encouragement. To my sisters for their love and sincere wishes. To my sons, Moustafa and Ismail, for putting up with their mom while spending most of her time away from 
them while studying and working on this dissertation. To my husband, Ihab, for his help and emotional support. This dissertation would have not been possible without his love and encouragement. 


\section{DEDICATION}

To

Papi and Mami

Moustafa and Ismail

And

Ihab 


\section{TABLE OF CONTENTS}

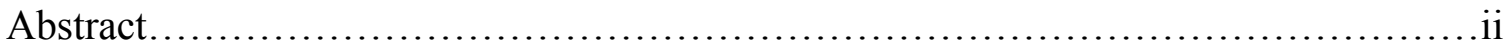

Acknowledgements.......................................................

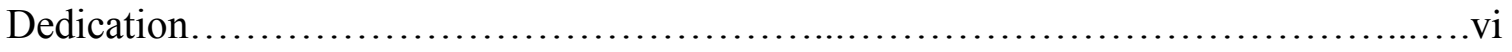

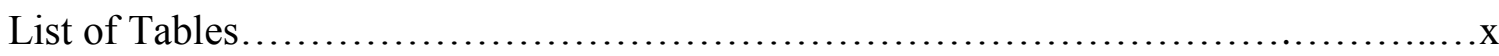

List of Figures...........................................................

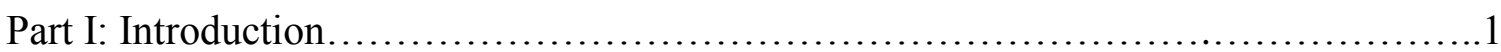

Part II: Chapter 1: Inflation Volatility, Institutional Environment, and Economic

Growth....................................................................6

1.1: Introduction....................................................6

1.2: Empirical Specification.......................................... 12

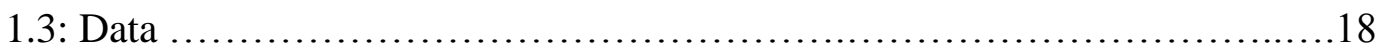

1.4: Estimation Results...........................................22

1.5: Total Effect of Inflation Volatility..................................32

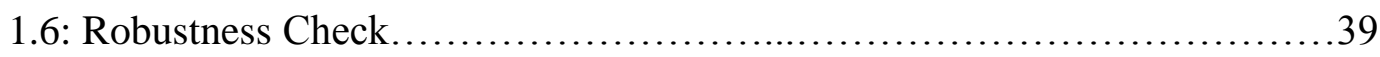

1.6.1: Reverse Causality Test...................................39

1.6.2: Regular Panel Estimation.......................................................41

1.7: Conclusion..................................................42

Part III: Chapter 2: Inflation Volatility, Financial Institutions, and Sovereign

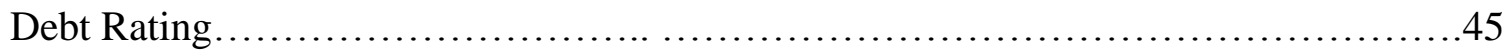

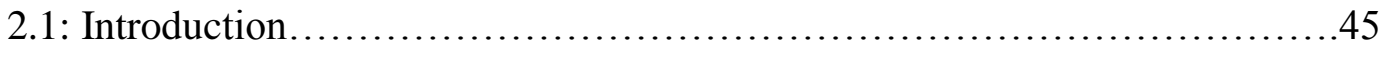

2.2: Empirical Specification..........................................54 
2.3: Data .58

2.4: Estimation Results...............................................64

2.5: Estimating the Impact of the Components of Financial Institutions..........71

2.6: Calculating the Total Effects....................................... 73

2.6.1: Total Effect of Inflation Volatility............................74

2.6.2: Total Effect of Financial Institutions........................78

2.7: Robustness Check................................................... 82

2.8: Impact of the Increase in Sovereign Debt Rating on Long-Term Bond



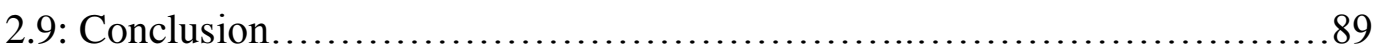

Part IV: Chapter 3: Welfare Implications of Inflation Volatility and Financial Institutions in a Small Open Economy........................................91

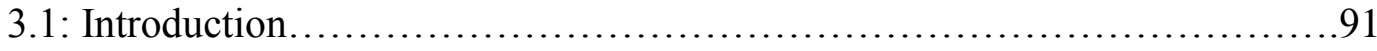

3.2: Monetary Small Open Economy Model................................98

3.2.1: Households.............................................98

3.2.2: Firms.................................................. 99

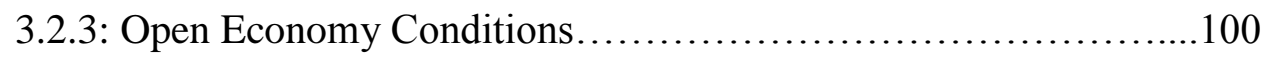

3.2.4: Defining the Equilibrium................................ 102

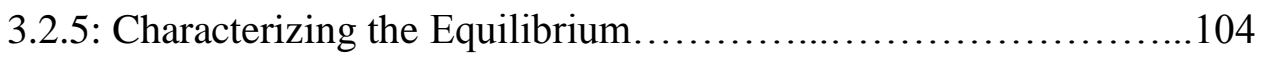

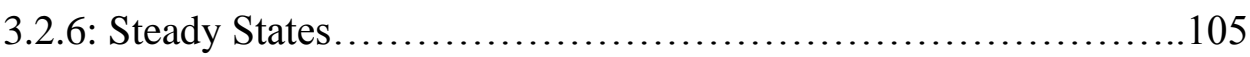

3.3: Calibration........................................................ 109

3.4: Results...................................................... 114

3.4.1: Impulse Response Functions for a Permanent Improvement 
3.4.2: Calculating the Welfare Implications of the Reduction in Inflation Volatility and the Improvement in institutions..............116

3.5: Transition Paths - Deterministic Model................................. 112

3.5.1: The Three Experiments Along the Transition Path...............121



3.6: Conclusion..................................................... 131

Appendix (I) ........................................................... 133

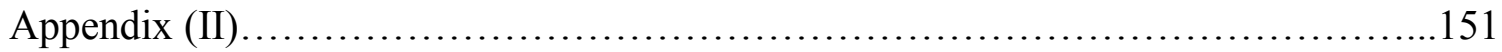

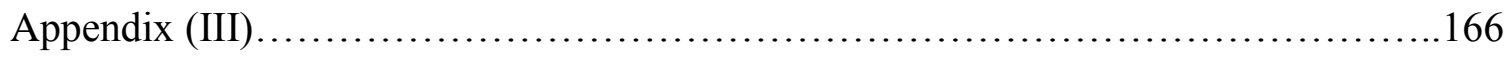

Bibliography......................................................... 177

Curriculum Vita........................................................ 189 


\section{List of Tables}

Table 1.1: The Base Model of Economic Growth...................................23

Table 1.2: Economic Growth and the Interaction between inflation Volatility

And Legal and Financial Institutions Indices.............................28

Table 1.3: Total Effect of Inflation Volatility on Growth (Given the LEGAL1 index)......33

Table 1.4: Total Effect of Inflation Volatility on Growth (Given the LEGAL2 index)......34

Table 1.5: List of Countries included in the Sample.................................133

Table 1.6: Summary Statistics of main variables................................. 133

Table 1.7: Correlations between the Main Variables............................... 134

Table 1.8: Legal and Financial Institutions indices............................... 134

Table 1.9: Economic Growth and the Interaction between inflation Volatility

And Economic Variables................................................ 138

Table 1.10: Economic Growth and the Interaction of inflation Volatility with LEGAL1

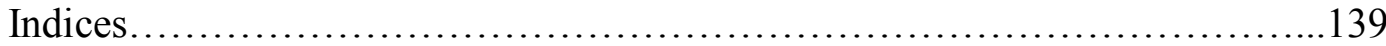

Table 1.11: Economic Growth and the Interaction of inflation Volatility with LEGAL2

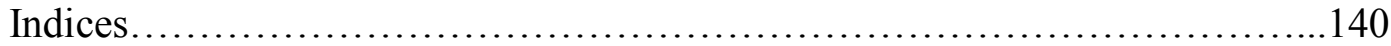

Table 1.12: Total Effect of Inflation Volatility on Growth (Given Corruption)..........142

Table 1.13: Total Effect of Inflation Volatility on Growth (Given Law \& Order)........143

Table 1.14: Total Effect of Inflation Volatility on Growth (Given Bureaucracy)..........144

Table 1.15: Total Effect of Inflation Volatility on Growth (Given Creditors' Rights).....145

Table 1.16: Total Effect of Inflation Volatility on Growth (Given Shareholders'

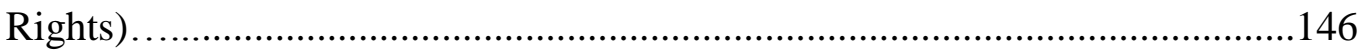


Table 1.17: Total Effect of Inflation Volatility on Growth (Given Enforcement)....

Table 1.18: Total Effect of Inflation Volatility on Growth (Given Accounts).

148

Table 1.19: Robustness Check: Economic Growth and the Interaction between inflation

Volatility and Legal and Financial Institutions Indices

149

Table 1.20: Robustness Check: Total Effect of Inflation Volatility (Given

LEGAL1ndex)

Table 1.21: Robustness Check: Total Effect of Inflation Volatility (Given

LEGAL2 index) 150

Table 2.1: List of Countries included in the Sample .58

Table 2.2: Definition of Variables..............................................60

Table 2.3: First Stage F-statistic of the TSLS ....................................66

Table 2.4: Sovereign debt rating and Inflation Volatility.........................67

Table 2.4': Robustness Check: Sovereign debt rating and Inflation Volatility..........163

Table 2.5: Sovereign debt rating and Inflation Volatility Interactions with

"LEGAL2" Sub-indices................................................. 72

Table 2.6: Total Effect of Inflation volatility on Sovereign Debt Rating (Given

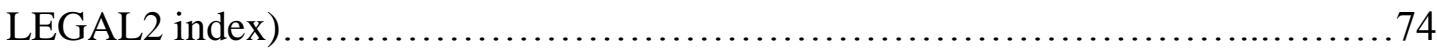

Table 2.6': Robustness Check: Using Panel Least Squares.............................85

Table 2.6": Robustness Check: Total Effect of Inflation volatility on Sovereign

Debt Rating (Given LEGAL1 index) ................................... 164

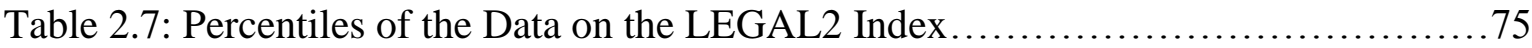

Table 2.8: Total Effect of LEGAL2 on Sovereign Debt Rating (Given

Inflation Volatility)

.79 
Table 2.8': Robustness Check: Using Panel Least Squares....

Table 2.8': Robustness Check: Total Effect of LEGAL1 on Sovereign Debt Rating

(Given Inflation Volatility)......................................... 164

Table 2.9: Percentiles of the Average of the Log of Inflation Volatility Data over the

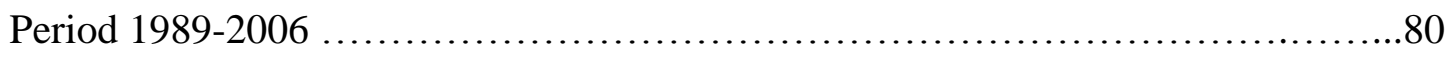

Table 2.10: Sovereign debt rating and Inflation Volatility........................... 83

Table 2.11: Descriptive Statistics................................................ 151

Table 2.12: Correlation Matrix ................................................ 151

Table 2.13: Regional Dummies..............................................152

Table 2.14: Wald Coefficients Test.......................................... 153

Table 2.15: Total Effect of Inflation Volatility on Sovereign Debt Rating

(Given Creditors' rights) ................................................ 154

Table 2.16: Total Effect of Inflation Volatility on Sovereign Debt Rating (Given Shareholders' rights) ........................................... 155

Table 2.17: Total Effect of Inflation Volatility on Sovereign Debt Rating

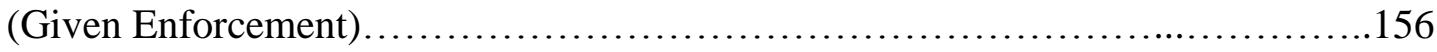

Table 2.18: Total Effect of Inflation Volatility on Sovereign Debt Rating

(Given Accounts).................................................. 157

Table 2.19: Definition of Moody's Sovereign debt rating.......................... 158

Table 2.20: Annual Yield in 2000 (first quarter) and Moody's rating in 2000.......... 160

Table 2.21: Correlation Matrix between LEGAL1 and LEGAL2 .....................161

Table 3.1: Values of the Calibrated Parameters for Mexico..........................112

Table 3.2: Effect of the Drop in $\mathrm{r}^{*}$ holding $\tau$ (at different values) on the New Steady 
State of Output per Worker (as a ratio to its initial level).

Table 3.3: Effect of the Drop in $\tau$ holding $\mathrm{r}^{*}$ (at 3.05\%) on the New Steady State of

Output per Worker (as a ratio to its initial level)

Table 3.4: Effect of the Drop in $\mathrm{r}^{*}$ when coupled with a drop in $\tau$ on the New Steady State of Output per Worker (as a ratio to its initial level).

Table 3.5: Values of the Calibrated Parameters for Mexico for Barro et al. (1995) Model

Table 3.6: Effect of the Drop in $r$ (holding $\tau$ at 0.20 ) on the New Steady State of Output per Worker (as a ratio to its initial level) in Barro et al. (1995) Model........173

Table 3.7: Effect of the Drop in $\tau$ holding $r$ (at 3.05\%) on the New Steady State of Output per Worker as a ratio to its initial level in Barro et al. (1995) Model..... .174

Table 3.8: Effect of the Drop in $\mathrm{r}^{*}$ when coupled with a drop in $\tau$ on the New Steady State of Output per Worker (as a ratio to its initial level) in Barro et al. (1995) Model. 


\section{List of Figures}

Figure 1.a: Scatter Plot of the Relation between Inflation Volatility and Growth.........135

Figure 1.b: Scatter Plot of the Relation between Inflation Volatility and Growth.........136

Figure 1.c: Scatter Plot of the Relation between Inflation Volatility and Growth.........137

Figure 1.1: Total Effect of Inflation Volatility on Growth (Given LEGAL1)..............141

Figure 1.2: Total Effect of Inflation Volatility on Growth (Given LEGAL2)..............141

Figure 1.3: Total Effect of Inflation Volatility on Growth (Given Corruption)............142

Figure 1.4: Total Effect of Inflation Volatility on Growth (Given Law and Order)........143

Figure 1.5: Total Effect of Inflation Volatility on Growth (Given Bureaucracy)...........144

Figure 1.6: Total Effect of Inflation Volatility on Growth (Given Creditors' rights)......145

Figure 1.7: Total Effect of Inflation Volatility on Growth (Given Shareholders' rights)...146

Figure 1.8: Total Effect of Inflation Volatility on Growth (Given Enforcement)..........147

Figure 1.9: Total Effect of Inflation Volatility on Growth (Given Accounts)..............148

Figure 2.1: Total Effect of Inflation Volatility on Rating (Given LEGAL2)................77

Figure 2.2: Total Effect of LEGAL2 on Rating (Given Inflation Volatility)................81

Figure 2.3: The negative relationship between Moody's rating in 2000 (first quarter)

And 5-year Annual Bond Yield in 2000 (first quarter).....................87

Figure 2.4: The Effect of Inflation Volatility on the Long Term Bond Yield...............88

Figure 2.5: The Effect of LEGAL2 on the Long Term Bond Yield.......................88

Figure 2.6: Total Effect of Inflation Volatility on Rating (Given Creditors' rights)........154

Figure 2.7: Total Effect of Inflation Volatility on Rating (Given Shareholders' rights)...155

Figure 2.8: Total Effect of Inflation Volatility on Rating (Given Enforcement)..........156 
Figure 2.9: Total Effect of Inflation Volatility on Rating (Given Accounts)............157

Figure 2.10: Invariant LEGAL2 and variant LEGAL1 ............................ 162

Figure 3.1: Inflation Volatility and LEGAL2 index ............................. 110

Figure 3.2: Impulse Response Functions for a 25\% Permanent Drop in $\tau$............115

Figure 3.3: The Effect of Inflation Volatility on Welfare............................118

Figure 3.4: The Effect of LEGAL2 on Welfare.................................. 120

Figure 3.5: Transition Path for the Drop in $r^{*}$ from 0.0305 to 0.0195

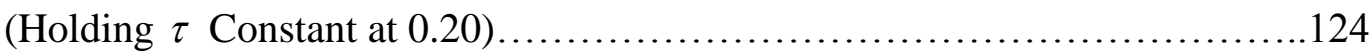

Figure 3.6: Transition Path for the Drop in $\tau$ from 0.20 to 0.15

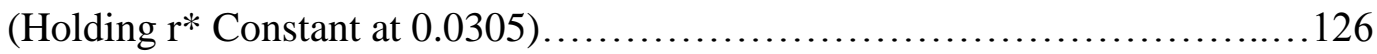

Figure 3.7 Transition Path for the Drop in $r^{*}$ from 0.0305 to 0.0198 Coupled with the

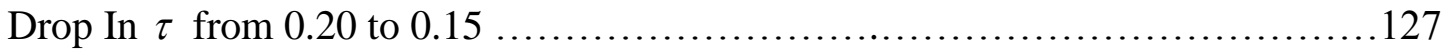






\section{Part I}

\section{INTRODUCTION}

A growing strand of literature focuses on the role of macroeconomic policies versus the role of institutions in generating growth in developing countries. While the policy view does not undermine the role of institutions in economic growth, it argues that the most important factor for the divergence in growth between countries of the world today stems from the differences in the policies implemented by their governments.

On the other hand, the institutions view argues that the level of development in institutions is the main factor explaining the divergence in growth between countries. This view does not consider that macroeconomic policy by itself is an important factor affecting growth. Instead macroeconomic policy is considered a channel through which institutions affect growth. According to this view, bad macroeconomic policy is simply a result of poor institutions in the economy.

This dissertation contributes to this debate of "policies or institutions" by separately quantifying the long-run welfare effects of policy -in particular monetary policy- versus the long-run welfare effects of institutions. The results show that although institutions were found to contribute more to welfare in the long-run, the significant role of monetary policy cannot be undermined. In addition, the results show that this significant role of monetary policy is not stemmed from the underlying institutions. The overall result from this dissertation is that inflation volatility, and not just the level of inflation, is an important factor in the determination of growth and welfare for a developing economy but that the level of financial institutions also is important and that a developing economy 
can get bigger welfare gains by reforming their financial institutions at the same time they reduce inflation volatility in their economy.

Against the above overview, the first chapter of this dissertation analyzes the effect of inflation volatility on growth in the presence of different degrees of institutional development. A panel-data growth regression using System GMM procedure is used to control for endogeneity and unobserved country specific factors for a sample of 37 developed and developing countries over the period 1989-2006. A non-linear growth regression specification that interacts inflation volatility with legal and financial institutions indices, developed by Chinn and Ito (2005), is estimated in this dissertation using the principal component analysis for the sample and the time period under study. The results of this chapter show that inflation does not have a statistical significant impact on growth. On the other hand, it is the volatility of inflation that has a statistically negative significant growth effect. In addition, and in contrast with the results of Acemoglu, Johnson, Robinson and Thaicharoen (2003) and Easterly (2004), the study finds that inflation volatility does not act as a proxy for institutions. Improving institutions will have a statistical significant positive impact on growth which will help to reduce the negative impact of inflation volatility. The magnitude of the effect of institutions on growth will be small and insignificant in institutionally developed countries, but relatively big and significant in institutionally poor countries. The results of this chapter were robust to the use of different estimation methodology.

Having found a significant impact of inflation volatility on growth that is separate from the significant impact of institutions on growth, the second chapter of this dissertation analyzes the channel through which inflation volatility versus institutions 
affect growth. The chapter identifies an important channel which is the investment channel, or the sovereign debt rating channel. To do that, the chapter empirically analyzes of the impact of inflation, inflation volatility, and financial institutions on a country's sovereign debt rating. Using a sample of 37 developed and developing countries over the period 1989-2006, the study estimates a non-linear rating regression that interact inflation volatility with the index for financial institutions. The results suggest that inflation does not have a statistical significant effect on sovereign debt rating once inflation volatility has been included in the regression. In addition, reducing inflation volatility can have a statistically and economically significant positive effect on a country's sovereign debt rating as compared to the level of inflation. The results also show that improving financial institutions has a statistically significant positive direct and indirect effect on a country's sovereign debt rating. For instance the study finds that for a developing country, with relatively poor financial institutions and moderately high inflation volatility, a one standard deviation decrease in the log of inflation volatility will lead to an increase in a country's sovereign debt rating of about two classifications. This increase in sovereign debt rating leads to a reduction in the average annual long-term bond yield by about $4.4 \%$. On the other hand, a one standard deviation increase in the financial institutions' index will lead to an increase in the ratings class of about one class, which in turn reduces the average annual long-term bond yield by about $4.27 \%$.

These empirical results were then used in chapter three to calibrate a monetary small open economy model of McCandless (2008) with cash in advance constraint, capital adjustment cost, foreign bonds, trade sector, and with four types of shocks; monetary, foreign price, technology, and institutions shocks. The main goal is to quantify the 
welfare implications under two policy scenarios; 1) a one standard deviation decrease in inflation volatility and 2) a one standard deviation increase in the level of financial institutions. The monetary small open economy model was calibrated using the quarterly data for Mexico; a country that, by the measure used in the study has poor financial institutions and moderately high inflation volatility. The results of the model suggest that a one standard deviation reduction in inflation volatility will increase welfare by at most $11.4 \%$ while a one standard deviation improvement in institutions will lead to an increase in welfare in the range of $17 \%$ to $23 \%$. The welfare implications of the monetary small open economy model were found to be much smaller when compared to the open economy model of Barro and Sala-i-Martin (1995) where the economy had neither access to trade nor access to foreign bonds. Further, simulations were undertaken in order to analyze the impulse response functions of the economy to a permanent shock in institutions. In addition, the study analyzes the impact of the reduction in inflation volatility versus the impact of the improvement in institutions on the behavior of the endogenous variables along the transition path.

An important policy implication of this dissertation suggests that developing economies can get larger welfare gains from improving their institutions than from reducing inflation volatility. This policy implication does not undermine the role that can be played by the monetary policy in growth, but improving institutions has a couple of positive effects; A direct effect on welfare through reducing the resource waste in the economy and an indirect effect on welfare that acts through the financial institutions' impact on reducing the harmful impacts of inflation volatility on growth. Also, this policy 
implication is intuitive in the sense that reducing inflation volatility is costly on output, while improving financial institutions is a cost free policy. 


\section{Part II}

\section{Chapter 1: Inflation Volatility, Institutional Environment And Economic Growth}

\subsection{Introduction}

There are many studies addressing the role of the economic policy versus the role of institutions in growth. However, few of these studies have addressed the role of the second moments of the policy instead of the policy itself in affecting growth. In this study, the role of inflation volatility versus the role of institutions in growth is studied by adding the volatility of inflation and its interaction term with legal and financial institutions to the growth regression. The aim is to determine how the total effect of inflation volatility on growth is affected by the level of institutional development.

The main contribution of this chapter is that it shows that while the level of inflation does not have a significant effect on growth, which is in line with previous studies; inflation volatility does significantly impact growth. Thus, inflation volatility does have an effect on growth even for countries with moderately high levels of inflation. This chapter also finds that improving either legal or financial institutions will statistically significantly help to reduce the harmful effects of inflation volatility on growth. In addition and in contrast to the results of Acemoglu, Johnson, Robinson and Thaicharoen (2003) and Easterly (2004), the chapter shows that inflation volatility does not act as a proxy for either type of institutions. Finally this chapter shows that the contribution of institutions in reducing the harmful impacts of inflation volatility on growth will be 
relatively small and insignificant in institutionally developed countries, but relatively big and significant in institutionally poor countries.

The Chinn and Ito (2005) indices of legal and financial institutions, "LEGAL1" and "LEGAL2" respectively, were estimated in this chapter for the sample of countries and time period under study. The LEGAL1 index was estimated using the principal component analysis from three indices; bureaucracy, corruption, and law and order. Similarly, the LEGAL2 index was constructed from four indices; the protection of creditors' rights, the protection of shareholders' rights, transparency of the company's account, and strong enforcement of laws.

Using a cross-section of 37 developed and developing countries over the period (1989-2006), the results of this chapter show that the impact of institutions is significant up to the countries on the $80^{\text {th }}$ percentile for either LEGAL1 or LEGAL2. A one standard deviation reduction in inflation volatility will lead to an increase in growth of about $0.93 \%$ and $0.90 \%$ in countries with the worst level of legal institutions and financial institutions respectively. Also, a one standard deviation reduction in inflation volatility will lead to an increase in growth of only about $0.13 \%$ and $0.08 \%$ for countries on the $80^{\text {th }}$ percentile of legal and financial institutions respectively. Finally, for countries with the best level of either legal or financial institutions, improving institutions will not have any statistical significant effect on growth.

The empirical model presented in this chapter is theoretically based on Choi, Smith and Boyd (1995). In their paper a theoretical model was developed and the inter-linkages between inflation, market frictions, inflation volatility, and growth were presented to prove that high inflation will lead to high inflation volatility which in turn leads to more 
financial frictions in the market and thereby inhibits growth. The type of friction assumed in this model is information asymmetry. A high inflation will reduce the real value of interest rates making it cheaper for those borrowers who were not borrowing at the high real interest rates. Accordingly, there will be a higher demand for credits by this type of borrowers. Credit owners on the other hand would fear lending them, and they would prefer to ration credits. The more credit rationing the higher is the inflation volatility which in turn affects the real activity. So the higher is inflation, the more information asymmetry, the more inflation volatility, and the lower is the real growth rate.

The model used by Choi, Smith, and Boyd (1995) analyzes how the transmission of the effect of inflation to real growth through the financial market depends on whether we are to analyze a relatively high average inflation country vs. a relatively low average inflation country. A high average inflation country will relatively experience more financial frictions than a low average inflation country. For the former country, a higher inflation will exert a strong negative impact on growth, while in the latter country this negative impact might not appear at all. As noted in Choi, Smith, and Boyd (1995), the low average inflation country will experience a "Mundell-Tobin effect", where a higher inflation leads to more growth as credit rationing might not appear at all in the financial market of this country. Accordingly, there is a threshold limit for inflation beyond which it will exert its negative impact on growth. And this is because there is a threshold limit for market frictions beyond which it will adversely affect growth.

The relation between inflation and growth has been extensively studied in many empirical papers. Although the general consensus among economists is that inflation has a statistical significant negative impact on growth, as in the work of Fisher (1993), 
Motley (1994) and Barro (1995) have showed, other economist believed that this result is not robust.

The work of Levine and Renelt (1992) showed that inflation growth relation is very sensitive to the regression specification. In a cross section study by Levine and Zervos (1993), they found that the growth-inflation relation depends on few outliers in their sample of countries; basically Uganda and Nicaragua. Also, in the study of Bruno and Easterly (1995), they found that the growth inflation relation depends on a threshold level of inflation of $40 \%$ where in countries with annual inflation below this percentage inflation will have an insignificant impact on growth. In addition, the study of Clark (1997) concluded that although the results show a general statistical significant negative relation between inflation and growth, this relation is however not robust to either the change in the sample of countries or to the change in the time period under study.

The harmful impacts of inflation volatility instead of the level of inflation has been highlighted long time ago in the work of Friedman (1977) where he found that although the long term monetary policy neutrality holds in the level of the policy, it does not hold in its second moment. The work of Levine and Zervos (1993) studied the separate effects of the level and the volatility of inflation on growth. They concluded that neither the level nor the volatility of inflation is robustly correlated with growth. On the other hand, using panel data Orphanides and Judson (1996) found that both inflation and inflation volatility were robustly negatively correlated with growth for the high inflation countries and they concluded that a good policy is a one that is able to reduce the level of inflation and at the same time stabilize inflation. In addition, using the square root of the conditional variance of inflation from a $\operatorname{GARCH}(1,1)$ model as the measure of inflation uncertainty, Coulson 
and Robbins (1985) found a positive association between this measure of inflation uncertainty and US economic performance. Jansen (1989) on the other hand found no significant relationship between the two variables. Coulson and Robbins (1985) results were however not also confirmed by Grier and Perry (2000) and Grier, Henry, Olekalns, and Shields (2004) who reported a negative relation between inflation uncertainty and growth in the US.

The literature on the importance of strong institutions, either legal or financial institutions, is rapidly growing. This literature started with the work of La Porta, Florencio, Andrei and Robert (1997) where they showed the importance of legal and financial institutions for firm's decisions. Rodrik (1999) showed that countries with the sharpest drop in growth after 1975 are those countries with weak institutions which was is measured by rule of law, democratic rights, and social safety nets. Acemoglu et al.(2003) showed that institutions matter more to growth than does the economic policy. Once institutions variable has been included in the regression, the coefficient of the macroeconomic policy turns insignificant. These results were confirmed by Easterly (2004).

In contrast to these results of Acemoglu et al. (2003) and Easterly (2004), in a cross section of 91 countries Fatas and Mihov (2005) studied the effect of fiscal policy volatility, institutions and growth. The results of their paper showed that fiscal policy volatility has a significant negative impact on growth and in addition they showed that institutions affect growth only through its effect on the policy and particularly the volatility of the policy. 
In line with the results of Acemoglu et al.(2003) and Easterly (2004), using a panel data on hundred countries over the period 1975-1999 Veiga and Aisen (2006) found a positive association between greater fragmentation, polarization, and political instability, as forms of market frictions and inflation volatility. And that these forms of market frictions constitute the main determinants of inflation volatility.

On the micro-economic level, Johnson, McMillan, and Woodruff (2002) showed from their survey on new firms in post communist countries that strong property rights affects the firms' decision to reinvest their profits. Also, using data on thousands of firms in 80 countries, Alberto and Mark (2006) concluded that volatility has a negative effect on the firm's growth and this negative effect is magnified with weak institutions. In their paper volatility is defined as the volatility in the firm's decisions to enter new projects which in turn depends on the government inability to create a credible policy. And institutions On the other hand were defined as high entry barriers. Beck, Demirguc-Kunt, Laeven, and Levine (2006) found that the financial constraints faced by firms will depend on the firm's size. Large firms are expected to face less financial constraints. In addition, they found that firms located in countries with well developed legal and financial institutions are facing less financial constraints and these institutions will be basically the driving force for economic development.

Against the above background, in what follows the empirical specification of a model is presented that extends previous studies and demonstrates that it is the volatility of the policy and not the level of the policy that has more impact on growth. Next the growth regression model is expanded by including the effect of institutions and is then used to 
compute the total effect of volatility of inflation on growth under different degrees of institutional development.

The study consists of the following sections; section 1.2 presents the empirical specification of the model, section 1.3 describes our data, section 1.4 discusses the estimation results, section 1.5 calculates the total effect of inflation volatility on growth, section 1.6 presents two robustness checks, section 1.7 concludes the chapter. Finally, Appendix (I) is by the end of the dissertation.

\subsection{Empirical Specification}

Most of the researches in economic growth focusing on the endogenous growth models have started at early 1990's. These models basically assume that growth arises from human capital accumulation. The endogenous growth models were found to be important for analyzing the different government policy measures on long run growth in the economy. Among many other economists, Lucas (1988), Romer (1990), King and Rebelo (1990), and Rebelo (1991) were the first to analyze the long run implications of these models on economic growth.

In line with the endogenous growth theory models and for the purpose of the analysis of this chapter, this section empirically estimates a growth model that is a function of the initial level of per capita GDP, the level of inflation, volatility of inflation, investment in human capital, and institutional development. In addition, the empirical growth model of this section includes a proxy for trade openness which was found by many endogenous 
growth models as in Young (1991), Grossman and Helpman (1991), Eicher (1993), and Lee (1993) to positively contribute to long-run growth.

The main focus of the empirical model of this chapter is to analyze the effect of inflation volatility on growth in a model that controls for the level of legal and institutional variables. Following Caselli, Equivel and Lefort (1996), Holtz-Eakin, Newey and Rosen (1988) and Arellano and Bond (1991), the growth model is estimated using dynamic panel System GMM.

Equation (1.1) provides the general form of the empirical model;

$$
y_{i, t}-y_{i, t-v}=\beta_{0} y_{t-v}+\beta_{1} C V_{i, t-v}+\eta_{i}+d_{t}+\varepsilon_{i, t}
$$

where the subscripts $i$ and $t$ represent the country and the time period respectively. The variable $y_{i, t}$ is the log GDP per capita. Hence, the left hand side of the above Equation represents the log difference of the real GDP per capita over a period of $v$ years, in other words it represents the growth rate over the period, where $v=3$. The explanatory variables consist of $y_{i, t-v}$ which represents the beginning of the period GDP per capita, $C V_{i, t-v}$ is the set of control variables that are measured either at the beginning of the period or as an average over the $v$ period. This set of control variables include level of inflation at the beginning of the period, log inflation volatility at the beginning of the period, the average over the period of the current account balance as a percentage to GDP as a proxy of trade openness, and the average over the period years of schooling as a proxy of human capital investment. This is in addition to the country specific effects and time period dummies that are represented by $\eta_{i}$ and $d_{t}$ respectively. 
Worth noting that the country specific effect can pick the impact of either economic or financial crises that affected about seven of the countries included in the sample. Also, the time period dummy can pick the impact of the contagion effects of a crisis on financial markets in developed or developing countries.

The System GMM proposed by Arellano and Bover (1995), Blundell and Bond (1998), and Blundell, Bond, and Windmeijer (2000) over comes the bias problems of the difference GMM estimator. It works by basically stacking together Equation (1.1) above with Equation (1.2) below,

$$
\left(y_{i, t}-y_{i, t-v}\right)-\left(y_{i, t}-y_{i, t-2 v}\right)=\beta_{0}\left(y_{t-\tau}-y_{t-2 v}\right)+\beta_{1}\left(C V_{i, t-\tau}-C V_{i, t-2 v}\right)+d_{t}+\left(\varepsilon_{i, t}-\varepsilon_{i, t}\right) .
$$

The main reason for differencing Equation (1.1) is to eliminate the country specific or unobserved effects following Arellano and Bond (1991). In addition to the assumptions of the Difference GMM ${ }^{1}$, the System GMM assumes that the first difference of the dependent variable and the explanatory variables are uncorrelated with the country specific effects which provides the following two extra moments conditions about the correlation between the dependent variable and the error term and the set of the independent variables and the error term,

$$
\begin{aligned}
& E\left[\Delta y_{i, t} \varepsilon_{i, t}\right]=0, \text { For } \mathrm{t}=2, \ldots \mathrm{T} \\
& E\left[\Delta X_{i, t} \varepsilon_{i, t}\right]=0, \text { For } \mathrm{t}=2, \ldots \mathrm{T},
\end{aligned}
$$

\footnotetext{
${ }^{1}$ More details on Difference GMM are available in Traub (2006).
} 
where $X_{i, t}$ is the set of all the explanatory variables of Equation (1.1) which includes $y_{i, t-v}, C V_{i, t-v}$. In order to satisfy these additional moments conditions, the correct set of instruments was chosen by regressing the dependent variable and each of the explanatory variables in levels, each variable in a turn, on all the possible lags of the dependent variable and the explanatory variables in first difference starting from the second lag in addition to time dummies. The instruments were chosen in such a way that a unique set of instrument for $y_{i, t-v}$ and $X_{i, t-v}$ can be found. This set of instruments usually consists of the second lag of $y_{i, t-v}$ and $X_{i, t-v}$ plus any other extra instruments that appear to be also significant.

For the set of instruments to be valid, it has to be both relevant and exogenous to the error term. The relevance test checks and makes sure that the first stage F-statistic equals or exceeds 10 or in other words that the bias of the Two Stage Least Squares is at most $10 \%$ of the bias of the Ordinary Least Squares methodology ${ }^{2}$. The exogeneity test or "Over Identification Test", or as know by Sargan test (Sargan 1988), tests that the moments conditions of Equation (1.3) above are satisfied.

To find the relevant set of instruments it is important to start by a small model in which $y_{i, t}$ and the components of the matrix $X_{i, t}$ are regressed, each one in a turn, on the lags of $\Delta y_{i, t-v}$ and $\Delta X_{i, t-v}$ starting from the second up to the fourth lag. The significance of the last lag of $\Delta y_{i, t-v}$ only is then checked. If it shows to be significant, its fifth lag is to be added. But if it is not significant, the fourth lag is removed and the model is reestimated again with lags starting from the second up to the third of $\Delta y_{i, t-v}$ while keeping

\footnotetext{
${ }^{2}$ The book of Stock \& Watson (2006) provides good explanation on the TSLS.
} 
the lags of $\Delta X_{i, t-v}$ unchanged (i.e. second up to the fourth lag). The process is repeated until the right set of instruments for $y_{i, t}$ is reached. Next, the same process is repeated for the components of the matrix $X_{i, t}$ each one in a turn, while keeping the set of instruments found for the $y_{i, t}$ model unchanged. After the process of finding the correct set of instruments for all the explanatory variables of the matrix $X_{i, t}$ is over, it is very important to check again that the final chosen set of instruments is significant in the $y_{i, t}$ model. If the last lag of $\Delta y_{i, t-v}$ is confirmed to be still significant this would mean that the correct set of instruments is finally found. If on the other hand, the last lag of $\Delta y_{i, t-v}$ turns out to be insignificant, one lag has to be reduced and the model is to be re-estimated. The process is repeated until the correct set of instruments is found. The significance of each instrument is judged by its t-statistic and also by the F-statistic of the whole regression. According to this process, the most relevant set of instrument for the base growth regression is the second and the third lag of; the beginning of the period GDP, the beginning of the period inflation, and the beginning of the period log inflation volatility. This is in addition to the second lag of the average trade volume as a percentage of GDP, and the second lag of the average over the period years of schooling.

Following Chang et al (2005) and Traub (2006) the base model is expanded by including interaction terms. The interaction terms include the legal and financial institutions indices and their seven sub-indices each one is interacted in a turn. The objective is to estimate the total effect of inflation volatility on growth when it is interacted with these legal and financial institutions variables (each one in a turn) and to analyze which interaction term contributes more and significantly to reducing the 
negative effects of inflation volatility on growth. The interaction term is estimated by adding $\beta_{3}\left(L 1_{i, t-v} *\right.$ Infvol $)$ to the right hand side of Equation (1.1) as shown below.

$$
\begin{aligned}
y_{i, t}-y_{i, t-v} & =\beta_{0} y_{t-v}+\beta_{1} C V_{i, t-v}+\beta_{2} \text { Infvol }_{i, t-v} \\
& +\beta_{3}\left(L 1_{i, t-v} * \text { Infvol }_{i, t-v}\right)+\eta_{i}+d_{t}+\varepsilon_{i, t}
\end{aligned}
$$

where Infvol $l_{i, t-v}$ is the beginning of the period inflation volatility and it is taken out of the $C V_{i, t-v}$ set and added to the regression above. The term $L 1_{i, t-v}$ represents the legal institutions index, or LEGAL1.

Similarly, Equation (1.1) will be expanded by adding the interaction term $\beta_{3}\left(L 2_{i} *\right.$ Infvol $)$ which represents the indirect effects of financial institutions index "LEGAL2" and the equation is shown as follows;

$$
\begin{aligned}
y_{i, t}-y_{i, t-v}=\beta_{0} y_{t-v}+ & \beta_{1} C V_{i, t-v}+\beta_{2} \text { Infvol }_{i, t-v} \\
& +\beta_{3}\left(L 2_{i} * \text { Infvol }_{i, t-v}\right)+\eta_{i}+d_{t}+\varepsilon_{i, t}
\end{aligned} .
$$

The total effect of inflation volatility on growth will then be estimated by adding the coefficient of inflation volatility $\beta_{2}$ to the coefficient of the interaction term $\beta_{3}$ times the factor interacted with volatility. Accordingly, in Equation (1.4) the total effect of inflation volatility equals $\beta_{2}+\left(\beta_{3} * L 1_{i, t-\nu}\right)$ when interacted with the LEGAL1 index and equivalently $\beta_{2}+\left(\beta_{3} * L 2_{i}\right)$ in Equation (1.5) when interacted with the LEGAL2 index. 


\subsection{Data}

The data set was constructed as a panel of country observations from the data base of the World Bank "World Development Indicators", and includes 37 countries over the period 1989-2006. In order to analyze the long-term effects of inflation volatility on growth, the data were averaged into three years' time periods. Data are thus available for six time series observations for each country.

The set of control variables is selected considering both their importance as growth determinants per se and their potential for affecting the growth response of inflation volatility. The control set includes variables that vary both across countries and over time, as well as variables that vary only across countries. Among the former, the set includes the beginning of the period inflation rate, the beginning of the period inflation volatility, the average over the period current account balance as a percentage of GDP as a measure of trade openness, the beginning of the period years of schooling to account for human capital investment, and the LEGAL1 index and its three components; bureaucracy, corruption, and law and order. Among the variables that vary only across countries, the set includes the LEGAL2 index and its four indices; creditors' rights, shareholders' rights, enforcement, and accounts.

The growth data was computed as the log difference of GDP per capita normalized by the length of the period. Data for the years of schooling were collected from the Barro and Lee (2000) data set. Following Coulson and Robins (1985), the data on inflation volatility was calculated as the log of the square root of the conditional variance series of inflation calculated by $\operatorname{GARCH}(1,1)$ model. As noted in Clark (1997) Measuring 
inflation volatility as the coefficient of variation of the level of inflation provides an assurance that the level of inflation is not correlated with its variance and hence will not pose any imperfect multicollinearity issues in estimating the growth regression when both the level and volatility of inflation are included.

As mentioned previously, the Chinn and Ito (2005) indices, LEGAL1 and LEGAL2 were estimated for the sample and time period under study in this dissertation. These two indices were developed using the principal component analysis. Concerning the first type of institutions index, LEGAL1 ${ }^{3}$, it contains the measures related to the general development of the legal systems. It was estimated by the principal component analysis of four indices namely corruption, law and order and bureaucracy. The corruption index ranges from 1 to 6 , where a highly corrupted country will take an index of 1 and the lowest corrupted country will take an index of 6 . For instance the Belgium has an index of 6 while Egypt has an index of 1. Next, the law and order index ranges from 1 to 6 , where the higher the index reflects a stricter criminal justice system. This index refers to a political platform which supports a strict criminal justice system, especially in relation to violent crime and property crimes, through harsher criminal penalties. These penalties may include longer terms of imprisonment, mandatory sentencing, and in some countries, capital punishment. Finally, the Bureaucracy index ranges from zero to 4, where the higher the index the less is the bureaucracy in the economy. The data on the three legal indices were collected from La Porta et al. (1998). The LEGAL1 index combines those

\footnotetext{
3 The first eigenvector of LEGAL1 was found to be (Bureaucracy, Corruption, Law \& Order)' $=(0.269$, $0.041,0.671,0.689)^{\prime}$. This index is normalized, centered at zero with a standard deviation equal to one.
} 
three indices using the principal component analysis and it ranges from -4.23 up to 1.73 where again the higher the index the more developed the legal institutions.

The second type of institutions index, LEGAL2 ${ }^{4}$, it contains legal indices that govern financial transactions. From here after it will be referred to as the financial institutions index. Again this index was estimated using the principal component analysis of the four indices namely protection of creditors' rights, effectiveness of the legal system in enforcing contracts, protection of shareholders' rights, and comprehensiveness of company reports. The index of creditors' protection ranges from 0 to 4 , where more protection for creditors implies a higher index. It is composed of the variables that incorporate the automatic stay proposition on the assets of a failing firm, the continuation of the old managers in a reorganization process, restrictions for going into reorganization and the seniority system of secured creditors. Next, the index of the degree of law enforcement ranges from 4.87 to 9.99 where again the higher the index the stricter is the system of law enforcement. This index consists of the average of the efficiency of judicial system, rule of law, risk of expropriation, and risk of contract repudiation. Concerning the third sub-index, the index of shareholders' rights, it ranges from 0.05 to 5.10 where the higher the index the more protection of shareholders' rights. This index is composed of the sum of the one share-one-vote, proxy by mail, shares not blocked before meeting, cumulative voting/proportional presentation, oppressed minorities, preemptive right to new issues and percentage of share capital to call an emergency shareholder meeting less than ten percent ${ }^{5}$. Finally, the accounts index ranges from 24 to 83 where a

\footnotetext{
4 The first eigenvector of LEGAL2 was found to be (Creditor, Shareholder, Enforcement, Account)' = $(0.269,0.041,0.671,0.689)^{\prime}$. This index is normalized, centered at zero with a standard deviation equal to one.

${ }^{5}$ More details on these sub-indices are provided in La Porta et al. (1998).
} 
higher index implies more transparency and comprehensiveness of the reports. The data on these four sub-indices of the LEGAL2 index were collected from the International Country Risk Guide- ICRG (country data). The LEGAL2 index ranges from -2.90 up to 1.83.

It is important to note that the countries of the data set were chosen on the basis of the availability of the data on the components of LEGAL1 and LEGAL2. The results might then be seen as conservative since the constraining the data set to only 37 countries might cause sample selection bias. The list of countries included in the sample is reported in Table 1.5 of Appendix (I). As shown in this table, the countries included in the sample consist of a set of low income developing countries and a set of developed countries. Most of the OECD countries were included in the sample. Also many of the countries in the sample are Latin American countries. In addition, the sample includes some countries which faced economic or financial crises in the past like Argentina (19992002), Brazil (1980’s), Mexico (1994), Uruguay (2002), Korea (1997), Thailand (1997), and Turkey (1980's, 1994, 2000-2001).

Figure 1.a, 1.b and 1.c of Appendix (I) plots the scatter plot of the time series data of inflation volatility (on the y-axis) against the data of GDP growth (on the x-axis) over the period of the study. As can be noticed from the spread of the volatility and growth combinations on the graphs, the negative expected relationship between these two variables was obvious in most of the countries but was hard to be noticed in some others. Also, from these graphs it can be noticed that three countries have experienced relatively high volatility over the period of the study Argentina, Brazil, and Peru. These countries 
were excluded from the sample based on a non-subjective criterion by excluding the top $10 \%$ of the log inflation volatility distribution.

\subsection{Estimation Results}

Using dynamic panel two-step System GMM with time dummies in the level equation and with using the finite sample correction for the variance matrix proposed by Windmeijer (2005), the growth model is estimated for the panel of 37 countries over the period 1989 to 2006. The estimation results of the benchmark model are presented on Table 1.1 below. The Table consists of five columns representing the results of five regressions. In each regression, the dependent variable is per-capita real GDP growth. As mentioned previously, in estimating the model the top $10 \%$ of the volatility distribution was discarded from the data. This is basically to remove the impact of the outliers on the estimation bias in the results.

The results presented in Column 1 shows an expected statistical significant negative effect of the initial level of GDP at the beginning of the period on growth over the period. As the beginning of the period GDP increases by $1 \%$, growth over the period decreases by about $0.62 \%$. This result confirms the convergence hypothesis; countries that are relatively advanced in their development process will grow slower than those countries lagged behind.

Adding the beginning of the period inflation to the regression as shown in Column 2 of the same table, the coefficient of inflation does not show any sign of statistical significance. This result goes in line with the implication of the theoretical model of 
Choi, Smith, and Boyd (1995) on which the empirical model of this chapter is based, that there is a threshold limit for inflation beyond which it will exert its negative impact on growth.

Table 1.1 The Base Model of Economic Growth

Cross-country panel data consisting of non-overlapping 3-year averages (1989-2006). Estimation Method: System GMM Estimation

\begin{tabular}{lccccc}
\hline & {$[1]$} & {$[2]$} & {$[3]$} & {$[4]$} & {$[5]$} \\
\hline Constant & $3.154 * * *$ & $2.796 * *$ & $2.762 * *$ & $2.936 * * *$ & $4.093 * * *$ \\
& $(0.620)$ & $(1.235)$ & $(1.298)$ & $(0.819)$ & $(1.153)$ \\
Initial & $-0.620 * * *$ & $-0.542 * *$ & $-0.532 * *$ & $-0.558^{* * *}$ & $-1.192 * * *$ \\
GDP/capita & $(0.135)$ & $(0.246)$ & $(0.257)$ & $(0.169)$ & $(0.332)$ \\
Inflation & & 0.018 & 0.026 & 0.019 & 0.050 \\
& & $(0.091)$ & $(0.109)$ & $(0.072)$ & $(0.085)$ \\
Volatility & & $-0.042 * * *$ & $-0.035 * * *$ & $-0.053 * * *$ \\
& & & $(0.164)$ & $(0.013)$ & $(0.015)$ \\
Openness & & & $0.028 *$ & 0.0397 \\
& & & & $(0.015)$ & $(.029)$ \\
Human Capital & & & & & $0.176 * *$ \\
Investment & & & & & \\
Countries/Obser & $34 / 161$ & $34 / 161$ & $34 / 161$ & $34 / 161$ & $34 / 161$ \\
vations & & & & & \\
\hline Sargan Test, & 36.65 & 33.37 & 32.88 & 28.35 & 30.01 \\
p-value & {$[0.30]$} & {$[0.35]$} & {$[0.33]$} & {$[0.49]$} & {$[0.36]$} \\
\hline
\end{tabular}

Notes: Numbers below coefficients are the corresponding robust standard errors.

(***), (**) and $(*)$ denotes statistical significance at the $1 \%, 5 \%$ and $10 \%$ levels respectively.

Number between [.] are the p-values of the Sargan Test.

In addition the insignificance of the coefficient of inflation confirms with the findings of Bruno and Easterly (1995) that excluding inflation levels above $40 \%$ from their sample, inflation will not have any sign of statistical significance to growth. As noted in their paper "... if we omit the set of countries that had inflation at some point pass 40 percent, then we fail to detect any significant association between inflation and growth." By looking at the data on the level of inflation for the 37 countries over the period of the study, it is found about $93 \%$ of the inflation observations are below $40 \%$ which is considered a relatively not high level of inflation that could lead to harmful 
effects on growth. This also goes in line with the results of Bullard and Keating (1994) that inflation will exert its negative impact on growth only in countries with relatively high initial level of inflation.

Also, the results of Clark (1997) that inflation is not robustly negatively affecting growth. And as noted in Levine and Renelt (1992), the relation between inflation and growth is not robust to the changes in; the regression specification, the sample of countries or the time period under study.

Adding inflation volatility to the model, Column 3 shows that its coefficient is statistically significant with an expected negative sign where a one percent increase in inflation volatility at the beginning of the $v=3$ period will lead to a reduction in growth over the period by about $0.042 \%$. This result is considered an important contribution of this chapter, where while the level of inflation does not have a significant effect on growth, which is in line with previous studies; inflation volatility does significantly impact growth.

Column 4 shows the results of adding the proxy for openness to the growth regression, as can be noticed from the table above, the coefficient of the initial level of GDP and the coefficient of the volatility of inflation both remained significant and with the expected sign. In addition, the coefficient of openness appeared to be also significant and with the expected positive sign. A one percent increase in the percentage of the current account to GDP at the beginning of the period will lead to about $0.028 \%$ increase in growth over the three years period.

Finally, Column 5 shows the results of adding the beginning of the period years of schooling to account for human capital investment. As obvious from above, the 
coefficient of the years of schooling appeared statistically significant and positive. This matches the results of previous studies by Edwards (2001) and Arteta, Eichengreen, and Wyplosz (2003) where human capital was also found to have a significant positive impact on growth. As shown in Column 5, a one year increase in the beginning of the period years of schooling will lead to an increase the growth over the three years period by about $0.176 \%$.

For all regression results of this Table, the p-value from the Sargan test of the validity of instruments indicates a failure to reject the null that instrumental variables are uncorrelated to some set of residuals, and therefore the instruments pass the test and are valid by this criterion.

It is worth to note that although the investment variable is a standard control variable in growth regressions, when the data on investment share of real GDP (\% in 2000 constant prices) ${ }^{6}$ was included in the regression it was found to be insignificant but with the expected positive sign. The insignificance of the investment variable might be either due to the relatively high correlation between it and the beginning of the period GDP/capita which reached about $44 \%$ or due to the relatively high correlation between it and LEGAL1 and LEGAL2 which reached 40\% and 50\% respectively.

In addition, several other factors have been tried to be included in the regression but turned to be insignificant because again of the correlation problem with some of the determinants of growth. For example, when the average over the period private domestic credit as a percentage of GDP, as a proxy for the impact of financial deepening on growth, was included in the regression its coefficient appeared to be positive as expected but statistically insignificant. The insignificant sign was basically due to the high

\footnotetext{
${ }^{6}$ Data on the investment share of real GDP was collected from Penn World Tables 6.2.
} 
correlation between financial depth and the beginning of the period GDP that reaches $51 \%$ this is in addition to the high negative correlation between financial depth and inflation volatility that also reaches $51 \%$.

Similarly, when the beginning of the period number of main telephone lines per thousand people as proxy for public infrastructure was added to the growth regression, its coefficient appeared insignificant. This is again explained by the very high correlation of $91 \%$ between good infrastructure at the beginning of the period and the beginning of the period GDP.

In addition, a dummy for the crises countries was added to the base model, where this dummy takes 1 for countries with a crisis, namely Argentina (1999-2002), Brazil (1980’s), Mexico (1994), Uruguay (2002), Korea (1997), Thailand (1997), and Turkey (1980's, 1994, 2000-2001). Adding this dummy to the model, the results show that it was not significant. The coefficient of the main variables in the model though, did not change its significance from the case in was shown in Table 1.1.

In order to estimate a parsimonious model, the investment share of real GDP, the proxy for financial depth, the proxy for public infrastructure, and the dummy for crises countries were discarded from all the regressions.

In all the regressions of Table 1.1 above, the coefficient of the volatility of inflation was statistically significant and with the expected negative magnitude despite the fact that the high levels of inflation volatility that might be deriving the results were discarded from all regressions. The level of inflation on the other hand was statistically insignificant in all regressions. This shows that the impact of inflation volatility is more important to growth than the impact of the level of inflation and this confirms the results of Stockman 
(1981) De Gregorio (1993) and Jones and Manuelli (1993) that inflation volatility significantly harms growth. The intuition here is that if the level of inflation is high but predicted, people can always change their behavior and react accordingly, thereby avoiding the negative effect of the high inflation. On the other hand, if the level of inflation is unpredictable people would be uncertain of what the future holds for them. Therefore, the future will not be safe to welcome domestic and international investments. Investors local and foreign will not have an incentive to invest in the country. Hence a high inflation volatility will have harmful effects on capital accumulation and thereby growth. This answers the first question of the study that the volatility of the policy is more important to growth than the policy itself.

Table 1.9 of Appendix (I) shows the interaction of the inflation volatility with the other determinants of growth included in the base model. For the sake of brevity, Table 1.9 reports the coefficients of inflation volatility and the coefficients of the interaction terms. As shown in the table, the coefficients of the interaction terms were only statistically significant with the expected sign for both the interaction with inflation and the interaction with openness. The coefficients of the interaction terms with the beginning of the period GDP and the average years of schooling were neither significant nor with the expected sign.

As Column 2 of Table 1.9 shows, the interaction of inflation volatility with inflation is statistically significant and with the expected negative sign. A high beginning of the period inflation will increase the negative impact of the beginning of the period inflation volatility on the average over the period growth. A one percent increase in inflation will lead to an increase in the negative impact of inflation volatility on growth by about 
$0.047 \%$. Also, Column 3 shows the results when the base growth model was interacted with the proxy of openness. This interaction term appeared statistically significant with the positive expected sign. A one percent increase in the percentage of current account to GDP will reduce the negative impact of inflation volatility on growth by about $0.078 \%$.

Table 1.2: Economic Growth and the Interaction between inflation Volatility and Legal and Financial Institutions Indices.

Cross-country panel data consisting of non-overlapping 3-year averages spanning 1989-2006 Dependent variable: Growth rate of real GDP per capita.

Estimation Method: System GMM

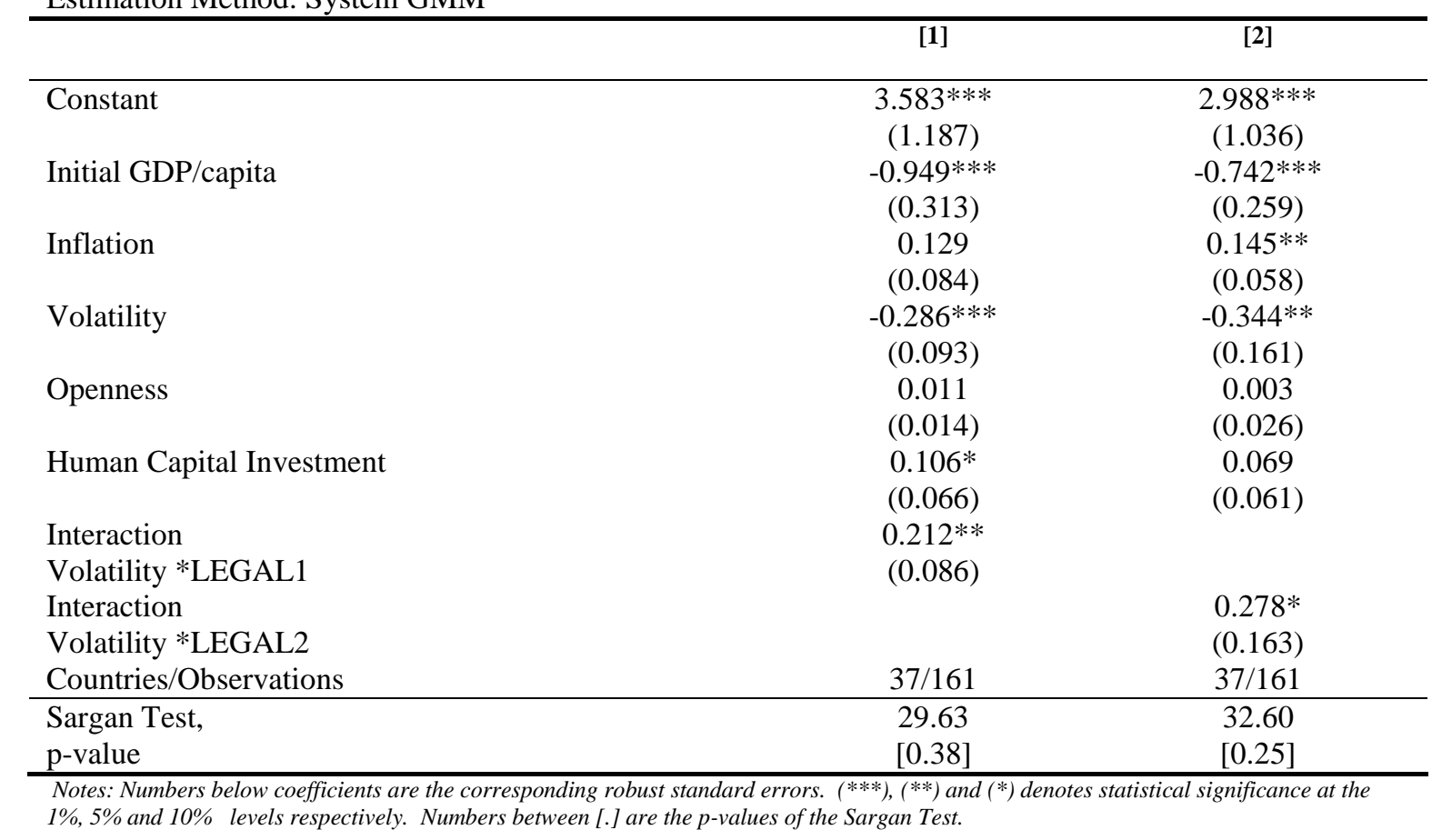

Table 1.2 shows the results of estimating Equations (1.4) and (1.5) where the indirect effects of the two types of institutions, LEGAL1 and LEGAL2, were added to the growth regression each one in a turn. These indirect effects were represented by adding the interaction terms between inflation volatility and the indices of LEGAL1 and LEGAL2 each one in a turn. The goal is to measure how the strength of legal and financial 
institutions affects the relationship between inflation volatility and growth. The direct effect of legal and financial institutions, or the LEGAL1 and LEGAL2 indices, will be included with the set of instruments.

Recall that the LEGAL1 indices contains the measures related to the general development of the legal systems and institutions, while LEGAL2 indices contains measures specifically related to financial transactions. Columns 1 and 2 of Table 1.2 show the results of adding the coefficients of the interaction terms of inflation volatility with LEGAL1 and LEGAL2 respectively. As shown in both columns, the addition of the legal and financial interactions does not change the sign and significance of the control variables. The initial GDP/capita, inflation, volatility, openness, human capital remained to hold the same sign and significance as they were in Table 1.1. The sign of inflation however showed a positive significant sign. A possible reason for this result is probably due to the fact that most of the inflation data, for the 37 countries over the period of the study, are considered moderate inflation countries where about $93 \%$ of the data are below $40 \%$, in addition most of these data are less than 10\%. In the Choi, Smith, and Boyd (1995) model, the low average inflation country will experience a "Mundell-Tobin effect", where a higher inflation leads to more growth as credit rationing might not appear at all in the financial market of this country.

The coefficient of inflation volatility on the other hand remained negatively significant. The coefficient of the interaction terms were found to be statistically significant and positive as expected. Thus the result of Table 1.2 above confirm that a country with better institutions will have less harmful effects of inflation volatility on growth. For instance, a one unit increase in the LEGAL1 index or the LEGAL2 index 
will reduce the negative impact of inflation volatility on growth by about $0.21 \%$ or $0.28 \%$ respectively.

It is worth noting that the results of Table 1.2 show that the negative significant coefficient of inflation volatility exceeds the positive coefficients of the interaction terms of either the LEGAL1 or LEGAL2 index. This implies that the total effect of inflation volatility on growth will be less negative when interacted with an improvement in the legal or the financial institutions. Also, it is important to note that once interaction terms are included in the regression what really matters is the significance of the total effect of inflation volatility, coefficient of volatility plus coefficient of the interaction term, and not simply the significance of each coefficient separately. The computation of the total effects of inflation volatility will be analyzed in more details in the next section.

Focusing on the components of LEGAL1 Table 1.10 summarizes the results of estimating Equation (1.4) where the interaction terms of corruption, law and order, and bureaucratic quality were added to the base model each one in a turn. In all the three regressions of Table 1.10, the coefficient of inflation volatility remained statistically significant with the expected negative magnitude. Column 1 of the table shows that the coefficient of the interaction term of inflation volatility with corruption is statistically significant with a positive expected magnitude. Based on the results shown in the table a one unit reduction in the corruption index would help in reducing the negative impact of inflation volatility on growth by about $0.065 \%$.

Column 2 of the same table shows that the interaction term of inflation volatility with law and order showed a statistical significant positive magnitude. A one unit increase in the law and order index will reduce the harmful effects of inflation volatility 
on growth by about $0.101 \%$. Finally, although the interaction term of inflation volatility with bureaucracy as appeared in Column 3 came with the expected sign, it was not statistically significant.

Similarly, Table 1.11 shows the results of estimating Equation (1.5) with the interaction terms of inflation volatility with the components of LEGAL2; Creditors' rights, shareholders' rights, enforcement, and transparency of accounts. These subindices were again included as interaction terms with inflation volatility each one at a time.

As obvious from the results of this Table, all the coefficients of inflation volatility and interaction terms with creditors' rights, enforcement, and accounts were statistically significant and with the expected sign. A one unit increase in the index of creditors' rights, enforcement, and accounts will lead to a reduction in the negative impact of inflation volatility on growth by about $0.15 \%, 0.11 \%$, and $0.02 \%$ respectively. In addition, neither the coefficient of inflation volatility nor its interaction term with shareholders' rights index appeared significant. This is simply because of the high correlation in the data between the two variables that reaches $94 \%$ so there is a high probability that the two coefficients are cancelling each other.

It is important to note that since interaction terms were included in the regressions of Table 1.10 and Table 1.11, it makes no sense to analyze their effects separately from the direct effect of inflation volatility. What will be needed then is to compute the total effect of inflation volatility by adding up the coefficient of inflation volatility to the interaction terms of inflation volatility with LEGAL1 and LEGAL2 each one in a turn. The same procedure was repeated for the three sub-indices of the LEGAL1 and the four sub-indices 
of LEGAL2, again each one in a turn. The statistical significance of an index in reducing the negative impacts of inflation volatility on growth will then be determined by the statistical significance of the total effect of inflation volatility when interacted with this index.

\subsection{Total Effect of Inflation Volatility}

Using the results of Table 1.2 above, this section calculates the total effect of a one standard deviation increase in inflation volatility at each level of legal and financial institutions indices. From the results of the first column of Table 1.2 above, the total effect of inflation volatility was calculated when it is interacted with the LEGAL1 index.

Recall that the LEGAL1 index falls in the interval $[-4.23,1.73]$ where the higher the value the more developed is the level of legal institutions. The first column of Table 1.3 below shows the quintiles of the index. The first number of this column , -4.23 , refers to the minimum value of the index, then the next value -3.04 refers to the $0-20^{\text {th }}$ percentile of the index, -1.84 refers to the $20^{\text {th }}-40^{\text {th }},-0.65$ refers to the $40^{\text {th }}-60^{\text {th }}, 0.54$ refers to the $60^{\text {th }}-80^{\text {th }}$, and finally 1.73 refers to the $80^{\text {th }}-100^{\text {th }}$ percentile of the index.

As obvious from the results of the Table, the higher the LEGAL1 index the less is the negative total effect of inflation volatility on growth. This total effect was statistically significant and with the expected signs at all percentiles except for the top quintile of the index where the effect was not significant. For instance, a country like Peru in early nineteen nineties was on the $20^{\text {th }}$ percentile of the LEGAL1 index where a one standard deviation increase in inflation volatility will lead to about $0.73 \%$ increase in growth. As a 
result in the enhancement in its bureaucracy system, it moved up to the $40^{\text {th }}$ percentile of the LEGAL1 index where a one standard deviation increase in inflation volatility would lead to only $0.53 \%$ drop in growth rate. Similarly, an improvement in Singapore's legal institutions from being at the $60^{\text {th }}$ percentile of the LEGAL1 index in the period 1989-91 to the $80^{\text {th }}$ percentile in the period $2004-06$ has lead in a reduction in the negative impact of inflation volatility on growth by about $60 \%$ as shown in the table below. From Table 1.3 also, the threshold level of LEGAL1 index can be computed by solving for it in an equation where the coefficient of inflation volatility is added to the interaction term between inflation volatility and the index then equating the sum to zero. The threshold level of LEGAL1 in the sample was found to be equal to 1.34 where a country with an index of this value will have a zero total effect of inflation volatility on growth. In addition, a country with a higher value than 1.34 will have a positive total effect however insignificant as shown in the table below.

Table 1.3: Total Effect of a One Standard Deviation Change in Inflation Volatility (Given the LEGAL1 index)

\begin{tabular}{|c|c|c|c|c|c|}
\hline $\begin{array}{c}(4) \\
\text { L1 } \\
\text { Index } \\
\end{array}$ & $\begin{array}{c}(5) \\
\text { equals (3) } \\
\text { times (4) } \\
\end{array}$ & $\begin{array}{c}\text { Total } \\
\text { Effect } \\
(2)+(5) \\
\end{array}$ & Variance & $\begin{array}{l}\text { Confidence } \\
\text { Interval }\end{array}$ & t-stat \\
\hline-4.23 & -0.71 & $-0.93 * * *$ & 0.127 & {$[-1.63,-0.23]$} & -2.61 \\
\hline-3.04 & -0.51 & $-0.73 * * *$ & 0.076 & {$[-1.27,-0.19]$} & -2.65 \\
\hline-1.84 & -0.31 & $-0.53 * * *$ & 0.038 & {$[-0.92,-0.15]$} & -2.72 \\
\hline-0.65 & -0.11 & $-\mathbf{0 . 3 3} * * *$ & 0.01 & {$[-0.56,-0.11]$} & -2.87 \\
\hline 0.54 & 0.09 & $-0.13 * * *$ & 0.002 & {$[-0.21,-0.06]$} & -3.47 \\
\hline 1.73 & 0.29 & 0.06 & 0.002 & {$[-0.03,0.16]$} & 1.33 \\
\hline \multicolumn{2}{|c|}{ (1) Standard Deviation Of Volatility } & 0.79 & & & \\
\hline \multicolumn{2}{|c|}{ (2) Volatility Coefficient times (1) } & -0.22 & & & \\
\hline \multicolumn{2}{|c|}{ (3) Interaction Coefficient times (1) } & 0.17 & & & \\
\hline
\end{tabular}


In other words the positive effect of good institutions outweighs the negative impact of inflation volatility. This is besides that the negative impact of inflation volatility might be minimal by itself since countries with good institutions are found to be with relatively low inflation volatility. For instance countries like Canada, New Zealand, Norway, Sweden, United Kingdom, and the United States all falls in this category. Figure 1.1 of Appendix (I) plots the total effect of inflation volatility graphically, the values on the $\mathrm{x}$ axis represents the LEGAL1 index while the values on the y-axis are the total effects of inflation volatility on growth.

Similarly, Table 1.4 below shows a detailed calculation of the total effect of inflation volatility when interacted with the LEGAL2 index. Recall that the LEGAL2 index falls in the interval $[-2.90,1.83]$ where the higher the value the more developed is the level of financial institutions. The first column of Table 1.4 below shows the quintiles of the index. The first number of this column , -2.90 , refers to the minimum value of the index, then the next value -1.95 refers to the $0-20^{\text {th }}$ percentile of the index, -1.01 refers to the $20^{\text {th }}-40^{\text {th }},-0.06$ refers to the $40^{\text {th }}-60^{\text {th }}, 0.88$ refers to the $60^{\text {th }}-80^{\text {th }}$, and finally 1.83 refers to the $80^{\text {th }}-100^{\text {th }}$ percentile of the index.

As obvious from Table 1.4 below, the total negative effect of inflation volatility on growth decreases as the index increases or as countries develop their financial institutions. This total effect is statistically significant and with the expected sign at all percentiles except at the top quintile of the index. For instance, a country like Mexico that is on the $40^{\text {th }}$ percentile of the LEGAL2 index, a one standard deviation increase in the inflation volatility will lead to a drop in growth by about $0.49 \%$. 
Solving for the threshold level of LEGAL2, it was found to be equal to 1.23 where a country like France having this value for the index will have exactly zero total effect of inflation volatility on growth. This zero total effect was however found to be statistically insignificant.

Table 1.4: Total Effect of a One Standard Deviation Change in Inflation Volatility (Given the LEGAL2 index)

\begin{tabular}{|c|c|c|c|c|c|}
\hline $\begin{array}{c}(4) \\
\text { L2 } \\
\text { Index }\end{array}$ & $\begin{array}{c}(5) \\
\text { equals (3) } \\
\text { times (4) }\end{array}$ & $\begin{array}{l}\text { Total } \\
\text { Effect } \\
(2)+(5)\end{array}$ & Variance & $\begin{array}{c}\text { Confidence } \\
\text { Interval }\end{array}$ & t-stat \\
\hline-2.90 & -0.63 & $-0.90 *$ & 0.246 & {$[-1.88,0.07]$} & -1.82 \\
\hline-1.95 & -0.43 & $-0.70 *$ & 0.141 & {$[-1.43,0.04]$} & -1.86 \\
\hline-1.01 & -0.22 & $-0.49 *$ & 0.065 & {$[-0.99,0.01]$} & -1.93 \\
\hline-0.06 & -0.01 & $-0.28 *$ & 0.018 & {$[-0.55,-0.02]$} & -2.12 \\
\hline 0.88 & 0.19 & $-0.08 * * *$ & 0.00 & {$[-0.12,-0.04]$} & -3.79 \\
\hline 1.83 & 0.40 & 0.13 & 0.012 & {$[-0.09,0.34]$} & 1.18 \\
\hline \multicolumn{2}{|c|}{ (1) Standard Deviation Of Volatility } & 0.79 & & & \\
\hline \multicolumn{2}{|c|}{ (2) Volatility Coefficient times (1) } & -0.27 & & & \\
\hline \multicolumn{2}{|c|}{ (3) Interaction Coefficient times (1) } & 0.22 & & & \\
\hline
\end{tabular}

Moreover, a country with an index value above 1.23 will have a positive total effect of inflation volatility on growth. Good examples in this respect are the cases of countries like Finland, New Zealand, Singapore, Sweden, and the United Kingdom. All these countries have relatively developed financial institutions and at the mean time relatively low inflation volatility. Combining these two effects together the total effect of inflation volatility becomes positive but not statistically significant. Figure 1.2 in Appendix (I) plots the total effect of inflation volatility graphically, the values on the $\mathrm{x}$-axis represents the LEGAL2 index while the values on the y-axis on the other hand reflects the total effects of inflation volatility on growth. 
Concerning the total effect of inflation volatility when interacted with the sub-indices of LEGAL1 index Table 1.12 through Table 1.14 show detailed calculations for the total growth effect of a change in one standard deviation of inflation volatility for the reform in each of the components of LEGAL1 index; corruption, law and order, and bureaucracy respectively.

Table 1.12 uses the results of the first column of Table 1.10 to calculate the total effect of inflation volatility when it is interacted with the corruption index. As expected the higher the corruption index the less is the negative effect of inflation volatility on growth. For example, in a country like Egypt which was on the $20^{\text {th }}$ percentile of the corruption index during the period 1989-1994, a one standard deviation increase in inflation volatility will lead to a drop in the growth by about $0.23 \%$. With the improvement in corruption in Egypt during the period 2004-2006, the one standard deviation increase in inflation volatility would only lead to a drop in growth by about $0.11 \%$. In addition, in countries on the top quintile of the corruption index, or with low degree of corruption, like Canada, Denmark, Finland, New Zealand, and Norway, a one standard deviation reduction in inflation volatility will not have any statistical significant effect on growth.

Similarly, Table 1.13 uses the results of the second Column of Table 1.10 to calculate the total effect of inflation volatility when interacted with the law and order index. Again the higher the index, the lower is the negative effect of inflation volatility on growth. Countries like Austria, Australia and Belgium which are on the $80^{\text {th }}$ percentile of the law and order index will have a drop in growth of about $0.03 \%$ for each one standard deviation increase in inflation volatility. This total effect is however not 
statistically significant. On the other hand, countries in which the system of criminal justice is not well developed like Peru which is on the minimal value of this index will have a total effect of about $0.43 \%$.

Finally, Table 1.14 calculates the total effect of inflation volatility when interacted with the bureaucracy index. From the table the same conclusion can be reached that countries with high bureaucracy like Argentina during the period 1989-2003 was on the $40^{\text {th }}$ percentile of this index, where a one standard deviation increase in inflation volatility would lead to a drop in growth by about $0.26 \%$. On the other hand, countries like Australia and Belgium which are on the top quintile of the bureaucracy index, a one standard deviation increase in inflation volatility will lead to a drop in growth of only about $0.03 \%$.

Figure 1.3 through Figure 1.5 of Appendix (I) present the total effects graphically. In these three graphs it can be noticed that the negative total effect of inflation volatility is decreasing as any of the three indices increases. Based on the definition of these indices in the previous section, this implies that the more corruption, and the stricter criminal law justice and the less degree of bureaucracy the lesser is the harmful effect of inflation volatility on growth.

Similarly, Table 1.15 through Table 1.18 of Appendix (I) calculates the total effects of inflation volatility when interacted with the sub-indices of the LEGAL2 index; creditors' rights, shareholders' rights, enforcement, and accounts respectively. Also Figures 6 through 9 present the results of Tables 1.15 through 1.18 graphically respectively. In all of the four total effects, an improvement in the sub-index will reduce the harmful impact of inflation volatility on growth. 
Table 1.15 uses the results from the first column of Table 1.11 to compute the total effect of inflation volatility when interacted with creditors' rights index. A country like Mexico for example which is on the lowest value of this index, a one unit increase in the standard deviation of inflation volatility will lead to a drop in growth by about $0.38 \%$. On the other hand, a country like New Zealand which has relatively developed laws that protects creditors' rights, this total effect is only about $0.03 \%$. Surprisingly, the total effect turns positive and significant for countries on the maximum value of this index like Singapore, and the UK. This would basically suggest that if the protection of creditors' rights is good, its positive impact can outweigh any negative impact of inflation volatility on growth.

From Table 1.16 it is obvious that although the improvement in the shareholder's rights index will lead to a statistical significant reduction on the negative impact of inflation volatility on growth, this reduction is very small and does not change greatly from a country on the $20^{\text {th }}$ percentile as compared to a country on the $80^{\text {th }}$ percentile of this index. For example, the total effect of a country on the $20^{\text {th }}$ percentile like Turkey will have a total growth effect of $0.1626 \%$ for each one standard deviation drop in inflation volatility. This number is very close to $0.1621 \%$ for a country on the $80^{\text {th }}$ percentile like the U.S.

As for the total growth effect of interacting the enforcement index with inflation volatility, Table 1.17 shows the results. This total effect was statistically significant at all the index's percentiles except for the $80^{\text {th }}$ and the maximum percentile. A country with relatively weak enforcement of laws, like Egypt on the $20^{\text {th }}$ percentile, will have a drop in growth by about $0.31 \%$ for each standard deviation increase in the volatility of inflation. 
On the other hand, a country on the $60^{\text {th }}$ percentile like Germany will have a total effect of only $0.04 \%$.

Finally, Table 1.18 calculates the total effect when inflation volatility is interacted with transparency of the company's accounts index. As obvious from the table, the total effect was only significant at the $20^{\text {th }}$ and the $40^{\text {th }}$ percentiles only but otherwise it was insignificant. Countries on the $20^{\text {th }}$ percentile like Columbia and Peru will experience a drop in growth of about $0.18 \%$ for each standard deviation increase in inflation volatility. On the other hand, Countries on the $40^{\text {th }}$ percentile like Austria and Belgium will experience a drop in growth by about $0.05 \%$.

\subsection{Robustness Check}

In this section two types of analysis are performed as a robustness check on the results. A reverse causality test is first undertaken in order to check for the non-existence of the reverse causality in the model. Second the model is re-estimated using regular panel estimation -with no instruments- in order to make sure that the general results in terms of the signs and significance of key variables do still hold.

\subsubsection{Reverse Causality Test}

In using System GMM it is assumed that the control variables are predetermined to the current growth process, in other words, it is assumed that there is no reverse causality. For example, the initial level of inflation volatility is not affected by 
growth over the current period. If this assumption is incorrect, then the instruments used might not be correct. Accordingly in this sub-section it is important to test for the validity of the "no reverse causality" assumption. And this is to be sure that the relation goes from inflation volatility to growth and not the other way round.

Basically, the initial level of inflation volatility will be regressed over the growth plus other all the other control variables excluding of course the volatility of inflation. The regression would then look as shown below,

$$
\text { Infvol }_{i, t}-\text { Infvol }_{i, t-v}=\beta_{0} \text { Infvol }_{i, t-v}+\beta_{1} C V_{i, t-v}+\beta_{2}\left(y_{i, t}-y_{i, t-v}\right)+\varepsilon_{i, t},
$$

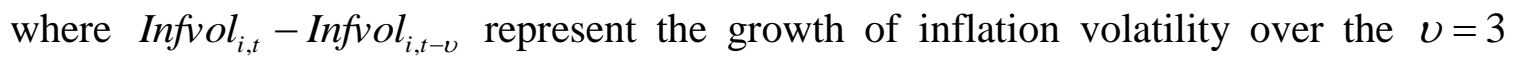
period. Next the interaction terms of growth over the period with the LEGAL1 and LEGAL2, $\left(L 1_{i, t-v} *\left(y_{i, t}-y_{i, t-v}\right)\right)$ and $\left(L 2_{i, j} *\left(y_{i, t}-y_{i, t-v}\right)\right)$ respectively, will be added to the above regression each one in a turn. If the coefficient of growth and both of its interaction terms are insignificant, then this would suggest that the reverse causality is irrelevant. And it would then be evidence that countries can enhance their growth by exogenously reducing its inflation volatility.

The regression results show that across these two regressions the coefficients of $\beta_{2}$ 's were statistically not significant. Accordingly the null hypothesis that growth leads to or cause inflation volatility is rejected. Also the coefficients of the interaction terms proved to be not statistically significant. In addition, repeating the same regression with the interaction terms of the seven sub-indices of LEGAL1 and LEGAL2 each one at a time, the results again show statistically insignificant coefficients of growth when controlled 
for the seven interaction terms. Hence the assumption on which the System GMM is based that reverse causality does not exist or that inflation volatility is predetermined for growth is confirmed.

\subsubsection{Regular Panel Estimation}

As robustness check on the results, in this sub-section the base regression is re-estimated using regular panel estimation with period dummies and cross-section fixed effects. This means that least squares regression model is estimated using panel data. Accordingly some of the coefficients are expected to be different since least squares method tends to have a positive bias $^{7}$, while the System GMM is known for its small bias property ${ }^{8}$. Hence in using the OLS it will be important to focus on the coefficients of the main variables, such as inflation, inflation volatility and the interaction terms of inflation volatility with legal and financial institutions indices. If those coefficients have the same sign and close in magnitudes in both the System GMM and OLS estimations, then this would suggest that the results are robust.

As shown in Table 1.19 of Appendix (I), the first column shows the results of estimating the base model when interacted with the LEGAL1 index. Column 2 of the same table shows the results of the base model when it is interacted with the LEGAL2 index. The results from these two columns confirm the results of the dynamic panel System GMM. All the coefficients appeared to be of the same sign and close in magnitudes to the previous results. The coefficient of inflation appeared again to be not

\footnotetext{
${ }^{7}$ This is due to endogeneity, especially on the initial level of GDP.

${ }^{8}$ More details on System GMM are available at Hayakawa, Kazuhiko (2007).
} 
statistically significant. The coefficient of inflation volatility on the other hand showed a statistical significant negative coefficient. The coefficient of both interaction terms appeared again to be statistically significant and positive.

Using the results of Table 1.19, the total effect of a one standard deviation increase in inflation volatility when interacted with LEGAL1 and LEGAL2 were calculated and presented in Table 1.20 and Table 1.21 respectively. As obvious from these two tables, the total effects were again with the expected sign but statistically significant only up to the $60^{\text {th }}$ percentile and not up to the $80^{\text {th }}$ percentile as it was the case with the System GMM estimation. But in general it can be confirmed that the results are robust.

In addition, the base model was estimated with the interaction terms of the subindices of the LEGAL1 and the LEGAL2 each one in a turn. The interaction terms of corruption, law and order, and accounts were again statistically significant and with the expected sign as were the cases using the System GMM. The interaction terms of bureaucracy and shareholders' rights were again statistically insignificant. The interaction terms of creditors' rights, and enforcement did not prove to be robustly significant.

\subsection{Conclusion}

Using a cross-section of 37 developed and developing countries over the period (19892006), and after excluding the top $10 \%$ of the inflation volatility distribution, the overall result from this chapter show that inflation volatility, and not just the level of inflation, is an important factor in the determination of growth in a developing economy. In addition, the degree of development in legal and financial institutions is also important and that 
developing economies can experience faster growth by reforming their institutions at the same time as they reduce inflation volatility in their economy.

In addition, the results of this chapter show that in contrast to the results of Easterly (2004) and Acemoglu et al. (2003), macroeconomic policy does not act as a proxy for institutions. The addition of the interaction term of either legal or financial institutions with inflation volatility did not change the sign and significance of inflation volatility and at the mean time the institutions' coefficients appeared positive and significant. Improving institutions, be it legal or financial, will have a positive significant impact on the channel through which inflation volatility affects growth. A high degree of corruption, weak enforcement of laws, high level of bureaucracy, lack of protection to creditors' or shareholders' rights, and lack of respect for the law will all prevent reducing the negative impact of inflation volatility on growth. Investors will be willing to invest in a country when they feel that their rights are protected where the laws in the country will allow them direct control on the goods provided by the debtors as collateral, in case those debtors default on their debts. Also investors will also be willing to provide credit when they feel that there is transparency in the companies' accounts. All such types of incentives will help providing the finance needed by entrepreneurs to either start new projects or expand on current ones, leading to increase in growth.

The results of the chapter also show that the impact of institutions is significant up to countries on the $80^{\text {th }}$ percentile for either LEGAL1 or LEGAL2 where improving institutions has a greater impact in the institutionally underdeveloped countries as compared with institutionally developed ones. A one standard deviation reduction in inflation volatility will lead to an increase in growth of about $0.93 \%$ and $0.90 \%$ in 
countries with the worst level of legal and financial institutions respectively. Also, a one standard deviation reduction in inflation volatility will lead to an increase in growth of only about $0.13 \%$ and $0.08 \%$ for countries on the $80^{\text {th }}$ percentile of legal and financial institutions respectively

The next Chapter examines the channel through which inflation volatility and institutions affect growth. It will basically concentrate on the investment channel or the sovereign debt rating channel. In addition, the next Chapter will quantify the impact of the changes in sovereign debt rating on the average annual long term bond yield. 


\section{Part III}

\section{Chapter 2: Inflation Volatility, Financial Institutions, and Sovereign Debt Rating}

\subsection{Introduction}

The previous chapter demonstrated that both inflation volatility and institutions have each a statistical significant impact on growth. And that improving institutions will help to reduce the negative impact of inflation volatility on growth. The goal of this chapter is to identify the channel through which inflation volatility and institutions affect growth. The channel explored in this chapter is the investment channel or the sovereign debt rating channel. Any decrease in inflation volatility or any improvement in institutions is expected to lead to a higher rating classification in a developing economy. As rating increases, the cost of borrowing decreases and the economy can then make use of the cheap credit, it will accumulate more capital and, therefore, its output will increase.

This chapter contributes to the sovereign debt rating literature by first showing that the negative impacts of high inflation volatility are more important to a country's sovereign debt rating as compared with the negative impacts of high levels of inflation. Once the level of the volatility of inflation has been included in the regression, the level of inflation turns insignificant. In addition, the study shows that improving financial institutions will have a statistically significant positive direct and indirect effect on sovereign debt rating where the latter effect acts through its positive interaction with inflation volatility. This positive interaction helps to reduce the negative impacts of inflation volatility on sovereign debt rating. 
From the results of the empirical estimation of a sovereign debt rating regression, the study finds that a one standard deviation reduction in the log of inflation volatility will lead to about two classifications increase in the sovereign debt rating. In addition, the study finds that a one standard deviation increase in the financial institutions index will lead to a one classification increase in the sovereign debt rating.

The increase in the sovereign debt rating that is either due to the decrease in a one standard deviation decrease in the log of inflation volatility or a one standard deviation increase in LEGAL2 will finally lead to drops in the average long-term bond yield, or the cost of the long-term borrowings that a country pays on its debts. By analyzing the data on sovereign debt rating and average long-term bond yields, these increases in the sovereign debt rating are equivalent to reductions in the average long-term bond yields by about $4.4 \%$ for a one standard deviation decrease in the log of inflation volatility and by about $4.27 \%$ for a one standard deviation increase in the financial institutions index.

Against the above background and despite the importance of the volatility of inflation and financial institutions to sovereign debt rating, the economic literature on the determinants of sovereign debt rating had mostly ignored the role played by either one of them. The literature on sovereign debt rating has mainly categorized the sovereign debt rating determinants into four main groups; the liquidity and solvency variables, macroeconomic variables, external shock variables, and dummy variables. The liquidity and solvency variables usually include debt to GDP ratio, international reserves to GDP, debt service to exports and the current account to GDP. The macroeconomic variables usually includes real growth, inflation rate, fiscal balance, and real exchange rate, the external shock variables usually includes international interest rates, and finally, the 
dummy variables ${ }^{9}$ usually includes those variables reflecting economic crises and other structural problems.

For instance, using OLS on pooled data for 35 developed and developing countries with a transformation of the rating into numerical values ${ }^{10}$, Cantor and Packer (1996a) studied the effect of the level of inflation, as a proxy for the quality of economic management, plus other macro-economic variable and a dummy for the country's default history. In their study they found that both inflation and the ratio of foreign currency external debt to exports each have a negative statistical significant effect on rating. On the other hand, both per capita income and GDP growth each has a positive significant effect. The Cantor and Packer (1996a) study has however been criticized for the use of the ordinary least squares and accordingly the use of ordered response model has been suggested instead for the multinomial choice nature of the rating data.

Using also the ordinary least squares methodology, the study of Bordo and Rockoff (1996) estimated a CAPM model on the determinants of the government bond rates for nine countries during the classical golden period (1870-1914). The set of control variables included a proxy for the monetary policy, a proxy for the fiscal policy, and a dummy for the adherence to the gold standard. The study found a positive correlation between the cost of borrowing and the adherence to the gold standard during the Classical Golden period (1870-1914). This adherence to the gold standard implied as they mention in their paper a "far more complex set of institutions and economic policies".

Using a stepwise procedure similar to the one employed in Haque (1996), Haque, Nadeem, Mark, and Mathieson (1998) tested the importance of macroeconomic

\footnotetext{
${ }^{9}$ Min, Hong G. (1998) provides a good literature review on these four groups.

${ }^{10} \mathrm{As}$ noted in their paper, this transformation of the rating into numerical numbers follows the literature that starts with Horrigan (1966) through Billet (1996).
} 
determinants versus political determinants in affecting a country's credit worthiness. Using the natural $\log$ of the level of inflation, the study found that the log of inflation has a statistically significant negative impact on the country's credit worthiness using both the credit worthiness rating provided by institutional investors and Euro money. However, the study did not find a significant effect when the rating provided by the Economic Intelligence Unit is used.

Applying the same methodology as in Cantor and Packer (1996) but with both the linear and logistic transformation of the rating on a sample of 81 developed and developing countries, Alfonso (2002) found that the logistic transformation improves the explanation of the model and the study reached the same conclusion as in Cantor and Packer (1996) in terms of the statistical significant negative effect of inflation on sovereign debt rating.

Since the determinants of the sovereign debt rating are expected to be similar to those of the spreads as both are measures of risk, the literature on the spreads can be then reviewed. For instance, using panel least squares methodology on 11 countries over the period (1991-1995), Min (1998) analyzed the determinants of yield spread of US dollar denominated fixed income securities. The results stressed on the importance of macroeconomic fundamentals including inflation if a country is to gain access to international bond market.

Eichengreen and Mody (1998), and Kamin and Kleist (1999) stressed on the importance of "market sentiment" in addition to country specific fundamentals and external factors in explaining variations in sovereign spreads in emerging markets. 
Applying panel data regression Ades, Frederico, Paulo, Rumi, and Daniel (2000) studied the impact of macroeconomic variables on the spread of 15 emerging countries with monthly data over the period from January 1996 until May 2000. The study concludes that macroeconomic variables have a significant impact on the sovereign spread. These variables include GDP growth rate, international interest rates, real exchange rate misalignment, export to GDP, ratio of foreign reserves, external debt to GDP ratio, total external amortizations as a ratio of foreign reserves and the default history.

Mauro, Sussman, and Yafeh (2002) compared the co-movement in spread in two periods, a historical period (1870-1913) "Golden Era" and a modern period which is the 1990's for a sample of ten emerging countries. The study shows that although the comovement in spread was highly related to the country-specific events during the Golden Era, it was related to global events during the 1990's. In addition, the study shows that the mean and volatility of spread were lower during the Golden Era than they were in the 1990's. As the study mentions, this is because most countries in the sample adhered to the gold standard during this Golden Era which is viewed as less risky environment from the investors' point of view.

In addition to the above literature, using historical data Obstfeld and Taylor (2003) used the Feasible Generalized Least Squares (FGLS) ${ }^{11}$ to study the determinants of the sovereign risk for a sample of 23 countries over the period from (1870-1930). The paper finds that adherence to gold standard was an important factor affecting credit worthiness

\footnotetext{
${ }^{11}$ The FGLS corrects for the presence of Heteroskedasticity or autocorrelations, under the condition that the number of time series is at least equal to the panel observations.
} 
during the period before 1914. After the 1914, public debt and British Empire membership were the most important determinants of borrowing spreads.

Using panel least squares regression estimation, Rowland, Peter, and Torres (2004) studied the macroeconomic determinants of spread of the US Treasuries of emerging market sovereign issues and the issuers' credit worthiness using the institutional investor credit worthiness index for a sample of 16 emerging countries. Although the authors use the same macroeconomic determinants for both regressions, the spread regression and the credit worthiness regression, their results show that inflation significantly affects the credit worthiness of the issuing country, but does not have a significant effect on the spread.

Bissoondoyal-Bheenick, Brooks and Yip (2005) have studied the determinants of sovereign debt rating using two different approaches, the ordered probit and the casebased reasoning ${ }^{12}$. Using these two approaches, they were able to reach the same conclusion where inflation and GDP appeared to be the most significant macro economic variables following the significance of the proxy for technological development. In addition, using an OLS regression framework, Rowland (2005) found that inflation is among other six macroeconomic variables that significantly affect credit ratings, credit worthiness and spreads.

Using OLS with panel corrected standard errors (PCSE) ${ }^{13}$, Ferguson and Schularick (2006) studied the determinants of country risk for a sample of 57 countries, colonies, or self-governing parts of the British Empire during the period (1880-1913). In their paper,

\footnotetext{
${ }^{12}$ A process of solving new problems based on the solution of similar past problems.

${ }^{13}$ This study makes a note that Nathaniel Beck and Jonathan Katz (1995) have shown that the PCSE method is not only better than FGLS but also superior to Kmenta's "Crosssectionally Heteroskedastic And Timewise Autocorrelated Model".
} 
they found that the British Empire Effect appeared to be more important than either the adherence to the gold standard or sustaining fiscal policy.

Finally and more recently, using panel regression estimation for 27 emerging countries, Remolona, Santigna, and Wub (2007) found that inflation was among many other variables that have a significant effect on their constructed measure of sovereign default risk "Rating Implied Expected Loss" (RIEL). This RIEL is measured by the agency credit rating and the historical default risk, and which as mentioned in their paper, decomposes the spread into a risk component and a risk premium component. Using the same independent variables of the RIEL regression, the estimation was repeated using other measures of country risk, namely the average agency ratings and the institutional investor ratings. The results of the regression confirm that inflation -among other variables- was found to significantly affect the average agency ratings but not the institutional investor ratings.

Unfortunately, few studies have addressed the role of the second moments of macroeconomic aggregates on sovereign debt rating. The literature on the impact of the macroeconomic policy volatility in general, and of the inflation volatility in particular, on sovereign debt rating is quite thin. For instance, Eaton and Gersovitz (1981) investigated the impact of macroeconomic volatility on sovereign default risk. The study concludes that in the presence of unexpected adverse shocks, there will be a positive relation between the volatility of macroeconomic aggregates and default. Using Logit estimation technique, Catao (2002) tested whether macroeconomic volatility helps in explaining the variation in sovereign default probability. The paper distinguishes between the externally induced volatility and the policy induced volatility. Using a sample of 25 emerging 
economies over the period (1970-2001), the study concludes that there is a positive relation between macroeconomic volatility and the sovereign default. In addition, the study finds that much of this macroeconomic volatility stems from the policy induced volatility, in particular from the procyclicality of the fiscal policy.

In addition, despite the growing literature on the importance of institutions to a country's long run economic growth, to the best of our knowledge, there has been only one study on the impact of institutions on sovereign debt rating. Using the two stage least squares (TSLS) methodology on a sample of 86 developed and emerging countries, Butler and Fauver (2006) investigated the effect of the legal and political institutions in addition to macroeconomic variables, including the level of inflation, on the sovereign debt rating measured by the institutional investor. The paper used the governance indicators provided by the World Bank data base and measured by Kaufman, Kraay and Mastruzzi (2003). These governance indicators include the voice of the people, political stability, government effectiveness, regulatory quality, rule of law, and corruption control. In addition, the authors developed a composite index for these six indices. The paper finds that inflation besides other macro economic variables have a statistical significant effect on rating. Adding the composite index, that represents the effect of the legal environment, the study finds that legal environment is the most influential variable in their regression. This effect was found to pass through the willingness to pay channel rather than the ability to pay channel.

Against the above background, using a sample of 37 developed and developing countries over the period (1989-2006), this chapter extends the previous literature on sovereign rating by first empirically test the role of volatility of inflation besides the role 
of the level of inflation in explaining the variation of the sovereign debt rating. Second, empirically test the direct and the indirect role of financial institutions on sovereign debt rating. Third, empirically compute the total effect of a one standard deviation reduction in $\log$ inflation volatility versus the total effect of a one unit improvement in the standard deviation of the LEGAL2 index. Finally, this chapter links the increase in sovereign debt rating to the drop in annual long term average bond yield.

The main findings of this chapter are; first, the level of inflation does not have a statistical significant impact on sovereign debt rating. Second, inflation volatility has a negative statistical significant robust effect on sovereign debt rating. Third, improving financial institutions has a positive direct and indirect effect on sovereign debt rating. Finally, the increase in sovereign debt rating that is due to a one standard deviation decrease in the $\log$ of inflation volatility or a one standard deviation increase in the institutions index will finally lead to drops in the average annual long-term bond yield by about $4.4 \%$ and $4.27 \%$ respectively.

This chapter is organized as follows; section 2.2 discusses the empirical specification of the model, section 2.3 presents the data, section 2.4 presents the empirical results, section 2.5 estimates the impact of the components of the financial institutions index on the sovereign debt rating, section 2.6 computes the total effect of a one standard deviation change in inflation volatility on sovereign debt rating versus the total effect of a one standard deviation change in the financial institutions, section 2.7 undertakes a robustness check, section 2.8 links the changes in sovereign debt rating to the changes in average annual long-term bond yield, section 2.9 concludes this chapter, and finally Appendix (II) is by the end of the dissertation. 


\subsection{Empirical Specification}

As mentioned in the previous section, previous empirical models studying the determinants of sovereign debt rating and spreads, usually classify these determinants into solvency variables and liquidity variables, macroeconomic variables, external shock variables, and dummy variables. In this section an empirical model of sovereign debt rating is presented that in line with previous empirical models include those three types of variables. For the solvency and liquidity determinants, the ratio of private domestic credit to GDP is used as a proxy for financial deepening. For the macroeconomic determinants, the variables used are; the log of GDP per capita, the level of inflation, and the volatility of inflation. Finally for the dummy variables, the regional dummy and the financial institutions index were used.

The study employs the Two Stage Least Square "TSLS" with regional dummies and period fixed effects to estimate the determinants of sovereign debt rating for the sample of 37 developed and developing countries over the period 1989-2006, using three years period averages. This means again that there are six periods to work with.

Equation (2.1) below represents the base model of the estimation;

$$
\operatorname{Sov}_{i, t}=\beta_{0}+\beta_{1} \operatorname{Sov}_{i, t-v}+\beta_{2} C V_{i, t}+\beta_{3} \operatorname{Infvol}_{i, t}+d_{t}+\varepsilon_{i, t} \text {. }
$$

The subscripts $i$ and $t$ represent the country and the time period respectively. The variable Sov $_{i, t}$ is the Moody's sovereign debt rating. The set of explanatory variables consist of Sov $_{i, t-v}$ which represents the first lag of the sovereign debt rating, $C V_{i, t}$ is the set of 
control variables that are measured as an average over the $v$ period, where $v=3$. This set of control variables includes the average level of inflation, the average ratio of private domestic credit to GDP, the average ratio of per capita GDP, and three regional dummies for the Latin American countries, Asian countries, and the African and Middle Eastern countries, $D_{L}, D_{A}$, and $D_{A M}$ respectively. To avoid the dummy variable trap, the dummy that represents the OECD countries has been omitted, but its effect is picked up by the intercept $\beta_{0}$. The average $\log$ of inflation volatility over the three years period is represented by $\operatorname{Infvol}_{i, t}$. Finally, the time period dummies are represented by $d_{t}$.

It is worth noting that additional variables were considered to be added to the model, but were excluded due to their statistically insignificant coefficients. These variables include the current account as a percentage of GDP, the log of the nominal GDP, unemployment as a percentage of the labor force, and the total reserves minus gold. The reason for this statistical insignificance is probably due to the high correlation between the variables. For example, the current account was highly correlated with the total reserves minus gold. Also, the nominal GDP was highly correlated with the per capita GDP. To choose a parsimonious model that can estimate the relations of interest for the purpose of this chapter, Equation (2.1) constituted the base model.

The base model was next expanded to include an interaction term of the financial institutions index, LEGAL2, with inflation volatility. This LEGAL2 index is the same financial institutions' index that was used in the previous chapter. The objective is to estimate the indirect effect of financial institutions on the relation between inflation volatility and sovereign debt rating. The interaction term is estimated by adding 
$\beta_{4}\left(L 2_{i} *\right.$ Infvol $)$ to the right hand side of Equation (2.1) where $L 2_{i}$ represents the LEGAL2 index for country $i$.

After adding the interaction term to Equation (2.1) above, the new model is shown below,

$$
\begin{array}{r}
\text { Sov }_{i, t}=\beta_{0}+\beta_{1} \text { Sov }_{i, t-v}+\beta_{2} C V_{i, t}+\beta_{3} \text { Infvol }_{i, t} \\
+\beta_{4}\left(\text { L2 }_{i} * \text { Infvol }_{i, t}\right)+d_{t}+\varepsilon_{i, t}
\end{array} .
$$

It is important to note that the estimation of Equation (2.2) above is crucial for the computation of the total effect of the log of inflation volatility on sovereign debt rating. This total effect is computed by adding the estimated coefficient of log inflation volatility $\hat{\beta}_{3}$ to the estimated coefficient of the interaction term $\hat{\beta}_{4}$ where this latter coefficient is multiplied by the $L 2_{i}$ index. Accordingly the total effect of the log of inflation volatility will be equal to $\hat{\beta}_{3}+\left(\hat{\beta}_{4} * L 2_{i}\right)$ in Equation (2.2) above.

It is important to note that since the objective from this last equation is to compute the total effect of a one standard deviation decrease in the log of inflation volatility on sovereign debt rating in the presence of different degrees of financial institutions rather than the direct effect of these institutions on sovereign debt rating per se, the financial institutions index is not to be added by itself in the list of regressors but it is only interacted with inflation volatility. It is also important to note that when Equation (2.2) was augmented by $\beta_{4}\left(L 2_{i} *\right.$ Infvol $\left._{i, t}\right)$ to represent the indirect effect of financial institutions, the variable $L 2_{i}$, or the direct effect of financial institutions, will be included in the set of instruments of the Two Stage Least Squares. 
Next, the total effect of a one standard deviation change in the LEGAL2 index can also be computed by adding $L 2_{i}$ to Equation (2.2) as shown in Equation (2.3) below. The total effect of LEGAL2 index will then be calculated as $\left(\hat{\beta}_{4} * \operatorname{Infvol}_{i, t}+\hat{\beta}_{5}\right)$.

$$
\begin{aligned}
\operatorname{Sov}_{i, t}=\beta_{0}+\beta_{1} \operatorname{Sov}_{i, t-v}+ & \beta_{2} C V_{i, t}+\beta_{3} \text { Infvol }_{i, t} \\
& +\beta_{4}\left(L_{i} * \text { Infvol }_{i, t}\right)+\beta_{5} L 2_{i}+d_{t}+\varepsilon_{i, t}
\end{aligned} .
$$

The calculation of the total effect of a one standard deviation decrease in the log of inflation volatility and the calculation of the total effect of a one standard deviation increase in the LEGAL2 index are presented in more details in Section 2.6.

Finally, the indirect effects of the four different components of the LEGAL2 index were estimated. Again, these four indices include creditor's right, shareholders rights, enforcement of laws and transparency of the companies' accounts. Each one of these indices is to be interacted with inflation volatility in a turn, and the objective is to analyze which interaction term contributes more to reducing the negative effects of inflation volatility on sovereign debt rating. This is done by replacing the variable $L 2_{i}$ in Equation (2.2) above by each of the four indices in a turn. This is discussed in more details in Section 2.5 . 


\subsection{Data}

The data set is constructed as a panel of country observations from the World Development Indicators of the World Bank's data base. The data set includes 37 developed and developing countries over the period (1989-2006).

Table 2.1 -List of Countries included in the Sample

\begin{tabular}{|l|l|l|l|}
\hline 1 & Argentina (Arg.) & 20 & Korea, Rep. (Kor.) \\
\hline 2 & Australia (Ausl.) & 21 & Malaysia (Mal.) \\
\hline 3 & Austria (Aus.) & 22 & Mexico (Mex.) \\
\hline 4 & Belgium (Bel.) & 23 & Netherlands (Neth.) \\
\hline 5 & Brazil (Bra.) & 24 & New Zealand (N.Z) \\
\hline 6 & Canada (Can.) & 25 & Norway (Nor.) \\
\hline 7 & Chile (Chi.) & 26 & Peru (Per.) \\
\hline 8 & Colombia (Col.) & 27 & Portugal (Por.) \\
\hline 9 & Denmark (Den.) & 28 & Singapore (Sin.) \\
\hline 10 & Egypt (Egy.) & 29 & South Africa ( S.A) \\
\hline 11 & Finland (Fin.) & 30 & Spain (Spa.) \\
\hline 12 & France (Fra.) & 31 & Sweden (Swe.) \\
\hline 13 & Germany (Ger.) & 32 & Switzerland (Swi.) \\
\hline 14 & Greece (Gre.) & 33 & Thailand (Tha.) \\
\hline 15 & Hong Kong (HK) & 34 & Turkey (Tur.) \\
\hline 16 & India (Ind.) & 35 & United Kingdom (U.K) \\
\hline 17 & Israel (Isr.) & 36 & United States (U.S) \\
\hline 18 & Italy (Ita.) & 37 & Uruguay (Uru.) \\
\hline 19 & Japan (Jap.) & & \\
\hline
\end{tabular}

Notes: The above countries are the ones chosen in the sample for which the Data on the indices of LEGAL1 and LEGAL2 were available. The letters in parentheses represents the abbreviation used for each county.

The data has been averaged into three-years time periods ${ }^{14}$ and thus are available for six time series observations for each country. The list of countries included in the sample is reported in Table 2.1 .

The data on the Sovereign debt rating, or the dependent variable, was collected from the Moody's sovereign debt ratings ${ }^{15}$. The sovereign debt rating for a given government

\footnotetext{
${ }^{14}$ According to Traub (2006) this is to overcome the problem of serial correlation and to remove any short term fluctuations in the data.
} 
is defined as the risk facing an investor who holds debt securities issued by that government. In other words, it reflects the government's “credit worthiness".

The Sovereign debt ratings of Moody's indicate the capacity and willingness of a government to repay back its obligations in full and on time. The Moody's rating focus on measuring the expected credit loss which depends on the probability of default and the expected recovery rate after the default has occurred ${ }^{16}$.

In addition, as noted in the Moody's guide provided by Moody's Investor ServiceGlobal Credit Research of Cailleteau, Cipriani, Lindow, and Byrne (2008), that despite the fact that assigning a rating classification to each country depends on a group of economic, financial, social and political factors, the rating is "strictly constructed as assessing credit risk. Therefore, one cannot directly infer general assessments about a country's economic prosperity, dynamism, competitiveness or governance from Moody's government bond ratings". Unfortunately, a more detailed explanation of how exactly Moody's agency assign a specific rating classification to each country is not available.

Table 2.2 below provides definitions on the data set used in this chapter. As shown from this Table, Inflation rate is defined as the growth of the consumer price index, and domestic credit data is defined as the domestic credit to the private sector as a percentage of GDP. Following Coulson and Robins (1985), the data on log inflation volatility was calculated as the $\log$ of the square root of the conditional variance series of inflation calculated by $\operatorname{GARCH}(1,1)$ model. It is important to note that the data on the average of inflation volatility ranges from a minimum of $-0.98 \%$ for Germany in 2002 to a

\footnotetext{
${ }^{15} \mathrm{Aaa}, \mathrm{Aa} 1, \mathrm{Aa} 2, \mathrm{Aa} 3, \mathrm{Aa}, \mathrm{A1}, \mathrm{A} 2, \mathrm{~A} 3, \mathrm{~A}$, ,Baa1, Baa2, Baa3,Ba1, Ba2, Ba3, B1, B2, B3,Caa1, Caa2, $\mathrm{Caa} 3, \mathrm{Ca}, \mathrm{C}$. For detailed definition on each rating classification check Rowland (2005).

${ }^{16} L_{e}=\rho(d) .\left(1-r_{e}\right)$, where $L_{e}$ is the expected loss, $\rho(d)$ is the probability of default, and $r_{e}$ is the expected recovery rate as noted in Bhatia (2002).
} 
Table 2.2 Definition of Variables

\begin{tabular}{|c|c|c|c|}
\hline $\begin{array}{c}\text { Variable } \\
\text { Name }\end{array}$ & Definition & $\begin{array}{c}\text { Unit of } \\
\text { Measurement }\end{array}$ & Data Source \\
\hline $\begin{array}{l}\text { Sovereign } \\
\text { debt rating }\end{array}$ & Ratings assigned by Moody's & $\begin{array}{l}\mathrm{Aaa}=23, \\
\mathrm{Aa} 1=22 \ldots ., \mathrm{C}=1\end{array}$ & Moody's \\
\hline Inflation & the percentage change in consumer price index & Percent & $\begin{array}{l}\text { World } \\
\text { Development } \\
\text { Indicators. }\end{array}$ \\
\hline $\begin{array}{l}\text { Inflation } \\
\text { volatility }\end{array}$ & $\begin{array}{l}\text { log of the square root of the conditional variance } \\
\text { series of inflation calculated by } \operatorname{GARCH}(1,1) \\
\text { model }\end{array}$ & Percent & $\begin{array}{l}\text { World } \\
\text { Development } \\
\text { Indicators. }\end{array}$ \\
\hline $\begin{array}{l}\text { Per capita } \\
\text { GDP }\end{array}$ & GDP per capita (constant 2000 US\$) & $\begin{array}{l}\text { Thousands of } \\
\text { dollars }\end{array}$ & $\begin{array}{l}\text { World } \\
\text { Development } \\
\text { Indicators. }\end{array}$ \\
\hline $\begin{array}{l}\text { Domestic } \\
\text { credit }\end{array}$ & $\begin{array}{l}\text { Domestic credit to private sector as a percentage of } \\
\text { GDP }\end{array}$ & Percent & $\begin{array}{l}\text { World } \\
\text { Development } \\
\text { Indicators. }\end{array}$ \\
\hline $\begin{array}{l}\text { LEGAL2 } \\
\text { Index }\end{array}$ & $\begin{array}{l}\text { Following Chinn and Ito (2005): LEGAL2 is the } \\
\text { principal component of Creditors' rights, } \\
\text { Shareholders 'rights, Accounts, and Enforcement } \\
\text { indices. It depicts the overall development of the } \\
\text { legal system governing financial transactions. }\end{array}$ & $\begin{array}{l}\text { Units within the } \\
\text { interval }-2.90 \text { and } \\
1.83\end{array}$ & $\begin{array}{l}\text { La Porta et al. } \\
\text { (1998) }\end{array}$ \\
\hline $\begin{array}{l}\text { Creditors' } \\
\text { rights index }\end{array}$ & $\begin{array}{l}\text { As defined in La Porta et al. (1998), it is composed } \\
\text { of the variables that incorporate the automatic stay } \\
\text { proposition on the assets of a failing firm, the } \\
\text { continuation of the old managers in a } \\
\text { reorganization process, restrictions for going into } \\
\text { reorganization and the seniority system of secured } \\
\text { creditors }\end{array}$ & $\begin{array}{l}\text { Units within the } \\
\text { interval } 0 \text { to } 4 .\end{array}$ & $\begin{array}{l}\text { La Porta et al. } \\
\text { (1998) }\end{array}$ \\
\hline $\begin{array}{l}\text { Shareholders } \\
\text { 'rights index }\end{array}$ & $\begin{array}{l}\text { As defined in La Porta et al. (1998), this index is } \\
\text { composed of the sum of the one share-one-vote, } \\
\text { proxy by mail, shares not blocked before meeting, } \\
\text { cumulative voting/proportional presentation, } \\
\text { oppressed minorities, preemptive right to new } \\
\text { issues and percentage of share capital to call an } \\
\text { emergency shareholder meeting less that ten } \\
\text { percent }^{17} \text {. }\end{array}$ & $\begin{array}{l}\text { Units within the } \\
\text { interval } 0.05 \text { to } \\
5.10\end{array}$ & $\begin{array}{l}\text { La Porta et al. } \\
\text { (1998) }\end{array}$ \\
\hline $\begin{array}{l}\text { Accounts } \\
\text { index }\end{array}$ & $\begin{array}{l}\text { As defined in La Porta et al. (1998), this index } \\
\text { reflects the transparency and comprehensiveness } \\
\text { of companies' accounting reports }\end{array}$ & $\begin{array}{l}\text { Units within the } \\
\text { interval } 24 \text { to } 83 \text {. }\end{array}$ & $\begin{array}{l}\text { La Porta et al. } \\
\text { (1998) }\end{array}$ \\
\hline $\begin{array}{l}\text { Enforcement } \\
\text { Index }\end{array}$ & $\begin{array}{l}\text { As defined in La Porta et al. (1998), it consists of } \\
\text { the average of the efficiency of judicial system, } \\
\text { rule of law, risk of expropriation and risk of } \\
\text { contract repudiation. }\end{array}$ & $\begin{array}{l}\text { Units within the } \\
\text { interval } 4.87 \text { to } \\
9.99\end{array}$ & $\begin{array}{l}\text { La Porta et al. } \\
\text { (1998) }\end{array}$ \\
\hline
\end{tabular}

maximum of $3.27 \%$ for Peru in 1989 . This suggests that the data on the average log of inflation volatility has some large values or outliers which might affect the estimated results. In order to deal with this problem, these outliers have been excluded based on a

\footnotetext{
${ }^{17}$ More details on these sub-indices are provided in La Porta et al. (1998).
} 
non-subjective criterion by discarding the top $10 \%$ of the volatility distribution. The data on the $\log$ of inflation volatility will then fall within the interval $[-0.98,1.3]$.

The index LEGAL2, as mentioned in Chapter one, is the Chinn and Ito (2005) index of that was estimated in this dissertation for the sample of countries and the time period under study. Again, this index reflects the level of development in financial institutions and was estimated using principal component analysis of four indices including; the protection of creditors' rights, the protection of shareholders' rights, transparency of the company's account, and strong enforcement of laws. This index falls in the interval [$2.90,1.83]$, where the higher the index the more developed is the level of financial institutions. The data on these four sub-indices were taken from La Porta, Lopez-deSilanes, Shieifer, and Vishny (1998).

The index of creditors' protection, or creditors' rights, is composed of the variables that incorporate the automatic stay proposition on the assets of a failing firm, the continuation of the old managers in a reorganization process, restrictions for going into reorganization and the seniority system of secured creditors. This index ranges from a minimum of zero to a maximum of 4 , where more protection for creditors implies a higher index.

The degree of law enforcement index consists of the average of the efficiency of judicial system, rule of law, risk of expropriation and risk of contract repudiation. This index ranges from a minimum of 4.87 to a maximum of 9.99 , where a higher index means a stricter system of law enforcement.

Next, the shareholder's rights, it is composed of the sum of the one share-one-vote, proxy by mail, shares not blocked before meeting, cumulative voting/proportional 
presentation, oppressed minorities, preemptive right to new issues and percentage of share capital to call an emergency shareholder meeting less than ten percent ${ }^{18}$. This subindex ranges from a minimum of 0.05 to a maximum of 5.10 , where the higher the index the better the shareholders' protection.

Finally the account index is an index of the transparency and comprehensiveness of companies' accounting reports. This index ranges from a minimum of 24 to a maximum of 83. Again a higher index implies more transparency and comprehensiveness of the reports.

The set of regional dummies includes; a dummy for Latin American countries, dummy for OECD countries ${ }^{19}$, a dummy for Asian countries, and a dummy for the African and the Middle Eastern countries ${ }^{20}$. The classification of countries between these four regions appears in Table 2.13 of Appendix (II).

The control set includes variables that vary both across countries and over time, as well as variables that vary only across countries. Among the former there are; the first lag of sovereign debt rating or an $\mathrm{AR}(1)$, the average over the period inflation, the average over the period log of inflation volatility, the average over the period ratio of private domestic credit to GDP, and the average over the period per capita GDP. Variables that vary only across countries include the LEGAL2 index and its four components; protection of creditors' rights, protection of shareholders' rights, transparency of companies accounts, and enforcement of laws.

\footnotetext{
${ }^{18}$ More details on these sub-indices are provided in La Porta et al. (1998).

${ }^{19}$ This dummy includes Japan and Turkey.

${ }^{20}$ This dummy includes South Africa.
} 
Before proceeding into more details on these regressors, it will be helpful to have a quick description of the relation between each variable and a country's sovereign debt rating;

- Inflation: the level of inflation acts as a proxy for the quality of the economic management of the country. It is an indicator of the government's control over fiscal and monetary policy. High inflation is expected to have a negative impact on sovereign debt rating.

- Inflation Volatility: A high variation in the level of inflation, or high volatility, will create an environment of uncertainty in the economy which is expected to have an additional impact on the credit worthiness of a country. High inflation volatility is expected to add to the negative effect of high inflation on sovereign debt rating.

- Per capita income: The greater the per capita income of a country the greater is its potential tax base which will increase the country's ability to repay its debts. A high per capita income is expected to lead to a high sovereign debt rating.

- Domestic credit: A high ratio of domestic credit to the private sector as a ratio of GDP indicates the government's policy towards encouraging the engagement of the private sector into the economy. This variable can serve as a proxy of financial deepening of the economy. A high ratio of domestic credit to GDP is expected to have a positive impact on sovereign debt rating.

- LEGAL2 index: As defined in Chinn and Ito (2005), this index pertains to the level of development of legal systems and institutions closely related to financial transactions. This variable can serve as a proxy for a country's financial 
institutions. Where better financial institutions is stemmed from better protection of creditors' rights and shareholders' rights, better law enforcement and more transparency in the companies' accounts. All of these components combined are all expected to encourage national and international investments, which would lead to higher economic growth. Higher economic growth would increase the country's ability to pay its existing debt burdens which would finally lead to higher sovereign debt rating.

\subsection{Estimation Results}

The TSLS methodology is used in order to avoid the endogeneity problem that might arise between the determinants of the sovereign debt rating. The model is estimated under eight specifications of the independent variables. In each specification, the dependent variable is sovereign debt rating. The focus is on the partial correlations between sovereign debt rating and the measures of inflation volatility and financial institutions, and their interaction term.

To estimate the model using TSLS, first the correct set of instruments for the regressors has to be found and these instruments must be valid; meaning that they pass the instrument relevance test as well as the instrument exogeneity test. For the former test the F-statistic for the regressions in which each regressor is regressed on the whole set of instruments including regional and period dummies must exceed 10. This implies that the bias of the TSLS is at most $10 \%$ of the bias of the OLS estimator. 
For the instrument exogeneity test, or overidentification test, the hypothesis that the instruments are exogenous to the error term is to be tested. The hypothesis is rejected if the calculated $\mathrm{J}$-statistic ${ }^{21}$ exceeds a chi-squared with $m$ minus $k$ restrictions at a chosen significant level, where $m$ and $k$ refer to the number of instruments and the number of endogenous regressors respectively. In addition, the Sargan p-value (Sargan (1988)) is calculated.

The set endogenous variables include level of inflation, volatility of inflation, domestic credit as a ratio to GDP, and GDP per capita. The set of exogenous variables, which are not correlated with the error term, include the constant term, the first lag of the sovereign debt rating, the LEGAL2 index, the period fixed effects, and the regional dummies.

The set of instruments used in the estimation was chosen in such a way that a unique set of instruments for all the endogenous variables can be found. This unique set of instruments consisted of all the exogenous variables mentioned above plus the first lag for each of the endogenous variables, the average value taken by each of the endogenous variables in the major trading partners of each country, longitudes, latitudes, and a dummy for English origin. The English origin dummy takes 1 if the legal origin of the country's law is English common law and 0 otherwise. The data for the English origin dummy were taken from La Porta et al. (1998).

This set of instrument passed both the relevance test and the exogeneity test mentioned above. For the former test, each one of the endogenous regressors was regressed in a turn on the whole set of instruments. Based on the values of the first stage F-statistic shown in Table 2.3 below the set of instruments was found to be relevant. In

\footnotetext{
${ }^{21}$ Equal to the number of instruments multiplied by the second stage F-statistic
} 
addition, the p-values of the Sargan test of all the regressions -shown in Table 2.4indicate that the hypothesis of over-identifying moment conditions cannot be rejected, and hence the instruments are exogenous to the error term.

Table 2.3 First Stage F-statistic of the TSLS
\begin{tabular}{|l|c|}
\hline Endogenous Variable & First Stage F-Statistic \\
\hline Inflation & 47.71 \\
\hline Inflation Volatility & 79.93 \\
\hline Domestic Credit & 58.38 \\
\hline Per Capita GDP & 4136.77 \\
\hline
\end{tabular}

Table 2.4 below shows the results of estimating eight regressions. Column 1 of Table 2.4 shows the results of the sovereign regression with only an $\mathrm{AR}(1)$ term or lagged rating in addition to regional dummies. The sign and significance of the lagged rating was as expected. When the average of the period level of inflation was added to the regression (Column 2), the coefficient of the lagged rating remained significant. The coefficient of inflation was also significant and the magnitude of this coefficient indicates that a one percent increase in the average over the period level of inflation corresponds to about 0.06 drop in sovereign debt rating which is a minimal impact.

Next, adding the average over the period inflation volatility to the regression (Column 3), the coefficient of the lagged rating again remained significant. Interestingly, once the $\log$ of inflation volatility was included in the regression the coefficient of the average over the period inflation turned insignificant and its magnitude decreased by almost $50 \%$. The coefficient of inflation volatility on the other hand proved to be significant and with the expected negative sign and magnitude. A one percent increase in the average over the period log of inflation volatility corresponds to about a one classification decrease in the sovereign debt rating. 
Table 2.4 Sovereign debt rating and Inflation Volatility

Cross-country panel data consists of non-overlapping 3-year averages spanning 1989-2006.

Dependent variable: Sovereign debt rating.

Estimation Method: TSLS with Regional Dummies and Period Fixed Effects.

\begin{tabular}{|c|c|c|c|c|c|c|c|c|}
\hline & [1] & [2] & [3] & [4] & [5] & [6] & [7] & [8] \\
\hline Constant & $\begin{array}{c}5.63 * * * \\
(1.24)\end{array}$ & $\begin{array}{c}7.79 * * * \\
(2.19)\end{array}$ & $\begin{array}{c}8.59 * * * \\
(2.03)\end{array}$ & $\begin{array}{c}8.33 * * * \\
(1.96)\end{array}$ & $\begin{array}{l}-1.23 \\
(3.02)\end{array}$ & $\begin{array}{c}2.57 \\
(3.36)\end{array}$ & $\begin{array}{c}0.92 \\
(2.84)\end{array}$ & $\begin{array}{c}2.22 \\
(3.48)\end{array}$ \\
\hline Lagged rating & $\begin{array}{c}0.73 * * * \\
(0.06)\end{array}$ & $\begin{array}{l}0.64 * * * \\
(0.96)\end{array}$ & $\begin{array}{c}0.61 * * * \\
(0.90)\end{array}$ & $\begin{array}{c}0.56 * * * \\
(0.1)\end{array}$ & $\begin{array}{l}0.44 * * * \\
(0.09)\end{array}$ & $\begin{array}{c}0.42 * * * \\
(0.10)\end{array}$ & $\begin{array}{c}0.44 * * * \\
(0.09)\end{array}$ & $\begin{array}{c}0.43 * * * \\
(0.09)\end{array}$ \\
\hline Inflation & & $\begin{array}{l}-0.06^{*} \\
(0.035)\end{array}$ & $\begin{array}{c}-0.03 \\
(0.041)\end{array}$ & $\begin{array}{l}-0.04 \\
(0.04)\end{array}$ & $\begin{array}{l}-0.03 \\
(0.03)\end{array}$ & $\begin{array}{l}-0.03 \\
(0.03)\end{array}$ & $\begin{array}{l}-0.001 \\
(0.03)\end{array}$ & $\begin{array}{l}-0.01 \\
(0.04)\end{array}$ \\
\hline Log Inflation volatility & & & $\begin{array}{l}-1.48^{*} \\
(0.87)\end{array}$ & $\begin{array}{l}-1.17 \\
(0.85)\end{array}$ & $\begin{array}{c}-1.82^{* * *} \\
(0.81)\end{array}$ & $\begin{array}{c}-1.60^{* * *} \\
(0.76)\end{array}$ & $\begin{array}{c}-1.58 * * * \\
(0.60)\end{array}$ & $\begin{array}{c}-1.53^{* *} \\
(0.65)\end{array}$ \\
\hline Domestic Credit/GDP & & & & $\begin{array}{c}0.011 * * \\
(0.004)\end{array}$ & $\begin{array}{c}0.001 \\
(0.004)\end{array}$ & $\begin{array}{c}0.001 \\
(0.004)\end{array}$ & $\begin{array}{l}-0.001 \\
(0.004)\end{array}$ & $\begin{array}{l}-0.001 \\
(0.004)\end{array}$ \\
\hline Log per capita GDP & & & & & $\begin{array}{c}3.08 * * * \\
(0.75)\end{array}$ & $\begin{array}{c}2.27 * * * \\
(0.76)\end{array}$ & $\begin{array}{c}2.66 * * * \\
(0.72)\end{array}$ & $\begin{array}{c}2.36^{* * * *} \\
(0.80)\end{array}$ \\
\hline LEGAL2 & & & & & & $\begin{array}{l}0.60^{*} \\
(0.32)\end{array}$ & & $\begin{array}{c}0.34 \\
(0.44)\end{array}$ \\
\hline $\begin{array}{l}\text { Interaction of } \\
\text { Volatility \& LEGAL2 }\end{array}$ & & & & & & & $\begin{array}{c}1.04 * * * \\
(0.38)\end{array}$ & $\begin{array}{l}0.60 \\
(0.51)\end{array}$ \\
\hline Dummy Latin & $\begin{array}{l}-1.20 \\
(0.88)\end{array}$ & $\begin{array}{l}-1.71 * \\
(0.87)\end{array}$ & $\begin{array}{c}-1.71 * * \\
(0.84)\end{array}$ & $\begin{array}{c}-1.73 * * \\
(0.79)\end{array}$ & $\begin{array}{l}-1.38 * \\
(0.73)\end{array}$ & $\begin{array}{l}-1.15^{*} \\
(0.70)\end{array}$ & $\begin{array}{l}-1.27 \\
(0.80)\end{array}$ & $\begin{array}{l}-1.19 \\
(0.73)\end{array}$ \\
\hline $\begin{array}{l}\text { Dummy } \\
\text { Africa/Middle-East }\end{array}$ & $\begin{array}{l}-0.56 \\
(0.83)\end{array}$ & $\begin{array}{l}-1.08 \\
(1.21)\end{array}$ & $\begin{array}{l}-1.77 \\
(1.32)\end{array}$ & $\begin{array}{l}-1.58 \\
(1.36)\end{array}$ & $\begin{array}{l}-0.91 \\
(1.09)\end{array}$ & $\begin{array}{l}-1.14 \\
(1.08)\end{array}$ & $\begin{array}{l}-1.20 \\
(1.11)\end{array}$ & $\begin{array}{l}-1.23 \\
(1.08)\end{array}$ \\
\hline Dummy Asian & $\begin{array}{c}-1.48 * * \\
(0.71)\end{array}$ & $\begin{array}{c}-2.01 * * \\
(0.95)\end{array}$ & $\begin{array}{c}-2.06 * * \\
(0.99)\end{array}$ & $\begin{array}{c}-2.21 * * \\
(1.11)\end{array}$ & $\begin{array}{l}-0.58 \\
(1.10)\end{array}$ & $\begin{array}{l}-1.32 \\
(1.09)\end{array}$ & $\begin{array}{l}-1.28 \\
(0.97)\end{array}$ & $\begin{array}{l}-1.43 \\
(1.01)\end{array}$ \\
\hline Countries/Observations & $34 / 167$ & $34 / 167$ & $34 / 166$ & $34 / 166$ & $34 / 165$ & $34 / 165$ & $34 / 165$ & $34 / 165$ \\
\hline Adjusted R-squared & 0.836 & 0.835 & 0.843 & 0.845 & 0.875 & 0.878 & 0.880 & 0.890 \\
\hline $\begin{array}{l}\text { J-Statistic / Sargan P- } \\
\text { value }\end{array}$ & $\begin{array}{c}4.31 \\
{[0.97]}\end{array}$ & $\begin{array}{l}15.35 \\
{[0.34]}\end{array}$ & $\begin{array}{l}14.55 \\
{[0.41]}\end{array}$ & $\begin{array}{l}15.40 \\
{[0.42]}\end{array}$ & $\begin{array}{l}12.97 \\
{[0.67]}\end{array}$ & $\begin{array}{l}10.39 \\
{[0.92]}\end{array}$ & $\begin{array}{l}10.48 \\
{[0.92]}\end{array}$ & $\begin{array}{l}9.58 \\
{[0.94]}\end{array}$ \\
\hline
\end{tabular}

When private domestic credit as a ratio of GDP was added to the regression (Column 4), the signs and magnitudes of the lagged rating and average over the period inflation did not change in terms of the signs and statistical significance discussed above. The average over the period log of inflation volatility on the other hand turned insignificant but with the correct sign. The coefficient of the domestic credit on the other hand, indicated a positive and statistical significant impact on sovereign debt rating though of a negligible magnitude. This indicates that the effect of domestic credit on sovereign debt rating is small and not economically significant, although it is statistically significant. 
When private domestic credit as a ratio of GDP was added to the regression (Column 4), the signs and magnitudes of the lagged rating and average over the period inflation did not change in terms of the signs and statistical significance discussed above. The average over the period log of inflation volatility on the other hand turned insignificant but with the correct sign. The coefficient of the domestic credit on the other hand, indicated a positive and statistical significant impact on sovereign debt rating though of a negligible magnitude. This indicates that the effect of domestic credit on sovereign debt rating is small and not economically significant, although it is statistically significant.

Adding the per capita GDP to the regression (Column 5), the coefficient of inflation volatility turned significant again. In addition, all the previous results in terms of significance and magnitudes did not change much except for the coefficient of private domestic credit as a ratio to GDP which became no longer significant. The reason for this might be due to the high and positive correlation between the per capita GDP and the private domestic credit as a ratio to GDP which is equal to 0.53 . Accordingly, the results of Column 5 indicate that there is at best a weak, indirect relationship between domestic credit and sovereign debt rating that is completely dwarfed by the per capita GDP. As Column 5 indicates, the coefficient of the per capita GDP proved to be highly significant and large in magnitude. A unit increase in per capita GDP corresponds to about 3 classifications increase in the sovereign debt rating.

Next, in order to estimate the direct effect of financial institutions on sovereign debt rating, the LEGAL2 index was added to the regression. As obvious from Column 6, the impact of financial institutions on sovereign debt rating appeared with expected positive sign, magnitude, and statistical significance. A one unit increase in LEGAL2 
index corresponds to about one unit increase in sovereign debt rating. In other words, a country with well developed financial institutions will also have a higher sovereign debt rating. Concerning the other coefficients in Column 6, the coefficient of the private domestic credit as a ratio to GDP stayed insignificant. In addition to the correlation issue between domestic the private domestic credit as a ratio to GDP and per capita GDP discussed above, the correlation between the the private domestic credit as a ratio to GDP and the LEGAL2 index was found to be also positive and relatively high of about 0.64 . Also it is important to note that the correlation between per capita GDP and sovereign debt rating is stronger than the correlation between the private domestic credit as a ratio to GDP and sovereign debt rating. So what is probably happening is that the impact of per capita GDP overshadows the private domestic credit as a ratio to GDP in the regression. It is worth to note that in this regression, the LEGAL2 index was treated as exogenous by adding it to the set of instruments besides its addition to the set of regressors.

In order to estimate the indirect effect of financial institutions, the interaction term of LEGAL2 index with inflation volatility was added to the rating regression (Column 7) while keeping the LEGAL2 index in the set of instruments. The results show a statistical significant negative coefficient for the average over the period inflation volatility. A one percent increase in inflation volatility will lead to a drop in sovereign debt rating of about 2 rating classifications. The LEGAL2 index will in turn indirectly reduce this negative impact on sovereign debt rating through its positive interaction term with inflation volatility. In other words, the results of Column 7 seem to say that strong financial institutions do significantly enhance the relationship between inflation volatility and 
sovereign debt rating in such a way that countries with high inflation volatility but well developed financial institutions will have higher sovereign debt rating over the next three years.

When adding both the financial institutions index and its interaction term with inflation volatility, or the direct and indirect effects of the financial institutions (Column 8), the results show that neither the direct effect nor the indirect effect of LEGAL2 is statistically significant. One possible explanation here is the possibility of the presence of imperfect multicollinearity between the two terms, the direct effect and the indirect effect of institutions. The correlation between the financial institutions' index and its interaction term is around 0.74 as shown in Table 2.12 of Appendix (II). Also, as shown in Table 2.14 of Appendix (II), computing the F-statistic of the test that $\beta_{L E G A L 2}=0$ and $\beta_{\text {interaction }}=0$, is equal to about 3.77. Under the null hypothesis, in large samples this statistic has $F_{2, \infty}$ distribution. And under the 5\% significance level, the $F_{2, \infty}$ distribution is 3.00. Since the value of the F-statistic from the data exceeds the critical value of 3.00, the null hypothesis that both coefficients are zero is rejected. In other words, at least one of the coefficients is significant. This suggests that the insignificance of the two coefficients $\beta_{L E G A L 2}$ and $\beta_{\text {interaction }}$ in Table 2.4 above is due to the imperfect multicollinearity between the LEGAL2 index and its interaction with inflation volatility.

In conclusion, this section proved that the magnitude of the negative impact of inflation volatility on sovereign debt rating is more important in terms of size and statistical significance as compared to the level of inflation. In addition, the negative impact of inflation volatility on sovereign debt rating is reduced with the presence of well developed financial institutions. Finally, financial institutions have a positive direct and 
indirect impact on sovereign debt rating, where the latter impact works through the financial institutions' interaction with inflation volatility.

\subsection{Estimating the impact of the components of LEGAL2}

From the previous section, the impact of financial institutions on the negative effect of inflation volatility on sovereign debt rating was found to be positive and statistically significant. The next questions are which type of financial institutions positively contributes more to the negative effect of inflation volatility on sovereign debt rating? Is it the protection of creditors' rights? Or is it the protection of shareholders' rights? Or is it the strong enforcement of laws? Or is it the transparency of the company's accounts? Or all of them combined?

To answer these questions, the model is re-estimated using the TSLS methodology by splitting the LEGAL2 index into its four sub-indices. Each sub-index is included in the regression as an interaction term with inflation volatility. A significant positive interaction term of a particular sub-index will simply mean that this sub-index reduces the harmful impacts of inflation volatility on sovereign debt rating.

Table 2.5 below reports the results of the interaction of the components of the financial institutions index with inflation volatility each one in a turn. For seek of brevity, only the coefficients of inflation volatility and the interaction terms were reported.

When the interaction term of creditor's rights was added to the regression (Column 1), the coefficient of inflation volatility remained negatively statistically significant, but the coefficient of the interaction term was insignificant. Similar results were reached for 
Table 2.5 Sovereign debt rating and Inflation Volatility Interactions with "LEGAL2" Sub-indices Cross-country panel data consists of non-overlapping 3-year averages spanning 1989-2006.

Dependent variable: Sovereign debt rating.

Estimation Method: TSLS with Regional Dummies and Period Fixed Effects.

\begin{tabular}{lccccc}
\hline & & Interaction Of & Volatility & With: & \\
& $\begin{array}{c}\text { Pred } \\
\text { sign }\end{array}$ & $\begin{array}{c}{[1]} \\
\text { Creditors } \\
\text { Rights }\end{array}$ & $\begin{array}{c}{[2]} \\
\text { Shareholders } \\
\text { Rights }\end{array}$ & $\begin{array}{c}{[3]} \\
\text { Enforcement }\end{array}$ & $\begin{array}{c}{[4]} \\
\text { Accounts }\end{array}$ \\
$\begin{array}{l}\text { Legal/Inst. Variable: } \\
\text { creditors' Rights }\end{array}$ & & & & \\
Volatility & - & $-2.75^{* *}$ & & \\
& & $(1.08)$ & & \\
INTERACTION: & + & 0.42 & & \\
Creditors' rights x Volatility & & $(0.36)$ & & \\
Sargan Test, p-value & & 14.16 & & \\
& & {$[0.58]$} & & \\
\hline
\end{tabular}

Legal/Inst. Variable:

Shareholders' Rights

Volatility

$-\quad-4.19 * * *$

INTERACTION:

$+$

Shareholder's Rights $\mathrm{x}$

$+\quad 1.12 * *$

Volatility

Sargan Test, p-value $\quad 12.97$

[0.67]

Legal/Inst. Variable:

Enforcement

Volatility

- $\quad-12.12 * * *$

INTERACTION:

$+$

(3.45)

Enforcement $x$ Volatility

$1.26^{* * *}$

Sargan Test, p-value

$(0.41)$

10.16

[0.86]

Legal/Inst. Variable:

Accounts

Volatility

$-\quad-3.12^{* *}$

$(1.60)$

INTERACTION:

$+$

0.02

Accounts x Volatility

(0.02)

Sargan Test, p-value

12.12

$[0.74]$

Notes: $* * *, * *$, and $*$ denotes statistical significance at the $1 \%, 5 \%$ and $10 \%$ levels respectively Numbers in round parentheses (.) are the standard errors, and numbers in square parentheses [.] are the Sargan P-values.

the interaction term of the transparency of the company's account. This might seem to suggest that protecting creditors' rights or improving the transparency of the company's accounts index each by itself does not have a strong impact on the total effect of inflation volatility on sovereign debt rating. 
Adding the interaction term of shareholders' rights (Column 2), both the coefficient of inflation volatility and the coefficient of the interaction term appeared to be significant and with the expected sign and magnitude. Also as shown in Column 3, the coefficient of inflation volatility and the coefficient of its interaction with the enforcement index appeared to be significant.

It is important to note that since there are interaction terms in the regression, the significance of the interaction term cannot be examined separately from the coefficient of inflation volatility. What matters in this case would be the significance of the total effect of inflation volatility which basically combines the coefficient of the interaction term with the coefficient of inflation volatility. This will be discussed in more details in the next section.

\subsection{Calculating The Total Effects}

Previous sections concluded that policies aiming at reducing inflation volatility would have a positive significant impact on sovereign debt rating. In addition, policies aiming at improving financial institutions will have a positive significant impact on sovereign debt rating, either a direct impact or an indirect impact.

In this section, the total effect of a one standard deviation decrease in the log of inflation volatility versus the total effect of a one standard deviation increase in the LEGAL2 index on the sovereign debt rating are to be compared. 


\subsubsection{Total Effect of Inflation of Volatility}

As the seventh Column of Table 2.4 above shows, improving financial institutions will lessen the harmful effects of inflation volatility on sovereign debt rating. But the question remains; what will be the total effect of the decrease in the log of inflation volatility on the sovereign debt rating? To answer this question, the total effect of a one standard deviation decrease in inflation volatility under different LEGAL2 percentiles is calculated.

Table 2.6 Total Effect of a One Standard Deviation Change in Inflation Volatility (Given the LEGAL2 index)

\begin{tabular}{|c|c|c|c|c|c|}
\hline $\begin{array}{c}(4) \\
\text { L2 } \\
\text { Index }\end{array}$ & $\begin{array}{c}(5) \\
\text { equals (3) } \\
\text { times (4) }\end{array}$ & $\begin{array}{c}\text { Total } \\
\text { Effect } \\
(2)+(5)\end{array}$ & Variance & $\begin{array}{l}\text { Confidence } \\
\text { Interval }\end{array}$ & t-stat \\
\hline-2.90 & -2.37 & $-3.61 * * *$ & 0.93 & {$[-5.50,-1.72]$} & -3.75 \\
\hline-1.95 & -1.60 & $-2.84 * * *$ & 0.54 & {$[-4.28,-1.40]$} & -3.87 \\
\hline-1.01 & -0.82 & $-2.07 * * *$ & 0.30 & {$[-3.15,-0.99]$} & -3.75 \\
\hline-0.06 & -0.05 & $-1.29 * * *$ & 0.23 & {$[-2.22,-0.36]$} & -2.72 \\
\hline 0.88 & 0.72 & -0.52 & 0.30 & {$[-1.60,0.56]$} & -0.94 \\
\hline 1.83 & 1.49 & 0.25 & 0.54 & {$[-1.18,1.69]$} & 0.35 \\
\hline \multicolumn{2}{|c|}{ (1) Standard Deviation Of Volatility } & 0.79 & & & \\
\hline \multicolumn{2}{|c|}{ (2) Volatility Coefficient times (1) } & -1.24 & & & \\
\hline \multicolumn{2}{|c|}{ (3) Interaction Coefficient times (1) } & 0.82 & & & \\
\hline
\end{tabular}

As Table 2.6 shows, the total effect is calculated by multiplying the coefficient of inflation volatility $\hat{\beta}_{3}$ of Equation (2.2) above with the standard deviation of inflation volatility $\operatorname{std}\left(\operatorname{infvol}_{\mathrm{i}, \mathrm{t}}\right)$ to get $\left[\hat{\beta}_{3} * \operatorname{std}\left(\operatorname{infvol}_{\mathrm{i}, \mathrm{t}}\right)\right]$. The coefficient of the interaction term of LEGAL2 with inflation volatility $\hat{\beta}_{4}$ of Equation (2.2) above is to be also multiplied 
by $\operatorname{std}\left(\operatorname{infvol}_{\mathrm{i}, \mathrm{t}}\right)$ to get $\left[\hat{\beta}_{4} * \operatorname{std}\left(\operatorname{infvol}_{\mathrm{i}, \mathrm{t}}\right)\right]$. Next, this latter product is multiplied by the LEGAL2 index which was divided into five quintiles. Each quintile was then multiplied by $\left[\hat{\beta}_{4} * \operatorname{std}(\right.$ infvol $\left.)\right]$ to get $\left[\operatorname{LEGAL2} 2_{i} *\left[\hat{\beta}_{4} * \operatorname{std}(\right.\right.$ infvol $\left.\left.)\right]\right]$.

The first column of Table 2.6 shows the quintiles of the index. The first number of this column, -2.90 , refers to the minimum value of the index, then the next value -1.95 refers to the $0-20^{\text {th }}$ percentile of the index, -1.01 refers to the $20^{\text {th }}-40^{\text {th }}$ percentile, -0.06 refers to the $40^{\text {th }}-60^{\text {th }}$ percentile, 0.88 refers to the $60^{\text {th }}-80^{\text {th }}$ percentile, and finally 1.83 refers to the $80^{\text {th }}-100^{\text {th }}$ percentile of the index.

As obvious from the "Total Effect" Column of Table 2.6, with the minimum value of the LEGAL2 index, a one standard deviation decrease in the log of inflation volatility will lead to about 4 rating classifications increase. As shown in Table 2.7 below, this would be the case for a country like Peru which has the worst level of financial institutional development in the sample.

Table 2.7 Percentiles of the Data on the LEGAL2 Index

\begin{tabular}{|l|l|l|l|l|l|l|l|l|l|l|l|}
\hline Min & & & & & & & & & & & \\
-2.9 & & -1.95 & & -1.01 & & -0.06 & & 0.88 & & 1.83 & \\
\hline Per. & -2.9 & Arg. & -1.98 & Bra. & -1.24 & Chi. & -0.80 & Ausl. & 0.44 & Aus. & 1.07 \\
& & Egy. & -2.68 & Col. & -1.92 & Ind. & -0.41 & Bel. & 0.54 & Can. & 1.04 \\
& & Uru. & -2.25 & Gre. & -1.12 & Kor. & -0.20 & Den. & 0.87 & Fin. & 1.23 \\
& & & Mex. & -1.32 & S.A & -0.11 & Fra. & 0.3 & H.K & 1.16 \\
& & & Por. & -1.61 & Tha. & -0.48 & Ger. & 0.73 & Mal. & 1.09 \\
& & & Tur. & -1.64 & & & Isr. & 0.36 & N.Z & 1.34 \\
& & & & & & & & Ita. & 0.11 & Nor. & 1.40 \\
& & & & & & & & Jap. & 0.84 & Sin. & 1.76 \\
& & & & & & & & Neth. & 0.8 & Swe. & 1.76 \\
& & & & & & & & Spa. & 0.1 & U.K & 1.83 \\
& & & & & & & & Swi. & 0.85 & U.S.A & 1 \\
\hline Avg. & -2.9 & Avg. & -2.30 & Avg. & -1.48 & Avg. & -0.40 & Avg. & 0.54 & Avg. & 1.33 \\
\hline
\end{tabular}

Notes: Check Table 2.1 for reference on the above abbreviations. 
With a relative improvement in financial institutions, or at the $20^{\text {th }}$ percentile for example, a one standard deviation decrease in the log of inflation volatility will result in about 3 rating classifications increase. Again as obvious from Table 2.7 below, there are three countries in the sample that fall under the $20^{\text {th }}$ percentile. These countries are Argentina, Egypt, and Uruguay.

Countries under the $40^{\text {th }}$ percentile, like Brazil, Colombia, Greece, Mexico, Portugal, and Turkey, are all having a lower total effect of inflation volatility. For this group of countries, a one standard deviation decrease in the log of inflation volatility will lead to about 2 classifications increase in the sovereign debt rating.

For the more institutionally developed countries, above the $60^{\text {th }}$ percentile, the total effect of inflation volatility on sovereign debt rating will have a statistical insignificant magnitude. As Table 2.6 shows, at the $60^{\text {th }}$ percentile the total effect would be of about 1 rating classification increase for each one standard deviation decrease in the log of inflation volatility. Countries included in this category include; Australia, Belgium, Denmark, France, Germany, Israel, Italy, Japan, Netherlands, Spain, and Switzerland. Finally, at both the $80^{\text {th }}$ percentile and at the top quintile of the LEGAL2 index, the total effect would be insignificant and somewhere around zero. This case include countries like Austria, Canada, Finland, Hong Kong, Malaysia, New Zealand, Norway, Singapore, Sweden, United Kingdom, and the United States.

Figure 2.1 below displays the results reported in Table 2.6 above. Each point on the graph corresponds to a different LEGAL2 percentile. As obvious from the graph, the higher the LEGAL2 percentile, or the better the financial institutions, the lower is the negative total effect of inflation volatility on sovereign debt rating. The impact of the one 
standard deviation decrease in log of inflation volatility will lead to a bigger effect at the low percentiles of the LEGAL2 index as compared with the high percentiles of the index. In other words, the elasticity of an economy to respond to an economic policy that reduces inflation volatility is higher in the economies suffering from bad institutions.

Figure 2.1

Total Effect of a one Standard Deviation of Inflation Volatility on Sovereign Debt Rating (Given the Level of LEGAL2)

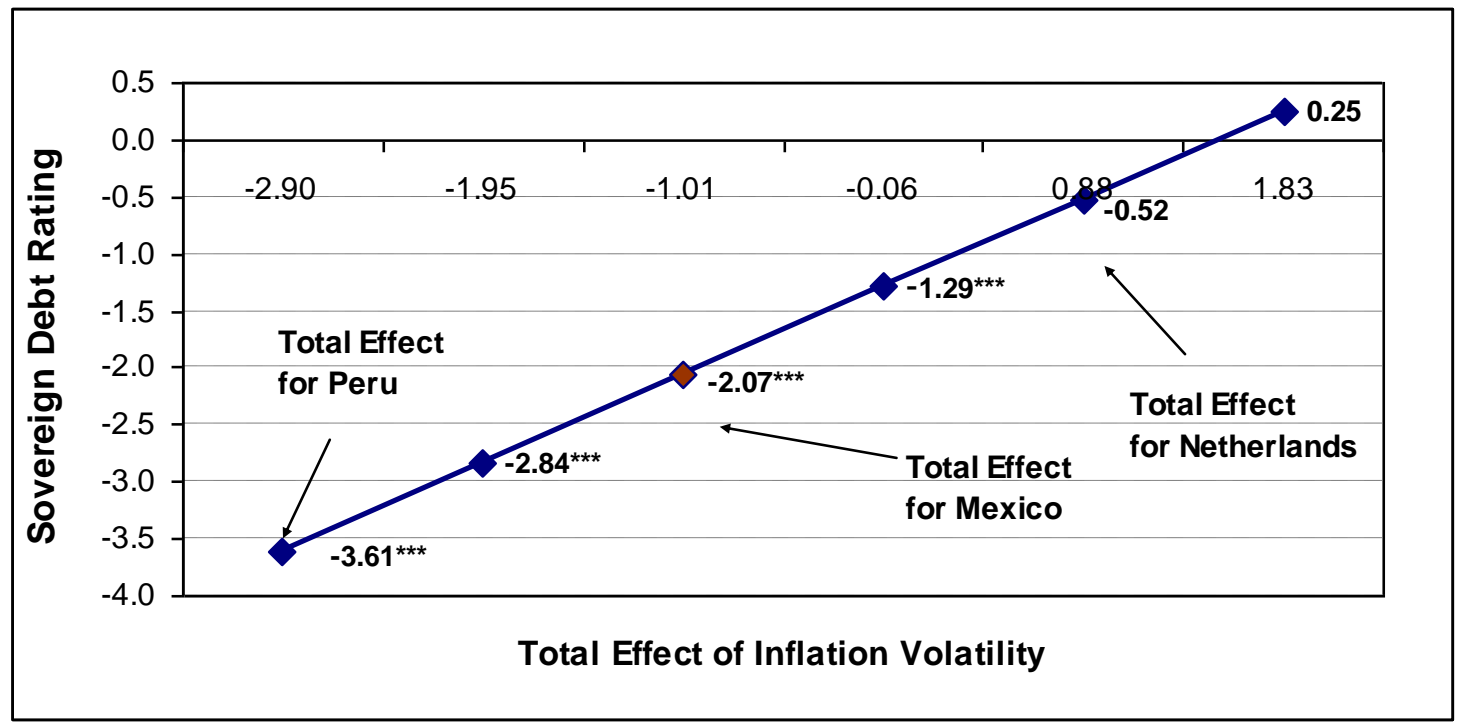

Notes: (***), (**) and $(*)$ denotes statistical significance at the 1\%,5\% and $10 \%$ levels respectively

Countries with relatively underdeveloped institutions have higher response to changes in inflation volatility as compared to countries with relatively good institutions. For instance, on one hand a one standard deviation reduction in the log of inflation volatility at the $40^{\text {th }}$ LEGAL2 percentile (e.g. Mexico) will lead to an increase in rating by about two classifications. On the other hand, a one standard deviation reduction of the $\log$ of inflation volatility under the $80^{\text {th }}$ LEGAL2 percentile (e.g. Japan) will lead to an increase in rating by about one rating point. This suggests that countries with well developed financial institutions; inflation volatility have smaller negative effect on ratings. 
Similar results have been reached by calculating the total effect of inflation volatility in the presence of different degrees of protecting creditors' rights, protecting shareholders' rights, transparency of the company's accounts, and enforcement of laws. The total effect of inflation volatility with each of these four sub-indices was calculated each one in a turn. Tables 2.15 through 2.18 of Appendix (II) report the results. As expected, the more improvement in any of the four sub-indices, the less is the harmful impact of inflation volatility on sovereign debt rating. The total effects were however only significant under the $20^{\text {th }}$ percentile for the creditors' rights index and shareholders' rights index. Figures 2.6 through 2.9 of Appendix (II) present the results graphically.

The results from this section are intuitive in the sense that well financially developed economies have more ways of controlling inflation volatility and dealing with its effects than less institutionally developed economies, and therefore investors do not care as much about the consequences of inflation volatility.

\subsubsection{Total Effect of Financial Institutions}

In this subsection, the total effect of improving financial institutions will be computed. Using the results of Table 2.4 Column 8, the total effect of in LEGAL2 will be calculated as $\left(\hat{\beta}_{4} *\right.$ Infvol $\left._{i, t}+\hat{\beta}_{5}\right)$. In order to calculate the total effect of a one standard deviation increase in LEGAL2, the interaction coefficient $\hat{\beta}_{4}$ and the LEGAL2 coefficient $\hat{\beta}_{5}$ were multiplied by the standard deviation of the LEGAL2 index. Accordingly, the total effect of a one standard deviation will be calculated as $\left(\operatorname{std}\left(L 2_{i}\right) * \hat{\beta}_{4} * \operatorname{Infvol} l_{i, t}\right)$ 
$+\hat{\beta}_{5} * s t d\left(L 2_{i}\right)$, where $s t d\left(L 2_{i}\right)$ refers to the standard deviation of the LEGAL2 index. The Infvol ${ }_{i, t}$ will be substituted for the values of the $20^{\text {th }}, 40^{\text {th }}, 60^{\text {th }}, 80^{\text {th }}$, and $90^{\text {th }}$ inflation volatility percentiles each one in a turn. As mentioned before, after excluding the top $10 \%$ of the log inflation volatility distribution, the data of log inflation volatility will fall in the interval $[0.02,2.94]$.

Table 2.8 Total Effect of a One Standard Deviation Change in LEGAL2 (Given Inflation Volatility)

\begin{tabular}{|c|c|c|c|c|c|}
\hline $\begin{array}{c}\text { (4) } \\
\text { Volatility } \\
\text { Percentiles }\end{array}$ & $\begin{array}{c}(5) \\
\text { equal (3) } \\
\text { times (4) }\end{array}$ & $\begin{array}{c}\text { Total } \\
\text { Effect } \\
(2)+(5)\end{array}$ & Variance & $\begin{array}{c}\text { Confidence } \\
\text { Interval }\end{array}$ & t-stat \\
\hline 0.02 & 0.02 & 0.46 & 0.31 & {$[-0.63,1.54]$} & 0.83 \\
\hline 0.08 & 0.06 & 0.50 & 0.28 & {$[-0.53,1.53]$} & 0.96 \\
\hline 0.22 & 0.17 & 0.61 & 0.22 & {$[-0.30,1.53]$} & 1.32 \\
\hline 0.37 & 0.29 & $0.73 *$ & 0.17 & {$[-0.08,1.54]$} & 1.76 \\
\hline 0.70 & 0.54 & $0.99 * * *$ & 0.14 & {$[0.24,1.73]$} & 2.60 \\
\hline 1.30 & 1.01 & $1.45 * *$ & 0.33 & {$[0.32,2.59]$} & 2.51 \\
\hline 2.94 & 2.28 & $2.73 *$ & 2.46 & {$[-0.35,5.80]$} & 1.74 \\
\hline \multicolumn{2}{|c|}{ (1) Standard Deviation Of LEGAL2 } & 1.29 & & & \\
\hline \multicolumn{2}{|c|}{ (2) LEGAL2 Coefficient times (1) } & 0.44 & & & \\
\hline \multicolumn{2}{|c|}{ (3) Interaction Coefficient times (1) } & 0.78 & & & \\
\hline
\end{tabular}

The first column of Table 2.8 above shows the quintiles of the log inflation volatility data. The first number of this column, $0.02 \%$, refers to the minimum value of the log of inflation volatility, the next value -0.08 refers to the $0-20^{\text {th }}$ percentile of the index, 0.22 refers to the $20^{\text {th }}-40^{\text {th }}$ percentile, 0.37 refers to the $40^{\text {th }}-60^{\text {th }}$ percentile, 0.70 refers to the $60^{\text {th }}-80^{\text {th }}$ percentile, and finally, 2.94 refers to the $80^{\text {th }}-100^{\text {th }}$ percentile of the index. Recall that the $90^{\text {th }}$ percentile, $1.3 \%$, is the cutoff point above which the extremely high log inflation volatility data were discarded from the sample. 
In addition, as obvious from Table 2.8 above for all the countries on the $40^{\text {th }}$ percentile of inflation volatility and below, the total effect of a one unit improvement in the standard deviation of the LEGAL2 index has a statistical insignificant impact on sovereign debt rating and the magnitude of the total effect reaches 0.61 rating classifications at most.

On the other hand, for all the countries that fall under the $60^{\text {th }}$ and above of the inflation volatility percentiles will have a significant positive total effect. For instance, under the $90^{\text {th }}$ percentile of inflation volatility, a one unit improvement in the LEGAL2 index, will lead to about a one classification increase in sovereign debt rating. As shown in Table 2.9 below, countries under the $90^{\text {th }}$ percentile of inflation volatility include Israel, Mexico, Turkey, and Uruguay.

Table 2.9 Percentiles of the Average of the Log of Inflation Volatility Data over the period 1989-2006

\begin{tabular}{|c|c|c|c|c|c|c|c|c|c|c|c|c|c|}
\hline $\begin{array}{l}\text { Min } \\
0.02\end{array}$ & & $\begin{array}{l}\text { 20th } \\
0.08\end{array}$ & & $\begin{array}{l}\text { 40th } \\
0.22\end{array}$ & & $\begin{array}{l}\text { 60th } \\
0.37\end{array}$ & & $\begin{array}{l}\text { 80th } \\
0.70\end{array}$ & & $\begin{array}{l}90 \text { th } \\
1.30\end{array}$ & & $\begin{array}{l}\text { Max } \\
2.94\end{array}$ & \\
\hline $\begin{array}{l}\text { Neth. } \\
\text { Fin. }\end{array}$ & $\begin{array}{l}0.02 \\
0.02\end{array}$ & $\begin{array}{l}\text { Aus } \\
\text { Bel. } \\
\text { Can. } \\
\text { Ita. } \\
\text { Swe. } \\
\text { Swi. } \\
\text { U.S }\end{array}$ & $\begin{array}{l}0.07 \\
0.05 \\
0.04 \\
0.07 \\
0.08 \\
0.08 \\
0.04\end{array}$ & $\begin{array}{l}\text { Fra. } \\
\text { Nor. } \\
\text { Spa. } \\
\text { U.K } \\
\text { Den. }\end{array}$ & $\begin{array}{l}0.19 \\
0.15 \\
0.14 \\
0.16 \\
0.19\end{array}$ & $\begin{array}{l}\text { Austl } \\
\text { Col. } \\
\text { H.K } \\
\text { Jap. } \\
\text { Mal. } \\
\text { N.Z } \\
\text { S.A } \\
\text { Tha. }\end{array}$ & $\begin{array}{l}0.29 \\
0.30 \\
0.26 \\
0.28 \\
0.28 \\
0.34 \\
0.31 \\
0.35\end{array}$ & $\begin{array}{l}\text { Chi. } \\
\text { Egy. } \\
\text { Ger. } \\
\text { Gre. } \\
\text { Ind. } \\
\text { Kor. } \\
\text { Por. } \\
\text { Sin. }\end{array}$ & $\begin{array}{l}0.40 \\
0.64 \\
0.50 \\
0.50 \\
0.59 \\
0.42 \\
0.58 \\
0.50\end{array}$ & $\begin{array}{l}\text { Isr. } \\
\text { Mex. } \\
\text { Tur. } \\
\text { Uru. }\end{array}$ & $\begin{array}{l}1.28 \\
1.12 \\
1.23 \\
1.28\end{array}$ & $\begin{array}{l}\text { Arg. } \\
\text { Bra. } \\
\text { Per. }\end{array}$ & $\begin{array}{l}2.39 \\
2.77 \\
2.94\end{array}$ \\
\hline Avg. & 0.02 & Avg. & 0.06 & Avg. & 0.17 & Avg. & 0.30 & Avg. & 0.52 & Avg. & 1.23 & Avg. & 2.70 \\
\hline
\end{tabular}

Figure 2.2 below displays the results reported in Table 2.8. As obvious from this figure, a one standard deviation increase in the LEGAL2 index has a greater effect on sovereign debt rating as the inflation volatility's percentiles increases. In other words, the elasticity of an economy to respond to a one unit improvement in financial institutions is 
higher if the inflation volatility is a big burden on this economy as compared to economies in which inflation volatility is not.

Figure 2.2

Total Effect of One Standard Deviation of LEGAL2 on Sovereign Debt Rating (Given Inflation Volatility)

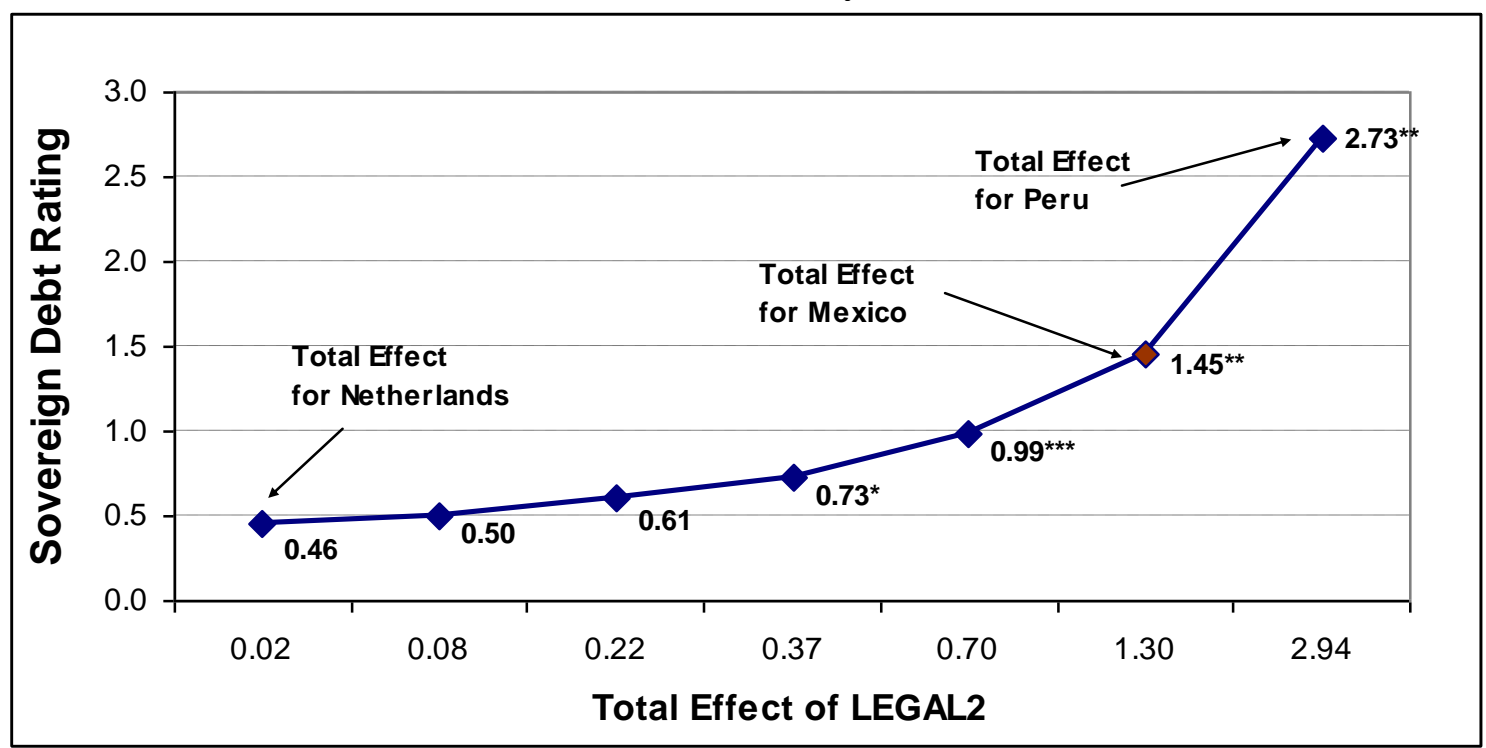

Notes: (***), (**) and (*) denotes statistical significance at the 1\%, 5\% and $10 \%$ levels respectively

These results basically match the previous results of Figure 2.1 above, where institutionally underdeveloped economies have higher elasticities in response to any changes in the inflation volatility as compared to institutionally developed economies.

At this point it is important to know how a developing country, like for example Mexico, can achieve this one standard deviation increase in its LEGAL2 index. An illustrative way to think about it is as follows, a one standard deviation increase in the LEGAL2 index will move Mexico's index to a value very close to the LEGAL2 index for countries like Switzerland, France, Hong Kong, Japan, Netherland, South Africa, New Zealand, and United States. By computing the averages of the individual components of the LEGAL2 index; creditors' rights, shareholders' rights, enforcement, and accounts, for 
these eight countries, the averages were $2,2.95,68.25$, and 9.10. These values were then compared to the Mexico's LEGAL2 sub-indices of $0,1.33,60$, and 6.2. The differences between the average values of these four indices for the eight countries and the four indices for Mexico, implies that Mexico needs a major improvement in all the four components of the LEGAL2. Most important problem in Mexico's financial institutions appeared to be the protection of creditor's rights which is considered one of the one of the greatest problems facing the businessmen in Mexico. Creditors are afraid to provide finances for current or new projects as long as they do not have a direct control over the goods provided by debtor as collateral in case of the debtor's default. Similarly, for the shareholders' rights protection. These improvements in the financial institutions in Mexico are crucial if it needs to enjoy the benefits of the one standard deviation increase in the LEGAL2 index.

\subsection{Robustness Check}

In general, the use of instrumental variables has some disadvantages. There are many variables that can serve as good instruments and the use of one will yield different results than the use of another. In order to check for the validity of the instruments, a robustness check is undertaken by re-estimating the regression model with another estimation methodology that does not require the use of instruments. If the coefficients of the main variables do not change in either size or statistical significance, then this would suggest that the results are robust. 
Using Panel "Least Squares with Regional Dummies Variables" (LSDV) and period fixed effects, the regression results are shown in Table 2.10 below. As obvious from the table, the general results are similar in magnitudes and statistical significance to the results of Table 2.4 above.

Table 2.10 Sovereign debt rating and Inflation Volatility

Cross-country panel data consists of non-overlapping 3-year averages spanning 1989-2006.

Dependent variable: Sovereign debt rating.

Estimation Method: Panel Least Squares with Regional Dummies and Period Fixed Effects.

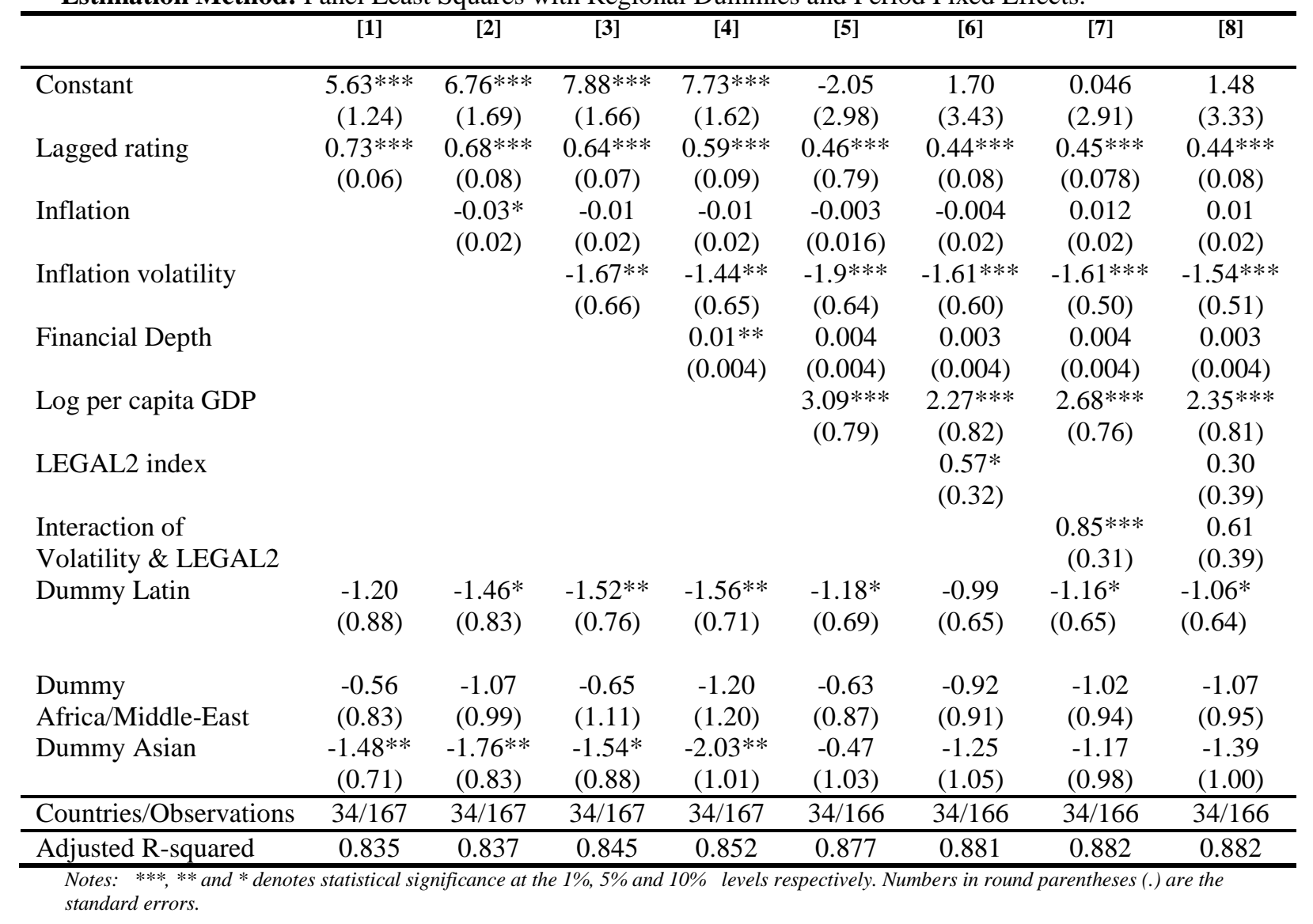

As shown from Table 2.10, the inflation rate (Column 2) appeared to be significant only before adding the log of inflation volatility. But once the log of inflation volatility was added to the regression, the level of inflation appeared insignificant throughout all 
regressions. The log of Inflation volatility (Column 3) was statistically significant in all regressions. The magnitude of the effect was again around two rating classifications for a one percentage change in the average over the period inflation volatility.

The direct effect of financial institution (Column 6) had again a positive and significant effect on the sovereign debt rating. A one unit increase in the financial institutions index will result in about a one classification increase in the sovereign debt rating.

When the indirect effect of financial institutions (Column 7) was added to the regression, again the results suggest a positive significant coefficient of around one rating classification increase for each one unit improvement in the financial institutions index. If the positive coefficient of the indirect effect of financial institutions is combined with the negative coefficient of the inflation volatility, the total effect of inflation volatility will then be less negative or less harmful for each one unit improvement in institution.

Adding the direct and the indirect effects of financial institutions to the regression (Column 8), both effects tends again to cancel each other due to the high correlation between the two variables and therefore their coefficients appeared again insignificant. Using the results of the Panel Least Squares of Table 2.10 above, Table 2.6' computes the total effect of a one standard deviation change in the log of inflation volatility on sovereign debt rating (given the LEGAL2 index).

As can be noticed from Table 2.6', the total effect of a one standard deviation drop in inflation volatility is almost the same as the total effect of Table 2.6 above. For instance, for Mexico, a one the standard deviation drop in inflation volatility will lead to about two classification increase in sovereign debt rating. 
Table 2.6': Robustness Check: Using Panel Least Squares

Total Effect of a One Standard Deviation Change in Inflation Volatility (Given the LEGAL2 index)

\begin{tabular}{|c|c|c|c|c|c|}
\hline $\begin{array}{c}\text { (4) } \\
\text { L2 } \\
\text { Index } \\
\end{array}$ & $\begin{array}{c}(5) \\
\text { equals (3) } \\
\text { times (4) }\end{array}$ & $\begin{array}{c}\text { Total } \\
\text { Effect } \\
(2)+(5) \\
\end{array}$ & Variance & $\begin{array}{l}\text { Confidence } \\
\text { Interval }\end{array}$ & t-stat \\
\hline-2.90 & -1.94 & $-3.21 * * *$ & 0.65 & {$[-4.79,-1.63]$} & -3.97 \\
\hline-1.95 & -1.31 & $-2.58 * * *$ & 0.38 & {$[-3.79,-1.36]$} & -4.17 \\
\hline-1.01 & -0.67 & $-1.94 * * *$ & 0.22 & {$[-2.86,-1.03]$} & -4.17 \\
\hline-0.06 & -0.04 & $-1.31 * * *$ & 0.16 & {$[-2.09,-0.54]$} & -3.31 \\
\hline 0.88 & 0.59 & -0.68 & 0.20 & {$[-1.56,0.20]$} & -1.51 \\
\hline 1.83 & 1.22 & -0.04 & $\mathbf{0 . 3 5}$ & {$[-1.21,1.21]$} & -0.07 \\
\hline \multicolumn{2}{|c|}{ (1) Standard Deviation Of Volatility } & 0.79 & & & \\
\hline \multicolumn{2}{|c|}{ (2) Volatility Coefficient times (1) } & -1.27 & & & \\
\hline \multicolumn{2}{|c|}{ (3) Interaction Coefficient times (1) } & 0.67 & & & \\
\hline
\end{tabular}

Similarly, Table 2.8 ' below reports the total effect of a one standard deviation change in the LEGAL2 index on sovereign debt rating (given inflation volatility). Again, similar results have been reached as the ones reported in Table 2.8 above. For Mexico, a one unit improvement in financial institutions given the inflation volatility will lead to about a one classification increase in the country's sovereign debt rating.

Table 2.8': Robustness Check: Using Panel Least Squares Total Effect of a One Standard Deviation Change in LEGAL2 (Given Inflation Volatility)

\begin{tabular}{|c|c|c|c|c|c|}
\hline $\begin{array}{c}\text { (4) } \\
\text { Volatility } \\
\text { Percentiles }\end{array}$ & $\begin{array}{c}(5) \\
\text { equals (3) } \\
\text { times (4) } \\
\end{array}$ & $\begin{array}{c}\text { Total } \\
\text { Effect } \\
(2)+(5) \\
\end{array}$ & Variance & $\begin{array}{c}\text { Confidence } \\
\text { Interval }\end{array}$ & t-stat \\
\hline 0.02 & 0.02 & 0.41 & 0.24 & {$[-0.56,1.37]$} & $\mathbf{0 . 8 3}$ \\
\hline 0.08 & 0.06 & 0.45 & 0.22 & {$[-0.47,1.38]$} & 0.96 \\
\hline 0.22 & 0.17 & 0.56 & 0.19 & {$[-0.30,1.42]$} & 1.29 \\
\hline 0.37 & 0.29 & $0.68 *$ & 0.17 & {$[-0.12,1.49]$} & 1.66 \\
\hline 0.70 & 0.55 & $0.94 * *$ & 0.16 & {$[0.17,1.72]$} & 2.38 \\
\hline 1.30 & $\mathbf{1 . 0 3}$ & $1.42 * * *$ & 0.27 & {$[0.39,2.44]$} & 2.71 \\
\hline 2.94 & 2.32 & $2.71 * *$ & 1.50 & {$[0.31,5.11]$} & 2.21 \\
\hline \multicolumn{2}{|c|}{ (1) Standard Deviation Of LEGAL2 } & 1.29 & & & \\
\hline \multicolumn{2}{|c|}{ (2) LEGAL2 Coefficient times (1) } & 0.39 & & & \\
\hline \multicolumn{2}{|c|}{ (3) Interaction Coefficient times (1) } & 0.79 & & & \\
\hline
\end{tabular}


Based on the results of this section, it can be concluded that the previous results using TSLS are robust to the use of a different estimation methodology and that the instruments used were good enough to well estimate the relations of interest.

\subsection{Impact of the Increase in Sovereign Rating on Long-Term Bond Yield}

Previous sections have concluded that a country can increase it sovereign debt rating by either following a monetary policy that decreases inflation volatility or by improving its financial institutions. The aim of this section is to link this increase in the sovereign debt rating to the changes in the annual average long term bond yield. What is expected is that a country with low rating will be paying more premiums on its foreign borrowings and therefore its long term bond yield is expected to be relatively high when compared with a higher rated country.

From Section 2.6.1, the study concludes that under the $40^{\text {th }}$ percentile of the LEGAL2 index, under which Mexico belongs, a one standard deviation decrease in the log of inflation volatility will lead to about 2 rating classifications increase given the institutions index. From Table 2.19 of Appendix (II), these two classifications increase in rating means an increase from the lowest level in the investment grade category of "Baa3" or 12 points, to which Mexico belonged in the first quarter of the year 2000, up to "Baa1" or 14 points.

A possible way of linking this increase in the sovereign debt rating to the annual long term bond yield is by plotting a bar chart linking the data of these two variables. Figure 2.3 shows this relationship. As obvious from Figure 2.3, a negative non-linear 
relationship is observed between the sovereign debt rating and the annual average longterm bond yield. A country with high rating is associated with low average long-term bond yield, and vice versa.

Figure 2.3: The negative relationship between Moody's rating in 2000 (first quarter) And 5-year Annual Bond Yield in 2000 (first quarter)

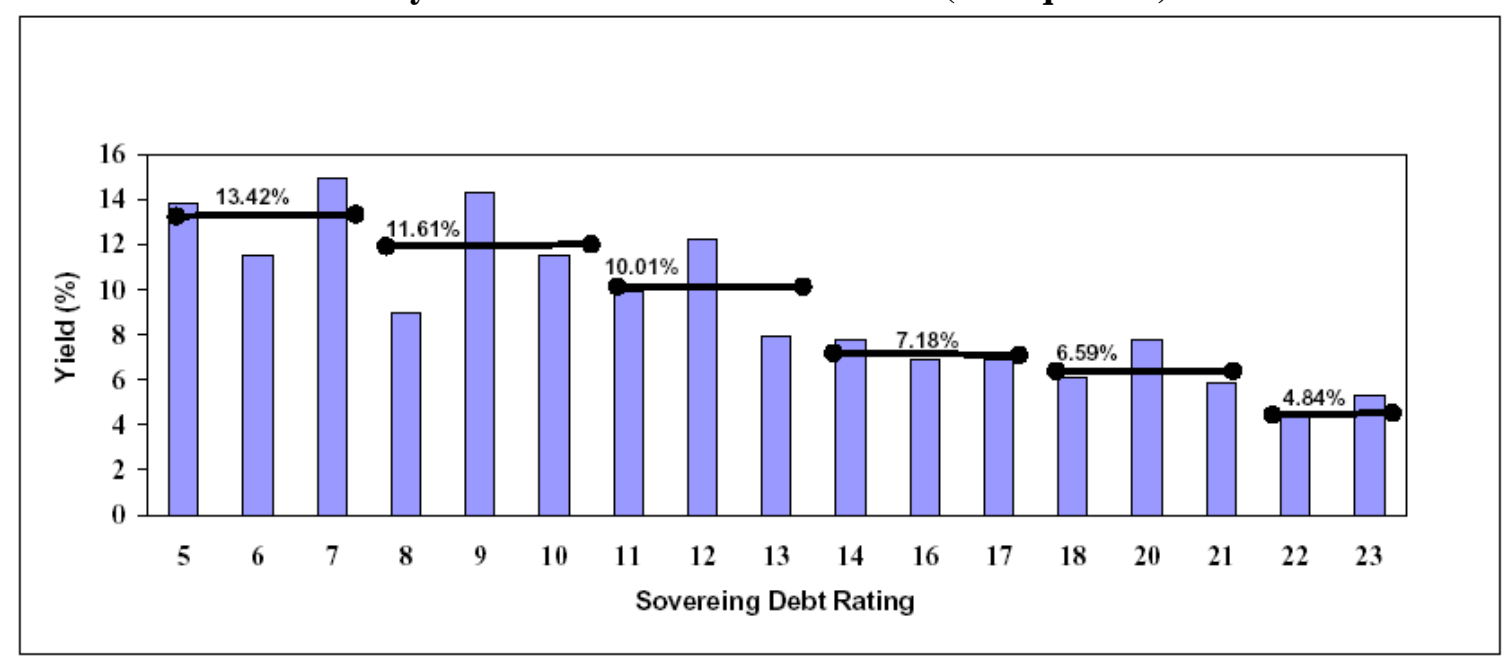

Source: Using Global Finance data for the annual 5-year Bond Yield.

From Figure 2.3 and also from Table 2.20 of Appendix (II), the two classifications increase in rating, from Baa3 to Baa1, are equivalent to a drop in the average annual 5-year bond yield from $12.21 \%$ to $7.81 \%$. In other words, a one standard deviation decrease in inflation volatility will lead to a drop in the country's cost of borrowings by about $4.4 \%$. Figure 2.4 shows a summary of this relationship between the decrease in inflation volatility and the drop in the cost of borrowing.

Similarly, the link between the one standard deviation increase in LEGAL2 index and the drop in the average long term bond yield can be found from the empirical results of section 2.6.2. Again for the Mexico's case, a one standard deviation increase in the 
Figure 2.4

The Effect of Inflation Volatility on the Long Term Bond Yield

One Standard Deviation Decrease in the Log of Inflation Volatility

(Given the level of institutions)

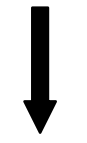

2 classifications Increase in Sovereign debt rating

(Empirical result from TSLS)

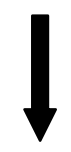

Drop in the Average Annual Long-Term Bond Yield from 12.21\% to 7.81\%

(From the data)

LEGAL2 index was found to lead to about one classification increase in rating from Baa3, which is the level to which Mexico belonged in the year 2000, up to Baa2. From Figure 2.3 and also from Table 2.20 of Appendix (II), the one classification increase in rating, from $\mathrm{Baa} 3$ to $\mathrm{Baa} 2$, are equivalent to a drop in the average annual 5-year bond yield from $12.21 \%$ to $7.94 \%$.

Figure 2.5

The Effect of LEGAL2 on the Long Term Bond Yield

One Standard Deviation increase in the LEGAL2 Index

(Given the level of Inflation Volatility)

1 classification increase in the Sovereign debt rating (Empirical result from TSLS)

Drop in the Average Annual Long-Term Bond Yield From 12.21\% to 7.94\%

(From the data) 
In other words, a one standard deviation increase in the LEGAL2 index will lead to a drop in the country's cost of borrowings by about $4.27 \%$. Figure 2.5 below shows a summary of this relationship between the improvement in financial institutions and the drop in the cost of borrowing.

Before ending this section, it is important to note that the drops in the cost of borrowing computed above that are either due to a one standard deviation decrease in the $\log$ of inflation volatility or a one standard deviation increase in the LEGAL2 index are crucial for the computation of the welfare implications in the next chapter. These drops in the cost of borrowing are to be used as the exogenous shock to the theoretical model presented in the next chapter.

\subsection{Conclusion}

While many studies have concentrated on the role of macroeconomic fundamentals in affecting sovereign debt rating, few of these studies have addressed the role of the second moments of macroeconomic aggregate. Also, while there is a growing literature on the importance of institutions for a country's economic growth, there have been very few studies on the importance of improving institutions in relation to the sovereign debt rating.

This chapter contributes to the sovereign debt rating by showing that: first, the level of inflation loses its significant impact on sovereign debt rating once the log of inflation volatility is included in the regression. Second, reducing log inflation volatility will have a statistical significant positive direct impact on sovereign debt rating where a one 
standard deviation decrease in the log of inflation volatility will lead to two rating classifications increase. Third, improving institutions has a statistical significant positive direct and an indirect impact on sovereign debt rating where a one standard deviation increase in the financial institutions index will lead to a one rating classification increase. Finally, the increase in sovereign debt rating that is either due to a one standard deviation decrease in the $\log$ of inflation volatility or a one standard deviation increase in the institutions index will finally lead to drops in the average annual long-term bond yield by $4.4 \%$ and $4.27 \%$ respectively.

The next chapter will depart from this last point where the welfare implications of the drop in the average annual long-term yield for both the decrease in inflation volatility and the improvement in institutions are to be quantified and compared. 


\section{Part IV \\ Chapter 3: Welfare Implications of Inflation Volatility and Financial Institutions in a Monetary Small Open Economy}

\subsection{Introduction}

Numerous studies have underlined the effect of inflation and institutions on the level of output of a country. However, there have been few studies that have focused on the effect of the volatility of inflation on a country's welfare. In this chapter, this issue is addressed by quantifying the effect of the reduction in inflation volatility on a country's level of welfare and comparing this to the effect of the improvement in a country's level of financial institutions on welfare. This is undertaken by using the results presented in the previous chapter related to the effect of inflation volatility and financial institutions on the cost of borrowing for a country. Since the reduction in inflation volatility will finally lead to a drop in the average long-term bond yield, this is expected to have positive impacts on economic welfare. Also, since the improvement in financial institutions will finally lead to a drop in the average long-term bond yield, this is expected to have positive impacts on economic welfare, especially that improving institutions has a couple of effects on welfare, one leads to a direct increase in welfare and another to an indirect increase in welfare through its interaction term with inflation volatility. This chapter finds that the welfare effect of improving institutions and of reducing inflation volatility is large with the largest effect being caused by an improvement in financial institutions. One policy implication of these results is that developing economies can achieve larger welfare gains from improving their institutions than from reducing inflation volatility. 
The previous chapter demonstrated that on one hand a one standard deviation increase in the $\log$ of inflation volatility will finally lead to a drop in the country's cost of borrowing, or the average of the annual long-term bond yield, by about $4.4 \%$. On the other hand, a one standard deviation increase in the LEGAL2 index will lead to a drop in the cost of borrowing by about $4.27 \%$. These reductions in the average long-term bond yields are used in this chapter as the exogenous shocks to a monetary Small Open Economy (SOE) model in order to quantify and compare the welfare implications of decreasing the $\log$ of inflation volatility versus the welfare effect of improving institutions. The welfare effect will be calculated as the ratio of the new steady state value of output per capita after the drop in the cost of borrowing, to the old steady state value of output per capita before the drop in cost of borrowing.

This drop in the long term bond yield is used in this chapter as the exogenous shock to a monetary SOE of McCandless (2008) model with cash in advance constraint, capital adjustment cost, foreign bonds, trade sector, and with four types of shocks; monetary, foreign price, technology, and institutions shocks. The model also incorporates a type of financial friction expressed by poor financial institutions. These bad institutions are assumed to affect the premium that a country pays on its borrowings from the international market and thereby affect its ability to pay. It is important to note that the presence of overseas borrowing and ability to export and import goods in this model are expected to reduce the impact of either domestic or international shocks on a SOE.

The monetary SOE model is used to analyze the impact of different policy scenarios on economic welfare. In particular, the model compares welfare implications of the exogenous reductions in the average long-term bond yields that is either due to a one 
standard deviation decrease in the volatility of inflation (given the level of institutions) or a one standard deviation improvement in financial institutions (given the level of inflation volatility). The model was calibrated for the Mexican economy which, over the period of the study, is characterized by relatively high average inflation volatility (on the $90^{\text {th }}$ percentile) and relatively underdeveloped financial institutions (on the $40^{\text {th }}$ percentile). The results of this chapter show that a one standard deviation decrease in inflation volatility will lead to at most $11.4 \%$ increase in welfare, while a one standard deviation increase in LEGAL2 will lead to an increase in welfare in the range of $17 \%$ to $23 \%$ depending on the degree of development in financial institutions. The results of this chapter also show that these welfare implications of the SOE are much smaller when compared with the welfare implications of a more standard large economy model of Barro and Sala-i-Martin (1995) which shows that the computed welfare effects for the small open economy model were much smaller when compared with an open economy model that had neither an access to foreign bonds nor to an access to a trade sector. The presence of foreign bonds and trade sector in the monetary SOE model help to reduce the impact of shocks.

In addition, this chapter analyzes the behavior of the endogenous variables along the transition path in response to the one standard deviation decrease in the volatility of inflation (given the level of institutions) versus the one standard deviation improvement in financial institutions (given the level of inflation volatility). The model suggests that along the transition path a SOE chooses to get rid of its foreign bond, or in other words increases its foreign debts. In this situation, production, capital, hours worked, and 
exports have to increase along the path in order for the country to get the foreign exchange required to pay for its foreign debts.

At this point it is important to note that models of SOE have been known for their computational problem which is due to the fact that the interest rate is taken by these countries as exogenously determined from abroad. The exogeneity of the interest rate in the SOE models makes finding the steady state in these models almost impossible. To overcome this computational problem, different modifications to the base SOE model have been proposed in the literature, which as discussed in details in Schmitt-Grohe and Uribe (2003) includes endogenizing the discount factor (Uzawa (1968)), debt elastic interest rate premium, convex portfolio adjustment costs, and complete asset markets.

Following Senhadji (1994), Mendoza and Uribe (2000), and Schmitt-Grohe and Uribe (2001), this chapter uses the debt elastic interest rate premium as the technique for inducing the model to have single steady state. This is done by making the foreign interest rate as a function of foreign bonds. Once the model has a unique steady state, a $\log$ linear version of the model around this steady state can be found. Also, following Mendonza (1991) and Schmitt-Grohe and Uribe (2003) among others, the model used in this paper includes capital adjustment cost (under some restrictions), as a way to resolve the high variability of investment problem stemmed from the fact that capital can be freely accumulated from abroad to fill in the gap between domestic savings and domestic investment in response to productivity shocks facing the SOE.

Within the context of the New Open Economy Models (NOEM) most of the models calibrated or estimated were the SOE models. For instance Del Negro and ObiolsHoms (2001) estimate a SOE VAR model for Mexico. The study finds that the most 
important shocks affecting the Mexican economy are those originated from the US business cycle while the exogenous shocks originated from monetary policy had a smaller effect.

Bergin (2003) used the maximum likelihood method to estimate the structural parameters of a SOE model using the data of Australia, Canada, and UK. Although the model showed some predictive ability for prices and output, it did not show any predictive ability for the exchange rate or the current account. Also, in contrast with the results of Obstfeld and Rogoff (2000), Bergin (2003) did not find any support for the wage stickiness but rather to the price stickiness. Also in line with Betts and Devereux (1996, 2000), Bergin (2003) found a support for the stickiness in the local currency prices rather than that of the producer currency.

Similarly, Dib (2003) estimated and compared the structural parameters in both a closed economy model and a small open economy model with nominal rigidities in the import sector and with capital adjustment cost. The structural parameters were estimated using the maximum likelihood procedure with Kalman filter for two countries Canada and U.S. In addition, this study compared the impulse response functions of both economies to the monetary, technology, and world interest rate shocks. This study concludes that both economies showed very similar behavior in response to the shocks.

Using Mexican data, Best (2003) estimated a DSGE model using Bayesian estimation technique to analyze the Mexican monetary policy before and after the 1994 crisis. The study finds the monetary policy did not respond strongly to changes in exchange rates during the floating exchange rate regime of after the crisis as it did during the targeted regime of before the crisis. The main conclusion is that the monetary policy 
in Mexico did not show any fear of floating. And in line with Del Negro and ObiolsHoms (2001), the study finds that the persistence of a US business cycle shock is longer than the persistence of the monetary policy shock.

Justiniano and Preston (2004) estimated the structural parameters of a SOE model using Bayesian methodology to fit the data on inflation, output, interest rates and real exchange rate for Australia, Canada and New Zealand under different degrees of exchange rate pass-through and in the presence of one or more mechanisms of endogenous persistence. In contrast to Betts and Devereux (1996, 2000), the study finds limited evidence for the local currency pricing assumption and no evidence for price indexation.

Adlfonso, Lanseen, Linde and Villani (2004) estimated a dynamic stochastic general equilibrium (DSGE) model using Bayesian estimation technique for the Euro area. The model incorporates various types of nominal and real frictions including sticky prices, sticky wages, variable capital utilization, capital adjustment costs and habit persistence. Among other findings, the study concludes that markup shock, inflation target shocks, and technology shock are the most important shocks affecting the fluctuation in inflation. As for output fluctuation, the study finds that supply shocks and technology shock were the most prominent. Finally, import and export markup shocks were mainly responsible for the real exchange rate fluctuations.

More recently, Del Negro and Schorfheide (2008) estimated a DSGE model and a Bayesian VAR of the Lubik and Schorfheide (2005) model using Chilean data on a group of macroeconomic variables. The results show that the Chilean central bank did not respond significantly to the exchange rate and terms of trade movements. Both the DSGE 
and the VAR showed that the observed inflation variability is mostly due to domestic shocks.

Against the above background, this chapter extends the SOE model of McCandless (2008) by adding to it a parameter reflecting for poor institutions. The objective is to analyze and compare the impact of reducing inflation volatility versus the impact of enhancing institutions on real variables and economic welfare. Welfare comparisons are then undertaken under three different policy scenarios. First a reduction of inflation volatility holding institutions constant, second an improvement in financial institutions holding volatility of inflation constant, and finally a reduction in inflation volatility with an improvement in financial institutions. To the best of our knowledge, our study is first to address the role of institutions within the context of NOEM.

This chapter is organized as follows; Section 3.2 presents an extension to the SOE model of McCandless (2008). Section 3.3 discusses the calibration of the parameters. Section 3.4 presents the results. Section 3.5 analyzes the transition path of the real variables out of the steady state. Section 3.6 concludes this chapter. Finally, Appendix (III) is by the end of this chapter. Besides the figures, this Appendix also contains a calibration of the open economy model of Barro and Sala-i-Martin (1995) on which the three experiments were repeated and compared with the monetary SOE model presented in this chapter. 


\subsection{Monetary Small Open Economy Model}

In this section a monetary SOE model of McCandless (2008) with cash in advance constraint and capital adjustment cost is presented. The model also includes three types of shocks; a monetary policy shock, a foreign price shock, and a technology shock. The model also incorporates a type of financial friction expressed by poor financial institutions.

\subsubsection{Households}

The economy is characterized by indivisible labor and cash in advance constraint. The utility function takes the following form where a family $i$ one of a continuum of a unit mass of households, maximizes

$$
\max _{\left\{c_{t}, h_{t}, k_{t+1}, b_{t}\right\}} E_{t} \sum_{j=0}^{\infty} \beta^{j}\left[\ln c_{t+j}^{i}\right]+B h_{t+j}^{i}
$$

where $c_{t}$ is the consumption at time $t$ and $h_{t}$ is the average hours worked at time $t$ and the parameter $B$ is equal to $\frac{A \ln \left(1-h_{0}\right)}{h_{0}}$, where $\mathrm{A}>0$, and $0<h_{0}<1$.

Given the cash in advance condition for family $i$ in period $t$ is $P_{t} c_{t}^{i}=m_{t-1}^{i}+\left(g_{t}-1\right) M_{t-1}$ , a family $i$ maximizes the above utility function subject to the budget constraint

$$
\begin{gathered}
c_{t}^{i}+\frac{m_{t}^{i}}{P_{t}}+\frac{e_{t} b_{t}^{i}}{P_{t}}+k_{t+1}^{i}=w_{t} h_{t}^{i}+r_{t} k_{t}^{i}+(1-\delta) k_{t}^{i}-\frac{\kappa}{2}\left(k_{t+1}^{i}-k_{t}^{i}\right)^{2}+\frac{e_{t}\left(1+r_{t-1}^{f}\right) b_{t-1}^{i}}{P_{t}} \\
+\frac{m_{t-1}^{i}+(g-1) M_{t-1}}{P_{t}},
\end{gathered}
$$


where $P_{t}$ is the domestic price level, $\frac{m}{P}_{t}^{i}$ is the real money balances held by each family in period $t, b_{t}^{i}$ is the nominal value of foreign bonds, $k_{t}^{i}$ is the physical capital that a family brings in period $t, h_{t}^{i}$ is the amount of hours worked per family in period $t, w_{t}$ is the real wage, $r_{t}$ is the rental rate, $e_{t}$ is the exchange rate where $e_{t}=\frac{P_{t}}{P_{t}^{*}}, \delta$ is the depreciation of capital parameter, and $g$ is the rate of growth in money supply. The parameter $\kappa$ is the capital adjustment cost parameter and is added to the model to avoid the high variability of domestic interest in response to changes in foreign interest rates.

By substituting the cash in advance constraint condition, the budget constraint can equivalently be written as;

$$
c_{t}^{i}+\frac{m_{t}^{i}}{P_{t}}+\frac{e_{t} b_{t}^{i}}{P_{t}}+k_{t+1}^{i}+\frac{\kappa}{2}\left(k_{t+1}^{i}-k_{t}^{i}\right)^{2}=w_{t} h_{t}^{i}+r_{t} k_{t}^{i}+(1-\delta) k_{t}^{i}+\frac{e_{t}\left(1+r_{t-1}^{f}\right) b_{t-1}^{i}}{P_{t}},
$$

Where any change in the amount of capital held per family will cost each family a capital adjustment cost of $\frac{\kappa}{2}\left(k_{t+1}^{i}-k_{t}^{i}\right)^{2}$.

\subsubsection{Firms}

The impact of the enhancement in financial institutions on economic welfare will be quantified by including a parameter " $\tau$ " in the model. Following Barro, Mankiw, and Sala-i-Martin (1995), this $\tau$ parameter refers to the rate of a proportional tax on output that is to be paid by the firms. In Barro, Mankiw, and Sala-i-Martin (1995), $\tau$ is assumed to reflect the various elements that affect the incentive to accumulate capital including 
risk of expropriation by the government, strong labor union, or foreign invaders. In this study it is assumed that again $\tau$ reflects the various elements that inhibit the incentive to accumulate capital including low protection to creditors' rights, low protection of shareholders' rights, weak enforcement of laws, and in-transparency of the companies account.

The parameter $\tau$ was added to the Cobb-Douglas production function as follows to reflect the impact of poor institutions on an economy

$$
Y_{t}=z_{t}(1-\tau) K_{t}^{\theta} H_{t}^{1-\theta}
$$

where $z_{t}$ refers to the random technology variable that follows a stochastic process $z_{t}=\rho_{z} z_{t-1}+\varepsilon_{z, t+1}$ with $0<\rho_{z}<1, \varepsilon_{z, t+1}>0$, and $E_{t} \varepsilon_{z, t+1}=1-\rho_{z}$.

The equilibrium conditions of the labor and the capital markets are $w_{t}=(1-\tau)(1-\theta) z_{t} K_{t}^{\theta} H_{t}^{-\theta}$ and $r_{t}=(1-\tau) \theta z_{t} K_{t}^{\theta-1} H_{t}^{1-\theta}$ respectively.

Real output, wages and capital returns depend in each period on the stock of capital, hours worked, and the level of institutional development in the economy which are all taken as given to each household.

\subsubsection{Open Economy conditions}

The open economy condition guarantees that any increase in the foreign interest rate that has to be paid on debts of period $t-1$, has to be met by an equal increase in exports so that the economy can generate the foreign exchange needed to pay for its interest on foreign debts. 
The Open Economy clearing condition states that the nominal value of foreign bonds expressed in foreign currency and held at period t minus the amount of interest that has to be paid on the debts of period $t-1$ is equal to the nominal value of exports expressed again in foreign currency,

$$
B_{t}-\left(1+r_{t-1}^{f}\right) B_{t-1}=P_{t}^{*} X_{t}
$$

Where $B_{t}$ refers to the nominal quantity of foreign bonds measured in foreign currency. The variables $r_{t}^{f}, P_{t}^{*}$, and $X_{t}$ refer to the foreign interest rate (interest rate on foreign assets), the foreign price level, and the total next exports respectively.

At this point it is important to note that models of SOE have been known for their computational problem which is due to the fact that the interest rate is taken by these countries as exogenously determined from abroad. The equilibrium will then possess a random walk dynamic which makes the unconditional variance of the endogenous variables infinite. Accordingly, finding a steady state in this model is not possible. To overcome this problem, the model used in this chapter included a capital adjustment cost and an endogenous rate of return on foreign assets that is a function of the country's foreign debt.

The foreign interest rate $r_{t}^{f}$ is in turn a function of the world interest rate $r^{*}$ and the real value of the quantity of nominal foreign bonds possessed by the home country.

$$
r_{t}^{f}=r^{*}-a \frac{B_{t}}{P_{t}^{*}}
$$


Note that if the world interest rate $r^{*}$ is high enough, there will be an increase in bond holdings. With the increase in bond holding the interest rate on foreign assets will in turn decreases. The foreign interest rate will decrease such that in equilibrium it will be equal to the net interest return to capital held by the domestic economy.

The foreign price level follows the following stochastic process $P_{t}^{*}=\left(1-\rho_{P^{*}}\right)+\rho_{P^{*}} P_{t-1}^{*}+\varepsilon_{P^{*}}$, where $E_{t-1} \varepsilon_{P^{*}}=0$ and $\varepsilon_{P^{*}}$ is bounded from below by $-\left(1-\rho_{p^{*}}\right)$ and bounded above.

\subsubsection{Defining the Equilibrium}

The Equilibrium is defined for the household's problem as a list of sequences $\left\{c_{t}^{i}\right\},\left\{m_{t}^{i}\right\},\left\{b_{t}^{i}\right\},\left\{h_{t}^{i}\right\}$, and $\left\{k_{t}^{i}\right\}$ such that, given $r_{t}$ and $w_{t}$ the household chooses to maximize the utility function

$$
\max _{\left\{c_{t}, h_{t}, k_{t+1}, b_{t}\right\}} E_{t} \sum_{j=0}^{\infty} \beta^{j}\left[\ln c_{t+j}^{i}\right]+B h_{t+j}^{i}
$$

Subject to the two budget constraints, first to the cash in advance condition,

$$
P_{t} c_{t}^{i}=m_{t-1}^{i}+\left(g_{t}-1\right) M_{t-1}
$$

And second to the flow budget constraint for each household,

$$
c_{t}^{i}+\frac{m_{t}^{i}}{P_{t}}+\frac{e_{t} b_{t}^{i}}{P_{t}}+k_{t+1}^{i}+\frac{\kappa}{2}\left(k_{t+1}^{i}-k_{t}^{i}\right)^{2}=w_{t} h_{t}^{i}+r_{t} k_{t}^{i}+(1-\delta) k_{t}^{i}+\frac{e_{t}\left(1+r_{t-1}^{f}\right) b_{t-1}^{i}}{P_{t}}
$$


Where $c_{t}^{i} \geq 0, k_{t}^{i} \geq 0,0<h_{0}<1$, and the transversality (limit) condition hold such that $\lim _{t \rightarrow \infty} \frac{b_{t}}{\left(1+r^{f}\right)^{t}}=\lim _{t \rightarrow \infty} \beta^{t} b_{t}=0$. Worth noting that, given the indivisibility of labor assumption, the flow budget constraint shows that all the households will receive the same income whether they are working or not.

Next, the Equilibrium definition for the firm's problem is defined as a list of sequence of $\left\{r_{t}\right\},\left\{w_{t}\right\},\left\{k_{t}^{i}\right\}$, and $\left\{h_{t}^{i}\right\}$ such that the firm chooses $\left\{k_{t}^{i}\right\}$ and $\left\{h_{t}^{i}\right\}$ to maximize

$$
\max _{K_{t}, H_{t}} z_{t}(1-\tau) K_{t}^{\theta} H_{t}^{1-\theta}-r_{t} K_{t}-w_{t} H_{t}
$$

Given that the aggregation conditions hold such that

$$
\begin{aligned}
& C_{t}=c_{t}^{i}, \\
& M_{t}=m_{t}^{i}, \\
& B_{t}=b_{t}^{i}, \\
& H_{t}=h_{t}^{i},
\end{aligned}
$$

and

$$
K_{t}=k_{t}^{i}
$$

This is in addition to the money supply rule $M_{t}=g_{t} M_{t-1}$ as noted in McCandless (2008). 


\subsubsection{Characterizing the Equilibrium}

Assuming that all the conditions for defining the equilibrium hold, the full model will then consists of the following set of equations which were derived from the first order conditions of the model. Solving for the first order condition for the aggregate consumption and then substituting the results in the first order condition of foreign bonds, the equilibrium condition is shown below,

$$
E_{t}\left[\frac{e_{t}}{P_{t+1} C_{t+1}}\right]=\beta E_{t}\left[\frac{e_{t+1}\left(1+r_{t}^{f}\right)}{P_{t+2} C_{t+2}}\right] .
$$

Also, from solving the first order condition of capital the following equilibrium condition is found,

$$
E_{t} \frac{P_{t}}{P_{t+1} C_{t+1}}\left[1+\kappa\left(K_{t+1}-K_{t}\right)\right]=\beta E_{t} \frac{P_{t+1}}{P_{t+2} C_{t+2}}\left(r_{t+1}+(1-\delta)+\kappa\left(K_{t+2}-K_{t+1}\right)\right) .
$$

And from the first order condition with respect to hours worked the equilibrium condition will be,

$$
\frac{B}{w_{t}}=\beta E_{t} \frac{P_{t}}{P_{t+1} C_{t+1}}
$$

The aggregate cash in advance equilibrium condition is,

$$
P_{t} C_{t}=M_{t}
$$

And the equilibrium condition of the flow budget constraint is,

$$
\frac{M_{t}}{P_{t}}+\frac{e_{t} B_{t}}{P_{t}}+K_{t+1}+\frac{\kappa}{2}\left(K_{t+1}-K_{t}\right)^{2}=w_{t} H_{t}+r_{t} K_{t}+(1-\delta) K_{t}+\frac{e_{t}\left(1+r_{t-1}^{f}\right) B_{t-1}}{P_{t}}
$$

The equilibrium condition for the labor market, 


$$
w_{t}=(1-\theta) z_{t}(1-\tau) k_{t}^{\theta} H_{t}^{-\theta}
$$

And equilibrium condition in the capital market,

$$
r_{t}=\theta z_{t}(1-\tau) k_{t}^{\theta-1} H_{t}^{1-\theta}
$$

Assuming purchasing power parity, the exchange rate is defined as the number of units of the domestic currency that each one unit of the foreign currency can buy. The equilibrium condition of the exchange rate will then be written as,

$$
e_{t}=\frac{P_{t}}{P_{t}^{*}}
$$

And the money supply rule is,

$$
M_{t}=g_{t} M_{t-1}
$$

The equilibrium condition for the stochastic processes of technology, monetary policy, and foreign price can be written as shown in the following three equations respectively

$$
\begin{aligned}
& z_{t}=\left(1-\rho_{z}\right)-\rho_{z} z_{t-1}-\varepsilon_{z, t}, \\
& g_{t}=\left(1-\rho_{g}\right)-\rho_{g} g_{t-1}-\varepsilon_{g, t}, \\
& P_{t}^{*}=\left(1-\rho_{P^{*}}\right)-\rho_{P^{*}} P_{t-1}^{*}-\varepsilon_{P^{*}, t} .
\end{aligned}
$$

\subsubsection{Steady States}

In steady state the foreign price level $\bar{P}^{*}=1$. Also in steady state the level of inflation $\pi=\frac{P_{t+1+j}}{P_{t+j}}$ is assumed to be equal to the constant growth rate of money $\bar{g}$, or $\bar{\pi}=\bar{g}$. It is 
also important to note here that since the capital adjustment cost is a function of the changes in capital, in steady state the capital adjustment cost will be equal to zero.

By computing the steady states values of all the endogenous real variables in the model using the set of equations of the full model, the steady state values of the variables are as follows;

The steady state value for the foreign interest rate is found to be,

$$
\overline{r^{f}}=\frac{1}{\beta}-1 .
$$

The amount of foreign bonds held by the country in the steady state will depend on the world interest rate $\mathrm{r}^{*}$ where,

$$
\bar{b}=\left(r^{*}+1-1 / \beta\right) / a
$$

As the steady state value of foreign bonds decreases (increase in debts) in response to any decrease in the cost of borrowing $r^{*}$, the steady state value of export will increase. The foreign exchange returns from exports has to be enough to pay for the foreign interest on international borrowings,

$$
\bar{x}=-\overline{r^{f}} \bar{b}
$$

The steady state value of the net return to domestic capital,

$$
\bar{r}=[1 / \beta-(1-\delta)]
$$

Also from the equilibrium condition of the capital markets, the following equation can be derived in steady state;

$$
\frac{\bar{r}}{\theta(1-\tau)}=\left(\frac{\bar{K}}{\bar{H}}\right)^{\theta-1} \text {. }
$$


And from the previous equation, the steady state value of capital/hour worked can be found as,

$$
\Rightarrow \frac{\bar{K}}{\bar{H}}=\left[\frac{\theta(1-\tau)}{\bar{r}}\right]^{\frac{1}{1-\theta}} .
$$

Now Equation (3.6) above is substituted in the labor market equilibrium condition to get the following steady state of wages,

$$
\bar{w}=(1-\tau)(1-\theta)\left(\frac{\theta(1-\tau)}{\bar{r}}\right)^{\theta / 1-\theta}
$$

The steady state of consumption depends on the steady state of wages and the steady state value of inflation in the economy,

$$
\bar{C}=\frac{\beta \bar{w}}{-B \bar{\pi}} .
$$

And the cash in advance constraint would entail that consumption has to be equal to the real value of money balances,

$$
\frac{\bar{M}}{\bar{P}}=\bar{C}
$$

The steady state value of capital would then directly depend on the steady state values of the real money balances and steady state value of foreign bond holdings,

$$
\bar{K}=\frac{\theta\left(\overline{M / P}-\bar{r}^{f} \bar{B}\right)}{\bar{r}-\theta \delta} .
$$

Next, hours worked in steady state would be negatively affected by the steady state value of wages, capital returns and capital held in the economy,

$$
\bar{H}=\frac{\bar{r}(1-\theta)}{\bar{w} \theta} \bar{K}
$$


The steady state value of real output is a function of the steady state values of both capital and hours worked,

$$
\bar{Y}=(1-\tau) \bar{K}^{\theta} \bar{H}^{1-\theta}
$$

The steady state value of the aggregate utility would then depend on the steady state values of consumption and hours worked.

$$
\bar{U}=\frac{\log \bar{C}+B \bar{H}}{1-\beta}
$$

A monetary shock to the economy, expressed by an exogenous increase in the cost of borrowing $\mathrm{r}^{*}$, will lead to a new steady state values of foreign bonds, exports, physical capital, hours worked, output, and utility as expressed by Equations (3.3), (3.4), (3.10), (3.11), (3.12), and (3.13) respectively. In addition, as in Table 13.3 of McCandless (2008), any change in $r^{*}$ does not lead to any changes in the steady state value of consumption. In this case the steady state value of utility will only be affected by the increase in the steady state value of hours worked as obvious from Equation (3.13) above. In addition, the steady state value of consumption will only change if the steady state value of money growth rate $\bar{g}$ (which is equal to the steady state value of gross inflation rate) changes.

On the other hand, any change in the value of $\tau$ is expected to affect the economy through its effect on the steady state value of output in Equation (3.12), and the steady state value of real wages in Equation (3.7). The changes in the steady state value of wages will in turn affect the steady state value of consumption (which is equal real money balances) Equation (3.9) and the steady state value of hours worked in Equation (3.11). The changes in the steady state value of consumption will in turn lead to a change 
in the steady state value of capital and utility, Equations (3.10) and (3.13) respectively. Finally, the new values for both capital and hours worked will lead to new steady state values for both output and output per hours worked. The changes in $\tau$ on the other hand will not have any effect on the steady state values of both foreign bonds and exports.

\subsection{Calibration}

This section calibrates a developing economy characterized by moderately high average inflation volatility and relatively poor financial institutions over the period of the study (1989-2006). One of the countries in the sample that fits these characteristics is Mexico. As was shown in Table 2.9 of chapter two, Mexico together with Turkey and Uruguay fall under the $90^{\text {th }}$ percentile of average log of inflation volatility. Also, as was shown in Table 2.7 of chapter two, Mexico falls under the $40^{\text {th }}$ percentile of the financial institutional index.

In addition, Figure 3.1 depicts a negative relationship between financial institutions index and the average over the period log inflation volatility. If the top $10 \%$ of the log inflation volatility distribution is discarded from the sample, three countries Argentina, Peru and Brazil will be excluded from the estimation and we will be left with a group of countries where Turkey, Uruguay and Mexico are at the top of the list in terms of the highest volatility and bad institutions. Since Mexico was located at the lowest end of the investment grade in the first quarter of the year 2000 while Turkey and Uruguay were located in the speculative grade, it was thought that studying the case of Mexico would be the most interesting as compared with the other two countries. 
Figure 3.1

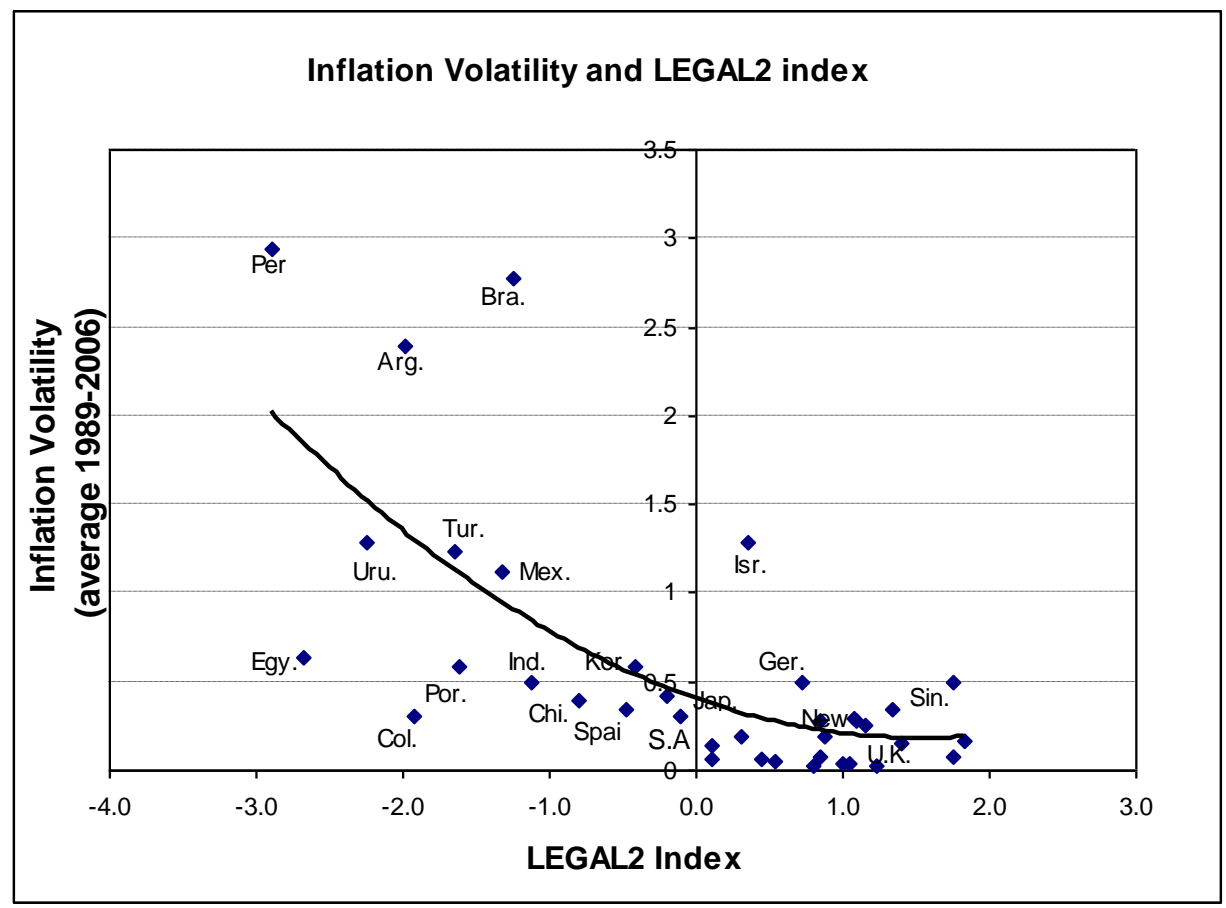

Based on the above discussion, a linearized version of the model is calibrated using Mexico quarterly data over the period 1989-2006. The parameters of the model were calibrated using the values shown in Table 3.1 below. The value of the income share of physical capital was taken from Mankiw (1992) as $\theta=0.33$. The discount rate $\beta$ is set equal to the value commonly used in the literature to be equal to 0.99 . The value for the depreciation of physical capital, $\delta=0.03$, is taken from Aguiar and Gopinath (2004). The value of the cost of borrowing $r^{*}$ is set to be equal to $12.21 \%$ per year (or $3.05 \%$ per quarter), this value was calibrated as the average of the annual 5-year bond yield of all countries that belong to the sovereign debt rating of 12 rating points, or "Baa3", at the first quarter of the year 2000 and to which Mexico belongs.

The capital adjustment cost parameter $\kappa$ was taken from Mendonza (1991) and was calculated to match the percentage deviation of the investment data in Mexico. The 
parameter $B$ was taken from McCandless (2008). The parameter "a" represents the positive constant of the foreign interest rate equation was taken from McCandless (2008) but divided by four to match the quarterly data. The parameter $\bar{g}$ represents the growth of money supply in steady state and was calculated as average inflation over the period 1989-2006 divided by four. In steady state, money supply will grow by one plus this number. Next, the parameter $r_{\text {floor }}^{*}$ represents the cost of borrowing paid by the highest rated countries and which is assumed to be 0.01 per quarter ( $1 \%$ per quarter or $4 \%$ per year).

Concerning the parameter of bad institutions $\tau$, this parameter is a tax on the economy. To the best of our knowledge, no one has attempted to calibrate this value before and there is a good reason of why this is the case. Calibrating a value for the $\tau$ parameter is not easy. In this chapter, it has been tried to find a value of this parameter by assuming that the differences in institutions between developed and developing countries can only be attributed to the differences in their institutions. The values of $\tau$ were calibrated by first computing the ratio of the per capita GDP (constant US dollars) of all the countries on the 40th percentile of LEGAL2 (including Mexico) to the GDP per capita of the countries on the highest LEGAL2 quintile. The ratio of the ratio of those on the $40_{\text {th }}$ percentile to those on the $60_{\text {th }}$ percentile was then computed. The resulting number was then equated to the ratio of the calibrated steady state values of the output per capita for the same two groups of countries using Equation (3.12) and using the rate of interest of $12.21 \%$ for finding the steady state output for countries on the 40 th percentile. The same thing was repeated for countries on the 60th percentile to which Mexico will move if it experience a ones standard deviation increase in LEGAL2 (as 
Table 3.1 Values of the Calibrated Parameters for Mexico

\begin{tabular}{|c|c|c|}
\hline Parameter & Value & Notes \\
\hline$\theta$ & 0.33 & Income share of physical capital - Mankiw (1992) \\
\hline $1-\theta$ & 0.67 & Income share of human capital - Mankiw (1992) \\
\hline$\delta_{k}$ & 0.03 & Depreciation of physical capital - Aguiar \& Gopinath (2004) \\
\hline$\beta$ & 0.99 & Discount rate - value as usually found in the literature \\
\hline$r^{*}$ & 0.0305 & $\begin{array}{l}\text { Average cost of borrowing }(3.05 \% \text { per quarter or } 12.21 \% \text { per } \\
\text { year) for all the countries on the Baa3 level of sovereign debt } \\
\text { rating to which Mexico belongs }\end{array}$ \\
\hline$\kappa$ & 0.026 & $\begin{array}{l}\text { Parameter of the quarterly capital adjustment cost taken from } \\
\text { Mendonza (1991). Calculated to match the } \% \text { of the standard } \\
\text { deviation of investment. }\end{array}$ \\
\hline $\mathrm{B}$ & -2.5805 & $\begin{array}{l}\text { Parameter in the utility function. Where } \mathrm{B}=\mathrm{A} \ln (1-\mathrm{h} 0) / \mathrm{h} 0 \\
\text { McCandless (2008) }\end{array}$ \\
\hline a & 0.0025 & McCandless (2008) $(\mathrm{a}=0.01 /$ annual data $)$ \\
\hline $\bar{g}$ & 1.036362 & $\begin{array}{l}\text { Quarterly average inflation. Annual average inflation divided } \\
\text { by four }(0.145448 / 4=0.036362)\end{array}$ \\
\hline$r_{\text {floor }}^{*}$ & 0.01 & $\begin{array}{l}\text { Assumed quarterly interest rate paid by highest rated countries } \\
\left(r_{\text {floor }}^{*}=0.04 / \text { annual data }\right)\end{array}$ \\
\hline$\tau$ & $\begin{array}{l}0.2 \rightarrow 0.15 \\
0.15 \rightarrow 0.10 \\
0.10 \rightarrow 0.05 \\
0.05 \rightarrow 0.01\end{array}$ & $\begin{array}{l}\text { Assumed values for the cost on the economy that is due to bad } \\
\text { institutions }\end{array}$ \\
\hline$\rho_{Z}$ & 0.911333 & $\begin{array}{l}\text { From estimating an AR(1) model of } \mathrm{Y} \text { deviation (log of } \\
\text { Mexico's real GDP) }\end{array}$ \\
\hline$\sigma_{Z}$ & $8.2031 \mathrm{E}-05$ & $\begin{array}{l}\text { Variance of the residual of regressing Y deviation on a AR(1) } \\
\text { model }\end{array}$ \\
\hline$\rho_{g}$ & 0.456541 & $\begin{array}{l}\text { From estimating an AR(1) model of P deviation (difference in } \\
\log \text { of Mexico's CPI) }\end{array}$ \\
\hline$\sigma_{g}$ & $\begin{array}{l}6.82339 \mathrm{E}- \\
05\end{array}$ & $\begin{array}{l}\text { Variance of the residual of regressing } \mathrm{P} \text { deviation on a AR(1) } \\
\text { model }\end{array}$ \\
\hline$\rho_{p^{*}}$ & 0.771140 & $\begin{array}{l}\text { From estimating an } \mathrm{AR}(1) \text { model of } \mathrm{P}^{*} \text { deviation (CPI of } \\
\text { USA) }\end{array}$ \\
\hline$\sigma_{p^{*}}$ & $\begin{array}{l}1.78426 \mathrm{E}- \\
06\end{array}$ & $\begin{array}{l}\text { Variance of the residual of regressing } \mathrm{P}^{*} \text { deviation on a AR(1) } \\
\text { model }\end{array}$ \\
\hline
\end{tabular}

demonstrated in Chapter 2). The difference between the empirical and the theoretical ratios of output for countries on the $40_{\text {th }}$ percentile to those on the $60_{\text {th }}$ percentile is assumed to be due to the difference in the ratio of their $1-\tau$. The resulting value of 
implied that the differences in output between developed and developing countries that are only attributed to the differences in their institutions was too big that exceeded about $60 \%$. Accordingly, the values of the parameter $\tau$ used here were just assumed conservative values as compared to the much bigger values of $\tau$ that were actually calibrated from using the data on per capita GDP and the steady state values of output per worker from the SOE model discussed above. The assumed numbers of $\tau$ basically implies that the worst level of institutions cost the economy about $20 \%$ of GDP. This assumed value is not big when compared to the study of Wei (2000), where one-grade increase in the corruption ${ }^{22}$ level is associated with a $26 \%$ reduction in the stock of foreign direct investment.

The parameters $\rho_{Z}$ and $\sigma_{Z}$ were calibrated using the quarterly data on the log of Mexico's real GDP by first filtering the series using the HP filter with smoothness parameter $\lambda=1600$. The deviation of the series was separated from the trend of the series. The deviation of the series was then regressed on an AR (1) model to estimate the parameter $\rho_{Z}$. The parameter $\sigma_{Z}$ was then computed using the square of the residual of the model divided by the sample size.

Similarly the parameter of the growth in money supply was computed as the growth of the Mexico's inflation (as they are equivalent in the model). Accordingly $\rho_{g}$ and $\sigma_{g}$ were computed using the quarterly data on the difference of the log of the CPI of Mexico. And finally the parameters $\rho_{p^{*}}$ and $\sigma_{p^{*}}$ were computed using the quarterly data of the log of USA consumer price index.

\footnotetext{
${ }^{22}$ Measured using the Business International (BI) index.
} 


\subsection{Results}

Using the above calibrated values for the parameters of the monetary SOE model, this section presents the results of; first the impulse response functions of the endogenous real variables in the model to a permanent improvement in institutions. Second, this section presents the results of the welfare implications under three experiments.

\subsubsection{Impulse Response Functions for a Permanent Improvement in Institutions}

Using the initial values for the cost of borrowing $\mathrm{r}^{*}$ and bad institutions $\tau$ as $\mathrm{r}^{*}=0.0305$ and $\tau=0.20$, the impulse response functions for the economy were undertaken to check its response to a permanent impulse on institutions of $-25 \%$. In other words, the idea is to see how the economy responds to a permanent improvement in institutions. Figure 3.2 below shows the impulse response functions of the endogenous variables for a $25 \%$ permanent drop in $\tau$.

With a permanent improvement in institutions shock output initially increases, where an improvement in institutions has a direct impact on output, or consumers' income. With the increase in income, consumers increase their consumption initially. With the initial increase in consumption and given no change in money supply, the prices respond by an initial decrease. The consumers' real wealth increases and accordingly they choose to reduce their hours worked initially. With the decrease in hours worked, the return of labor, wages, initially increase. In addition, with the increase in output, an economy chooses to get rid of the foreign bonds it holds, so foreign bonds initially decreases and exports initially increases to meet interest payments required on these foreign bonds. 
Figure 3.2

Impulse Response Functions for a 25\% Permanent Drop in $\tau$
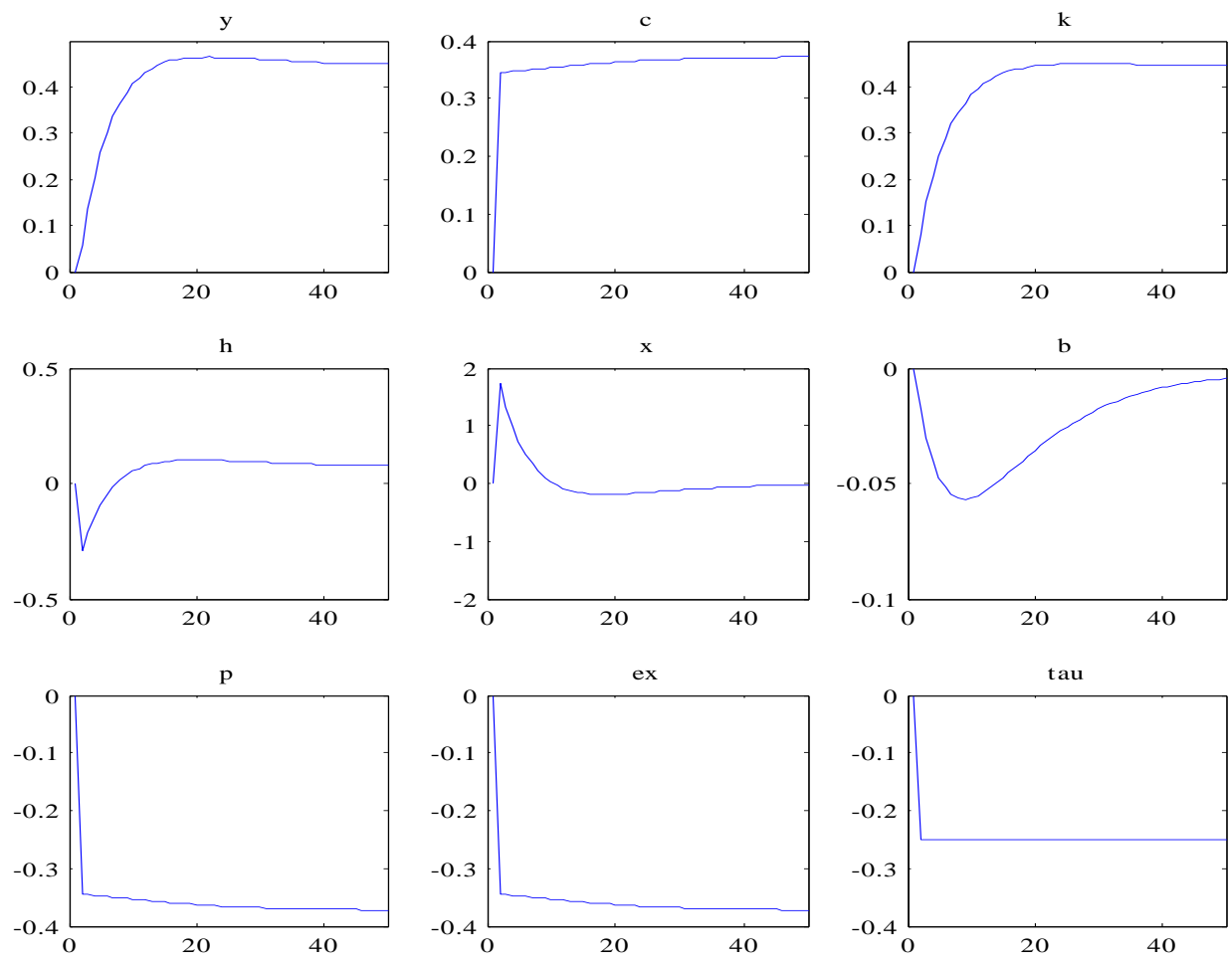

In the long run, as the economy accumulates more capital it reaches a new higher steady state level. Also, with the increase in capital, the return to supplying labor increases and hours worked respond by an increase to a new higher steady state level. With the increase in both capital and hours worked, output also increases and reaches a new higher steady state. With the permanent increase in output, given no foreign price shocks, both domestic prices and exchange rate decreased permanently to a new lower steady state level. Consumption responds by an increase to a new steady state level. Although in this economy the accumulation of foreign bonds is not affected by the drop in $\tau$ in the long run, it initially dropped before it returned back again to its initial level. Also, exports initially increased but then return back again to its initial steady state level. 
Having got an idea about the response of the economy to a permanent shock to institutions, it will next be interesting to analyze and compare the welfare implications of decreasing inflation volatility versus improving institutions in this economy.

\subsubsection{Calculating the Welfare Implications of the Reduction in Inflation Volatility and the Improvement in institutions}

In this subsection, the welfare implications were computed and then compared under three different experiments; first a reduction in inflation volatility holding bad institutions constant (drop in $\mathrm{r}^{*}$ holding $\tau$ constant), second improving institutions with holding inflation volatility constant (drop in $\tau$ holding $\mathrm{r}^{*}$ constant), and finally a reduction in inflation volatility coupled with improving institutions (drop in both $\tau$ and $\mathrm{r}^{*}$ ).

From the results of Chapter two it was demonstrated that a one standard deviation decrease in inflation volatility will lead to two rating classifications increase. Accordingly, a country like Mexico with rating of Baa3 in the first quarter of the year 2000 will increase up to classification Baal. This increase in rating will be accompanied by a drop in the average annual bond yield, or the cost of borrowing, from $12.21 \%$ to $7.81 \%$ (or $3.05 \%$ to $1.95 \%$ per quarter) and will in turn lead to an increase in welfare measured by the new steady state of output per worker as a ratio to its initial level.

Using the results of chapter two, Table 3.2 below reports the results of the first experiment, where the welfare effect of the drop in average annual yield is computed for different values of $\tau$ as an initial level. For example in Column 3 with the initial levels of $\mathrm{r}^{*}$ and $\tau$ equal to $12.21 \%$ and 0.2 respectively, a one standard deviation decrease in 
inflation volatility will lead to about $11.4 \%$ increase in welfare. Also, Column 7 shows that with initial levels of $\mathrm{r}^{*}$ and $\tau$ equal to $12.21 \%$ and 0 respectively, the welfare effect increases by only $7.8 \%$. Figure 3.3 below provides an illustration of the impact of inflation volatility on economic welfare.

Table 3.2

Effect of the Drop in $\mathbf{r}^{*}$ holding $\tau$ (at different values) on the New Steady State of Output per Worker (as a ratio to its initial level)

\begin{tabular}{|c|c|c|c|c|c|c|}
\hline $\begin{array}{c}\text { (1) } \\
\text { Rating }\end{array}$ & $\begin{array}{c}\text { (2) } \\
\text { Average } \\
\text { Annual } \\
\text { Yield, } r^{*} \\
(\mathbf{\%})\end{array}$ & $\begin{array}{c}y^{* \prime} \\
y^{*}\end{array}$ & $\frac{y^{* \prime}}{y^{*}}$ & $\frac{y^{*^{\prime}}}{y^{*}}$ & $\frac{y^{* \prime}}{y^{*}}$ & $\frac{y^{* \prime}}{y^{*}}$ \\
& $\mathbf{\tau}=0.2$ & $\tau=0.15$ & $\tau=0.10$ & $\tau=0.05$ & $\tau=0.01$ \\
\hline Baa3 =12 & $\mathbf{1 2 . 2 1 \%}$ & $\mathbf{1}$ & $\mathbf{1}$ & $\mathbf{1}$ & $\mathbf{1}$ & $\mathbf{1}$ \\
\hline
\end{tabular}

It is worth to note that the welfare implications of a one standard deviation drop in inflation volatility in this monetary small open economy model are much smaller when compared to the results of the open economy model of Barro and Sala-i-Martin (1995) presented in Appendix (III) where the welfare effect in the latter model was about $21 \%$ for the same drop in $\mathrm{r}^{*}$. The main reason for this smaller welfare implication in this model is the presence of bonds and trade sector which give households in the economy the opportunity to smooth their consumption over time and this makes the economy less vulnerable to shocks.

In the second experiment, the direct welfare impact of the improvement in institutions was computed under different initial levels of $\tau$ where as mentioned in the calibration section, the drop in $\tau$ was calibrated from the data to be equivalent to a one standard deviation increase in LEGAL2. 


\section{Figure 3.3}

The Effect of Inflation Volatility on Welfare

A One Standard Deviation Decrease in the Log of Inflation Volatility

(Given LEGAL2)



2 classifications Increase in Sovereign debt rating

(Empirical result from chapter two)

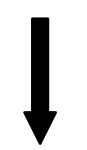

Drop in the Average Long-Term Bond Yield from 12.21\% to 7.81\%

(From chapter two)

$11.4 \%$ increase in Economic Welfare

(Using McCandless (2008) model)

Table 3.3 reports the results of the second experiment in which the direct welfare implications of the improvement in institutions are computed. The first row of this table calculates the welfare when the initial levels of $\tau$ and $\mathrm{r}^{*}$ were 0.2 and 0.0305 respectively. From the calibration section it was discussed that a one standard deviation increase in LEGAL2 will lead to a drop in $\tau$ from about 0.2 to 0.15 . From the first row of Table 3.3 below, this drop in $\tau$ will lead to about $11 \%$ increase in welfare. Also, as the last row of Table 3.3 shows, for more institutionally developed countries, where the initial level of $\tau$ is only $5 \%$ of real output, a one standard deviation increase in LEGAL2 will lead to a drop in $\tau$ from 0.05 to 0 . Given the level of $\mathrm{r}^{*}$, this drop in $\tau$ will lead to a bit smaller welfare of about $9.1 \%$. Again, comparing the results of this monetary small open economy with the results of the open economy model of Barro and Sala-i-Martin (1995) presented in Appendix (III), the welfare magnitudes were higher and were about $20 \%, 18 \%, 17 \%$, and $16 \%$ for each row of Table 3.3 respectively. 
Table 3.3

Effect of the Drop in $\tau$ holding $\mathbf{r}^{*}$ (at $3.05 \%$ ) on the New Steady State of Output per Worker (as a ratio to its initial level)

\begin{tabular}{|c|c|}
\hline$\tau$ & $\frac{y^{* \prime}}{y^{*}}$ \\
\hline $0.2 \rightarrow \mathbf{0 . 1 5}$ & $\mathbf{1 . 1 1}$ \\
\hline $\mathbf{0 . 1 5} \rightarrow \mathbf{0 . 1 0}$ & $\mathbf{1 . 1 0}$ \\
\hline $\mathbf{0 . 1 0} \rightarrow \mathbf{0 . 0 5}$ & $\mathbf{1 . 0 9 9}$ \\
\hline $\mathbf{0 . 0 5} \rightarrow \mathbf{0 . 0 1}$ & $\mathbf{1 . 0 7 4}$ \\
\hline
\end{tabular}

Finally, the third experiment was undertaken where the drop in $\mathrm{r}^{*}$ was coupled with a drop in $\tau$. As shown in Table 3.4 below, the welfare magnitudes were much higher when compared with those in Table 3.2 and Table 3.3 above. Recall that from the results of the previous chapter, a one standard deviation increase in LEGAL2 will lead to an increase in the sovereign debt rating by one rating classification, or from Baa3 to Baa2 for Mexico. This one classification increase in the sovereign debt rating will lead to a drop in the average long term annual yield $\mathrm{r}^{*}$ from $12.21 \%$ to $7.94 \%$ (or from $3.05 \%$ to $1.98 \%$ per quarter).

Table 3.4

Effect of the Drop in $\mathbf{r}^{*}$ from 0.0305 to 0.0198 Coupled with the Drop in $\tau$ on the New Steady State of Output per Worker (as a ratio to its initial level)

\begin{tabular}{|c|c|c|c|c|c|}
\hline $\begin{array}{c}\text { (1) } \\
\text { Rating }\end{array}$ & $\begin{array}{c}(2) \\
\text { Average Long-Term Annual Yield } \\
\mathbf{r}^{*} \\
(\%)\end{array}$ & $\begin{array}{c}\text { (3) } \\
\frac{y^{* \prime}}{y^{*}} \\
\tau \\
0.20 \text { to } 0.15\end{array}$ & $\begin{array}{c}(4) \\
\frac{y^{* \prime}}{y^{*}} \\
\tau \\
0.15 \text { to } 0.10\end{array}$ & 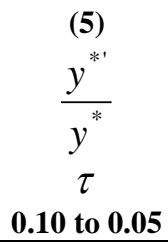 & 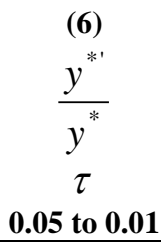 \\
\hline Baa3 $=12$ & 12.21 & 1 & 1 & 1 & 1 \\
\hline Baa2 $=13$ & 7.94 & 1.23 & 1.21 & 1.19 & 1.16 \\
\hline
\end{tabular}

As shown in Table 3.4 (Column 3), when this drop in $r^{*}$ is coupled with a drop in $\tau$ from 0.20 to 0.15 , this will lead to about $23 \%$ increase in welfare. In addition, if this 
drop in $r^{*}$ on the other hand is accompanied by a drop in $\tau$ from 0.05 to 0 the welfare effect will be about $17 \%$ as shown in Column 6. Again, the equivalent values for the open economy model of the previous chapter were much bigger and were around $45 \%, 44 \%$, $42 \%$, and $41 \%$ for each of Columns 3, 4, 5, and 6 of Table 3.4 respectively. Figure 3.4 provides an illustration of the impact of financial institutions on economic welfare.

Figure 3.4

The Effect of Financial Institutions on Welfare

\begin{tabular}{|c|}
\hline $\begin{array}{c}\text { One Standard Deviation increase in the LEGAL2 Index } \\
\text { (Given inflation volatility) }\end{array}$ \\
1 classification increase in the Sovereign debt rating \\
(Empirical result from chapter two) \\
Drop in the Average Long-Term Bond Yield From 12.21\% to 7.94\% \\
(Indirect welfare effect from chapter two) \\
And with the Improvement in Institutions from 0.20 to 0.15 \\
(Direct welfare effect) \\
23\% Increase in Economic Welfare \\
(Using McCandless (2008) model)
\end{tabular}

\subsection{The Transition Path - The Deterministic Model}

In this section, the behavior of the real endogenous variables along the transition path is analyzed under the three previous experiments. This section also includes a comparison of the three experiments in order to analyze the effect of the decrease in inflation 
volatility versus the effect of the improvement in institutions on the steady states of the real endogenous variables of the model.

\subsubsection{The Three Experiments along the Transition Path}

As noticed in the previous section, the three experiments had a common initial steady state values where these values computed using $\mathrm{r}^{*}=0.0305$ and $\tau=0.20$. The new steady state values of the first experiments, which represents the effect of a one standard deviation decrease in inflation volatility, were computed using $\mathrm{r}^{*}=0.0195$ holding $\tau$ at 0.20 . The new steady state values of the second experiment, which represents the direct effect of improving institutions, were computed using $\tau=0.15$ holding $\mathrm{r}^{*}$ at 0.0305 . And finally, the steady state values of third experiment, which represents the full effect of improving institutions ${ }^{23}$, were computed using $\mathrm{r}^{*}=0.0198$ and $\tau=0.15$.

The transition paths were created using the parameter values of the steady state values for the new steady state, or the model whose parameter values are the ones after the change. This suggests that the steady state values for this economy should be equal to zero for all variables. Also since the model is linear, the variables were computed in terms of $\log$ deviation from the steady state. And the initial value for each variable will be then equal to the $\log$ of the first steady state minus the $\log$ of the second steady state, or the old steady state computed as percentage deviation from the new steady state.

Using the transition path permits to analyze how the economy moves from the old steady state to the new steady state. More specifically, it permits to analyze how each

\footnotetext{
${ }^{23}$ Direct effect through the drop in the parameter $\tau$ and indirect effect through the impact of a one standard deviation increase in the LEGAL2 index on the increase in sovereign debt rating which finally leads to a drop in $\mathrm{r} *$ from 0.0305 to 0.0198 .
} 
endogenous variable behaves along the transition path, whether there will be no change, an overshooting, or an undershooting in response to an exogenous shock.

Worth noting here that the most important behavior is what happens to a variable initially in response to a shock, or the initial reaction. This will basically measure the difference between the values of the old steady state value and the new steady state value. However, along the transition path, the behavior of the variables could be different from their initial response.

The first experiment analyzes how a one standard deviation decrease in inflation volatility (given the level of institutions) will move the economy from an initial steady state to a new steady state. Again, the initial steady states of real variables were computed using the calibrated parameters of Table 3.1 with $\mathrm{r}^{*}=0.0305$ and $\tau=0.2$ and the new steady states were computed using $\mathrm{r}^{*}=0.0195$ and $\tau=0.2$. The initial values for the transition path were then calculated as the difference between the log of the steady states under the initial value of $\mathrm{r}^{*}$ (given $\tau$ ) and under the new value of $\mathrm{r}^{*}$ (given $\tau$ ).

Similarly, the second experiment was undertaken to analyze the behavior of the endogenous real variables of the model along the transition path in response to a one standard deviation increase in LEGAL2 (given inflation volatility). The initial values for this transition path were calculated as the difference between the log of the initial steady states values under $\mathrm{r}^{*}=0.0305$ and $\tau=0.2$ and the new steady states values under $\mathrm{r}^{*}=$ 0.0305 and $\tau=0.15$ for all the endogenous variables in the model.

Finally the last experiment analyzes the impact of the full positive effect of the improvement in institutions, which consists of the indirect effect of institutions expressed by a one standard deviation increase in LEGAL2 which will finally lead to a drop in $r^{*}$ to 
0.0198. And the direct effect of institutions on the economy expressed by the drop in $\tau$. The initial values of the transition paths of this experiment were calculated as the difference between the $\log$ of the initial steady states under $\mathrm{r}^{*}=0.0305$ and $\tau=0.2$ and the new steady states under $\mathrm{r}^{*}=0.0198$ and $\tau=0.15$.

Figure 3.5 shows the transition path of the first experiment with a drop in $\mathrm{r}^{*}$ from 0.0305 to 0.0195 holding $\tau$ at 0.20 , where in this figure and thereafter, "y" refers to real output, "c" refers consumption, "k" refers to physical capital, "h" refers to hours worked, "x" refers to exports, "b" refers to foreign bonds, "p" refers to domestic prices, "ex" refers to exchange rate, and "w" refers to wages.

The drop in interest rate, or the cost of borrowing $r^{*}$, is a negative demand shock, where both output and prices decrease initially. As the interest rate drops, the returns from holding foreign bonds decreases, so the economy receives less income from holding these bonds, and accordingly the amount of foreign bonds held by the economy decreases. Exports experienced an overshooting initial response the drop in interest rate coupled with the decrease in bonds (or the increase in debts) were the main reasons for this overshooting in the short run. A small country that accumulates foreign debt need to increase its exports to get the foreign exchange needed to pay for its debts. This is besides the need to increase its output, capital, and hours worked to meet both the interest rate payments and to smooth out its consumption over time.

In addition, the drop in income leads to a drop in prices next period as consumers spend less. But since the drop in prices is large, given no change in money supply, consumption in real terms increases. Also, hours worked decreases and in response wages increases. 
This short run behavior of consumption and prices in response to the drop in the cost of borrowing explains the liquidity effect of the cash in advance constraint. With limited amount of cash that the household holds, as domestic prices decreases in response to the decrease in output, households instantly become wealthier in real terms, with no initial extra hours worked, and therefore increase their consumption and reduce their working hours.

In the long run with the drop in cost of borrowing, the economy will borrow more, capital will accumulate until it reaches a new higher steady state level leading to a new higher steady state level of output and hours worked. As for consumption, although it increased initially in response to the drop in $\mathrm{r}^{*}$, over time consumption declines back to its initial steady state level following the rise of prices back to its initial level.

\section{Figure 3.5}

Transition Path for the Drop in $\mathbf{r}^{*}$ from 0.0305 to 0.0195

(Holding $\tau$ Constant at 0.20)
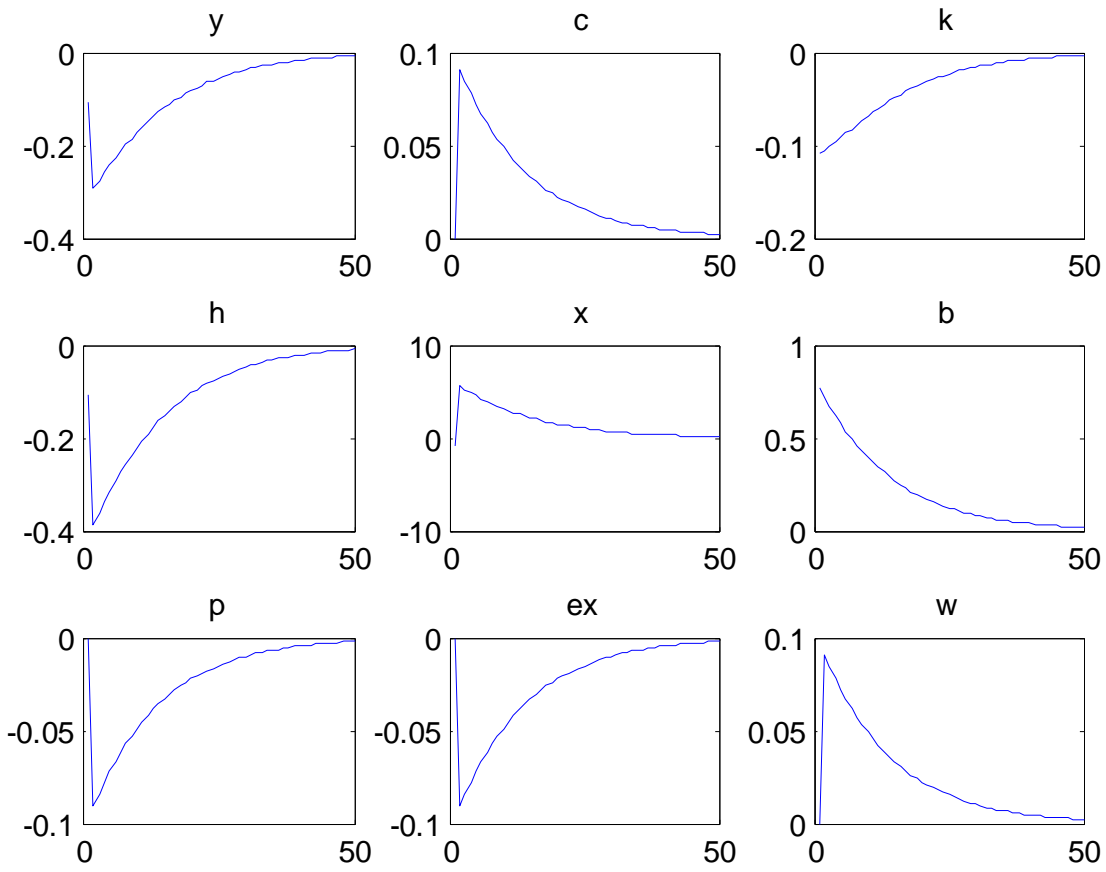
In addition, in the long run, foreign bonds decreased along the transition path in response to the decrease in the cost of borrowing, as the country gets rid of foreign bonds and chooses to borrow under the lower cost of borrowing. Foreign bonds keep on decreasing along the transition path until it reaches a steady state lower than its initial steady state. Exports also decreases along the transition path from its overshooting value and reaches a steady state higher than the initial one.

Worth to note here that, when this first experiment of the drop in interest rate from 0.0305 to 0.0195 was repeated with holding $\tau$ constant at other lower values, the transition paths for all the endogenous variables were very similar to the ones discussed above.

Next, the second experiment was undertaken to analyze the impact of the direct effect of the improvement in institutions on the behavior of the endogenous real variables along the transition path. Figure 3.6 below shows the effect of a drop in $\tau$ from 0.20 to 0.15 with holding $\mathrm{r}^{*}$ constant at 0.0305 . The exogenous decrease in $\tau$ is considered a positive demand shock, where both output and prices initially increase. As income of the consumers increase initially in response to the drop in $\tau$, consumption responds by a sharp increase. With the initial increase in consumption, prices will initially increase too. In addition, consumers will choose to work less, so hours worked initially decreases and wages initially increases.

In the long run, with the improvement in institutions, the economy accumulates more capital, output and hours worked increases until they both reach a new higher steady state levels. Consumption and wages also reach a new higher steady state levels as compared to their initial ones. Although, exports and foreign bonds did initially respond to the drop 
in $\tau$ at $\mathrm{t}=0$, with the increase in income, the economy gets rid of foreign bonds (less need for income from bonds), which undershoots along the transition path before it increases back to its initial level. Exports on the other hand overshoots before it decreases to its initial level and.

Figure 3.6

Transition Path for the Drop in $\tau$ from 0.20 to 0.15

(Holding $r *$ Constant at 0.0305)


It is worth to note that when second experiment was repeated for the drop in $\tau$ from 0.15 to 0.10 , from 0.10 to 0.05 , and from 0.05 to 0 , the behavior of the variables along the transition paths was very similar to Figure 3.5 . The only difference is that the magnitude of the peak of exports when it overshoots was getting smaller with smaller starting values of $\tau$. The same thing happened with other variables too but their cases were not as 
obvious as with exports. This means that the response of the variables to the drop in $\tau$ is decreasing, though very slightly, with the decrease in $\tau$.

Finally, the third experiment was undertaken to analyze the full impact (direct and indirect) of the improvement in institutions on the transition paths of the real endogenous variables in the model. Recall from the results of the previous chapter, a one standard deviation increase in LEGAL2 will lead to a drop in the average long term annual bond yield, $\mathrm{r}^{*}$, from about $12.21 \%$ to about $7.94 \%$ (or $3.05 \%$ to $1.98 \%$ per quarter).

\section{Figure 3.7}

Transition Path for the Drop in $\mathbf{r}^{*}$ from 0.0305 to 0.0198 Coupled with the Drop in $\tau$ from 0.20 to 0.15
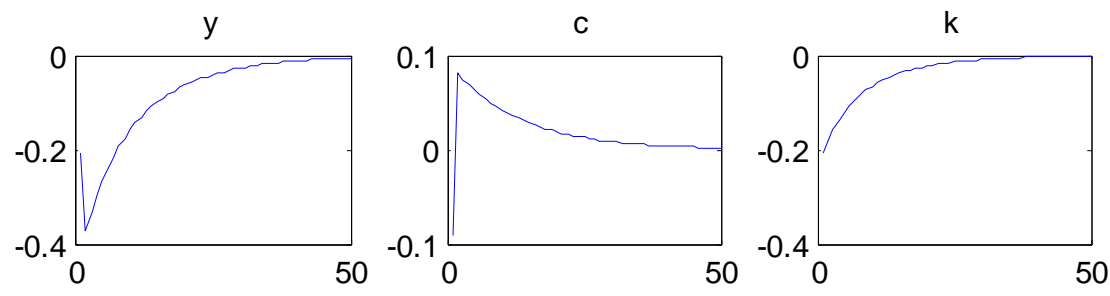

h
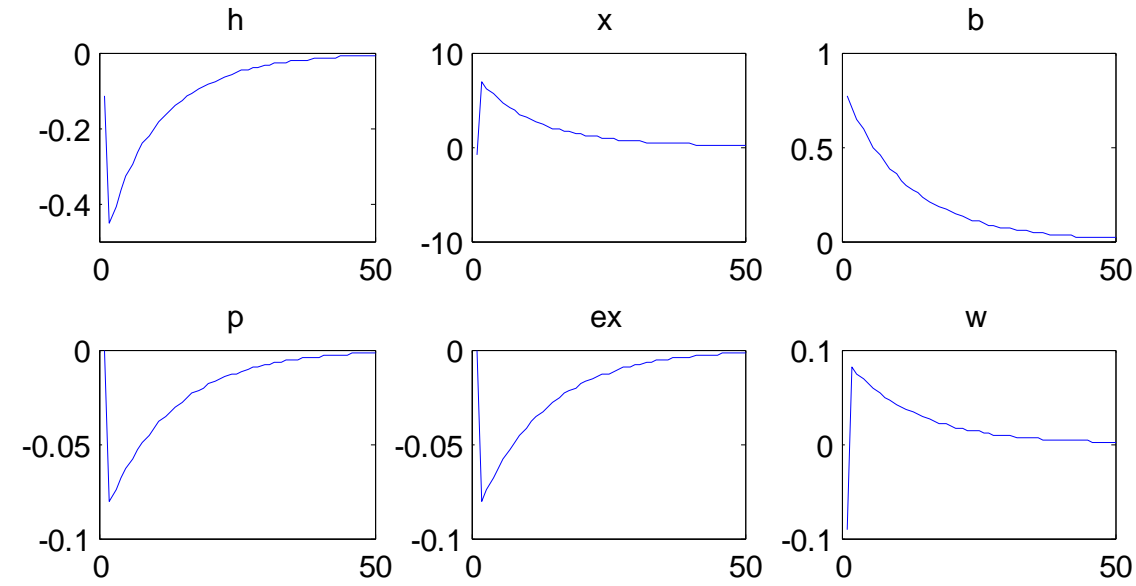

Figure 3.7 shows the impact of this drop in $\mathrm{r}^{*}$ (indirect effect of improving institutions) when coupled with a reduction in $\tau$ from 0.20 to 0.15 (direct effect of improving institutions) on the transition path of the real endogenous variables of the 
model. The behavior of this economy is very similar to the behavior of the economy under the first experiment; however the response of real variables were larger in this case.

When the drop in cost of borrowing is coupled with an increase in $\tau$, full effect of institutions, all the variables in this economy including consumption, exports, and foreign bonds, will have a new steady state different from the old one. The monetary SOE gets rid of the foreign bonds it had at the initial steady state and start accumulating foreign debt in response to the drop in interest rate. With the reduction in foreign bonds held by the economy, income from these bonds decreases, so output initially drops. Prices respond by an initial drop too leading to an initial increase in consumers' real wealth. Accordingly, consumption initially increases and hours worked initially decreases, and in response wages initially increases.

In the long run, in response to the decrease in cost of borrowing and the increase in $\tau$, bonds decreases until it reaches a new lower steady state level. Also, exports decreases from its overshooting value until it reaches a new higher steady state level. In addition, in the long run, the economy accumulates more capital in response to these direct and indirect positive effects of the improvement in institutions. Capital then increases to a new higher steady state value. Hours worked also increases to a new higher steady state level in response to the increase in capital. Output therefore increases to a new higher steady state level in response to the increase in capital and hours worked. Finally, as Prices increases back to its initial steady state level, consumption decreases from its overshooting value until it reaches a new higher steady state level, and similar response is experienced in wages. Accordingly in the long run, the economy has to increase its 
production, hours worked, and exports to meet the increasing interest payments and the increasing consumption.

\subsubsection{Comparison of Experiments}

In this subsection the transition paths of the three experiments are compared by putting them together in one graph. The idea is to analyze which experiment produces higher impacts on the steady state values of the endogenous variables.

\section{Figure 3.7 Comparison of Experiments}
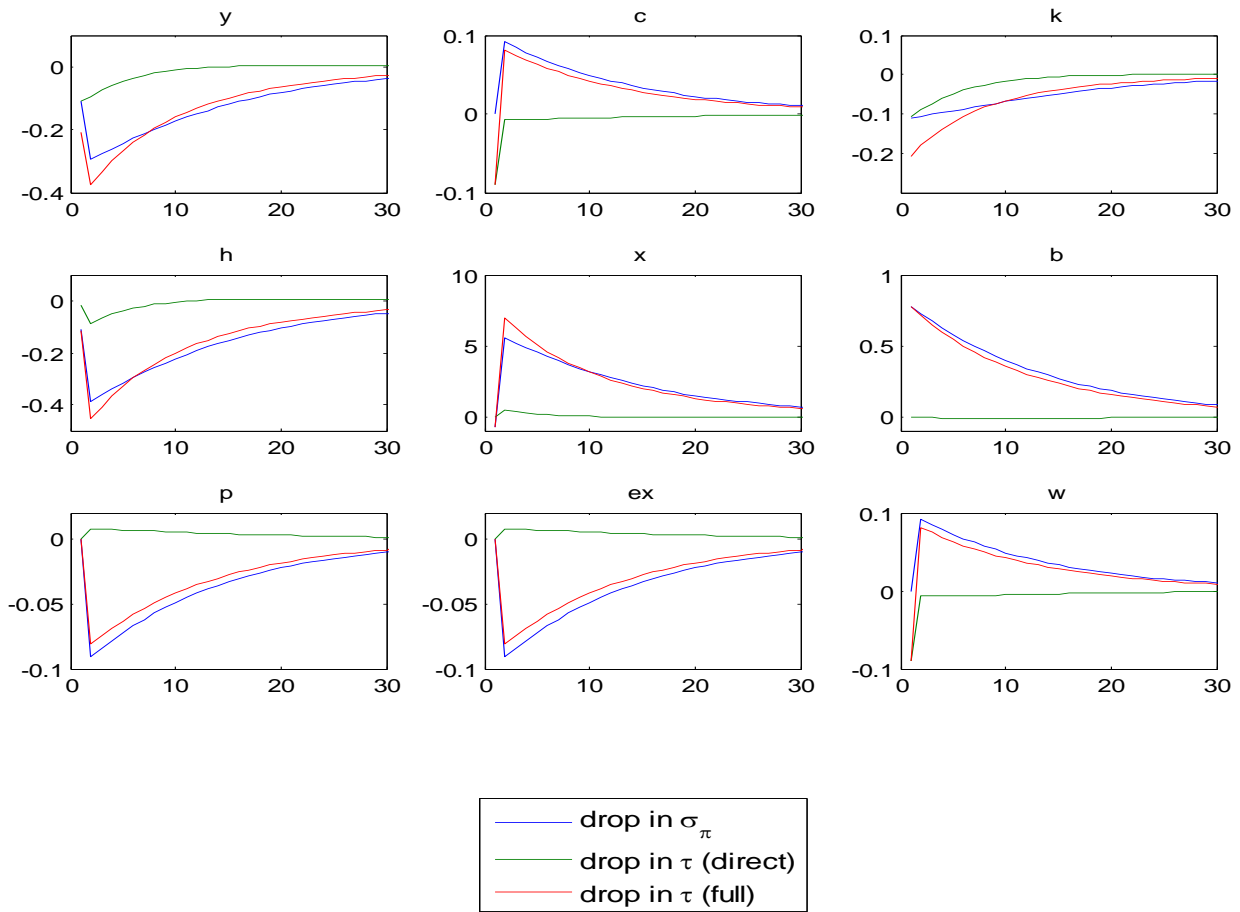

Figure 3.7 below shows three lines per each graph, where the blue line refers to the first experiment of the drop in $\mathrm{r}^{*}$ holding $\tau$ constant. The green line refers to the second experiment or the direct effect of institutions, drop in $\tau$ holding $\mathrm{r}^{*}$ constant. 
Finally, the red line refers to the full effect of institutions, or drop in $r^{*}$ (indirect effect of improving institutions) when coupled with a drop in $\tau$ (direct effect of improving institutions).

Worth to note here that if the initial steady state value of the transition path is negative, computed as log of old steady state minus log of new steady state, this means that the new economy has a steady state value that is higher than the old steady state value. So, if a line is higher and positive initially it means that the variable has a higher increase than another model. Also, if a line is lower and negative initially it means that the variable has a higher increase than another model. In both cases, this will mean that the effect is bigger if it is more positive or more negative.

From the results of the three experiments of section 3.4.2, it was demonstrated that the welfare effect of the full effect of the improvement in institutions, or experiment three, was higher than the welfare effect of the decrease in inflation volatility, experiment one. Accordingly, this should lead to the red line being lower than the blue line (at least initially) in the graphs of capital, hours worked, output, and exports.

As Figure 3.7 shows, by comparing the transition paths of the first experiment with the transition paths of the third experiment, the blue and red lines respectively, it can be noticed that the impact of the full effect of the improvement in institutions is larger on capital, hours worked, output, and exports in the third experiments as compared with the first experiment. This means that the full effect of the improvement in institutions will produce larger impacts on capital, hours worked, exports, and output as compared with the effect of the decrease in inflation volatility. 


\subsection{Conclusion}

This chapter studies a monetary small open economy (SOE) model with cash in advance constraint, capital adjustment cost, foreign bonds, trade sector, and with four types of shocks; monetary, foreign price, technology, institutions shocks. The model also incorporates a type of financial friction expressed by bad financial institutions. In response to a permanent shock on improving institutions by $25 \%$, output and capital responded by a permanent increase in their steady state values, hours worked decreased initially but then started to increase until it reached a

new higher steady state value. Both domestic prices and exchange rate decreased permanently to a new lower steady state level. Consumption reacted then by a permanent increase to a new higher steady state level. Finally, the long run values of bonds and exports were not affected by this shock.

This chapter then compares welfare implications of a one standard deviation decrease in inflation volatility versus a one standard deviation increase in LEGAL2. The results show that a one standard deviation decrease in inflation volatility will lead to at most 11.4 $\%$ increase in welfare, while a one standard deviation increase in LEGAL2 (indirect institutions effect) coupled with a drop in the institutions index (direct effect of institutions) will lead to an increase in welfare in the range of $17 \%$ to $23 \%$ depending on the degree of development in financial institutions. The welfare effects to the drop in the cost of borrowing or the improvement in institutions are much smaller in the case of the monetary SOE as compared with a standard open economy model of Barro and Sala-iMartin (1995) shown in the Appendix (III). The monetary SOE makes use of the international bonds to smooth out the effect of these two exogenous policy changes on most of the variables in the model. 
By analyzing the behavior of the endogenous variables along the transition path in response to a drop in cost of borrowing or to an improvement in institutions or both, the model suggest that the improvement in institutions has bigger effects on the steady state values of the capital, hours worked, output, and exports, where in response to a drop in cost of borrowing coupled with an improvement in institutions, a SOE chooses to get rid of its foreign bond, and accordingly the economy has to increase its production, capital, hours worked, and exports along the transition path in order for it to get the foreign exchange required to pay for its foreign debts. In addition, the transition paths were found to be smoother in economies with developed financial institutions as compared with economies with underdeveloped ones.

The main conclusion of this chapter is that the welfare effect of improving institutions and of reducing inflation volatility is large with the largest effect being caused by an improvement in financial institutions. One policy implication of these results is that developing economies can get larger welfare gains from improving their institutions than from reducing inflation volatility. The impact of improving institutions has a couple of positive effects; A direct effect on welfare through reducing the resource waste in the economy and an indirect effect on welfare that acts through the financial institutions' effect on sovereign debt rating. This result is intuitive in the sense that reducing inflation volatility is costly on output, while improving financial institutions is a cost free policy. 


\section{Appendix (I)}

Table 1.5 List of Countries included in the Sample

\begin{tabular}{|l|l|l|l|}
\hline 1 & Argentina (Arg.) & 20 & Korea, Rep. (Kor.) \\
\hline 2 & Australia (Ausl.) & 21 & Malaysia (Mal.) \\
\hline 3 & Austria (Aus.) & 22 & Mexico (Mex.) \\
\hline 4 & Belgium (Bel.) & 23 & Netherlands (Neth.) \\
\hline 5 & Brazil (Bra.) & 24 & New Zealand (N.Z) \\
\hline 6 & Canada (Can.) & 25 & Norway (Nor.) \\
\hline 7 & Chile (Chi.) & 26 & Peru (Per.) \\
\hline 8 & Colombia (Col.) & 27 & Portugal (Por.) \\
\hline 9 & Denmark (Den.) & 28 & Singapore (Sin.) \\
\hline 10 & Egypt (Egy.) & 29 & South Africa ( S.A) \\
\hline 11 & Finland (Fin.) & 30 & Spain (Spa.) \\
\hline 12 & France (Fra.) & 31 & Sweden (Swe.) \\
\hline 13 & Germany (Ger.) & 32 & Switzerland (Swi.) \\
\hline 14 & Greece (Gre.) & 33 & Thailand (Tha.) \\
\hline 15 & Hong Kong (HK) & 34 & Turkey (Tur.) \\
\hline 16 & India (Ind.) & 35 & United Kingdom (U.K) \\
\hline 17 & Israel (Isr.) & 36 & United States (U.S) \\
\hline 18 & Italy (Ita.) & 37 & Uruguay (Uru.) \\
\hline 19 & Japan (Jap.) & & \\
\hline
\end{tabular}

Notes: The above countries are the ones chosen in the sample for which the data of the components of LEGAL1 and LEGAL2 index were available.

The letters in parentheses represent the abbreviation used for each county.

Table 1.6 Summary Statistics of main variables

\begin{tabular}{|l|c|c|c|c|c|c|}
\hline & GROWTH & $\begin{array}{c}\text { Beginning of } \\
\text { the } \\
\text { period real } \\
\text { GDP }\end{array}$ & Inflation & Volatility & $\begin{array}{c}\text { Current } \\
\text { Account }\end{array}$ & $\begin{array}{c}\text { Years of } \\
\text { Schooling }\end{array}$ \\
\hline Mean & $\mathbf{0 . 6 6}$ & 3.97 & 1.52 & 0.53 & 0.18 & 8.19 \\
\hline Median & 0.67 & 4.15 & 1.28 & 0.29 & -0.70 & 8.32 \\
\hline Maximum & 2.37 & 4.59 & 8.13 & 3.59 & 26.48 & 12.05 \\
\hline Minimum & -1.36 & 2.49 & -4.07 & -0.61 & -9.05 & 3.95 \\
\hline Std. Dev. & 0.66 & 0.48 & 1.41 & 0.79 & 5.12 & 2.14 \\
\hline Sum & 140.21 & 838.19 & 320.13 & 111.30 & 37.75 & 1728.56 \\
\hline Observations & 211 & 211 & 211 & 211 & 211 & 211 \\
\hline
\end{tabular}


Table 1.7 Correlations between the Main Variables

\begin{tabular}{|l|c|c|c|c|c|}
\hline & $\begin{array}{c}\text { Beginning of } \\
\text { the } \\
\text { period real } \\
\text { GDP }\end{array}$ & Inflation & Volatility & $\begin{array}{c}\text { Current } \\
\text { Account }\end{array}$ & $\begin{array}{c}\text { Years of } \\
\text { Schooling }\end{array}$ \\
\hline $\begin{array}{l}\text { Beginning of } \\
\text { The period } \\
\text { real GDP }\end{array}$ & 1.00 & -0.51 & -0.47 & 0.24 & 0.76 \\
\hline Inflation & -0.51 & 1.00 & 0.59 & -0.29 & -0.43 \\
\hline Volatility & -0.47 & 0.59 & 1.00 & -0.21 & -0.26 \\
\hline $\begin{array}{l}\text { Current } \\
\text { Account }\end{array}$ & $\mathbf{0 . 2 4}$ & -0.29 & -0.21 & 1.00 & 0.12 \\
\hline $\begin{array}{c}\text { Years of } \\
\text { Schooling }\end{array}$ & $\mathbf{0 . 7 6}$ & -0.43 & -0.26 & 0.12 & 1.00 \\
\hline
\end{tabular}

Table 1.8 Legal and Financial Institutions indices

\begin{tabular}{|l|c|c|c|c|c|c|c|c|c|}
\hline & LEGAL1 $^{24}$ & LEGAL2 $^{25}$ & Bur. & Corr. & $\begin{array}{c}\text { L\& } \\
\text { O }\end{array}$ & Creditors & Shareholder & Acc. & Enfor. \\
\hline Min & -4.23 & -2.90 & 0 & 1 & 1 & 0 & 0.05 & 24 & 4.87 \\
\hline Max & 1.73 & 1.83 & 4 & 6 & 6 & 4 & 5.10 & 83 & 9.99 \\
\hline
\end{tabular}

\footnotetext{
24 The first eigenvector of LEGAL1 eigenvector for Legal2 was found to be (Bureaucracy, Corruption, Law \& Order $)^{\prime}=(0.269,0.041,0.671,0.689)^{\prime}$.

25 The first eigenvector of LEGAL2 eigenvector for Legal2 was found to be (Creditor, Shareholder, Enforcement, Account $)^{\prime}=(0.269,0.041,0.671,0.689) '$.
} 
Figure 1.a

Scatter Plot of the Relation between Inflation Volatility and Growth
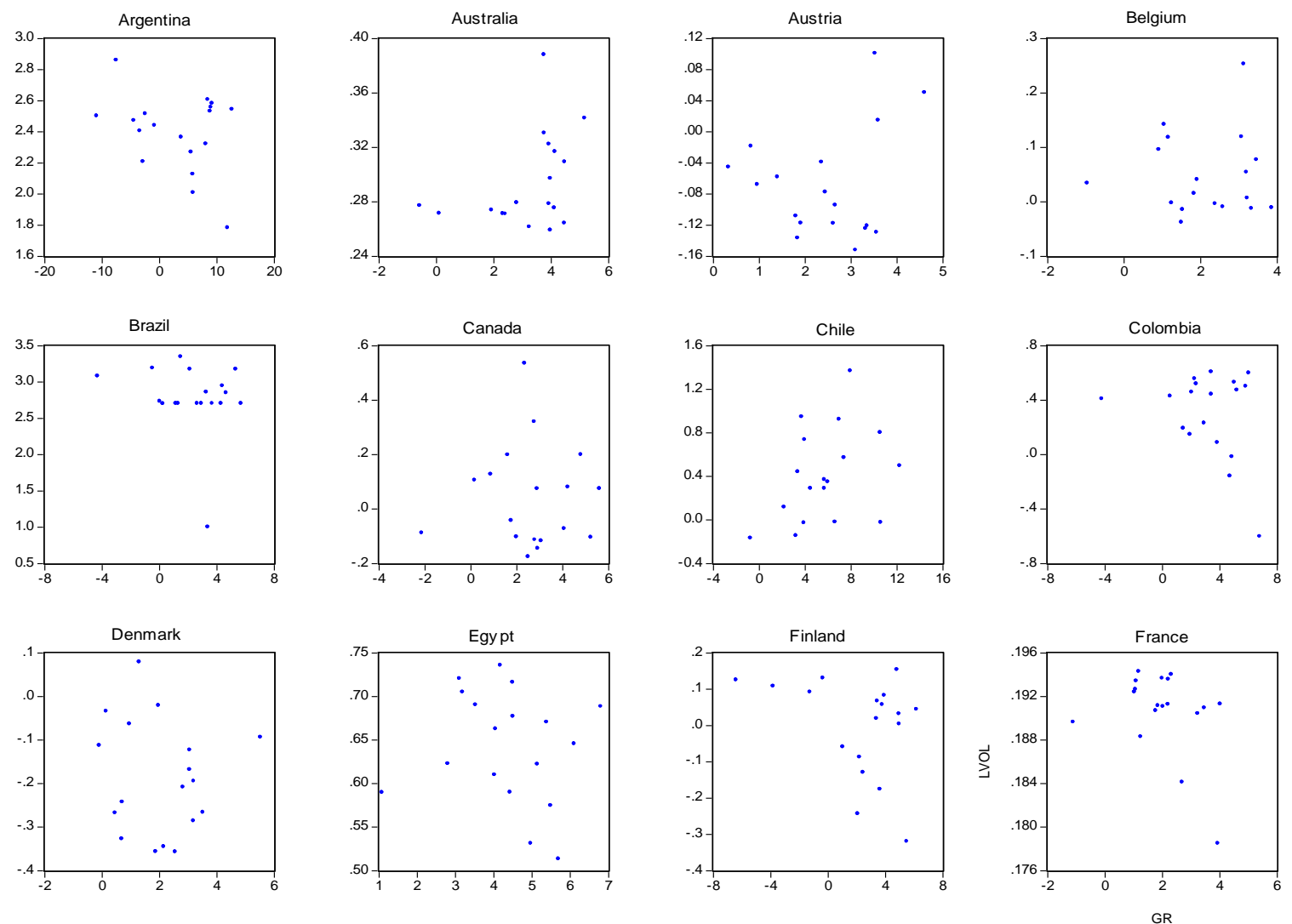
Figure 1.b

Scatter Plot of the Relation between Inflation Volatility and Growth
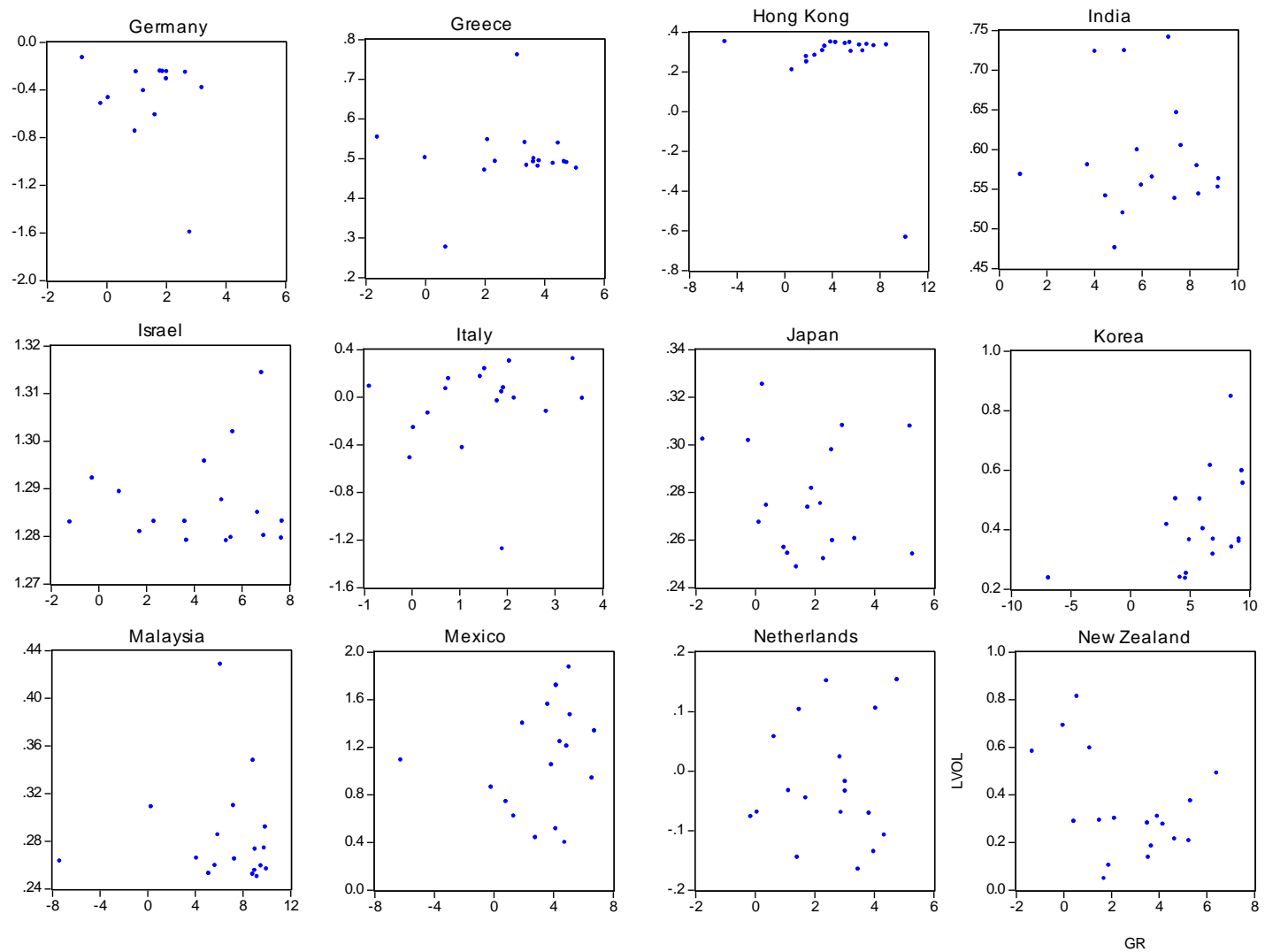
Figure 1.c

Scatter Plot of the Relation between Inflation Volatility and Growth
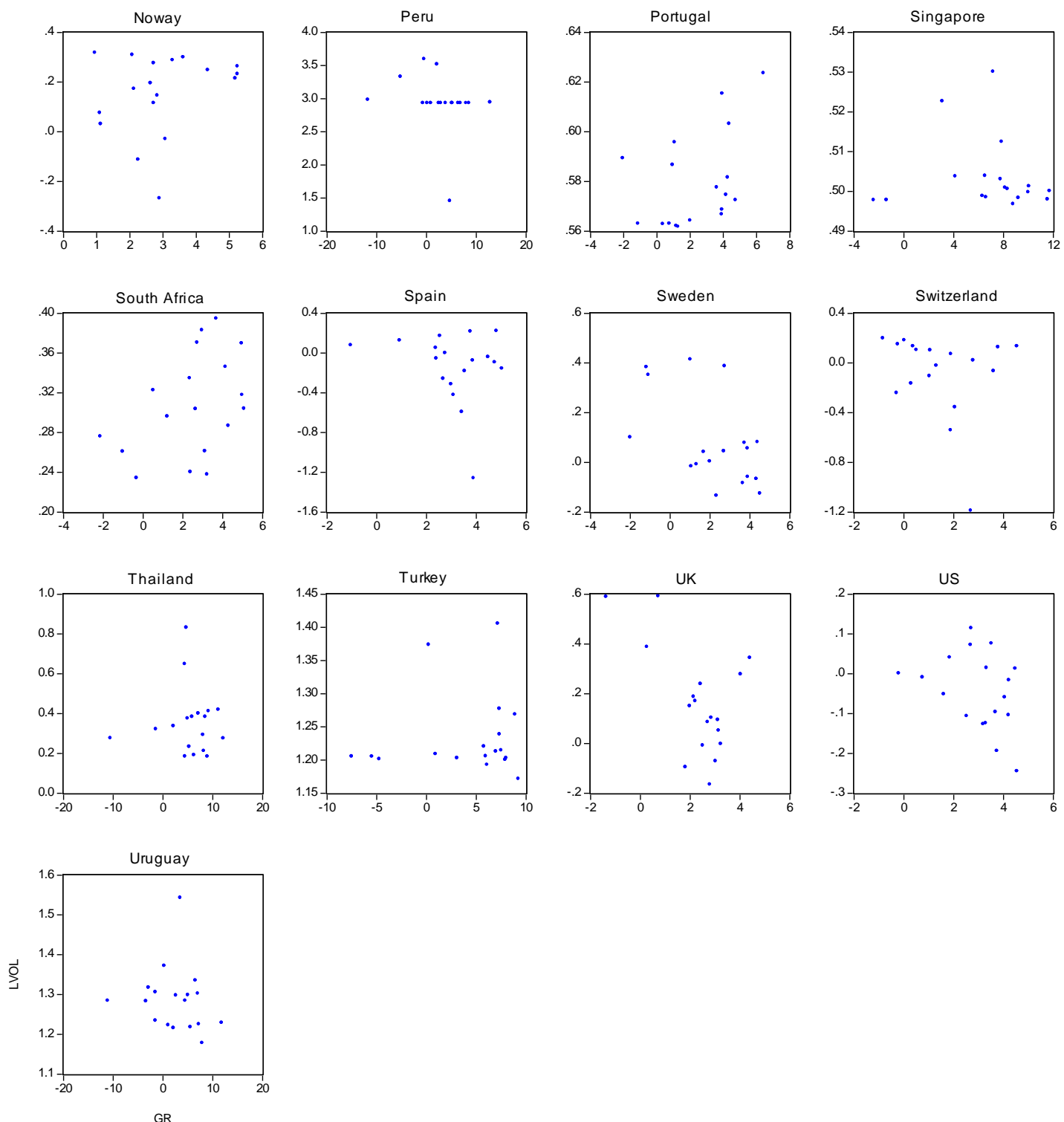
Table 1.9

Economic Growth and the Interaction between inflation Volatility and Economic Variables Cross-country panel data consisting of non-overlapping 3-year averages spanning 1989-2006 Dependent variable: Growth rate of real GDP per capita.

Estimation Method: System GMM

\begin{tabular}{|c|c|c|c|c|c|}
\hline & $\begin{array}{l}\text { Pred } \\
\text { sign }\end{array}$ & [1] & {$[2]$} & [3] & [4] \\
\hline Volatility & - & $\begin{array}{c}-0.035 \\
(0.025)\end{array}$ & & & \\
\hline Interaction & - & -0.009 & & & \\
\hline Volatility*Initial & & $(0.007)$ & & & \\
\hline \multicolumn{6}{|l|}{ GDP/capita } \\
\hline Sargan Test, p-value & & $\begin{array}{c}30.37 \\
{[0.35]}\end{array}$ & & & \\
\hline Volatility & - & & $\begin{array}{l}-0.006 \\
(0.040)\end{array}$ & & \\
\hline Interaction & - & & $-0.047 *$ & & \\
\hline Volatility*Inflation & & & $(0.026)$ & & \\
\hline \multirow[t]{2}{*}{ Sargan Test, p-value } & & & 29.45 & & \\
\hline & & & [0.39] & & \\
\hline Volatility & - & & & $\begin{array}{c}-0.008 \\
(0.032)\end{array}$ & \\
\hline Interaction & + & & & $0.078 * * *$ & \\
\hline Volatility* Openness & & & & $(0.028)$ & \\
\hline \multirow[t]{2}{*}{ Sargan Test, p-value } & & & & 29.90 & \\
\hline & & & & {$[0.373]$} & \\
\hline \multirow[t]{2}{*}{ Volatility } & - & & & & $-0.039 *$ \\
\hline & & & & & $(0.023)$ \\
\hline Interaction & + & & & & -0.003 \\
\hline Volatility* Human & & & & & $(0.002)$ \\
\hline \multicolumn{6}{|l|}{ Capital Investment } \\
\hline \multirow[t]{2}{*}{ Sargan Test, p-value } & & & & & 30.33 \\
\hline & & & & & {$[0.35]$} \\
\hline
\end{tabular}


Table 1.10

Economic Growth and the Interaction of inflation Volatility with LEGAL1 indices:

Cross-country panel data consisting of non-overlapping 3-year averages spanning 1989-2006

Dependent variable: Growth rate of real GDP per capita

Estimation Method: System GMM

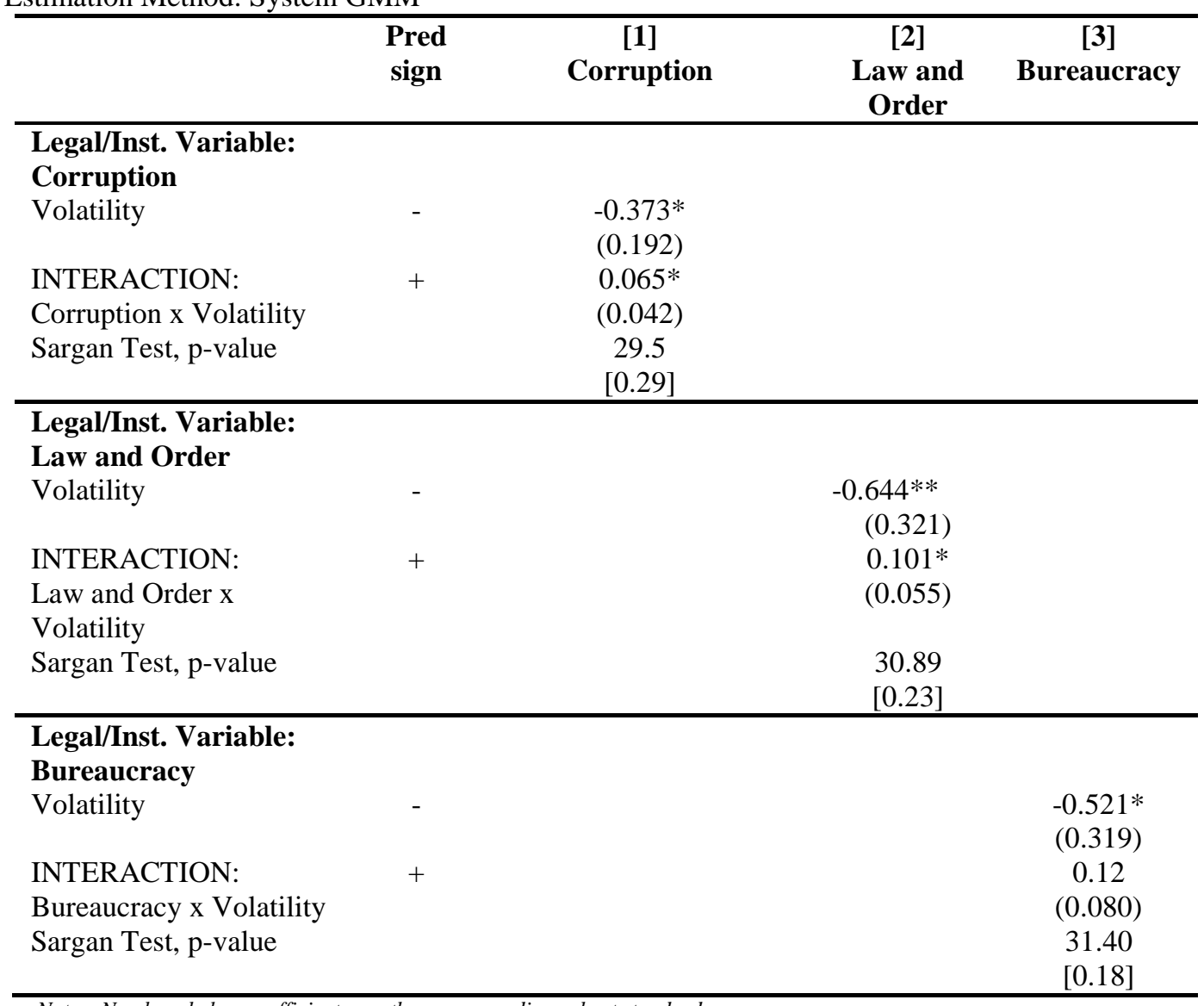

Notes: Numbers below coefficients are the corresponding robust standard errors.

$(* * *),(* *)$ and $(*)$ denotes statistical significance at the $1 \%, 5 \%$ and $10 \%$ levels respectively.

Number between [.] are the p-values of the Sargan Test. 
Table 1.11

Economic Growth and the Interaction of inflation Volatility with LEGAL2 indices:

Cross-country panel data consisting of non-overlapping 3-year averages spanning 1989-2006

Dependent variable: Growth rate of real GDP per capita

Estimation Method: System GMM

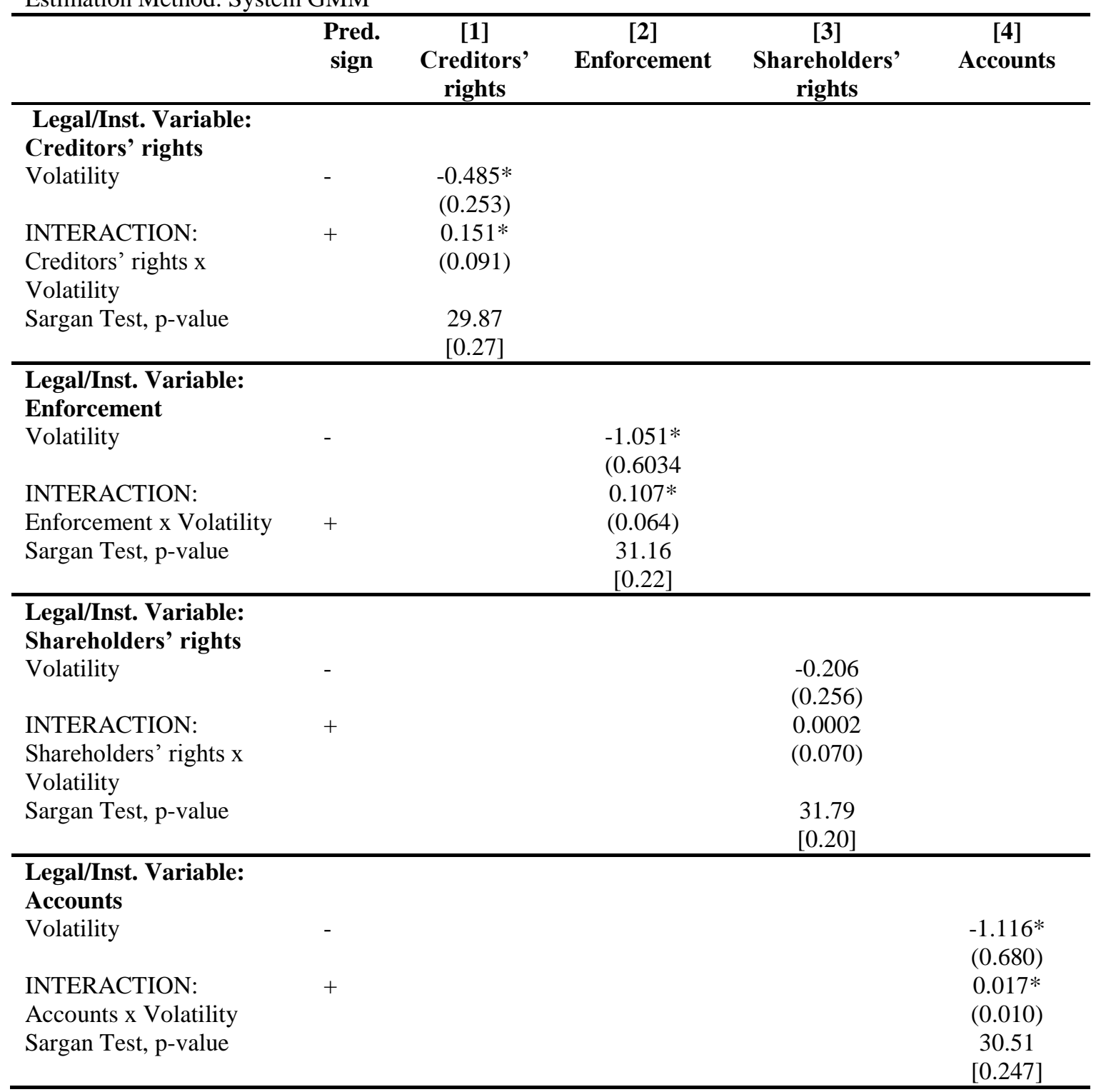

Notes: Numbers below coefficients are the corresponding robust standard errors.

$(* * *),(* *)$ and $(*)$ denotes statistical significance at the $1 \%, 5 \%$ and $10 \%$ levels respectively.

Number between [.] are the p-values of the Sargan Test. 
Figure 1.1

Total Effect of a One Standard Deviation Change of Inflation Volatility on Growth (Given the Level of LEGAL1)

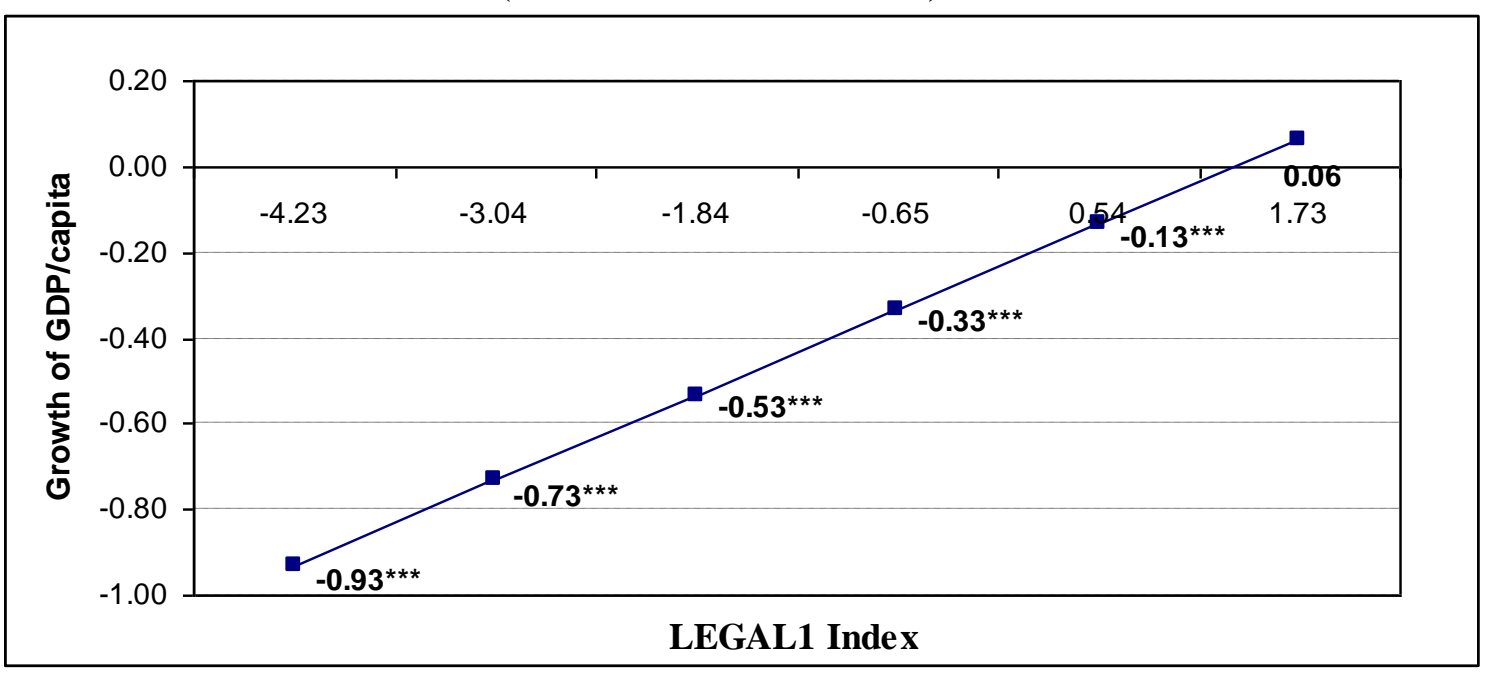

Notes: (***), (**) and (*) denotes statistical significance at the 1\%, 5\% and $10 \%$ levels respectively

Figure 1.2

Total Effect of a One Standard Deviation Change of Inflation Volatility on Growth (Given the Level of LEGAL2)

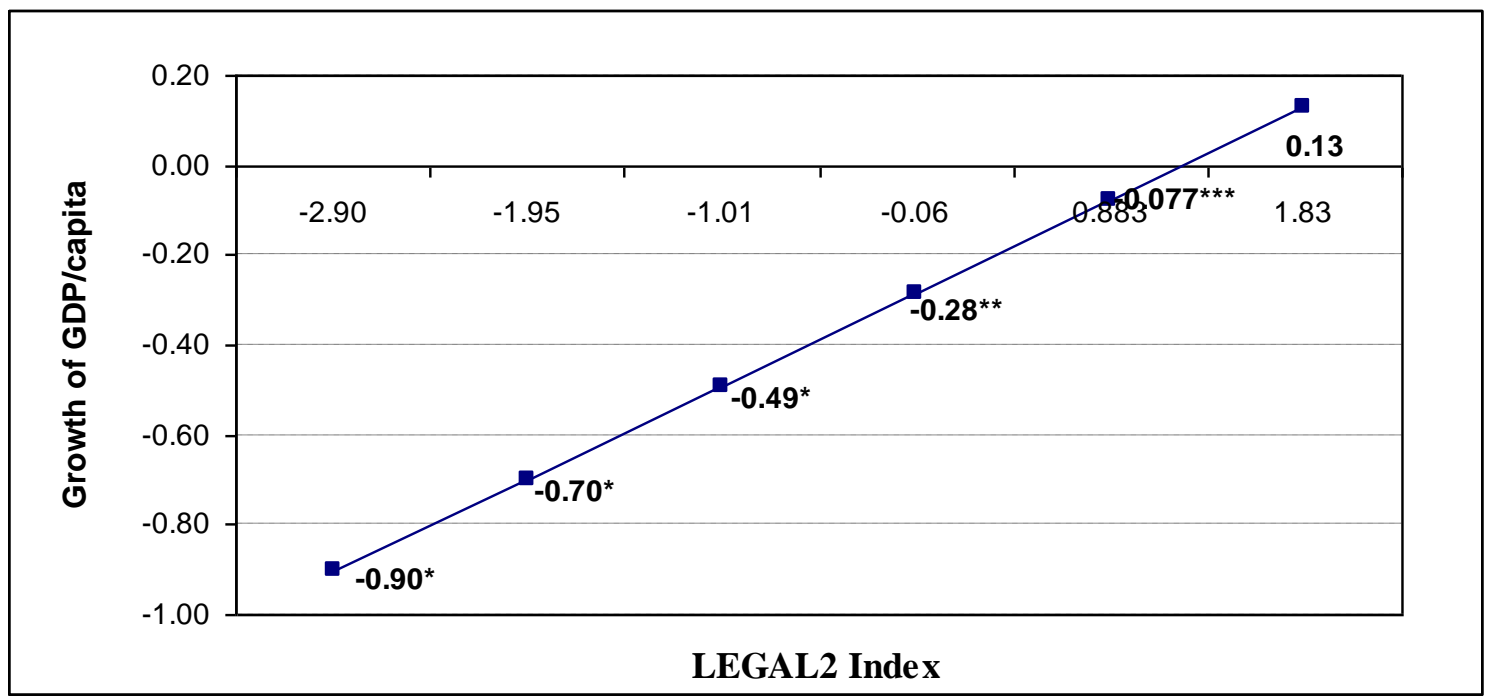

Notes: $(* * *),(* *)$ and $(*)$ denotes statistical significance at the $1 \%, 5 \%$ and $10 \%$ levels respectively 
Table 1.12

Total Effect of a One Standard Deviation Change of Inflation Volatility on Growth

(Given the Corruption Index)

\begin{tabular}{|c|c|c|c|c|c|}
\hline $\begin{array}{c}(4) \\
\text { Corruption } \\
\text { Index } \\
\end{array}$ & $\begin{array}{c}(5) \\
\text { equals (3) } \\
\text { times (4) } \\
\end{array}$ & $\begin{array}{c}\text { Total } \\
\text { Effect } \\
(2)+(5) \\
\end{array}$ & Variance & $\begin{array}{c}\text { Confidence } \\
\text { Interval }\end{array}$ & t-stat \\
\hline 1.00 & 0.05 & $-0.24 * *$ & 0.01 & {$[-0.47,-0.01]$} & -2.05 \\
\hline 1.20 & 0.06 & $-0.23 * *$ & 0.01 & {$[-0.45,-0.01]$} & -2.08 \\
\hline 2.40 & 0.12 & $-0.17 * *$ & 0.01 & {$[-0.31,-0.03]$} & -2.32 \\
\hline 3.60 & 0.18 & $-0.11 * *$ & 0.00 & {$[-0.18,-0.03]$} & -2.86 \\
\hline 4.80 & 0.25 & $-0.05 *$ & 0.00 & {$[-0.10,0.01]$} & -1.77 \\
\hline 6.00 & 0.31 & 0.01 & 0.00 & {$[-0.10,0.12]$} & 0.24 \\
\hline \multicolumn{2}{|c|}{ (1) Standard Deviation Of Volatility } & 0.79 & & & \\
\hline \multicolumn{2}{|c|}{ (2) Volatility Coefficient times (1) } & -0.29 & & & \\
\hline \multicolumn{2}{|c|}{ (3) Interaction Coefficient times (1) } & 0.05 & & & \\
\hline
\end{tabular}

Figure 1.3

Total Effect of a One Standard Deviation Change of Inflation Volatility on Growth (Given Corruption Index)

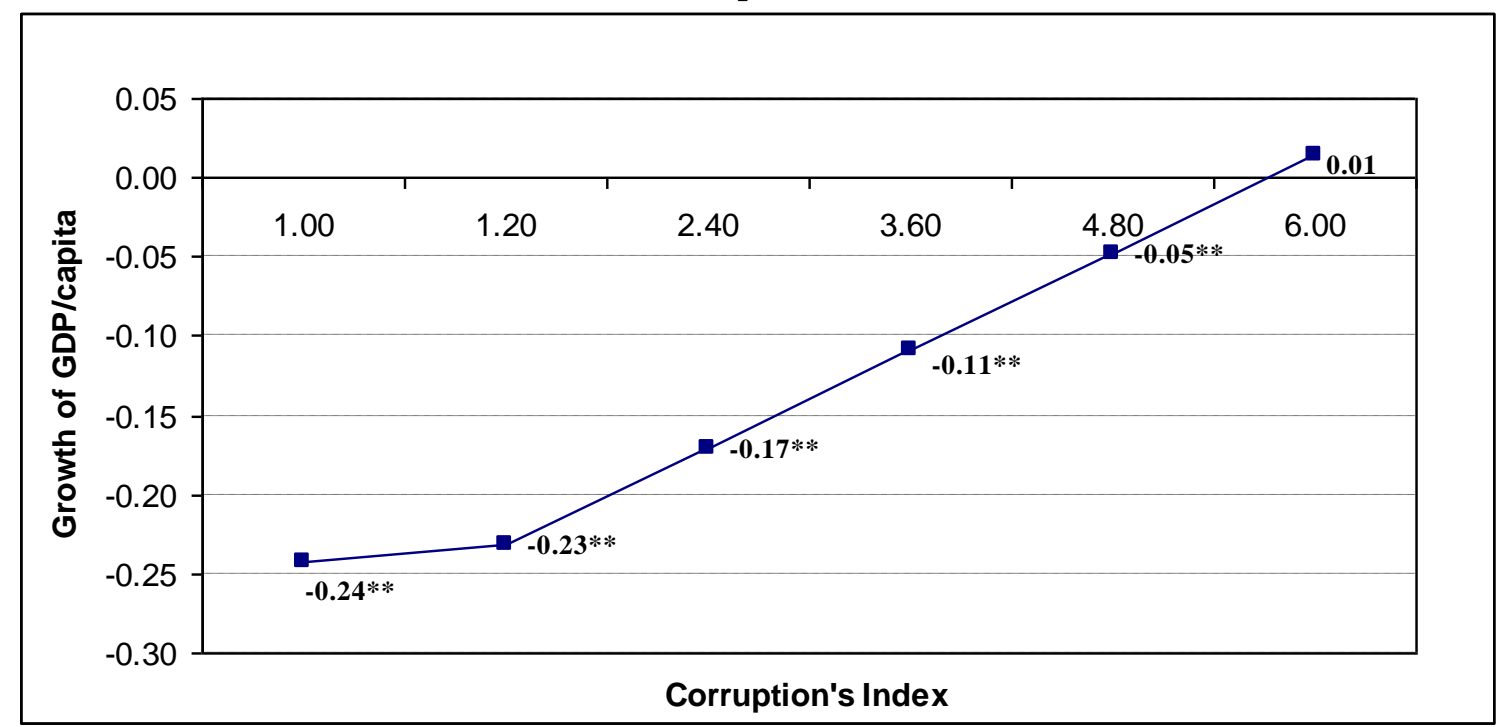

Notes: $(* * *),(* *)$ and $(*)$ denotes statistical significance at the $1 \%, 5 \%$ and $10 \%$ levels respectively 
Table 1.13

Total Effect of a One Standard Deviation Change of Inflation Volatility on Growth (Given the Law \& Order Index)

\begin{tabular}{|c|c|c|c|c|c|}
\hline $\begin{array}{c}\text { (4) } \\
\text { Law \& Order } \\
\text { Index } \\
\end{array}$ & $\begin{array}{c}(5) \\
\text { equals (3) } \\
\text { times (4) } \\
\end{array}$ & $\begin{array}{l}\text { Total } \\
\text { Effect } \\
(2)+(5) \\
\end{array}$ & Variance & $\begin{array}{c}\text { Confidence } \\
\text { Interval }\end{array}$ & t-stat \\
\hline 1.00 & 0.08 & $-0.43 * *$ & 0.04 & {$[-0.84,-0.02]$} & -2.04 \\
\hline 1.20 & 0.10 & $-0.41 * *$ & 0.04 & {$[-0.80,-0.02]$} & -2.05 \\
\hline 2.40 & 0.19 & $-0.31 * *$ & 0.02 & {$[-0.61,-0.02]$} & -2.12 \\
\hline 3.60 & 0.29 & $-0.22 * *$ & 0.01 & {$[-0.41,-0.03]$} & -2.26 \\
\hline 4.80 & 0.38 & $-0.12 * *$ & 0.00 & {$[-0.22,-0.03]$} & -2.61 \\
\hline 6.00 & 0.48 & $-\mathbf{- 0 . 0 3}$ & 0.00 & {$[-0.07,0.01]$} & -1.28 \\
\hline \multicolumn{2}{|c|}{ (1) Standard Deviation Of Volatility } & 0.79 & & & \\
\hline \multicolumn{2}{|c|}{ (2) Volatility Coefficient times (1) } & -0.51 & & & \\
\hline \multicolumn{2}{|c|}{ (3) Interaction Coefficient times (1) } & 0.08 & & & \\
\hline
\end{tabular}

Figure 1.4

Total Effect of a One Standard Deviation Change of Inflation Volatility on Growth (Given Law \& Order Index)

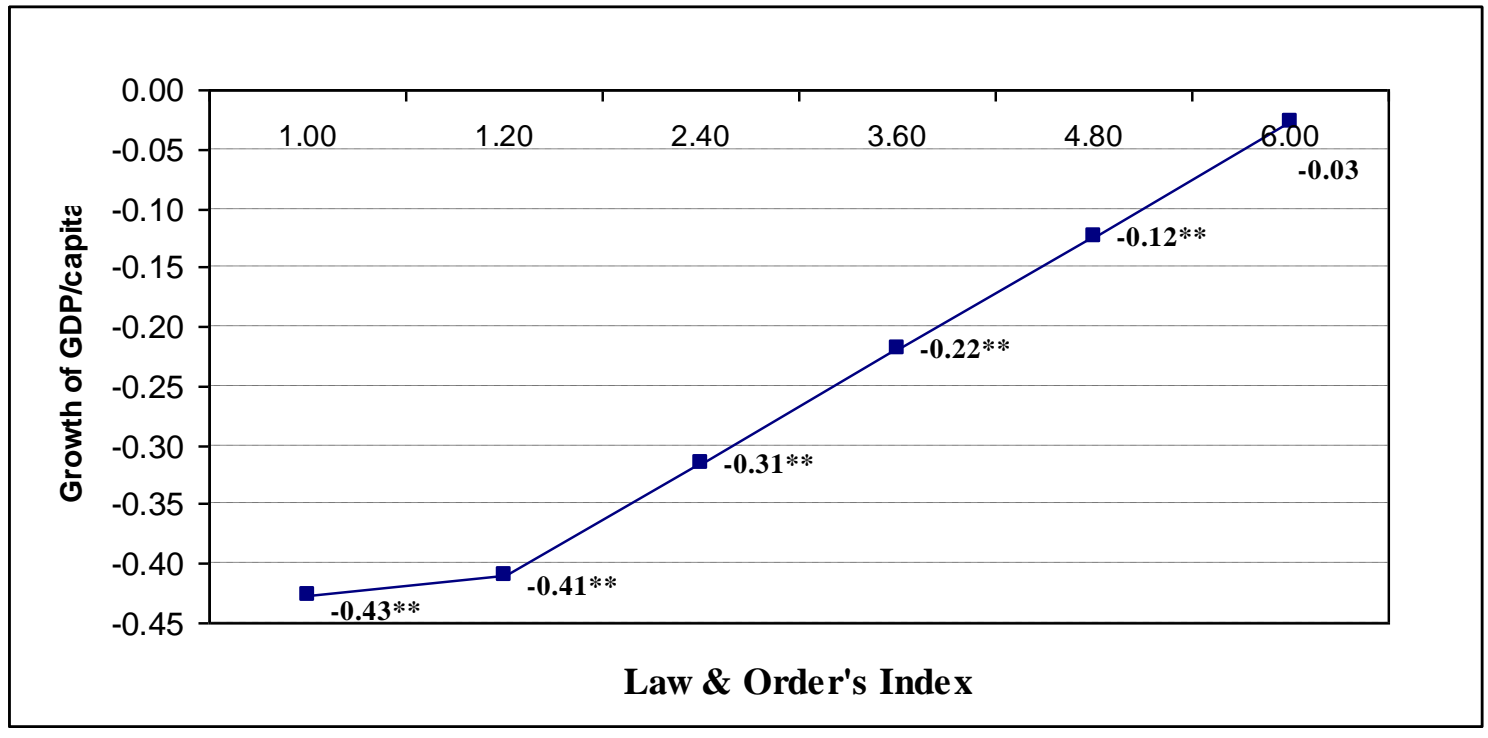

Notes: (***), (**) and $(*)$ denotes statistical significance at the $1 \%, 5 \%$ and $10 \%$ levels respectively 
Table 1.14

Total Effect of a One Standard Deviation Change of Inflation Volatility on Growth (Given Bureaucracy Index)

\begin{tabular}{|c|c|c|c|c|c|}
\hline $\begin{array}{c}\text { (4) } \\
\text { Bureaucracy } \\
\text { Index }\end{array}$ & $\begin{array}{c}(5) \\
\text { equals }(3) \\
\text { times }(4)\end{array}$ & $\begin{array}{c}\text { Total } \\
\text { Effect } \\
(2)+(5)\end{array}$ & Variance & $\begin{array}{l}\text { Confidence } \\
\text { Interval }\end{array}$ & t-stat \\
\hline 0.00 & 0.00 & $-0.41 *$ & 0.063 & {$[-0.90,0.08]$} & -1.64 \\
\hline 0.80 & 0.08 & $-0.33 *$ & 0.040 & {$[-0.73,0.06]$} & -1.66 \\
\hline 1.60 & 0.15 & $-0.26 *$ & 0.023 & {$[-0.55,0.04]$} & -1.72 \\
\hline 2.40 & 0.23 & $-0.18 *$ & 0.01 & {$[-0.38,0.01]$} & -1.82 \\
\hline 3.20 & 0.30 & $-0.11 * *$ & 0.00 & {$[-0.21,-0.01]$} & -2.09 \\
\hline 4.00 & 0.38 & -0.03 & 0.00 & {$[-0.06,0.00]$} & -1.93 \\
\hline \multicolumn{2}{|c|}{ (1) Standard Deviation Of Volatility } & 0.79 & & & \\
\hline \multicolumn{2}{|c|}{ (2) Volatility Coefficient times (1) } & -0.41 & & & \\
\hline \multicolumn{2}{|c|}{ (3) Interaction Coefficient times (1) } & 0.09 & & & \\
\hline
\end{tabular}

Figure 1.5

Effect Total Effect of a One Standard Deviation Change of Inflation Volatility on Growth (Given Bureaucracy Index)

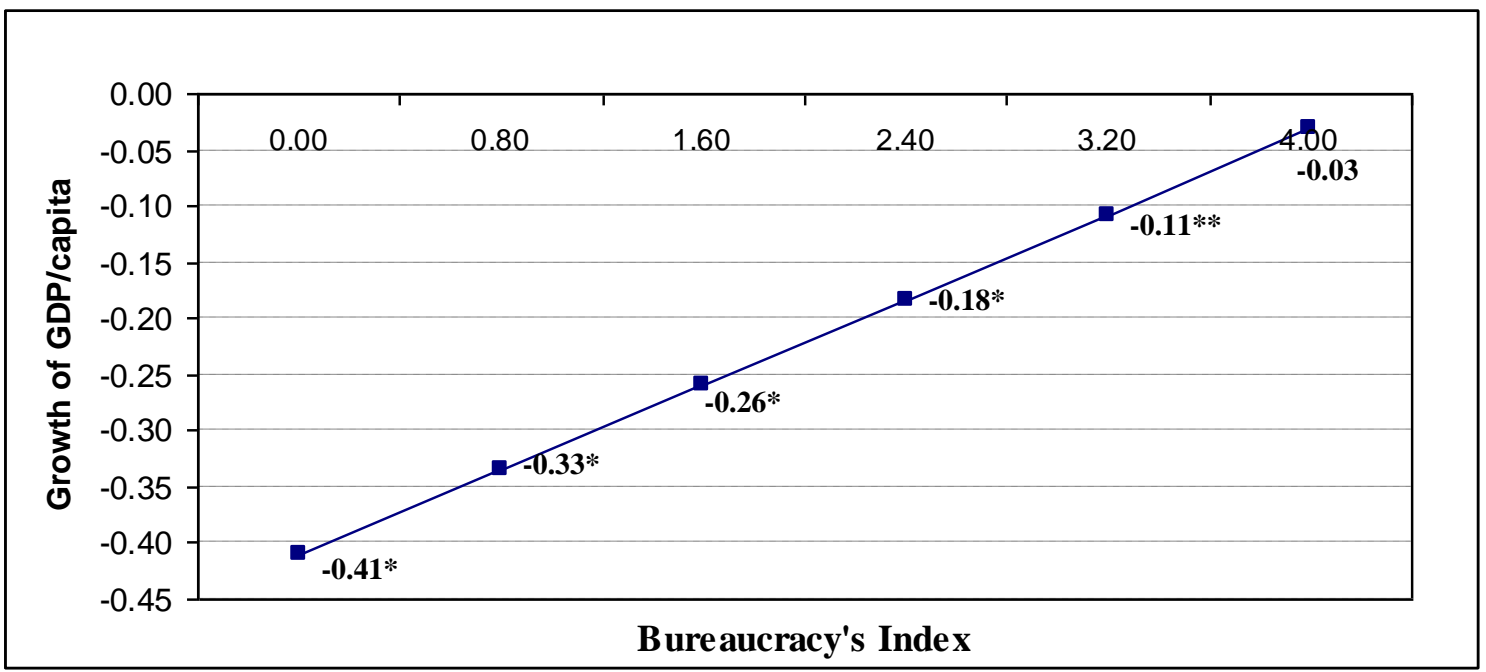

Notes: (***), (**) and $(*)$ denotes statistical significance at the $1 \%, 5 \%$ and $10 \%$ levels respectively 
Table 1.15

Total Effect of a One Standard Deviation Change of Inflation Volatility on Growth

(Given Creditors' rights Index)

\begin{tabular}{|c|c|c|c|c|c|}
\hline $\begin{array}{c}(4) \\
\text { Creditors' rights } \\
\text { Index } \\
\end{array}$ & $\begin{array}{c}(5) \\
\text { equals (3) } \\
\text { times (4) } \\
\end{array}$ & $\begin{array}{l}\text { Total } \\
\text { Effect } \\
(2)+(5) \\
\end{array}$ & Variance & $\begin{array}{c}\text { Confidence } \\
\text { Interval }\end{array}$ & t-stat \\
\hline $\mathbf{0}$ & 0.00 & $-0.38 * * *$ & 0.0095 & {$[-0.57,-0.19]$} & -3.94 \\
\hline 1 & 0.12 & $-0.26 * * *$ & 0.0039 & {$[-0.39,-0.14]$} & -4.22 \\
\hline 2 & 0.24 & $-0.14 * * *$ & 0.0008 & {$[-0.20,-0.09]$} & -5.09 \\
\hline 3 & 0.36 & $-0.03 * * *$ & 0.0001 & {$[-0.05 .0 .00]$} & -2.13 \\
\hline 4 & 0.48 & $0.09 * * *$ & 0.0019 & {$[0.01,0.18]$} & 2.15 \\
\hline \multicolumn{2}{|c|}{ (1) Standard Deviation Of Volatility } & 0.79 & & & \\
\hline \multicolumn{2}{|c|}{ (2) Volatility Coefficient times (1) } & -0.38 & & & \\
\hline \multicolumn{2}{|c|}{ (3) Interaction Coefficient times (1) } & 0.12 & & & \\
\hline
\end{tabular}

Figure 1.6

Total Effect of a One Standard Deviation Change of Inflation Volatility on Growth (Given Creditors' rights Index)

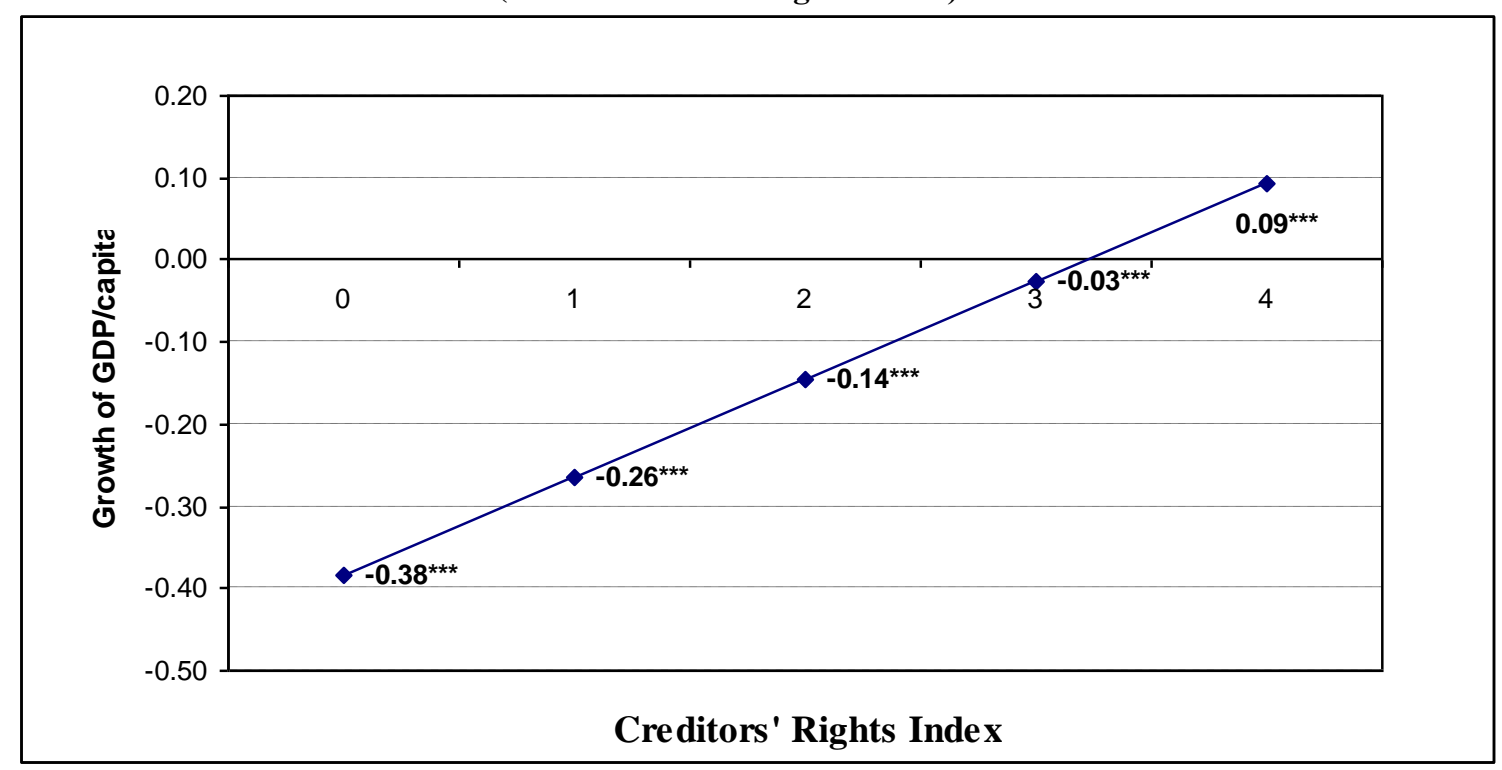

Notes: $(* * *),(* *)$ and $(*)$ denotes statistical significance at the $1 \%, 5 \%$ and $10 \%$ levels respectively 
Table 1.16

Total Effect of a One Standard Deviation Change of Inflation Volatility on Growth (Given Shareholders' rights Index)

\begin{tabular}{|c|c|c|c|c|c|}
\hline $\begin{array}{c}\text { (4) } \\
\text { Shareholders' } \\
\text { rights } \\
\text { Index } \\
\end{array}$ & $\begin{array}{c}(5) \\
\text { equals (3) } \\
\text { times (4) } \\
\end{array}$ & $\begin{array}{c}\text { Total } \\
\text { Effect } \\
(2)+(5) \\
\end{array}$ & Variance & $\begin{array}{c}\text { Confidence } \\
\text { Interval }\end{array}$ & t-stat \\
\hline 0.05 & 0.0000 & $-0.1627 * * *$ & 0.0017 & {$[-0.24,-0.08]$} & -3.96 \\
\hline 1.10 & 0.0002 & $-0.1626 * * *$ & 0.0009 & {$[-0.22,-0.10]$} & -5.32 \\
\hline 2.10 & 0.0003 & $-0.1624 * * *$ & 0.0005 & {$[-0.21,-0.12]$} & -7.44 \\
\hline 3.05 & 0.0005 & $-0.1623 * * *$ & 0.0003 & {$[-0.20,-0.13]$} & -9.60 \\
\hline 4.10 & 0.0006 & $-0.1621 * * *$ & 0.0003 & {$[-0.20,-0.13]$} & -8.68 \\
\hline \multicolumn{2}{|c|}{ (1) Standard Deviation Of Volatility } & 0.79 & & & \\
\hline \multicolumn{2}{|c|}{ (2) Volatility Coefficient times (1) } & -0.16 & & & \\
\hline \multicolumn{2}{|c|}{ (3) Interaction Coefficient times (1) } & 0.0002 & & & \\
\hline
\end{tabular}

Figure 1.7

Total Effect of a One Standard Deviation Change of Inflation Volatility on Growth (Given Shareholders' rights Index)

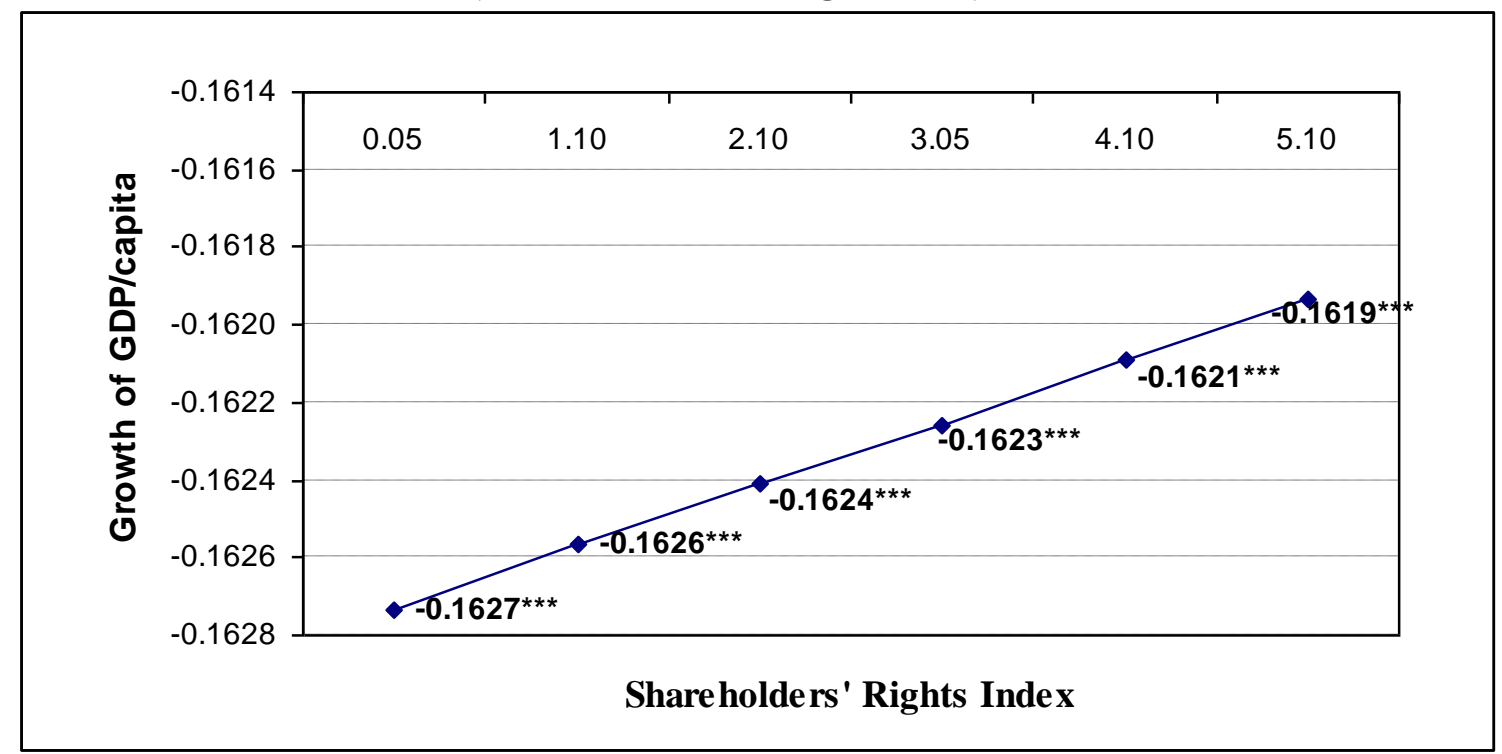

Notes: (***), (**) and $\left({ }^{*}\right)$ denotes statistical significance at the $1 \%, 5 \%$ and $10 \%$ levels respectively 
Table 1.17

Total Effect of a One Standard Deviation Change of Inflation Volatility on Growth (Given Enforcement Index)

\begin{tabular}{|c|c|c|c|c|c|}
\hline $\begin{array}{l}\text { (4) } \\
\text { Enforcement } \\
\text { Index }\end{array}$ & $\begin{array}{c}(5) \\
\text { equals (3) } \\
\text { times (4) }\end{array}$ & $\begin{array}{c}\text { Total } \\
\text { Effect } \\
(2)+(5) \\
\end{array}$ & Variance & $\begin{array}{c}\text { Confidence } \\
\text { Interval }\end{array}$ & t-stat \\
\hline 4.87 & 0.41 & $-0.42 *$ & 0.06 & {$[-0.89,0.05]$} & -1.73 \\
\hline 6.20 & 0.52 & $-0.31 *$ & 0.03 & {$[-0.64,0.03]$} & -1.80 \\
\hline 7.65 & 0.65 & $-0.18^{* * *}$ & 0.01 & {$[-0.37,0.00]$} & -1.96 \\
\hline 9.34 & 0.79 & $-0.04 * *$ & 0.00 & {$[-0.07,-0.01]$} & -2.55 \\
\hline 9.71 & 0.82 & -0.01 & 0.00 & {$[-0.06,0.04]$} & -0.40 \\
\hline 9.99 & 0.84 & 0.01 & 0.00 & {$[-0.06,0.09]$} & 0.39 \\
\hline \multicolumn{2}{|c|}{ (1) Standard Deviation Of Volatility } & 0.79 & & & \\
\hline \multicolumn{2}{|c|}{ (2) Volatility Coefficient times (1) } & -0.83 & & & \\
\hline \multicolumn{2}{|c|}{ (3) Interaction Coefficient times (1) } & 0.08 & & & \\
\hline
\end{tabular}

Figure 1.8

Total Effect of a One Standard Deviation Change of Inflation Volatility on Growth (Given Enforcement Index)

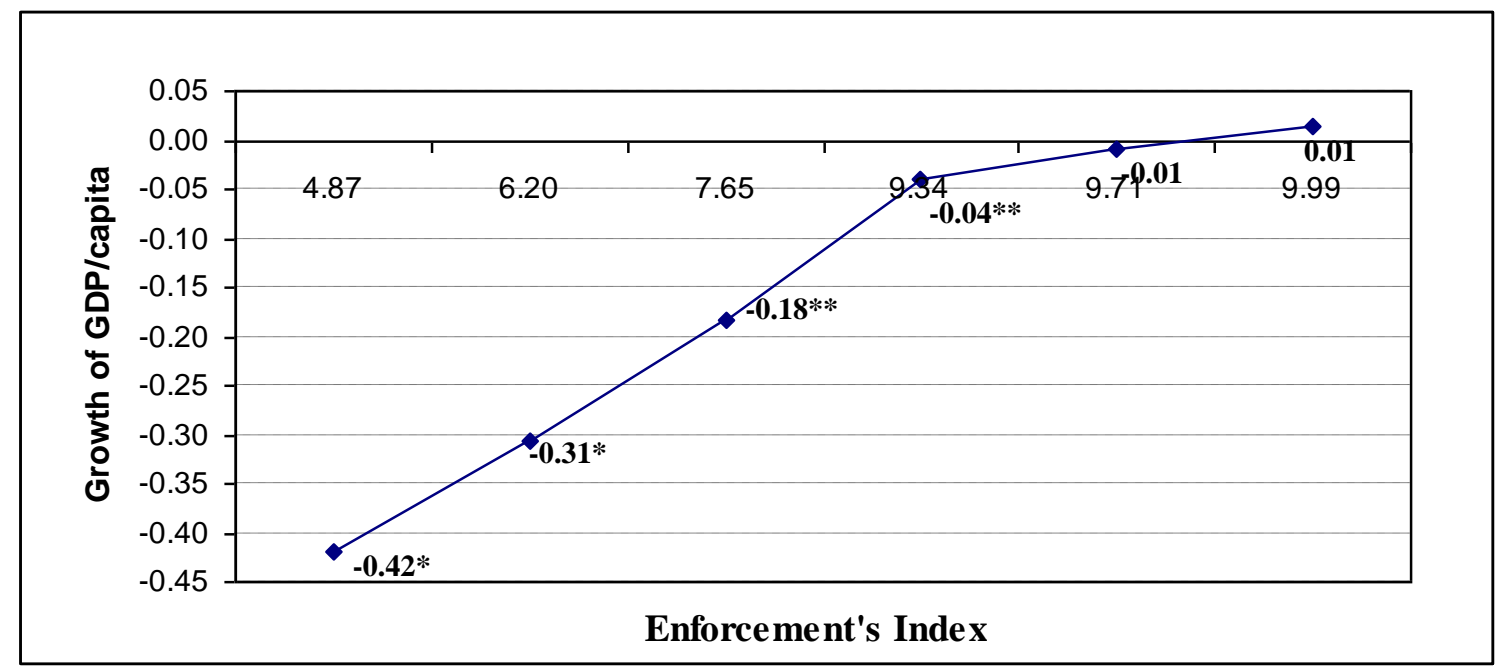

Notes: $(* * *),(* *)$ and $(*)$ denotes statistical significance at the $1 \%, 5 \%$ and $10 \%$ levels respectively 
Table 1.18

Total Effect of a One Standard Deviation Change of Inflation Volatility on Growth (Given Accounts Index)

\begin{tabular}{|c|c|c|c|c|c|}
\hline $\begin{array}{l}\text { (4) } \\
\text { Accounts } \\
\text { Index }\end{array}$ & $\begin{array}{c}(5) \\
\text { equals }(3) \\
\text { times (4) }\end{array}$ & $\begin{array}{c}\text { Total } \\
\text { Effect } \\
(2)+(5)\end{array}$ & Variance & $\begin{array}{c}\text { Confidence } \\
\text { Interval }\end{array}$ & t-stat \\
\hline 24 & 0.32 & -0.56 & 0.1343 & {$[-1.28,0.16]$} & -1.53 \\
\hline 52 & 0.70 & $-0.18 * *$ & 0.0083 & {$[-0.36,0.00]$} & -2.01 \\
\hline 62 & 0.83 & $-0.05 *$ & 0.0007 & {$[-\mathbf{0 . 1 0 , 0 . 0 0 ]}$} & -1.84 \\
\hline 65 & 0.87 & -0.01 & 0.0003 & {$[-0.04,0.02]$} & -0.51 \\
\hline 74 & 0.99 & 0.11 & 0.0135 & {$[-0.12,0.34]$} & 0.96 \\
\hline 83 & 1.11 & 0.23 & 0.04 & {$[-0.17,0.64]$} & 1.14 \\
\hline \multicolumn{2}{|c|}{ (1) Standard Deviation Of Volatility } & 0.79 & & & \\
\hline \multicolumn{2}{|c|}{ (2) Volatility Coefficient times (1) } & -0.88 & & & \\
\hline \multicolumn{2}{|c|}{ (3) Interaction Coefficient times (1) } & 0.01 & & & \\
\hline
\end{tabular}

Figure 1.9

Total Effect of a One Standard Deviation Change of Inflation Volatility on Growth (Given Accounts Index)

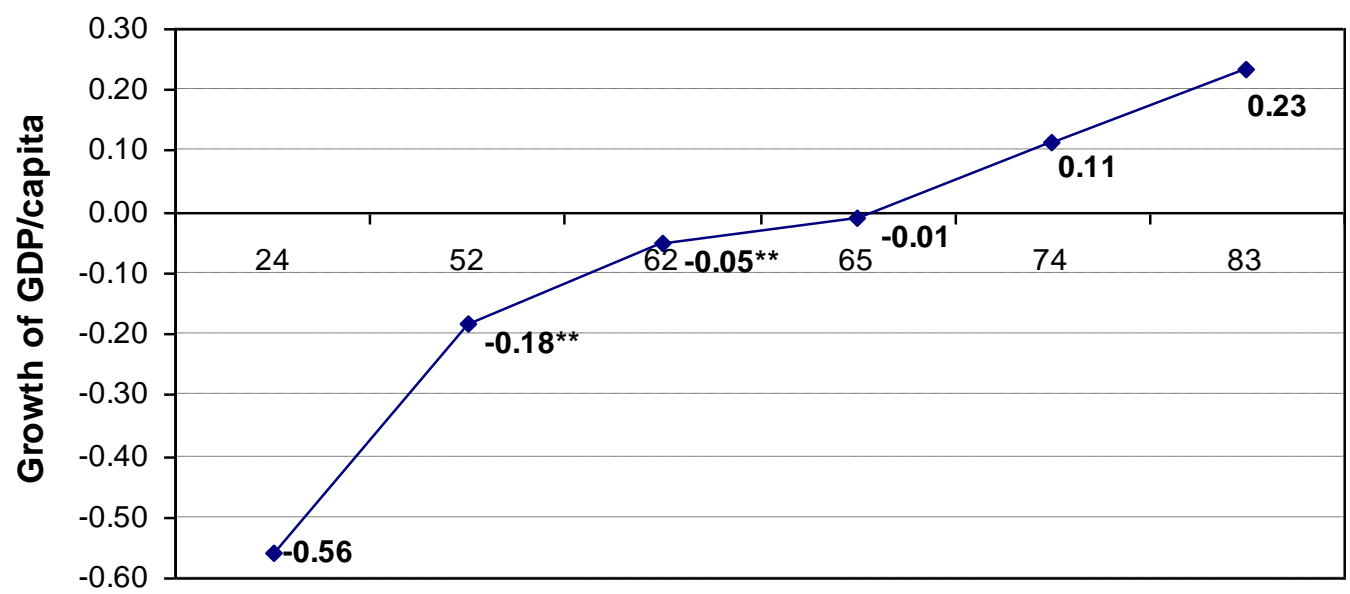

Transparency of Accounts' Index

Notes: $(* * *),(* *)$ and $(*)$ denotes statistical significance at the $1 \%, 5 \%$ and $10 \%$ levels respectively 
Table 1.19

Robustness Check: Economic Growth and the Interaction between inflation Volatility and Legal and Financial Institutions Indices.

Cross-country panel data consisting of non-overlapping 3-year averages spanning 1989-2006 Dependent variable: Growth rate of real GDP per capita.

Estimation Method: Panel Least Squares with period dummies and cross section fixed effects

\begin{tabular}{|c|c|c|}
\hline & [1] & [2] \\
\hline Constant & $\begin{array}{c}3.094 * * * \\
(0.551)\end{array}$ & $\begin{array}{c}2.977 * * * \\
(0.546)\end{array}$ \\
\hline Initial GDP/capita & $\begin{array}{c}-0.789 * * * \\
(0.155)\end{array}$ & $\begin{array}{c}-0.752 * * * \\
(0.153)\end{array}$ \\
\hline Inflation & $\begin{array}{c}0.043 \\
(0.071)\end{array}$ & $\begin{array}{c}0.048 \\
(0.061)\end{array}$ \\
\hline Volatility & $\begin{array}{c}-0.115^{*} \\
(0.071)\end{array}$ & $\begin{array}{c}-0.138 * \\
(0.075)\end{array}$ \\
\hline Openness & $\begin{array}{c}0.028 * * * \\
(0.010)\end{array}$ & $\begin{array}{c}0.025 * * \\
(0.010)\end{array}$ \\
\hline Human Capital Investment & $\begin{array}{c}0.095 * * * \\
(0.032)\end{array}$ & $\begin{array}{c}0.086 * * * \\
(0.032)\end{array}$ \\
\hline $\begin{array}{l}\text { Interaction } \\
\text { Volatility *LEGAL1 }\end{array}$ & $\begin{array}{c}0.113 * * \\
(0.056)\end{array}$ & \\
\hline $\begin{array}{l}\text { Interaction } \\
\text { Volatility *LEGAL2 }\end{array}$ & & $\begin{array}{l}0.138 * * \\
(0.062)\end{array}$ \\
\hline Countries/Observations & $34 / 161$ & $34 / 161$ \\
\hline Adjusted R-Squared & 0.131 & 0.137 \\
\hline F-statistic, $p$-value & 4.03 & 4.17 \\
\hline
\end{tabular}


Table 1.20 Robustness Check

Total Effect of a One Standard Deviation Change of Inflation Volatility on Growth (Given the LEGAL1 index)

\begin{tabular}{|c|c|c|c|c|c|}
\hline $\begin{array}{l}\text { (4) } \\
\text { LEGAL1 } \\
\text { Index } \\
\end{array}$ & $\begin{array}{c}(5) \\
\text { equals }(3) \\
\text { times }(4) \\
\end{array}$ & $\begin{array}{c}\text { Total } \\
\text { Effect } \\
(2)+(5) \\
\end{array}$ & Variance & $\begin{array}{c}\text { Confidence } \\
\text { Interval }\end{array}$ & t-stat \\
\hline-4.23 & -0.38 & $-0.47 * *$ & 0.05 & {$[-0.90,-0.03]$} & -2.09 \\
\hline-3.04 & -0.27 & $-0.36 * *$ & 0.030 & {$[-0.70,-0.02]$} & -2.09 \\
\hline-1.84 & -0.16 & $-0.25 * *$ & 0.015 & {$[-0.49,-0.01]$} & -2.08 \\
\hline-0.65 & -0.06 & $-0.15^{*}$ & 0.01 & {$[-0.30,0.00]$} & -1.95 \\
\hline 0.54 & 0.05 & -0.04 & 0.00 & {$[-0.13,0.05]$} & -0.93 \\
\hline 1.73 & 0.15 & 0.06 & 0.004 & {$[-0.06,0.19]$} & 1.00 \\
\hline \multicolumn{2}{|c|}{ (1) Standard Deviation Of Volatility } & 0.79 & & & \\
\hline \multicolumn{2}{|c|}{ (2) Volatility Coefficient times (1) } & -0.09 & & & \\
\hline \multicolumn{2}{|c|}{ (3) Interaction Coefficient times (1) } & 0.09 & & & \\
\hline
\end{tabular}

Table 1.21 Robustness Check

Total Effect of a One Standard Deviation Change of Inflation Volatility on Growth

(Given the LEGAL2 index)

\begin{tabular}{|c|c|c|c|c|c|}
\hline $\begin{array}{c}(4) \\
\text { LEGAL2 } \\
\text { Index } \\
\end{array}$ & $\begin{array}{c}(5) \\
\text { equals }(3) \\
\text { times }(4) \\
\end{array}$ & $\begin{array}{c}\text { Total } \\
\text { Effect } \\
(2)+(5) \\
\end{array}$ & Variance & $\begin{array}{c}\text { Confidence } \\
\text { Interval }\end{array}$ & t-stat \\
\hline-2.90 & -0.31 & $-0.42 * *$ & $\mathbf{0 . 0 3}$ & {$[-0.78,-0.06]$} & -2.29 \\
\hline-1.95 & -0.21 & $-0.32 * *$ & 0.02 & {$[-0.59,-0.05]$} & -2.29 \\
\hline-1.01 & -0.11 & $-0.22 * *$ & 0.01 & {$[-0.41,-0.03]$} & -2.23 \\
\hline-0.06 & -0.01 & $-0.12 *$ & 0.00 & {$[-0.23,0.00]$} & -1.90 \\
\hline 0.88 & 0.10 & -0.01 & 0.00 & {$[-0.10,0.08]$} & -0.28 \\
\hline 1.83 & $\mathbf{0 . 2 0}$ & 0.09 & $\mathbf{0 . 0 0}$ & {$[-0.05,0.22]$} & 1.30 \\
\hline \multicolumn{2}{|c|}{ (1) Standard Deviation Of Volatility } & 0.79 & & & \\
\hline \multicolumn{2}{|c|}{ (2) Volatility Coefficient times (1) } & -0.11 & & & \\
\hline \multicolumn{2}{|c|}{ (3) Interaction Coefficient times (1) } & 0.11 & & & \\
\hline
\end{tabular}

Notes: $\left.{ }^{* * *}\right),(* *)$ and $\left(^{*}\right)$ denotes statistical significance at the $1 \%, 5 \%$ and $10 \%$ levels respectively 


\section{Appendix (II)}

\section{(a) Tables and Figures}

Table 2.11

Descriptive Statistics

\begin{tabular}{|c|c|c|c|c|c|c|c|}
\hline & Rating & Inf. & Inf. Vol. & DC & GDP/cap. & L2 & intL2 \\
\hline Mean & 16.88 & 48.43 & 0.51 & 86.04 & 4.00 & -0.01 & -0.68 \\
\hline Median & 20.33 & 3.45 & 0.28 & 80.84 & 4.19 & 0.36 & -0.05 \\
\hline Maximum & 23.00 & 3398.68 & 3.27 & 228.07 & 4.60 & 1.83 & 0.93 \\
\hline Minimum & 0.00 & -1.58 & -0.99 & 9.17 & 2.49 & -2.90 & -9.49 \\
\hline Std. Dev. & 6.75 & 328.58 & 0.79 & 48.99 & 0.48 & 1.32 & 1.78 \\
\hline Skewness & -0.94 & 8.92 & 1.78 & 0.48 & -0.93 & -0.58 & -2.89 \\
\hline Kurtosis & 2.90 & 84.89 & 5.97 & 2.57 & 3.12 & 2.17 & 12.00 \\
\hline Jarque-Bera & 32.13 & 64102.52 & 195.56 & 10.18 & 31.77 & 18.50 & 1044.83 \\
\hline Probability & 0.00 & 0.00 & 0.00 & 0.01 & 0.00 & 0.00 & 0.00 \\
\hline Sum & 3696.00 & 10605.80 & 111.61 & 18842.17 & 875.35 & -1.82 & -149.21 \\
\hline Sum Sq. Dev. & 9945.84 & 23536444.00 & 135.43 & 523284.60 & 49.67 & 379.61 & 693.75 \\
\hline Observations & 219.00 & 219.00 & 219.00 & 219.00 & 219.00 & 219.00 & 219.00 \\
\hline
\end{tabular}

Note: Inf. Refers to inflation, inf.vol refers to inflation volatility, DC refers to Domestic credit as a ratio to GDP, GDP/cap is the percapita GDP, L2 is the LEGAL2 index, and finally intL2 is the interaction term of the LEGAL2 index with inflation volatility.

Table 2.12

Correlation Matrix

\begin{tabular}{|c|c|c|c|c|c|c|c|}
\hline & Rating & Inf. & Inf. Vol. & DC & GDP/cap. & L2 & intL2 \\
\hline Rating & 1.00 & -0.30 & -0.72 & 0.59 & 0.76 & 0.77 & 0.62 \\
\hline Inf. & -0.30 & 1.00 & 0.41 & -0.15 & -0.15 & -0.22 & -0.42 \\
\hline Inf. Vol. & -0.72 & 0.41 & 1.00 & -0.51 & -0.48 & -0.65 & -0.84 \\
\hline DC & 0.59 & -0.15 & -0.51 & 1.00 & 0.53 & 0.64 & 0.50 \\
\hline GDP/cap. & 0.76 & -0.15 & -0.48 & 0.53 & 1.00 & 0.70 & 0.43 \\
\hline $\mathbf{L 2}$ & 0.77 & -0.22 & -0.65 & 0.64 & 0.70 & 1.00 & 0.74 \\
\hline intL2 & 0.62 & -0.42 & -0.84 & 0.50 & 0.43 & 0.74 & 1.00 \\
\hline
\end{tabular}

Note: Inf. Refers to inflation, inf.vol refers to inflation volatility, DC refers to Domestic credit as a ratio to GDP, GDP/cap is the percapita GDP, L2 is the LEGAL2 index, and finally intL2 is the interaction term of the LEGAL2 index with inflation volatility. 
Table 2.13 Regional Dummies

\begin{tabular}{|c|c|c|c|c|c|}
\hline Code & Countries & Dasian & Doecd & Dlatin & Dafmid \\
\hline 1 & Argentina & $\mathbf{0}$ & $\mathbf{0}$ & 1 & $\mathbf{0}$ \\
\hline 2 & Australia & $\mathbf{0}$ & 1 & $\mathbf{0}$ & $\mathbf{0}$ \\
\hline 3 & Austria & $\mathbf{0}$ & 1 & $\mathbf{0}$ & $\mathbf{0}$ \\
\hline 4 & Belgium & $\mathbf{0}$ & 1 & $\mathbf{0}$ & $\mathbf{0}$ \\
\hline 5 & Brazil & 0 & $\mathbf{0}$ & 1 & $\mathbf{0}$ \\
\hline 6 & Canada & 0 & 1 & 0 & 0 \\
\hline 7 & Chile & $\mathbf{0}$ & $\mathbf{0}$ & 1 & $\mathbf{0}$ \\
\hline 8 & Colombia & $\mathbf{0}$ & $\mathbf{0}$ & 1 & $\mathbf{0}$ \\
\hline 9 & Denmark & 0 & 1 & 0 & 0 \\
\hline 10 & Egypt & 0 & 0 & $\mathbf{0}$ & 1 \\
\hline 11 & Finland & $\mathbf{0}$ & 1 & $\mathbf{0}$ & $\mathbf{0}$ \\
\hline 12 & France & $\mathbf{0}$ & 1 & $\mathbf{0}$ & $\mathbf{0}$ \\
\hline 13 & Germany & $\mathbf{0}$ & 1 & $\mathbf{0}$ & $\mathbf{0}$ \\
\hline 14 & Greece & 0 & 1 & 0 & 0 \\
\hline 15 & Hong Kong,Chi & 1 & $\mathbf{0}$ & $\mathbf{0}$ & $\mathbf{0}$ \\
\hline 16 & India & 1 & 0 & 0 & 0 \\
\hline 17 & Israel & 0 & $\mathbf{0}$ & 0 & 1 \\
\hline 18 & Italy & 0 & 1 & 0 & $\mathbf{0}$ \\
\hline 19 & Japan & 0 & 1 & 0 & 0 \\
\hline 20 & Korea, Rep. & $\mathbf{0}$ & 1 & $\mathbf{0}$ & $\mathbf{0}$ \\
\hline 21 & Malaysia & 1 & 0 & 0 & $\mathbf{0}$ \\
\hline 22 & Mexico & 0 & 1 & $\mathbf{0}$ & $\mathbf{0}$ \\
\hline 23 & Netherlands & 0 & 1 & $\mathbf{0}$ & $\mathbf{0}$ \\
\hline 24 & New Zealand & 0 & 1 & 0 & 0 \\
\hline 25 & Norway & $\mathbf{0}$ & 1 & $\mathbf{0}$ & $\mathbf{0}$ \\
\hline 26 & Peru & 0 & 0 & 1 & 0 \\
\hline 27 & Portugal & 0 & 1 & $\mathbf{0}$ & $\mathbf{0}$ \\
\hline 28 & Singapore & 1 & 0 & $\mathbf{0}$ & 0 \\
\hline 29 & South Africa & 0 & 0 & 0 & 1 \\
\hline 30 & Spain & 0 & 1 & 0 & $\mathbf{0}$ \\
\hline 31 & Sweden & 0 & 1 & 0 & $\mathbf{0}$ \\
\hline 32 & Switzerland & $\mathbf{0}$ & 1 & $\mathbf{0}$ & $\mathbf{0}$ \\
\hline 33 & Thailand & 1 & $\mathbf{0}$ & $\mathbf{0}$ & 0 \\
\hline 34 & Turkey & 0 & 1 & 0 & $\mathbf{0}$ \\
\hline 35 & United Kingdom & 0 & 1 & 0 & $\mathbf{0}$ \\
\hline 36 & United States & 0 & 1 & 0 & 0 \\
\hline 37 & Uruguay & 0 & 0 & 1 & 0 \\
\hline
\end{tabular}

Notes: Dasian; refers to the dummy for Asian countries, Doecd; refers to the dummy for the OECD countries (Includes Japan, Mexico, and Turkey), Dlatin, refers to the dummy for the Latin American countries, and Dafmid; refers to the dummy for the North African and Middle Eastern countries (Includes South Africa) 
Table 2.14

Wald Coefficients Test

Wald Test:

Equation: BASE

\begin{tabular}{lrrr}
\hline \hline Test Statistic & Value & df & Probability \\
\hline \hline F-statistic & 3.766590 & $(2,150)$ & 0.0253 \\
Chi-square & 7.533179 & 2 & 0.0231 \\
\hline \hline
\end{tabular}

Null Hypothesis Summary:

\begin{tabular}{lcc}
\hline \hline Normalized Restriction $(=0)$ & Value & Std. Err. \\
\hline \hline $\mathrm{C}(7)$ & 0.341208 & 0.438961 \\
$\mathrm{C}(8)$ & 0.604794 & 0.514689 \\
\hline \hline
\end{tabular}

Restrictions are linear in coefficients. 
Table 2.15

Total Effect of a One Standard Deviation Change of Inflation Volatility on Rating (Given Creditors' rights index)

\begin{tabular}{|c|c|c|c|c|c|}
\hline $\begin{array}{c}\text { (4) } \\
\text { Creditors' rights } \\
\text { Index }\end{array}$ & $\begin{array}{c}(5) \\
\text { equals (3) } \\
\text { times (4) } \\
\end{array}$ & $\begin{array}{l}\text { Total } \\
\text { Effect } \\
(2)+(5) \\
\end{array}$ & Variance & $\begin{array}{c}\text { Confidence } \\
\text { Interval }\end{array}$ & t-stat \\
\hline $\mathbf{0}$ & 0.00 & $-2.18 * *$ & 0.73 & {$[-3.85,-0.51]$} & -2.55 \\
\hline 1 & 0.33 & $-1.85 *$ & 1.15 & {$[-3.95,0.25]$} & -1.72 \\
\hline 2 & 0.67 & -1.51 & 1.73 & {$[-4.09,1.06]$} & -1.15 \\
\hline 3 & 1.00 & -1.18 & 2.47 & {$[-4.26,1.90]$} & -0.75 \\
\hline 4 & 1.33 & -0.85 & 3.37 & {$[-4.45,2.75]$} & -0.46 \\
\hline \multicolumn{2}{|c|}{ (1) Standard Deviation Of Volatility } & 0.79 & & & \\
\hline \multicolumn{2}{|c|}{ (2) Volatility Coefficient times (1) } & -2.18 & & & \\
\hline \multicolumn{2}{|c|}{ (3) Interaction Coefficient times (1) } & 0.33 & & & \\
\hline
\end{tabular}

Figure 2.6

Total Effect of a One Standard Deviation Change of Inflation Volatility on Rating (Given the Level of Creditors' Rights Index)

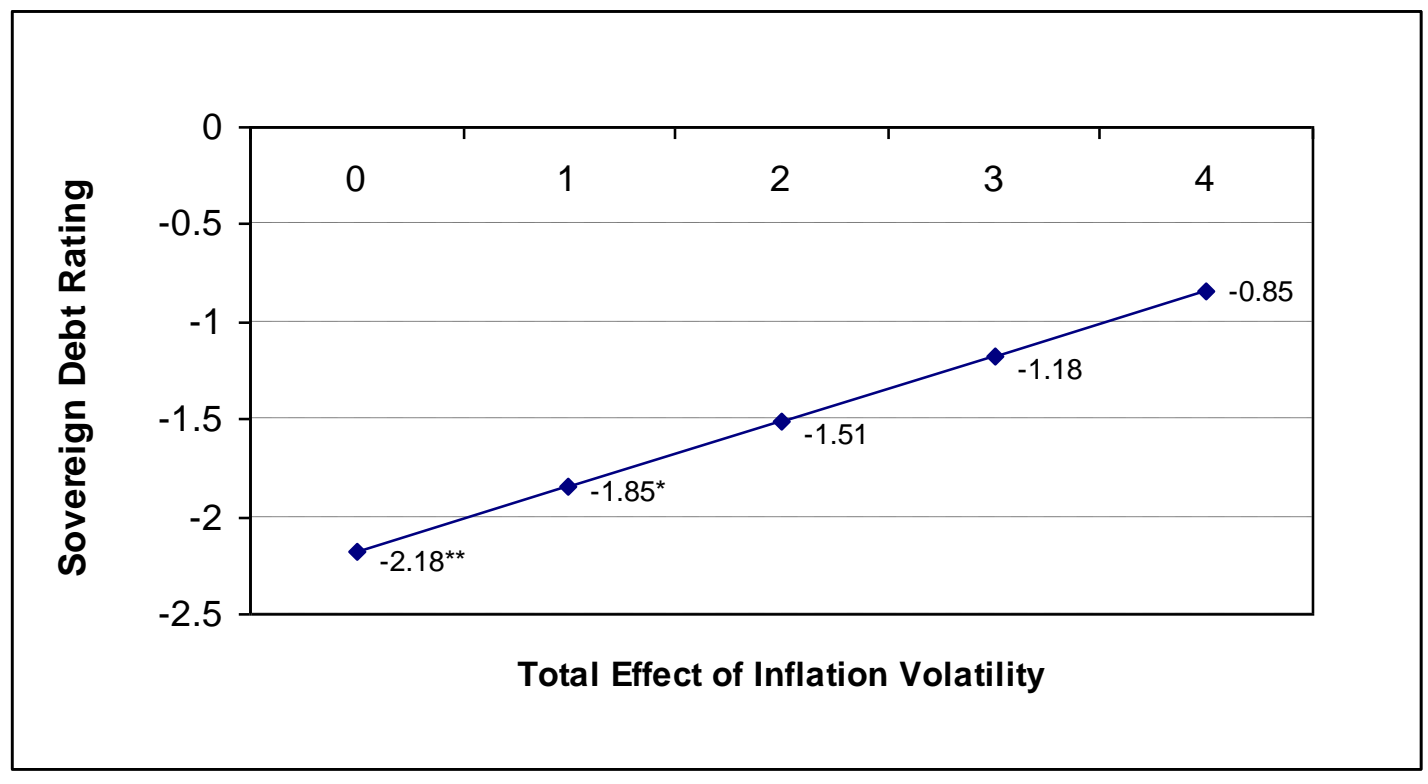


Table 2.16

Total Effect of a One Standard Deviation Change of Inflation Volatility on Rating (Given the Shareholders Rights' index)

\begin{tabular}{|c|c|c|c|c|c|}
\hline $\begin{array}{l}\text { (4) } \\
\text { Shareholders' } \\
\text { rights } \\
\text { Index } \\
\end{array}$ & $\begin{array}{c}(5) \\
\text { equals (3) } \\
\text { times (4) } \\
\end{array}$ & $\begin{array}{l}\text { Total } \\
\text { Effect } \\
(2)+(5) \\
\end{array}$ & Variance & $\begin{array}{l}\text { Confidence } \\
\text { Interval }\end{array}$ & t-stat \\
\hline 0.05 & 0.04 & $-3.26 * * *$ & 0.97 & {$[-5.19,-1.33]$} & -3.31 \\
\hline 1.1 & 0.98 & $-2.33 *$ & 1.76 & {$[-4.93,0.27]$} & -1.76 \\
\hline 2.1 & 1.86 & -1.44 & 2.85 & {$[-4.76,1.87]$} & -0.86 \\
\hline 3.05 & 2.71 & -0.61 & 4.20 & {$[-4.62,3.41]$} & -0.29 \\
\hline 4.1 & 3.64 & 0.33 & 6.02 & {$[-4.48,5.14]$} & 0.13 \\
\hline 5.1 & 4.52 & 1.22 & 8.10 & {$[-4.36,6.80]$} & 0.43 \\
\hline \multicolumn{2}{|c|}{ (1) Standard Deviation Of Volatility } & 0.79 & & & \\
\hline \multicolumn{2}{|c|}{ (2) Volatility Coefficient times (1) } & -3.31 & & & \\
\hline \multicolumn{2}{|c|}{ (3) Interaction Coefficient times (1) } & 0.89 & & & \\
\hline
\end{tabular}

Figure 2.7

Total Effect of a One Standard Deviation Change of Inflation Volatility on Rating (Given the Level of Shareholders' Rights Index)



\section{Total Effect of InIfation Volatility}

Notes: (***), (**) and (*) denotes statistical significance at the 1\%,5\% and $10 \%$ levels respectively. 
Table 2.17

Total Effect of a One Standard Deviation Change of Inflation Volatility on Rating (Given the Enforcement' index)

\begin{tabular}{|c|c|c|c|c|c|}
\hline $\begin{array}{c}(4) \\
\text { Enforcement } \\
\text { Index } \\
\end{array}$ & $\begin{array}{c}(5) \\
\text { equals }(3) \\
\text { times (4) } \\
\end{array}$ & $\begin{array}{l}\text { Total } \\
\text { Effect } \\
(2)+(5) \\
\end{array}$ & Variance & $\begin{array}{l}\text { Confidence } \\
\text { Interval }\end{array}$ & t-stat \\
\hline 4.87 & 4.86 & -4.64 & 18.33 & {$[-13.03,3.75]$} & -1.08 \\
\hline 6.20 & 6.18 & -3.31 & 22.16 & {$[-12.54,5.91]$} & -0.70 \\
\hline 7.65 & 7.63 & -1.87 & 26.76 & {$[-12.01,8.27]$} & -0.36 \\
\hline 9.34 & 9.31 & -0.18 & 32.68 & {$[-11.39,11.02]$} & -0.03 \\
\hline 9.71 & 9.68 & 0.19 & 34.05 & {$[-11.25,11.62]$} & $\mathbf{0 . 0 3}$ \\
\hline 9.99 & 9.96 & 0.46 & 35.11 & {$[-11.15,12.08]$} & 0.08 \\
\hline \multicolumn{2}{|c|}{ (1) Standard Deviation Of Volatility } & 0.79 & & & \\
\hline \multicolumn{2}{|c|}{ (2) Volatility Coefficient times (1) } & -9.49 & & & \\
\hline \multicolumn{2}{|c|}{ (3) Interaction Coefficient times (1) } & 1.00 & & & \\
\hline
\end{tabular}

Figure 2.8

Total Effect of a One Standard Deviation Change of Inflation Volatility on Rating (Given the Level of Enforcement Index)

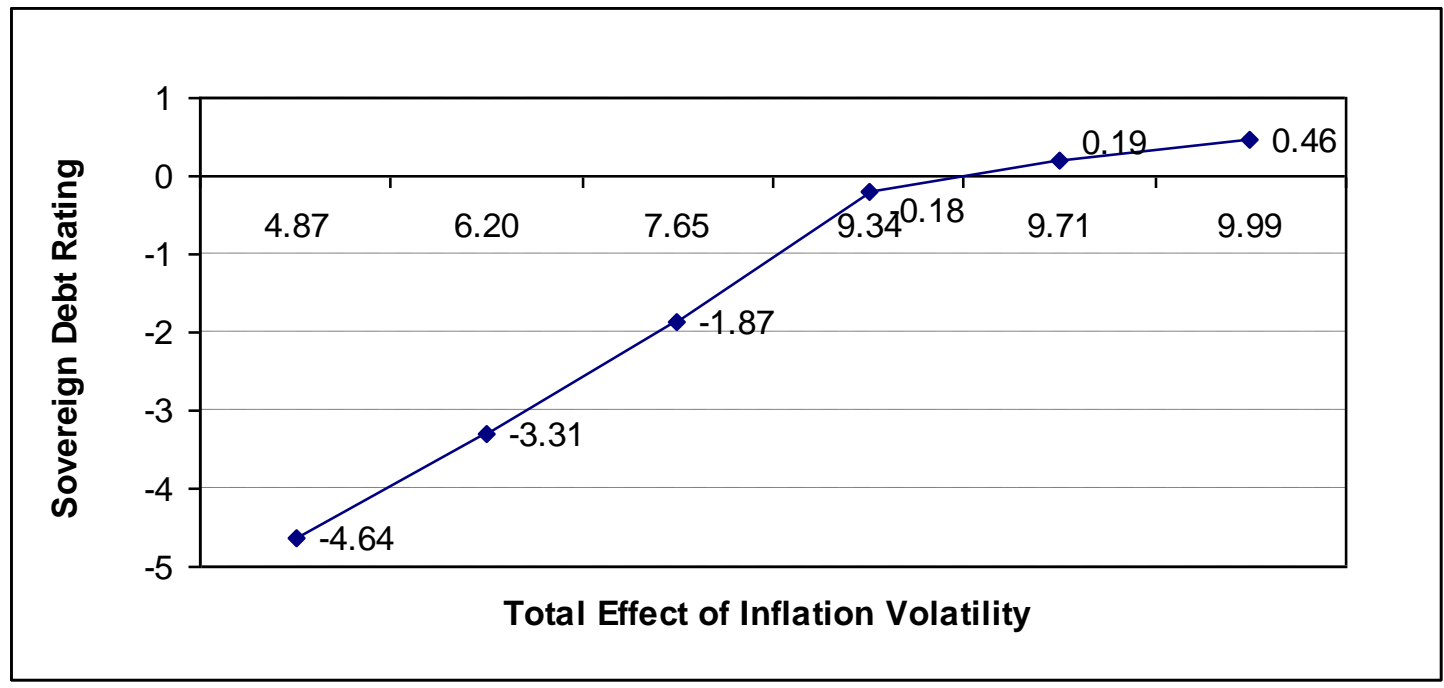

Notes: (***), (**) and $(*)$ denotes statistical significance at the 1\%, 5\% and $10 \%$ levels respectively. 
Table 2.18

Total Effect of a One Standard Deviation Change of Inflation Volatility on Rating (Given the Accounts' index)

\begin{tabular}{|c|c|c|c|c|c|}
\hline $\begin{array}{l}\text { (4) } \\
\text { Accounts } \\
\text { Index } \\
\end{array}$ & $\begin{array}{c}(5) \\
\text { equals (3) } \\
\text { times (4) } \\
\end{array}$ & $\begin{array}{c}\text { Total } \\
\text { Effect } \\
(2)+(5) \\
\end{array}$ & Variance & $\begin{array}{l}\text { Confidence } \\
\text { Interval }\end{array}$ & t-stat \\
\hline 24 & 0.45 & -2.01 & 2.72 & {$[-5.24,1.22]$} & -1.22 \\
\hline 52 & 0.98 & -1.49 & 4.46 & {$[-5.62,2.65]$} & -0.70 \\
\hline 62 & 1.16 & -1.30 & 5.20 & {$[-5.76,3.16]$} & -0.57 \\
\hline 65 & 1.22 & -1.24 & 5.43 & {$[-5.81,3.32]$} & -0.53 \\
\hline 74 & 1.39 & -1.07 & 6.16 & {$[-5.93,3.79]$} & -0.43 \\
\hline 83 & 1.56 & -0.91 & 6.94 & {$[-6.06,4.25]$} & -0.34 \\
\hline \multicolumn{2}{|c|}{ (1) Standard Deviation Of Volatility } & 0.79 & & & \\
\hline \multicolumn{2}{|c|}{ (2) Volatility Coefficient times (1) } & -2.46 & & & \\
\hline \multicolumn{2}{|c|}{ (3) Interaction Coefficient times (1) } & 0.02 & & & \\
\hline
\end{tabular}

Figure 2.9

Total Effect of a One Standard Deviation Change of Inflation Volatility on Rating (Given the Level of Accounts Index)



Notes: (***), (**) and $(*)$ denotes statistical significance at the 1\%, 5\% and $10 \%$ levels respectively. 
Table 2.19

Definition of Moody's Sovereign debt rating

\begin{tabular}{|c|c|c|}
\hline \multirow{13}{*}{ Investment Grade } & $\begin{array}{c}\text { Moody's } \\
\text { Rating }\end{array}$ & Classification \\
\hline & 23 & Aaa \\
\hline & 22 & Aa1 \\
\hline & 21 & Aa2 \\
\hline & 20 & Aa3 \\
\hline & 19 & Aa \\
\hline & 18 & A1 \\
\hline & 17 & A2 \\
\hline & 16 & A3 \\
\hline & 15 & $\mathbf{A}$ \\
\hline & 14 & Baa1 \\
\hline & 13 & Baa2 \\
\hline & 12 & Baa3 \\
\hline \multirow[t]{11}{*}{$\underline{\text { Speculative Grade }}$} & 11 & Ba1 \\
\hline & 10 & Ba2 \\
\hline & 9 & Ba3 \\
\hline & 8 & B1 \\
\hline & 7 & B2 \\
\hline & 6 & B3 \\
\hline & 5 & Caa1 \\
\hline & 4 & Caa2 \\
\hline & 3 & Caa3 \\
\hline & 2 & $\mathbf{C a}$ \\
\hline & 1 & $\mathbf{C}$ \\
\hline
\end{tabular}


Table 2.20: Annual Yield in 2000 (first quarter) And Moody's rating in 2000

\begin{tabular}{|c|c|c|c|}
\hline Country & Yield & Rating & Average Yield \\
\hline \multirow{12}{*}{$\begin{array}{l}\text { Australia } \\
\text { Austria } \\
\text { Denmark } \\
\text { Finland } \\
\text { France } \\
\text { Germany } \\
\text { Ireland } \\
\text { Netherlands } \\
\text { Norway } \\
\text { Switzerland } \\
\text { U.K } \\
\text { U.S } \\
\end{array}$} & 6.40 & 23 & \multirow[b]{12}{*}{5.30} \\
\hline & 5.46 & 23 & \\
\hline & 5.39 & 23 & \\
\hline & 4.91 & 23 & \\
\hline & 4.96 & 23 & \\
\hline & 4.86 & 23 & \\
\hline & 5.06 & 23 & \\
\hline & 5.03 & 23 & \\
\hline & 6.18 & 23 & \\
\hline & 4.18 & 23 & \\
\hline & 5.86 & 23 & \\
\hline & 5.88 & 23 & \\
\hline \multirow{5}{*}{$\begin{array}{l}\text { Belgium } \\
\text { Canada } \\
\text { Japan } \\
\text { Singapore } \\
\text { Sweden } \\
\end{array}$} & 5.09 & 22 & \multirow[b]{5}{*}{4.37} \\
\hline & 6.07 & 22 & \\
\hline & 1.07 & 22 & \\
\hline & 3.72 & 22 & \\
\hline & 5.32 & 22 & \\
\hline \multirow{3}{*}{$\begin{array}{l}\text { New Zealand } \\
\text { Portugal } \\
\text { Spain } \\
\end{array}$} & 7.02 & 21 & \multirow[b]{3}{*}{5.86} \\
\hline & 5.25 & 21 & \\
\hline & 5.09 & 21 & \\
\hline \multirow{2}{*}{$\begin{array}{l}\text { Iceland } \\
\text { Italy } \\
\end{array}$} & 10.50 & 20 & \multirow[b]{2}{*}{7.80} \\
\hline & 5.04 & 20 & \\
\hline Czech Republic & 6.11 & 18 & 6.11 \\
\hline \multirow{4}{*}{$\begin{array}{l}\text { Botswana } \\
\text { Cyprus } \\
\text { Greece } \\
\text { Israel } \\
\end{array}$} & 8.00 & 17 & \multirow[b]{4}{*}{6.87} \\
\hline & 7.35 & 17 & \\
\hline & 6.03 & 17 & \\
\hline & 5.60 & 17 & \\
\hline \multirow{3}{*}{$\begin{array}{l}\text { Hong Kong } \\
\text { Hungary } \\
\text { Malta } \\
\end{array}$} & 6.90 & 16 & \multirow[b]{3}{*}{6.85} \\
\hline & 8.33 & 16 & \\
\hline & 5.33 & 16 & \\
\hline \multirow{3}{*}{$\begin{array}{l}\text { Chile } \\
\text { Estonia } \\
\text { Poland } \\
\end{array}$} & 5.90 & 14 & \multirow[b]{3}{*}{7.81} \\
\hline & 10.82 & 14 & \\
\hline & 6.70 & 14 & \\
\hline \multirow{3}{*}{$\begin{array}{l}\text { Korea } \\
\text { Latvia } \\
\text { Malaysia }\end{array}$} & 9.54 & 13 & \multirow[b]{3}{*}{7.94} \\
\hline & 9.13 & 13 & \\
\hline & 5.15 & 13 & \\
\hline
\end{tabular}

Source: Global Finance for the annual yield data 
Table 2.20: (Continued)

Annual Yield in 2000 (first quarter)

And Moody's rating in 2000

\begin{tabular}{|c|c|c|c|}
\hline Country & Yield & Rating & Average Yield \\
\hline \multirow{3}{*}{$\begin{array}{l}\text { Mexico } \\
\text { South Africa } \\
\text { Thailand } \\
\end{array}$} & 17.40 & 12 & \multirow[b]{3}{*}{12.21} \\
\hline & 13.57 & 12 & \\
\hline & 5.67 & 12 & \\
\hline \multirow{4}{*}{$\begin{array}{l}\text { Lithuania } \\
\text { Morocco } \\
\text { Philippines } \\
\text { Slovak Republic }\end{array}$} & 11.62 & 11 & \multirow[b]{4}{*}{9.89} \\
\hline & 5.80 & 11 & \\
\hline & 13.50 & 11 & \\
\hline & 8.64 & 11 & \\
\hline \multirow{3}{*}{$\begin{array}{l}\text { Colombia } \\
\text { Fiji } \\
\text { India } \\
\end{array}$} & 18.00 & 10 & \multirow[b]{3}{*}{11.53} \\
\hline & 5.26 & 10 & \\
\hline & 11.32 & 10 & \\
\hline \multirow{3}{*}{$\begin{array}{l}\text { Jamaica } \\
\text { Jordan } \\
\text { Peru } \\
\end{array}$} & 24.75 & 9 & \multirow[b]{3}{*}{14.32} \\
\hline & 7.00 & 9 & \\
\hline & 11.21 & 9 & \\
\hline \multirow{5}{*}{$\begin{array}{l}\text { Argentina } \\
\text { Brazil } \\
\text { Kazakhstan } \\
\text { Lebanon } \\
\text { Turkey }\end{array}$} & 9.73 & 8 & \multirow[b]{5}{*}{8.97} \\
\hline & 11.31 & 8 & \\
\hline & 9.98 & 8 & \\
\hline & 8.99 & 8 & \\
\hline & 4.87 & 8 & \\
\hline \multirow{3}{*}{$\begin{array}{l}\text { Bulgaria } \\
\text { Honduras } \\
\text { Venezuela } \\
\end{array}$} & 9.31 & 7 & \multirow[b]{3}{*}{14.96} \\
\hline & 14.16 & 7 & \\
\hline & 21.42 & 7 & \\
\hline Indonesia & 11.48 & 6 & \\
\hline \multirow{2}{*}{$\begin{array}{l}\text { Ecuador } \\
\text { Pakistan }\end{array}$} & 13.66 & 5 & \multirow[b]{2}{*}{13.82} \\
\hline & 13.98 & 5 & \\
\hline
\end{tabular}

Source: Global Finance for the annual yield data 


\section{(b) Robustness Check on the LEGAL2 index}

As mentioned in the data section of chapter two, the Chinn and Ito (2005) LEGAL2 index was estimated using the principal component analysis of four indices including the protection of creditors' rights, the protection of shareholders' rights, the transparency of companies' accounts, and the enforcement of laws. The data on these four sub-indices were collected from La Porta et al. (1998).

One major weakness of using the LEGAL2 index is its time invariability over the period of the study (1989-2006). In order to check on the robustness of the results from using the time invariant LEGAL2, the Chinn and Ito (2005) LEGAL1 index was estimated using the principal component analysis of three time variant indices namely Bureaucracy, Corruption, and Law \& Order. The data on these three sub-indices were collected from the International Country Risk Guide (ICRG).

By calculating the correlation between the time invariant LEGAL2 index and the time variant LEGAL1 index, the results are shown in Table 2.21 below. As obvious from this table, there exist a high positive correlation of 0.83 between the measure of financial institutions, LEGAL2, and the measure of legal institutions, LEGAL1. Also, Figure 2.10 below depicts this positive correlation between the two variables. This result is intuitive, as it is expected that a country with well developed legal institutions will also maintain a well developed level of financial institutions.

Table 2.21

Correlation Matrix Between

LEGAL1 and LEGAL2

\begin{tabular}{|c|c|c|}
\hline & LEGAL1 & LEGAL2 \\
\hline LEGAL1 & 1 & 0.84 \\
\hline LEGAL2 & 0.84 & 1 \\
\hline
\end{tabular}


Figure 2.10

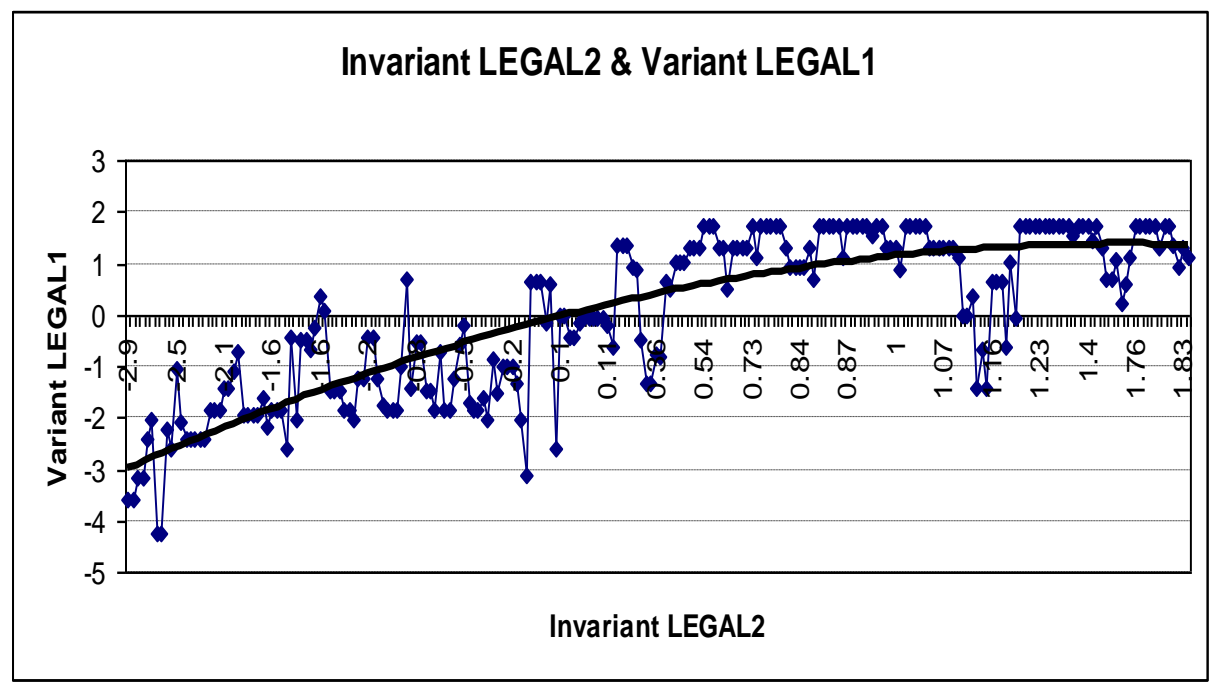

Because of this high correlation between the two measures, it will then be possible to use the LEGAL1 index in the model and run the regressions to check on the significance and magnitudes of the pre-estimated coefficients using LEGAL2 index. If there are no big changes in the estimated coefficients when using LEGAL1, it could be then concluded that the previous results were robust to the use of the time invariant LEGAL2 index.

By re-estimating the $6^{\text {th }}$ to the $8^{\text {th }}$ Column of Table 2.4 using the LEGAL1 index instead of the LEGAL2, the results are shown in Table 2.4' below. Comparing the results of Table 2.4 in the chapter with Table 2.4 ' below, it is obvious that the results of the estimated coefficients did not change much in terms of statistical significance, signs, and magnitudes. Also, the general conclusions are the same. The LEGAL1 index will help to reduce the negative impacts of the increase in inflation volatility on sovereign debt rating. ${ }^{26}$

\footnotetext{
${ }^{26}$ Same conclusions were reached by using the Panel Least Squares regression for estimating the impact of the LEGAL1 index instead of the LEGAL2 index.
} 
Table 2.4' Sovereign debt rating and Inflation Volatility Cross-country panel data consists of non-overlapping 3-year averages spanning 1989-2006.

Dependent variable: Sovereign debt rating.

Estimation Method: TSLS with Regional Dummies and Period Fixed Effects.

\begin{tabular}{llll}
\hline & {$[6]$} & {$[7]$} & {$[8]$} \\
\hline Constant & 4.98 & 1.13 & 4.73 \\
Lagged rating & $0.35 * * *$ & $0.38 * * *$ & $0.34 * * *$ \\
Inflation & -0.03 & -0.02 & -0.01 \\
Inflation volatility & $-1.29 *$ & $-1.52 * * *$ & $-1.25 * *$ \\
Domestic Credit/GDP & -0.001 & -0.004 & -0.002 \\
Log per capita GDP & $1.93 * * *$ & $2.96 * * *$ & $2.11 * * *$ \\
LEGAL1 & $0.97 * * *$ & & $0.76 * * *$ \\
Interaction of & & $1.81 * * *$ & $0.81 * *$ \\
Volatility \& LEGAL1 & & & \\
Dummy Latin & -1.27 & -1.27 & $-1.21 * *$ \\
Dummy & -1.20 & -1.20 & -1.34 \\
Africa/Middle-East & & & \\
Dummy Asian & -1.28 & -1.28 & -0.83 \\
Countries/Observations & $34 / 165$ & $34 / 165$ & $34 / 165$ \\
Adjusted R-squared & 0.893 & 0.888 & 0.898 \\
\hline J-Statistic / & 9.37 & 17.41 & 7.16 \\
Sargan P-value & $(0.95)$ & $(0.50)$ & $(0.99)$ \\
\hline Notes: (***), (**) and $(*)$ denotes statistical significance at the $1 \%, 5 \%$ and 10\% \\
levels respectively. & & &
\end{tabular}

In addition, the calculations of the total effect of a one standard deviation drop in the $\log$ of inflation volatility and the total effect of a one standard deviation increase in the LEGAL2 index can be compared with the same total effects using the time variant LEGAL1 index instead. Comparing Table 2.6 in the chapter with Table 2.6 " below, it is obvious that in using the time variant LEGAL1 the magnitudes are bigger, where the total effect of a one standard deviation decrease in the log of inflation volatility will lead to about four classifications increase in the sovereign debt rating for countries on the $40^{\text {th }}$ percentile of the LEGAL1 index and to which Mexico belongs. Worth noting that since the LEGAL1 index is time variant, a period has been chosen to calculate the total effect. The period was chosen randomly to be the second period (1992-1994). 
Table 2.6" Total Effect of a One Standard Deviation Change in Inflation Volatility on Sovereign debt rating (Given the time variant LEGAL1 index)

\begin{tabular}{|c|c|c|c|c|c|}
\hline $\begin{array}{l}\text { (4) } \\
\text { L1 } \\
\text { Index }\end{array}$ & $\begin{array}{c}(5) \\
\text { equals }(3) \\
\text { times }(4)\end{array}$ & $\begin{array}{c}\text { Total } \\
\text { Effect } \\
(2)+(5)\end{array}$ & Variance & $\begin{array}{l}\text { Confidence } \\
\text { Interval }\end{array}$ & t-stat \\
\hline-4.23 & -6.02 & $-7.21 * * *$ & 4.62 & {$[-11.43,-3.00]$} & -3.35 \\
\hline-3.04 & -4.32 & $-5.52 * * *$ & 2.29 & {$[-8.48,-2.55]$} & -3.65 \\
\hline-1.84 & -2.62 & $-3.82 * * *$ & 0.83 & {$[-5.60,-2.03]$} & -4.19 \\
\hline-0.65 & -0.93 & $-2.12 * * *$ & 0.26 & {$[-3.11,-1.13]$} & -4.20 \\
\hline 0.54 & 0.77 & -0.43 & 0.56 & {$[-1.89,1.04]$} & -0.57 \\
\hline 1.73 & 2.47 & 1.27 & 1.75 & {$[-1.32,3.86]$} & 0.96 \\
\hline \multicolumn{2}{|c|}{ (1) Standard Deviation Of Volatility } & 0.79 & & & \\
\hline \multicolumn{2}{|c|}{ (2) Volatility Coefficient times (1) } & -1.19 & & & \\
\hline \multicolumn{2}{|c|}{ (3) Interaction Coefficient times (1) } & 1.42 & & & \\
\hline
\end{tabular}

In addition to the above analysis, the total effect of a one standard deviation increase in the LEGAL2 index versus a one standard deviation increase in the LEGAL1 index were compared.

Table 2.8", Total Effect of a One Standard Deviation Change in the Time Variant LEGAL1 index on Sovereign Debt Rating (Given Inflation Volatility)

\begin{tabular}{|c|c|c|c|c|c|}
\hline $\begin{array}{c}(4) \\
\text { Volatility } \\
\text { Percentiles }\end{array}$ & $\begin{array}{c}(5) \\
\text { equals (3) } \\
\text { times (4) } \\
\end{array}$ & $\begin{array}{l}\text { Total } \\
\text { Effect } \\
(2)+(5) \\
\end{array}$ & Variance & $\begin{array}{c}\text { Confidence } \\
\text { Interval }\end{array}$ & t-stat \\
\hline 0.02 & 0.03 & $1.20 * * *$ & 0.08 & {$[0.66,1.74]$} & 4.38 \\
\hline 0.08 & 0.10 & $1.28 * * *$ & 0.07 & {$[0.77,1.78]$} & 4.97 \\
\hline 0.22 & 0.28 & $1.45^{* * * *}$ & 0.05 & {$[1.02,1.89]$} & 6.49 \\
\hline 0.37 & 0.47 & $1.64 * * *$ & 0.04 & {$[1.24,2.05]$} & 7.94 \\
\hline 0.70 & 0.88 & $2.06 * * *$ & 0.06 & {$[1.57,2.55]$} & 8.28 \\
\hline 1.30 & 1.64 & $2.82 * * *$ & 0.22 & {$[1.90,3.74]$} & 6.00 \\
\hline 2.94 & 3.71 & $4.89^{* * * *}$ & 1.47 & {$[2.51,7.26]$} & 4.03 \\
\hline \multicolumn{2}{|c|}{ (1) Standard Deviation Of LEGAL1 } & 1.55 & & & \\
\hline \multicolumn{2}{|c|}{ (2) LEGAL1 Coefficient times (1) } & 1.18 & & & \\
\hline \multicolumn{2}{|c|}{ (3) Interaction Coefficient times (1) } & 1.26 & & & \\
\hline
\end{tabular}


Comparing Table 2.8 in the chapter with Table $2.8^{\prime}$ ', it can be concluded that the results for the case of Mexico were again higher as was the case with Tables 2.6 and 2.6' above. This results actually works in favor of institutions, where the results from using a time variant variable to represent the impact of institutions gives bigger magnitudes as compared with the case of using a time invariant variable.

Based on the above analysis, it can concluded that the results using the time invariant LEGAL2 index were smaller as compared with the results of using the time variant LEGAL1 index. Accordingly it can be concluded that this robustness check confirmed the importance of direct and the indirect (through its impact on inflation volatility) effects of institutions on sovereign debt rating. 


\section{Appendix (III)}

\subsection{Barro and Sala-i-Martin (1995) Model: The Welfare Implications of the Reduction in Inflation Volatility and the Improvement in Institutions}

Using the neoclassical one-sector growth model of Barro and Sala-i-Martin (1995), this section quantifies the welfare impacts of the exogenous drop in the cost of borrowing faced by a developing country like Mexico; a country that by the measure used in this chapter has poor financial institutions and moderately high inflation volatility. The Barro et al. (1995) model is an open economy model but with neither foreign bonds nor trade sector. The goal is to show that a model with these specifications will produce larger welfare impacts for any decrease in the standard deviation of the log of inflation volatility or for any increase in the standard deviation of LEGAL2. Similar to the monetary SOE model of chapter three in order to link this theoretical model to the empirical model of chapter two, it is assumed that the drop in the cost of borrowings is due to the increase in sovereign debt rating, which is in turn due to a one standard deviation decrease in the log of inflation volatility estimated in Section 2.6.1 or to a one standard deviation increase in the LEGAL2 index estimated in Section 2.6.2 of chapter two.

Assuming that the model has a simple consumer who does not do any discounting over time or that there is no time preference, the production function will then be of the following form;

$$
Y_{t}=K_{t}^{\alpha} H_{t}^{\theta}\left(A_{t} L_{t}^{1-\alpha-\theta}\right)
$$

where; 


$$
\begin{aligned}
& L_{t}=L_{t-1}(1+n), \\
& A_{t}=A_{t-1}(1+g), \\
& L_{0}=I .
\end{aligned}
$$

And where $\alpha<1, \theta<1$ and $A_{t}$ is the productivity index that grows at rate $\mathrm{g}$.

A representative firm will then maximize the following profit function;

$$
\Pi_{t}=Y_{t}-w_{t} L_{t}-\left(r+\delta_{k}\right) k_{t}-\left(q+\delta_{h}\right) H_{t},
$$

where $w_{t}$ refers to the wage rate, $r$ is the rental rate for physical capital, $q_{t}$ is the return to human capital, $\delta_{k}$ and $\delta_{H}$ are the depreciation of physical and human capital respectively.

Taking the first order condition of the profit function of Equation (3.15) with respect to physical capital, the following equality can be found;

$$
\alpha \frac{Y_{t}}{K_{t}}=r+\delta_{k}
$$

Solving Equation (3.16) above for the physical capital, the following equality can be found;

$$
k_{t}=\left(\frac{\alpha}{r+\delta_{k}}\right) y_{t} \text {. }
$$

By substituting Equation (3.17) into Equation (3.14) above, we get an equation in which output is a function of human capital and labor plus other parameters as shown in Equation (3.18) below;

$$
Y_{t}=\left(\frac{\alpha}{r+\delta_{k}}\right)^{\frac{\alpha}{1-\alpha}} H_{t}^{\frac{\theta}{1-\alpha}}\left(A_{t} L_{t}\right)^{\frac{1-\alpha-\theta}{1-\alpha}}
$$


Following Barro et al. (1995) and Landon-Lane et al. (2008), it is assumed that agents in the economy can use the physical capital that they have as a form of collateral for borrowing in the international market. The interest that they pay for their borrowings is assumed to be equal to $r$. Accordingly, the accumulation of human capital is done through domestic savings. Where agents save a fixed portion of their net income to accumulate human capital as follows;

$$
H_{t+1}=\left(1-\delta_{h}\right) H_{t}+s\left(Y_{t}-\left(r+\delta_{k}\right) k_{t}\right)
$$

where $i_{t}$ refers to the amount invested in period $\mathrm{t}$, and which is equal to the gross investment rate $s$ times the agent's net income $\left(Y_{t}-\left(r+\delta_{k}\right) k_{t}\right)$.

It is important to note that the cost of borrowing $r$ is defined to be equal to $\bar{r}+\rho$ , where $\bar{r}$ is the world interest rate, and $\rho$ is the premium. For a small country, the world interest rate is given which means it cannot affect $\bar{r}$. Also, although the premium is a function of the country's rating which is in turn a function of either a reduction in inflation volatility or an enhancement in the country's institutions (as was shown in section four of chapter two), it cannot affect the premium for each rating class set by the rating agency. A country can do its best in terms of setting its financial institutions or monetary policies right but then the final decision of upgrading the rating of such a country will depends on the rating agency's decision. In that sense, $r$ is assumed to be exogenously determined.

Since from Equation (3.16) it was found that $\left(r+\delta_{k}\right) k_{t}=\alpha Y_{t}$, by substituting this result into Equation (3.19) above, the human capital accumulation equation becomes;

$$
H_{t+1}=\left(1-\delta_{h}\right) H_{t}+s(1-\alpha) Y_{t} .
$$


Now along the balanced growth path, $h_{t} \equiv \frac{H_{t}}{A_{t} L_{t}}$ and $y_{t} \equiv \frac{Y_{t}}{A_{t} L_{t}}$ are constant, $i_{t}$ and $Y_{t}$ are growing at the same rate $(1+\mathrm{n})(1+\mathrm{g})$, dividing Equation (3.18) by $A_{t} L_{t}$ we get;

$$
\frac{Y_{t}}{A_{t} L_{t}}=\left(\frac{\alpha}{r+\delta_{k}}\right)^{\frac{\alpha}{1-\alpha}} H_{t}^{\frac{\theta}{1-\alpha}}
$$

Substituting the definitions of $y_{t}$ and $h_{t}$ into Equation (3.21) above, the following equation for output per worker is found;

$$
y_{t}=\left(\frac{\alpha}{r+\delta_{k}}\right)^{\frac{\alpha}{1-\alpha}} h_{t}^{\frac{\theta}{1-\alpha}} .
$$

Also, dividing Equation (3.20) above through by $H_{t}$ we get;

$$
\begin{aligned}
& \frac{H_{t+1}}{H_{t}}=\left(1-\delta_{h}\right) \frac{H_{t}}{H_{t}}+s(1-\alpha) \frac{Y_{t}}{H_{t}}, \\
\Rightarrow & (1+g)(1+n)=\left(1-\delta_{h}\right) \frac{H_{t}}{H_{t}}+s(1-\alpha)\left(\left(\frac{\alpha}{r+\delta_{k}}\right)^{\frac{\alpha}{1-\alpha}} \frac{H_{t}^{\frac{\theta}{1-\alpha}}}{H_{t}}\left(A_{t} L_{t}\right)^{\frac{1-\alpha-\theta}{1-\alpha}}\right), \\
\Rightarrow & (1+g)(1+n)=\left(1-\delta_{h}\right) \frac{H_{t}}{H_{t}}+s(1-\alpha)\left(\left(\frac{\alpha}{r+\delta_{k}}\right)^{\frac{\alpha}{1-\alpha}}\left(\frac{H_{t}}{A_{t} L_{t}}\right)^{\frac{\theta}{1-\alpha}-1}\right) .
\end{aligned}
$$

Substituting for $\frac{H_{t}}{A_{t} L_{t}}=h_{t}$ in Equation (3.23) above and solving for $h_{t}^{*}$ which represents the value of the balanced growth path of human capital as a function of the parameters of the model; 


$$
h^{*}=\left[\frac{(1+g)(1+n)-\left(1-\delta_{h}\right)}{s(1-\alpha)\left(\frac{\alpha}{r+\delta_{k}}\right)^{\frac{\alpha}{1-\alpha}}}\right]^{\frac{1-\alpha}{\theta+\alpha-1}} .
$$

Based on the above, the model consists of a set of variables $h^{*}, k^{*}, y^{*}, r, s, i^{*}$, and a set of parameters $n, g, \delta_{k}, \delta_{h}, \alpha, \theta$, and $A_{0}$. Using these variables and parameters, the "Welfare Effect" of a one standard deviation decrease in the log of inflation volatility versus a one standard deviation increase in the LEGAL2 index will be theoretically quantified. The welfare gain is defined as the increase in the ratio $\frac{y^{* \prime}}{y^{*}}$, where $y^{* \prime}$ refers to the new steady state value of output per worker as a ratio to its initial steady state level $y^{*}$.

In order to quantify and compare the welfare impact of reducing inflation volatility versus the welfare impact of enhancing institutions, an experiment will be undertaken for the decrease in the cost of borrowing " $r$ " faced by an economy that is due to the increase in sovereign debt rating, which is in turn due to either the reduction in inflation volatility or to the enhancement in institutions or both.

Adding the parameter $\tau$ to the model above, Equation (3.14) becomes;

$$
Y_{t}=(1-\tau) K_{t}^{\alpha} H_{t}^{\theta}\left(A_{t} L_{t}^{1-\alpha-\theta}\right)
$$

The steady state value of physical capital per worker becomes;

$$
k^{*}=\left(\frac{\alpha}{r+\delta_{k}}\right) y^{*} .
$$


The steady state value of output per worker of Equation (3.19) becomes;

$$
y^{*}=(1-\tau)^{\frac{1}{1-\alpha}}\left(\frac{\alpha}{r+\delta_{k}}\right)^{\frac{\alpha}{1-\alpha}} h^{* \frac{\theta}{1-\alpha}} .
$$

Finally the balanced growth path value of human capital per worker becomes;

$$
\left.h^{*}=\left[\frac{(1+g)(1+n)-\left(1-\delta_{h}\right)}{s(1-\alpha)\left[(1-\tau)^{\frac{1}{1-\alpha}}\left(\frac{\alpha}{r+\delta_{k}}\right)^{\frac{\alpha}{1-\alpha}}\right]}\right]\right]^{\frac{1-\alpha}{\theta+\alpha-1}} .
$$

A shock to the economy, such as an exogenous decrease in the cost of borrowing facing an economy, $r$ will increase the steady state level of $h^{*}$ in Equation (3.24') and will in turn lead to a new steady state level of output per worker in Equation (3.22'). This new steady state level of output per worker will in turn lead to a new steady state of physical capital per worker of Equation (3.15').

Based on the above presentation of the model, the study runs three experiments on the welfare impacts of; a reduction in the average long-term bond yield given the level of institutions, an improvement in institutions given the level of the average long-term bond yield, and finally a reduction in the average long-term bond yield coupled with an improvement in institutions. 


\subsubsection{Calibration}

Table 3.5 below reports the calibrated values of the parameters used in simulating the neoclassical one-sector growth model of Barro et al. (1995). Following Landon-Lane et al. (2008), the values of the income share of physical capital and income share for human capital were taken from Mankiw (1992) as $\alpha=0.33$ and $\theta=0.33$ respectively. The value for the depreciation of physical capital, $\delta_{k}=0.03$, is taken from Aguiar and Gopinath (2004). The value of the depreciation of human capital, $\delta_{h}=0.01$, is taken from Davis and Whalley (1998). The long run productivity growth rate, $\mathrm{g}=0.02$, is taken from Prescott (1998). The rate of population growth, $\mathrm{n}=0.023$, is calculated from the Mexican data. The gross saving rate, $s=0.195$, is calculated from the Mexican data as the average of the gross saving rate as a ratio to GDP over the period of the study (1989-2006). Finally, the values for the parameter $\tau$ were assumed values as explained previously in chapter three.

Table 3.5 Values of the Calibrated Parameters for Mexico

\begin{tabular}{|c|l|l|}
\hline Parameter & Value & \multicolumn{1}{c|}{ Notes } \\
\hline$\alpha$ & 0.33 & Income share of physical capital \\
\hline$\theta$ & 0.33 & Income share of human capital \\
\hline$\delta_{k}$ & 0.03 & Depreciation of physical capital \\
\hline$\delta_{h}$ & 0.01 & Depreciation of human capital \\
\hline $\mathrm{g}$ & 0.02 & Growth rate of productivity \\
\hline $\mathrm{n}$ & 0.023 & Growth rate of labor \\
\hline$s$ & 0.195 & Gross investment rate \\
\hline$r$ & 0.1221 & Marginal Product of capital \\
\hline$\tau$ & $\begin{array}{l}0.2 \rightarrow 0.15 \\
0.15 \rightarrow 0.10 \\
0.10 \rightarrow 0.05 \\
\end{array}$ & $\begin{array}{l}\text { Assumed values for the } \\
\text { cost on the economy that } \\
\text { is due to bad institutions }\end{array}$ \\
\hline
\end{tabular}




\subsubsection{Results}

Table 3.6 below reports the results of comparing steady states of the Barro et al. (1995) one sector growth model using both the parameters values calibrated for Mexico and the empirical results of the total effects from Section 2.6 of chapter two. The first shaded row of Table 3.6 below shows the starting values of rating, average annual yield and the ratio of output per worker as a ratio of its initial level.

Taking the $12.21 \%$ as the starting value for $r$ and simulating the drop in $r$ form this $12.21 \%$ to $7.81 \%$ given the level of $\tau$, Table 3.6 below reports the results. As shown in this Table, the drop in the cost of borrowing from $12.21 \%$ to $7.81 \%$, will lead to an increase in the steady state value of output by worker by about $21 \%$.

Table 3.6

The Effect of the Drop in $\mathbf{r}$ (holding $\tau$ at 0.20 ) on the New Steady State of Output per Worker (as a ratio to its initial level)

\begin{tabular}{|c|c|c|}
\hline $\begin{array}{c}\text { (1) } \\
\text { Rating }\end{array}$ & $\begin{array}{c}(2) \\
\text { Average } \\
\text { Annual Yield, } r \\
(\%)\end{array}$ & $\begin{array}{c}\text { (3) } \\
\frac{y^{* \prime}}{y^{*}} \\
\tau=0.2\end{array}$ \\
\hline Baa3 = 12 & $12.21 \%$ & 1 \\
\hline Baa1 $=14$ & $7.81 \%$ & 1.21 \\
\hline
\end{tabular}

Next, a second experiment was undertaken to quantify the welfare impact of improving institutions (drop in $\tau$ ) given the level of the average annual bond yield, or the direct effect of improving institutions on economic welfare.

Table 3.7 below reports the calculation results where the value of the cost of borrowings was set at $12.21 \%$ per year (or $3.05 \%$ per quarter). For each one standard 
deviation increase in the LEGAL2 index the welfare impact of the drop in $\tau$ is calculated. For example, as can be noticed from the first row of Table 3.7, as $\tau$ drops from $20 \%$ to $15 \%$, given the level of the average annual bond yield at $3.05 \%$, the new steady state value of output per worker (as a ratio to its initial level) increases by about $20 \%$.

Table 3.7

Effect of the Drop in $\tau$ holding $r$ (at 3.05\%) on the New Steady State of Output per Worker as a ratio to its initial level

\begin{tabular}{|l|c|}
\hline \multicolumn{1}{|c|}{$\tau$} & $\frac{y^{*}}{{ }^{*}}$ \\
\hline $\mathbf{0 . 2} \rightarrow \mathbf{0 . 1 5}$ & 1.20 \\
\hline $\mathbf{0 . 1 5} \rightarrow \mathbf{0 . 1 0}$ & 1.18 \\
\hline $\mathbf{0 . 1 0} \rightarrow \mathbf{0 . 0 5}$ & 1.17 \\
\hline $\mathbf{0 . 0 5} \rightarrow \mathbf{0}$ & $\mathbf{1 . 1 6}$ \\
\hline
\end{tabular}

Further improvement in institutions, as $\tau$ drops from 0.10 to 0.05 , will lead to smaller welfare effects of only about $17 \%$. Finally, with an improvement in institutions from $\tau$ of 0.05 to $\tau$ of $0 \%$, or with reaching the best level of institutions, economic welfare increases by about $16 \%$. The results confirm the convergence hypothesis where countries with less developed institutions grow faster than those with more developed ones.

Finally, the third experiment was undertaken in order to theoretically quantify the impact of the improvement in institutions when coupled with a reduction in the average long-term bond yield, or the indirect effect of improving institutions.

From the empirical results of section 2.6.2 of chapter two, and again for the Mexico's case, a one standard deviation increase in the LEGAL2 index will lead to about one 
classification increase in rating, from Baa3 to Baa2. From the data of ratings and average annual yields, this increase is equivalent to a drop in the average annual yield from $12.21 \%$ to $7.94 \%$. Setting the initial values of $r$ at $12.21 \%$, Table 3.8 reports the results of the reduction in $r$ when coupled with a reduction in $\tau$.

Table 3.8

Effect of the Drop in $\mathbf{r}^{*}$ when coupled with a drop in $\tau$ on the New Steady State of Output per Worker (as a ratio to its initial level)

\begin{tabular}{|c|c|c|c|c|c|}
\hline $\begin{array}{c}\text { (1) } \\
\text { Rating }\end{array}$ & $\begin{array}{c}\text { (2) } \\
\text { Average Long- } \\
\text { Term Annual } \\
\text { Yield } \\
r \\
(\%)\end{array}$ & $\begin{array}{c}\stackrel{(3)}{y^{* \prime}} \text { With } \\
\frac{y^{*}}{\text { improvement in }} \\
\tau \\
\text { from } 0.20 \text { to } 0.15\end{array}$ & $\begin{array}{c}\stackrel{(4)}{y^{* \prime}} y^{*} \text { With } \\
\text { improvement in } \\
\tau \\
\text { from } 0.15 \text { to } 0.10\end{array}$ & $\begin{array}{c}\stackrel{(5)}{y^{* \prime}} y^{*} \text { With } \\
\text { improvement in } \\
\tau \\
\text { from } 0.10 \text { to } 0.05\end{array}$ & $\begin{array}{c}\quad(6) \\
\frac{y^{* \prime}}{y^{*}} \text { With } \\
\text { improvement in } \\
\tau \\
\text { from } 0.05 \text { to } 0\end{array}$ \\
\hline Baa3 = 12 & 12.21 & 1 & 1 & 1 & 1 \\
\hline Baa2 $=13$ & 7.94 & 1.45 & 1.44 & 1.42 & 1.41 \\
\hline
\end{tabular}

Notes: The row Baa3=12 refers to the initial starting values.

For example, reducing $r$ from $12.21 \%$ to $7.94 \%$ when coupled with a drop in $\tau$ from 0.20 to 0.15 , the new steady state of the output per worker will increase by about 45\%. Also, if the decrease in $r$ is coupled with a bigger drop in $\tau$ from 0.15 to 0.10 , the increase in new steady state of output (as a ratio to its initial level) will be about $44 \%$. Finally, if this increase in rating is coupled with a drop in $\tau$ from 0.05 to 0 , the increase in the new steady state of output relative to its initial level steady state will be equal to $41 \%$.

From the above section it can be concluded that a one standard deviation increase in the LEGAL2 index will lead to higher positive impacts on economic welfare as compared to the impact of a one standard deviation reduction in the log of inflation volatility. 
Accordingly, it can be concluded that for a country like Mexico characterized by relatively bad institutions and relatively high inflation volatility, it is better for this country to concentrate first on improving its financial institutions which leads to an increase in output by at least $41 \%$, while reducing inflation volatility leads to increasing output by only $21 \%$. These welfare results are much higher than the welfare results of the monetary Small Open Economy of chapter three, where households had the option to buy foreign bonds or trade with the rest of the world to smooth out their consumption over time and the economy will then be less vulnerable to domestic or international shocks. 


\section{Bibliography}

Acemoglu, Daron, Simon Johnson, James Robinson and Yunyong Thaicharoen (2003), "Institutional Causes, Macroeconomic Symptoms: Volatility, Crises and Growth," Journal of Monetary Economics 50, 49-123.

Ades, Alberto, Frederico Kaune, Paulo Leme, Rumi Masih, and Daniel Tenengauzer (2000), "Introducing GS-ESS: A New Framework for Assessing Fair Value in Emerging Markets Hard-Currency Debt," Global Economic Paper No. 45, Goldman Sachs, New York.

Afonso Antonio (2003), "Understanding the Determinants of Sovereign debt ratings: Evidence for the Two Leading Agencies," Journal of Finance and Economics, Vol. 27, No.1.

Adolfson, Malin, Stefan Laseen, Jesper Linde, and Mattias Villani (2004), "Bayesian Estimation of an Open Economy DSGE Model with Incomplete Pass-Through," Manuscript, Sveriges Riksbank.

Aghion Philip, Angeletos George-Marios, Banerjee Abhijit, Manova, Kalina (2005), "Volatility and Growth: Credit Constraints and Productivity Enhancing Investment," NBER WP\# 11349.

Aisen, Ari and Francisco José Veiga (2005), "The Political Economy of Seigniorage," IMF Working Paper 05/175.

Aisen, Ari and Francisco José Veiga (2006), "Does Political Instability Lead to Higher Inflation? A panel data analysis," Journal of Money, Credit and Banking, Vol. 38, No. 5, August 2006.

Alesina, Alberto and Allan Drazen (1991), "Why are Stabilizations Delayed?," American Economic Review 81(5), 1170-1188.

Alberto Chong, Mark Gradstein (2006), "Policy Volatility and Growth," Inter-American Development Bank Banco, Research Department Working Paper \#578.

Ambler, Steve, Ali Dib and N. Rebei (2004), "Optimal Taylor Rules in an Estimated Model of a Small Open Economy," Manuscript, Bank of Canada.

Andrea Bassanini, Stefano Scarpetta and Philip Hemmings (2001), "Economic Growth: The Role of Policies and Institutions - Panel data - Evidence From OECD Countries," Economic Department, W.P No. 283. 
Antonio Fatas , Ilian Mihov (2005), "Do Good Policies Promote Economic Growth? Policy Volatility, Institutions and Economic Growth," INSEAD Working Paper, Reference: 2005/76/EPS.

Arellano, Manuel and Stephen Bond (1991), "Some Tests of Specification for Panel Data: Monte Carlo Evidence and an Application of Employment Equations," Review of Economic Studies 58: 277-297.

Aron Janine (2000), "Growth and Institutions: A Review of the Evidence," The World Bank Research Observer, vol. 15, no. 1, pp. 99-135.

Arteta, Carlos, Barry Eichengreen and Charles Wyplosz (2003), "When Does Capital Account Liberalization Help More than it Hurts?" in Elhanan Helpman and Efraim Sadka, eds., Economic Policy in the International Economy, Cambridge University Press, pp. 177 - 206.

Barro, Robert and Mankiw, Gregory, and Sala-I-Martin, Xavier (1995), "Capital Mobility in Neoclassical Models of Growth," The American Economic Review, Vol. 85, No. 1, pp. 103-115.

Bhatia, Ashok (2002), "Sovereign Credit Ratings Methodology: An Evaluation," IMF, WP/02/170, October.

Barro, Robert and Sala-I Marting, Xavier (1995), "Economic Growth," McGraw Hill, Singapore.

Barro, Robert (1995), "Inflation and economic growth," mimeo, October.

Barro, Robert and Jong-Wha Lee (2000), "International Data on Educational Attainment: Updates and Implications," CID Working Paper No. 42, April.

Beck, Thorsten, Asli Demirguc-Kunt, Luc Laeven, and Ross Levine (2006), "Finance, firm size, and growth”, Mimeo. Washington, D.C.: World Bank.

Beck, Thorsten, Asli Demirgüç-Kunt, and Vojislav Maksimovic (2006), "The influence of financial and legal institutions on firm size," Journal of Banking and Finance, 30(11)

Beck, Nathaniel, and Jonathan Katz (1995), "Nuisance vs. Substance: Specifying and Estimating Time-Series Cross-Section Models," Political Analysis 6, 1-36.

Bergin, Paul (2003), "Putting the New Open Economy Macroeconomics to a Test," Journal of International Economics, 60, 3-34.

Bergin, Paul (2004), "How Well Can the New Open Economy Macroeconomics Explain the Exchange Rate and the Current Account?," Journal of International Money and Finance, 25 (5), 675-701 August. 
Betts, Caroline and Michael Devereux (2000), "Exchange rate dynamics in a model of pricing to market," Journal of International Economics, 50, 215-44.

Beyer, Andreas and Roger Farmer (2004), "On the Indeterminacy of New Keynesian Economics," ECB Working Paper, 323.

Bissoondoyal-Bheenick, Emawtee, Robert Brooks, and Angela Yip (2005), "Determinants of sovereign debt ratings: A comparison of case-based reasoning and ordered probit approaches," Monash Econometrics and Business Statistics Working Papers 9/05, Monash University, May.

Bordo, Michael and Hugh Rockoff (1996), "The Gold Standard as a .Good Housekeeping Seal of Approval," Journal of Economic History 56, 389 - 428.

Bound, John, David A. Jaeger and Regina M. Baker (1995), "Problems with Instrumental Variables Estimation When the Correlation Between the Intstruments and the Endogenous Explanatory Variables is Weak," Journal of American Statistical Association 90, p. $443-450$.

Brian, Loasby (2000), "Market Institutions and Economic Evolution," Journal of Evolutionary Economics, Vol. 10, pp-297-309.

Bruno, Michael, and William Easterly (1995), "Inflation Crises and Long-Run Growth," NBER Working Paper No. 5209.

Bullard, James and John Keating (1994), "Super Neutrality in Post War Economies," Manuscript, Federal Reserve Bank of St.Louis.

Butler, Alexander and Larry Fauver (2006), "Institutional Environment and Sovereign Credit Ratings,” Financial Management Vol. 35, No. 3, Autumn 2006.

Cailleteau, Pierre, Guido Cipriani, Kristin Lindow, Tom Byrne (2008), "Rating Methodologdy: A Guide to Moody's Sovereign Ratings," http://www.moodys.com/moodys/cust/research/MDCdocs/22/2005800000424849.pdf?do c_id=2005800000424849\&frameOfRef=corporate

Caselli, Francesco, Gerardo Esquivel and Fernando Lefort (1996), "Reopening the Convergence Debate: A New Look at Cross-Country Growth Empirics," Journal of Economic Growth 1:3, p. 363-389.

Castro, Vítor and Francisco José Veiga (2004), "Political Business Cycles and Inflation Stabilization," Economics Letters 83(1), 1-6.

Chang Roberto, kaltani Linda, and Loayza Norman (2005), “Openness Can Be Good For Growth: The Role of Policy Complementarities,” NBER Working Paper No. 11787. 
Chin Menzie and Ito Hiro (2005), "What Matters For Financial Development? Capital Controls, Institutions and Iteractions," NBER wp 11370.

Choi, Sangmok, Smith, Bruce and Boyd John (1995), "Inflation, Financial Markets and Capital Formation," Federal Reserve Bank of Minneapolis, Research Department, WP\#556.

Clark, Todd (1997), "Cross-Country Evidence on Long-Run Growth and Inflation," Economic Inquiry.

Clarida, Richard, Jordi Galy, and Mark Gertler (1999), "The Science of Monetary Policy: A New Keynesian Perspective," Journal of Economic Literature, 37, 1661-1707.

Coulson, Edward and Russell Robbins (1985), "Inflation uncertainty and real economic activities," Applied Economic Letters, volume 2 number 11.

Cukierman, Alex, Sebastian Edwards, and Guido Tabellini (1992), "Seigniorage and Political Instability,” American Economic Review 82(3), 537-555.

Catão, Luis, and Bennett Sutton, (2002), "Sovereign Defaults: The Role of Volatility," IMF Working Paper 02/149, Washington.

Cantor, Richard Martin and Packer, Frank (1996), "Determinants and Impact of Sovereign Credit Ratings," Economic Policy Review, October, Vol. 2, No 2.

Chinn Menzie and Ito Hiro (2005), "What Matters For Financial Development? Capital Controls, Institutions and Iteractions", NBER WP 11370.

Corsetti, Giancarlo and Paolo Pesenti (2001), "Welfare and Macroeconomic Interdependence," Quarterly Journal of Economics, 116, 421-445.

Cosset, Claude and Jean Roy (1991), "The Determinants of Country Risk Ratings," Journal of International Business Studies, 22: 135-142.

Coulson and Robbins (1985), "Inflation uncertainty and real economic activities," Applied Economic Letters, volume 2 number 11.

Daron Acemoglua, Simon Johnsonb, James Robinsonc, Yunyong Thaicharoen (2003), "Institutional causes, macroeconomic symptoms: volatility, crises and growth," Journal of Monetary Economics 50 49-123.

Del Negro, Marco and Frank Schorfheide (2004), "Priors from General Equilibrium Models for VAR's," International Economic Review, 45, 643-673. 
Del Negro, Marco and Frank Schorfheide (2008), "Inflation Dynamics in a Small OpenEconomy Model under Inflation Targeting: Some Evidence from Chile," Federal Reserve Bank of New York, Staff Report no. 329.

Del Negro, Marco, Frank Schorfheide, Frank Smets, and Raf Wouters (2004), "On the Fit and Forecasting Performance of New Keynesian Models," Manuscript, University of Pennsylvania.

Del Negro, Marco, and Francesc Obiols-Homs (2001), "Has Monetary Policy Been So Bad That It Is Better to Get Rid of It? The Case of Mexico," Journal of Money Credit and Banking, 33, pp. 273-297.

De Walque, Gregory and Raf Wouters (2004), "An Open Economy DSGE Model Linking the Euro Area and the U.S. Economy," Manuscript, National Bank of Belgium.

Devereux, Michael and Caroline Betts (2000), "Exchange Rate Dynamics in a Model of Pricing to Market", Journal of International Economics, 50,1 215-244.

Dib, Ali (2003), "Monetary Policy in Estimated Models of Small Open and Closed Economies," Bank of Canada Working Paper, 2003-27.

Easterly, William (2004), "National Policies and Economic Growth: A Reappraisal", mimeo NYU, available at http://www.nyu.edu/fas/institute/dri/Easterly/File/national\%20politics\%20and\%20econo mic\%20growth.pdf

Eaton, Jonathan and Mark Gersovitz (1981), "Debt with potential repudiation: theoretical and empirical analysis," Review of Economic Studies, No. 48, pages 289 -309.

Edwards, Sebastian (2001), "Capital Mobility and Economic Performance: Are Emerging Economies Different?” NBER Working Paper No. 8076, January.

Eichengreen Barry and Mody Ashoka (1998), "What Explains Changing Spreads on Emerging-Market Debt: Fundamentals or Market Sentiment?," Working Paper No. 6408, National Bureau of Economic Research, Cambridge, Massachusetts.

Eicher, Theo (1993),"Trade and Converging Growth Rates in a Model with Endogenous Human Capital and Technological Change: Dynamic Gains from Trade Reconsidered," Unpublished paper. Columbia University.

Ferguson, Niall, Moritz Schularick (2006), "The Empire Effect: The Determinants of Country Risk in the First Age of Globalization, 1880 - 1913," Journal of Economic History 66, 283 - 312.

Fernandez-Villaverde, Jesus and Juan Rubio-Ramirez (2004), "Comparing Dynamic Equilibrium Models to Data," Journal of Econometrics, 123, 153-187. 
Ferrucci Gianluigi (2003), "Empirical determinants of emerging market economies' sovereign bond spreads," Working Paper no. 205, Bank of England.

Fatás, Antonio and Ilian Mihov. (2005), "Policy Volatility, Institutions and Economic Growth,” CEPR Discussion Paper No. 5388.

Fisher, Stanley, Ratna Sahay and Carlos Végh (2002), "Modern Hyper- and High Inflations," Journal of Economic Literature XL(3), 837-880.

Fischer, Stanley (1993), "The Role of Macroeconomic Factors in Growth," Journal of Monetary Economics, 485-512.

Fischer, Stanley, and Franco Modigliani (1978),'Towards an Understanding of the Real Effects and costs of Inflation," Weltwirtschaftliches Archiv, 810-33.

Franciisco José Veiiga and Arii Aiisen (2006), "Political instability and inflation volatility," NIPE WP 2, Universade do Minho.

Friedman, Milton (1977), "Nobel Lecture: Inflation and Unemployment," Journal of Political Economy 85, 451-472.

Huntington, Samuel (1968), "Political Order in Changing Societies," New Haven, CT: Yale University Press.

Friedrich, Carl (1972), “The Pathology of Politics, Violence, Betrayal, Corruption, Secrecy and Propaganda," New York: Harper and Row.

Gabriela Best (2006), "Fear of Floating or Monetary Policy as Usual? A Structural Analysis to Mexico’s Monetary Policy," University of California, Irvine.

Galy, Jordi and Tommaso Monacelli (2005), "Monetary Policy and Exchange Rate Volatility in a Small Open Economy," Review of Economic Studies, 72, 707-734.

Galy, Jordi and Pau Rabanal (2004), "Technology Shocks and Aggregate Fluctuations: How Well Does the RBC Model Fit of Postwar U.S. Data," NBER Macroeconomics Annual, 19.

Ghironi, Fabio (2000), "Towards a New Open Economy Macroeconometrics," Boston College Economics Department Working Paper, 469.

Grier, Kevin and Mark Perry (2000), "The effects of real and nominal uncertainty on inflation and output growth in the USA," Journal of Applied Econometrics 1, 45-58. 
Grier, Kevin, Olan Henry, Nilss Olekalns, and Kalvlnder Shields (2004), "The asymmetric effects of uncertainty on inflation and output growth," Journal of Applied Econometrics, 19, 551-565.

Grossman, Gene and Elhanan Helpman (1991), "Innovation and Growth in the Global Economy,’Cambridge, Mass.: MIT Press.

Haque, Nadeem, Mark Nelson, and Donald Mathieson (1998), "The Relative Importance of Political and Economic Variables in Creditworthiness Ratings," IMF Working Paper 98/46 Washington

Hayakawa, Kazuhiko (2007), "Small sample bias properties of the system GMM estimator in dynamic panel data models," Economics Letters, Elsevier, vol. 95(1), pages 32-38, April.

Holtz-Eakin, Douglas, Whitney Newey and Harvey Rosen (1988), "Estimating Vector Autoregressions with Panel Data,” Econometrica 56:6, p. 1371-1395.

Huntington, S. P. (1968), "Political Order in Changing Societies," New Haven: Yale University Press.

Jansen, Denni (1989), "Does Inflation Uncertainty Affect Output Growth? Further Evidence," Federal Reserve Bank of St. Louis Review (July/August), 43-54.

Johnson, S., J. McMillan and C. Woodruff (2002), "Property rights and finance," American Economic Review 92(5): 1335-1356.

Jose De Gregorio (1993), "Credit Markets and Stagnation in an Endogenous Growth Model," IMF Working Papers 93/72, International Monetary Fund.

Justiniano, Alejandro and Bruce Preston (2004), "Small Open Economy DSGE Models Specification, Estimation, and Model Fit," Manuscript, International Monetary Fund and Department of Economics, Columbia University.

Kamin, Steven and Karsten Kleist (1999),"The Evolution and Determinants of Emerging Market Credit Spreads in the 1990's," Bank for International Settlements, Working Paper No. 68.

Kaufmann, Daniel, Aart Kraay, and Massimo Mastruzzi (2003), "Governance Matters III: Governance Indicators for 1996-2002," World Bank Working Paper \#3106.

King, Robert and Sergio Rebelo(1990), "Public Policy and Economic Growth: Developing Neoclassical Implications," Journal of Political Economy, University of Chicago Press, vol. 98(5), pages S126-50, October. 
Klein, Michael and Giovanni Olivei (2006),"Capital Account Liberalization, Financial Depth and Economic Growth," Working Paper, Tufts University.

Kräussl R. (2000), "Sovereign debt ratings and Their Impact on Recent Financial Crises," Center for Financial Studies, Frankfurt/Main.

Krueger, Anne (1974),"The Political Economy of Rent Seeking," The American Economic Review, 64(3), pp.291-303.

La Porta, Rafael, Florencio Lopez-de-Silanes, Andrei Shleifer and Robert W. Vishny (1998),"Law and Finance," Journal of Political Economy 106, p. 113-1155.

La Porta, Rafael, Florencio Lopez-de-Silanes and Andrei Shleifer (2000), "Government Ownership of Banks," NBER Working Paper no 7620.

La Porta, Rafael, Florencio Lopez-de-Silanes, Andrei Shleifer and Robert Vishny (1997), "Legal Determinants of External Finance," Journal of Finance 52, p. 1131-1150.

Landon-Lane, John and Peter Robertson (2008), "Factor Accumulation and Growth Miracles In a two sector Model," The Manchester School, Volume 77, Number 2, March 2009 , pp. 153-170(18).

Lane, Philip (2001), "The New Open Macroeconomics: A Survey," Journal of International Economics, 54, Pages 235-266.

Larraín Guillermo, Helmut Reisen and Julia Von Maltzan (1997), "Emerging Market Risk and Sovereign Credit Ratings," OECD Development Centre, Technical Papers, No.124.

Larry Jones \& Rodolfo Manuelli (1993), "Growth and the Effects of Inflation," NBER Working Papers 4523, National Bureau of Economic Research.

Laxton, Doug and Paolo Pesenti (2003), "Monetary Policy Rules for Small, Open, Emerging Economies," Journal of Monetary Economics, 50, 1109-1146.

Lee, Jong-Wha (1993), "International Trade, Distortions, and Long-Run Economic Growth,’International Monetary Fund Staff Papers 40(2): 299-328.

Leigh, Daniel and Thomas Lubik (2005), "Monetary Policy and Imperfect Pass-through: A Tale of Two Countries," Manuscript, Department of Economics, Johns Hopkins University.

Leff, Nathaniel (1964), "Economic Development Through Bureaucratic Corruption," The American Behavior Scientist 8:8-14. 
Levine, Ross, and David Renelt (1992), "A Sensitivity Analysis of Cross-Country Growth Regresssions," American Economic Review, 942-63.

Levine, Ross, and Sara Zervos (1993), "What Have We Learned About Policy and Growth from Cross-Country Analysis," American Economic Review Papers and Proceedings, 83, May, 426-430.

Lubik, Thomas, and Frank Schorfheide (2003), "Do Central Banks Respond to Exchange Rate Fluctuation A Structural Investigation," Manuscript, Department of Economics, University of Pennsylvania.

Lubik, Thomas and Frank Schorfheide (2006), "Bayesian Look at New Open Economy Macroeconomics,” NBER Macro Annual 2005, 313-366.

Lucas, Robert Jr. (1988), "On the mechanics of economic development," Journal of Monetary Economics, Elsevier, vol. 22(1), pages 3-42, July.

Manasse, Paolo, Nouriel Roubini, and Axel Schimmelpfennig, 2003, "Predicting Sovereign debt rating Crises," IMF Working Paper 03/221, Washington.

Mauro, Paolo (1995), "Corruption and growth," Quarterly Journal of Economics. 110(3):681-712.

Mauro, Paolo , Sussman, Nathan and Yafeh, Yishay (2002), "Emerging Market Spreads: Then Versus Now," Quarterly Journal of Economics 117(2), 695 - 733.

Max Gillman, Mark Harris and Laszlo Matyas (2003), "Inflation and growth: Explaining a negative effect," Empirical Economics 29, pp.149-167.

Mankiw, N. Gregory, David Romer and David N. Weil (1992), "A Contribution to the Empirics of Economic Growth," Quarterly Journal of Economics, 407-38.

McMullan, M. (1961),“A Theory of Corruption,” Sociological Review 9 (2):181-201.

McCandless, Greorge (2008): “The ABC's of the RBC's: An Introduction to Dynamic Macroeconomic Models," Harvard University Press.

Min, Hong G. (1998), "Determinants of Emerging Market Bond Spread: Do Economic Fundamentals Matter?," World Bank Policy Research Working Paper No. WPS 1899, the World Bank, Washington D.C.

Monacelli, Tommaso (2005): "Monetary Policy in a Low Pass-Through Environment," Journal of Money, Credit, and Banking, forthcoming.

Motley, Brian (1994), "Growth and Inflation: A Cross-Country Study," Federal Reserve Bank of San Francisco Working Paper 94-08. 
Myrdal Gunnar (1968), "Asian Drama: An Inquiry into the Poverty of Nations," NY, Pantheons Books.

Nye, Joseph (1967), "Corruption and Political Development: A Cost-Benefit Analysis," in Heidenheimer, Arnold, Johnston Michael and Victor LeVine (eds). IRIS Discussion Paper No. 04/03, "Political Corruption: A Handbook," Transaction Publishers: New Brunswick, N.J.

Obstfeld, Maurice and Rogoff, Kenneth (1995), "Exchange Rate Dynamic Redux," Journal of Political Economy, 103, 624-660.

Obstfeld, Maurice and Rogoff, Kenneth (2000), "New directions for stochastic open economy models," Journal of International Economics, 50, 117-53.

Obstfeld, Maurice and Alan Taylor (2003), "Sovereign Risk, Credibility and the Gold Standard: 1870 - 1913 versus 1925 - 31,” Economic Journal 113(April), 241 - 275.

Orphanides, Athanasios, and Robert M. Solow (1990), "Money, Inflation, and Growth," in Hand- book of Monetary Economics, edited by Benjamin M. Friedman, and Frank H. Hahn. Amsterdam: North Holland.

Orphanides, Athanasios, and Judson Ruth (1996), "Inflation, Volatility and Growth," Board of Governors of the Federal Reserve System.

Rebelo, Sergio (1991) "Long-Run Policy Analysis and Long-Run Growth," Journal of Political Economy, University of Chicago Press, vol. 99(3), pages 500-521, June.

Reisen H. and von Maltzan J. (1999), "Boom and Bust and Sovereign debt ratings," OECD Development Centre, Working Papers No.148.

Romer, Paul and Luis Rivera-Batiz (1990), "Economic Integration and Endogenous Growth,’NBER Working Paper No. W3528.

Remolona, Elim, Santigna, Michael, and Wub Eliza (2007), "A Rating Based Approach To Measuring Sovereign Risk," International Journal of Finance and Economics, Published online in Wiley InterScience (www.interscience.wiley.com).

Rodrik, Dani, (1999), "Where Did All the Growth Go? External Shocks, Social Conflict, and Growth Collapses," Journal of Economic Growth, 4(4), December.

Rotemberg, Julio and Michael Woodford (1997), "An Optimization-Based Econometric Framework for the Evaluation of Monetary Policy," NBER Macroeconomics Annual, 12, 297-346. 
Rother, Philipp C. (2004), "Fiscal Policy and Inflation Volatility," ECB Working Paper No. 317.

Rowland, Peter, and José L. Torres (2004), "Determinants of Spread, Credit Ratings and creditworthiness for Emerging Market Sovereign debt rating: A Panel Data Study," A Follow-Up Study Using Pooled Data Analysis”, Central Bank of Columbia.

Rowland, Peter (2005), "Determinants of spread, credit ratings and creditworthiness for emerging market sovereign debt rating: a follow-up study using pooled data analysis," Banco de la Republica de Colombia. Bogotá, Colômbia: 2004. disponível em:

<http://www.banrep.gov.co/docum/ftp/borra296.pdf> Acesso em: dez. 2005.

Sangmok Choi, Bruce D. Smith, and John H. Boyd (1995), "Inflation, Financial Markets, and Capital Formation," Federal Reserve Bank of Minneapolis, working paper 556.

Sarel, Michael (1996)," Nonlinear Effects of Inflation on Economic Growth," IMF Staff Papers, 43:1 March, 199-215.

Sargan, J.D. (1988), “Testing for Misspecification after Estimating Using Instrumental Variables," in Maasoumi, E. (ed.) Contributions to Econometrics: John Denis Sargan, Vol. 1, Cambridge: Cambridge University Press.

Schmitt-Grohe, Stephanie and Martin Uribe (2003), "Closing small open economy models," Journal of International Economics, 61, 163-185.

Selçuk Akçay (2006), "Corruption and Human Development," Cato Journal, Vol. 26 No. 1.

Shleifer, Andrei and Robert Vishny (1993), "Corruption," The Quarterly Journal of Economics 108(3): 599-617.

Smets, Frank and Raf Wouters (2003), "An Estimated Stochastic Dynamic General Equilibrium Model for the Euro Area," Journal of the European Economic Association, 1 (5), 1123-1175.

Smets, Frank and Raf Wouters (2004), "Comparing Shocks and Frictions in U.S. and Euro Area Business Cycles: A Bayesian DSGE Approach," National Bank of Belgium Working Paper, 61.

Staiger, Douglas and James Stock (1994), "Instrumental Variables Regression with Weak Instruments,” NBER Technical Working Paper 151.

Stiglitz , Joseph and Andrew Weiss, (1981), "Credit Rationing in Markets with Imperfect Information," American Economic Review 71, 393-410. 
Stockman, Alan C. (1981), "Anticipated inflation and the capital stock in a cash-inadvance economy," Journal of Monetary Economics 8, 387-393.

Sy Amadou (2001), "Emerging Market Bond Spreads and Sovereign Credit Ratings: Reconciling Market Views with Economic Fundamentals," IMF Working Paper, WP/01/165.

Tanzi, Vito, and Davoodi, Hamid (1997), "Corruption, Public Investment, and Growth," IMF Working Paper No. 139. Washington: International Monetary Fund.

Traub, Leah (2006), "Financial Openness and Growth: The Importance of Public and Private Sector Protections," Ph.D thesis, Rutgers University, Unpublished.

Truglia, V., Cailleteau, P.(2006), “A Guide To Moody’s Sovereign Rating-Special Comment,” Moody’s Investor Service, Global Credit Research, August.

Wei, Shang-Jin (2000), "How Taxing is Corruption on International Investors?," Reviw of Economics and Statistics, Vol LXXXII, Number 1.

Woo, Jaejoon (2003), “Economic, political, and institutional determinants of public deficits," Journal of Public Economics 87, 387-426.

Woodford, Michael (1999b), "Optimal Monetary Policy Inertia," NBER Working Paper no. 7261 .

Woodford, Michael (2003), "Interest and prices: Foundations of a theory of monetary policy," Princeton, NJ: Princeton University Press.

Young, Alwyn (1991), "Learning by Doing and the Dynamic Effects of International Trade,’Quarterly Journal of Economics 106(2): 369-405. 


\section{CURRICULUM VITA}

Noha M.F. Emara

2006-2009 Ph.D. in Economics, Rutgers University

2004-2006 M.A. in Economics, Rutgers University

1997-1999 M.A. in World Economy, Jawaharlal Nehru University, India

1994-1999 M.A. in Economics, Ain Shams University, Egypt

1989-1993 B.Sc. in Foreign Trade, Helwan University, Egypt

Spring 2009 Teaching Assistant, Economics Department, Rutgers University

Summer 2008 Internship at the United Nations Head Quarter, New York, NY:

Department of Economic and Social Affairs - Division of Policy Analysis

Fall 2008 Research Assistant, Economics Department, Rutgers University

Fall 2008 Instructor, Economics Department, Rutgers University

Spring 2008 Instructor, Economics Department, Rutgers University

Fall 2007 Instructor, Economics Department, Rutgers University

Spring 2007 Teaching Assistant, Economics Department, Rutgers University

1994-present Faculty Member (on leave), Helwan University, Egypt 